\title{
Ist Beten sinnvoll?
}

Die 5. Rede des Maximos von Tyros

Scripta Antiquitatis Posterioris ad Ethicam REligionemque pertinentia XXXI

\section{Mohr Siebeck}




\section{SAPERE}

Scripta Antiquitatis Posterioris

ad Ethicam REligionemque pertinentia

Schriften der späteren Antike

zu ethischen und religiösen Fragen

\section{Herausgegeben von}

Reinhard Feldmeier, Rainer Hirsch-Luipold, und Heinz-Günther Nesselrath

unter der Mitarbeit von

Simone Seibert und Andrea Villani

\section{Band XXXI}

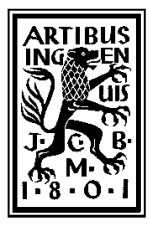





\title{
Ist Beten sinnvoll?
}

Die 5. Rede des Maximos von Tyros

\author{
eingeleitet, übersetzt und \\ mit interpretierenden Essays versehen von \\ Barbara E. Borg, Franco Ferrari, Alfons Fürst, \\ Rainer Hirsch-Luipold, Michael Trapp, \\ Vincenzo Vitiello
}

herausgegeben von

Rainer Hirsch-Luipold und Michael Trapp

Mohr Siebeck 
SAPERE ist ein Forschungsvorhaben der Akademie der Wissenschaften zu Göttingen im Rahmen des Akademienprogramms der Union der Deutschen Akademien der Wissensichaften.

ISBN 978-3-16-153953-4 / eISBN 978-3-16-156856-5

DOI 10.1628/978-3-16-156856-5

ISSN 1611-5945 (SAPERE. Scripta antiquitatis posterioris ad ethicam religionemque pertinentia)

Die Deutsche Nationalbibliothek verzeichnet diese Publikation in der Deutschen Nationalbibliographie; detaillierte bibliographische Daten sind im Internet über http://dnb.dnb.de abrufbar.

(C) 2019 Mohr Siebeck Tübingen www.mohrsiebeck.com

Das Werk einschließlich aller seiner Teile ist urheberrechtlich geschützt. Jede Verwertung außerhalb der engen Grenzen des Urheberrechtsgesetzes ist ohne Zustimmung des Verlags unzulässig und strafbar. Das gilt insbesondere für Vervielfältigungen, Übersetzungen, Mikroverfilmungen und die Einspeicherung und Verarbeitung in elektronischen Systemen

Der Band wurde vonseiten des Herausgebergremiums von Rainer Hirsch-Luipold betreut und von Marius Pfeifer, Maurice Jensen und Andrea Villani in der SAPERE-Arbeitsstelle in Göttingen gesetzt. Druck von Gulde Druck in Tübingen auf alterungsbeständiges Werkdruckpapier, gebunden von der Buchbinderei Spinner in Ottersweier. 


\section{SAPERE}

Griechische und lateinische Texte der späteren Antike (1.-4. Th. n. Chr.) haben lange Zeit gegenüber den sogenannten ,klassischen' Epochen im Schatten gestanden. Dabei haben die ersten vier nachchristlichen Jahrhunderte im griechischen wie im lateinischen Bereich eine Fülle von Werken zu philosophischen, ethischen und religiösen Fragen hervorgebracht, die sich ihre Aktualität bis heute bewahrt haben. Die - seit Beginn des Jahres 2009 von der Union der detutschen Akademien der Wissenschaften geförderte - Reihe SAPERE (Scripta Antiquitatis Posterioris ad Ethicam REligionemque pertinentia, "Schriften der späteren Antike zu ethischen und religiösen Fragen") hat sich zur Aufgabe gemacht, gerade solche Texte über eine neuartige Verbindung von Edition, Übersetzung und interdisziplinärer Kommentierung in Essayform zu erschließen.

Der Name SAPERE knüpft bewusst an die unterschiedlichen Konnotationen des lateinischen Verbs an. Neben der intellektuellen Dimension (die Kant in der Übersetzung von sapere aude, „Habe Mut, dich deines eigenen Verstandes zu bedienen", zum Wahlspruch der Aufklärung gemacht hat), soll auch die sinnliche des, Schmeckens ${ }^{\prime}$ zu ihrem Recht kommen: Einerseits sollen wichtige Quellentexte für den Diskurs in verschiedenen Disziplinen (Theologie und Religionswissenschaft, Philologie, Philosophie, Geschichte, Archäologie ...) aufbereitet, andererseits aber Leserinnen und Leser auch, auf den Geschmack' der behandelten Texte gebracht werden. Deshalb wird die sorgfältige wissenschaftliche Untersuchung der Texte, die in den Essays aus unterschiedlichen Fachperspektiven beleuchtet werden, verbunden mit einer sprachlichen Präsentation, welche die geistesgeschichtliche Relevanz im Blick behält und die antiken Autoren zugleich als Gesprächspartner in gegenwärtigen Fragestellungen zur Geltung bringt. 



\section{Vorwort zu diesem Band}

Maximos von Tyros, der im 2. Jh. n. Chr. unter den Kaisern Mark Aurel und Commodus wirkende philosophische Lehrer und Redner, verbindet seine philosophischen Überlegungen mit einer gefälligen literarischen Darstellung im Dienst der pädagogischen Vermittlung, oftmals mit dezidiert ethischem Impetus. Seine Reden kann man mit Fug und Recht als "philosophical sermons " bezeichnen, ${ }^{1}$ zumal sein Werk mit Themen der Religion und Theologie durchsetzt ist, wobei das Interesse des philosophischen Lehrers auch Aspekte der gelebten Religion ${ }^{2}$ einschließt. An der hier vorgelegten oratio 5 zur philosophischen Legitimität des Bittgebets lässt sich die Bedeutung religiös-theologischer Themen im Werk des Maximos exemplarisch vorführen. Zudem erweist er sich darin als ein einzigartiger Zeuge für die Bedeutung von Bildungsvermittlung, speziell der Vermittlung religiöser Bildung, in der frühen Kaiserzeit. Ausgehend von Beispielen aus der Praxis des Gebets, die er der literarischen Tradition entnimmt, beleuchtet Maximos die philosophischen Implikationen des Gebets im Blick auf die Lehre vom Göttlichen, von der Vorsehung und vom Menschen.

Philosophisch-theologische Reflexionen an die Traditionen der gelebten Religion anzuschließen und von ihnen her zu entwickeln kann als ein Wesenszug der westlichen Geistes- und Religionsgeschichte gelten - zugrunde gelegt in der platonischen Philosophie im ausgehenden Hellenismus und in der frühen Kaiserzeit. Herausragende Repräsentanten dieser Entwicklung, die den Aufstieg des Christentums entscheidend begünstigt hat, sind auf jüdischer Seite Philon von Alexandria, auf christlicher Seite Klemens von Alexandria und später Origenes, auf pagan-religiöser Seite der Philosoph und Priester des Apollon in Delphi Plutarch, dem Maximos nach dem Urteil von Rohdich $(1879,1 \mathrm{f}$ ) in seiner Philosophie in besonderer Weise verpflichtet ist.

Es sind gerade diese vielfach aufgrund ihrer literarischen und rhetorischdidaktischen Darstellungsform unter dem Verdikt des "Unphilosophischen" geringgeschätzten Autoren der frühen Kaiserzeit, denen der konsequent interdisziplinär ausgerichtete Interpretationsansatz von SAPERE besser gerecht zu werden versucht. In fürSAPERE typischer Manierwurde eine Forschergruppe aus Klassischen Philologen, Philosophen, Archäolo-

\footnotetext{
${ }^{1}$ Vgl. Trapp $1997 \mathrm{~b}$.

2 Vgl. J. Alerecht u.a., ", Religion in the making: the Lived Ancient Religion approach", Religion 2018 (online: DOI: 10.1080/0048721X.2018.1450305); J. Rüркв, "Lived Ancient Religion. Questioning 'Cults' and 'Polis Religion'", Mythos. Rivista di Storia delle Religioni 5 (2011) 191-204.
} 
gen, Kirchengeschichtlern und Exegeten zusammengestellt, die bei einer Tagung in der SAPERE-Arbeitsstelle in Göttingen die vorläufigen Manuskripte diskutierte.

Grundlage der Arbeit bildete der von dem klassischen Philologen $\mathrm{Mi}$ chael Trapp (London) 1995 vorgelegte, für diese Ausgabe erneut durchgesehene und korrigierte Text. Rainer Hirsch-Luipold, der in Bern Netues Testament und Antike Religionsgeschichte lehrt, zeichnet für die Übersetzung verantwortlich; gemeinsam erstellten sie die Anmerkungen zur Übersetzung (ergänzt durch Simone Seibert) und die Einleitung. Gemäß den Gepflogenheiten von SAPERE wird hier nach einer kurzen Einführung in das Thema des Gebets zunächst der Autor umfassend biographisch und literarisch vorgestellt, sodann die oratio 5 ins Gesamtwerk der 41 orationes eingeordnet und dieses schließlich im Rahmen der Geistes- und Religionsgeschichte der Zeit ausgeleuchtet.

Auf Text, Übersetzung und Anmerkungen folgen fünf Essays aus unterschiedlichen Fachperspektiven. Am Anfang steht eine philosophiegeschichtliche Einordnung des Maximos. Ausgehend von der 5. Rede arbeitet Franco Ferrari, Professor für antike Philosophie aus Salerno, die platonischen Elemente im Werk des philosophischen Lehrers heraus und ordnet ihn auf diese Weise in die Geschichte des (sog. Mittleren) Platonismus ein. Zunächst allerdings fragt er danach, inwiefern dieses Werk überhaupt als philosophisches Werk im eigentlichen Sinne begriffen werden kann. Eine besondere Nähe zum dogmatischen Platonismus zeigt sich in der Sicht eines fürsorglichen Göttlichen, das als tunveränderlich tnd gütig definiert wird. Diese Züge des Göttlichen werden gerade an dem in der 5. Rede diskutierten Thema des Gebets offenbar. Im Gespräch mit Platon und der platonischen Tradition arbeitet Maximos das Thema des Gebets im Blick auf die mangelnde Kenntnis des Guten auf Seiten der Menschen, die Unveränderlichkeit Gottes und die Lehre von der Vorsehung als Problem der Gebetstheorie auf, um auf ein philosophisches Verständnis des Gebets als Annäherung an Gott hinzuführen.

Rainer Hirsch-Luipold bringt die Kritik des Maximos am Bittgebet ins Gespräch mit Texten aus dem Neuen Testament, dem frïhen Judentum und einer weiteren prominenten pagan-religiösen Position, nämlich der des Platonikers und delphischen Priesters Plutarch. Übereinstimmungen zeigen sich im pädagogischen Zugriff und der Pragmatik der Diskussion, die auf eine gereinigte Gebetspraxis zielt, sowie im Blick auf einzelne Gedankenfiguren und Bilder. Dem stehen Unterschiede in dem jeweils zugrundegelegten Gottesbegriff gegenüber.

Alfons Fürst, Kirchenhistoriker aus Münster, interpretiert mit der Schrift des Origenes "Über das Gebet” den gewichtigsten christlichen Beitrag zur antiken philosophischen Diskussion über das Gebet, der sich mit den in der philosophischen Tradition diskutierten Fragen zu Sinn und Unsinn des 
Gebets auseinandersetzt und dazu eine eigene, dezidiert christliche Position formuliert. Origenes ordnet die Lehre vom Gebet in einer ausführlichen Auseinandersetzung mit den zeitgenössischen Texten zum Gebet in seine Metaphysik der Freiheit ein.

Barbara Borg, Archäologin aus Exeter, wendet sich dem Betgestus in der Bildkunst zu. Dabei zeigt sich nicht nur, dass die Bildzeugnisse, die wesentlich der Selbststilisierung der Dargestellten dienen, eine Religiosität in den Vordergrund stellen, die von dem von Maximos kritisierten Bittgebet bestimmt ist, sondern auch, dass ein solches Gebet als Ausdruck der pietas der Dargestellten erscheint, bei denen es sich vorwiegend um Frauen handelt.

Vincenzo Vitiello, Philosoph aus Mailand, öffnet die Diskussion für allgemeine religionsphilosophische Gedanken zum Gebet im Horizont sowohl der christlichen als auch der pagan-religiösen Tradition. Hierzu stellt er den Ödipus des Sophokles neben Jesus als dem christlichen Urexempel des Betenden.

Wie immer bei SAPERE ist der Band das Produkt einer intensiven interdisziplinären Zusammenarbeit und des Austatusches untereinander sowie mit dem Herausgebergremium und den Mitarbeitern der Arbeitsstelle. Allen Beteiligten sei an dieser Stelle ganz herzlich für ihren Einsatz, die kollegiale, zielgerichtete und menschlich erfreuliche Zusammenarbeit und für vielfache Anregungen und Korrekturen gedankt.

Bern, im August 2018

Rainer Hirsch-Luipold 



\section{Inhaltsverzeichnis}

SAPERE $\ldots \ldots \ldots \ldots \ldots \ldots \ldots \ldots \ldots \ldots$ v

Vorwort zum Band $\ldots \ldots \ldots \ldots \ldots \ldots \ldots$ VII

\section{A. Einführung}

Einführung (Rainer Hirsch-Luipold / Michael Trapp) $\ldots \ldots \ldots . \ldots$

1. Zum Gegenstand: Das Gebet . . . . . . . . . . . . . . 3

1.1. Einleitung . . . . . . . . . . . . . . . . . 3

1.2. Das Gebet als Thema philosophischer Diskussion . . . . . . . . 6

2. Der Autor . . . . . . . . . . . . . . . . . . 8

2.1. Leben und Kontext . . . . . . . . . . . . . 8

2.2. Das Werk: Die Dialexeis und ihr Publikum im Überblick . . . . . . . 11

2.2.1. Die Dialexeis . . . . . . . . . . . . . . . . . 11

2.2.2. Das Publikum, sein Bildungshintergrund und das Bildungsziel der Dissertationes . . . . . . . . . . . . . . . . . . . . 13

3. Die Schrift "Ist beten siturvoll?" - Thema, Stil und Aufbat . . . . . . . . 26

4. Götter und Religion im pädagogisch-philosophischen Werk des Maximos von Tyros . . . . . . . . . . . . . . . . . . . . 28

4.1. Philosophie und religiös-kütnstletische Tradition im Dienst der Gotteserkenntris und einer Kommunikation mit dem Göttlichen . . . . 29

4.2. Zur Verbindung von Gott und Mensch: Geschichtstheologie, Ethik, Anthropologie, Daimonologie und Seelenlehre . . . . . . . . . . 31

4.3. Gottes machtvolle Gerechtigkeit und die menschliche Freiheit . . . . 33

5. Maximos, der philosophische Lehrer, und die religiös-philosophische

Literatur der Kaiserzeit . . . . . . . . . . . . . . . . . 36

6. Die Bedeutung der orationes - Wirkungsgeschichtliche Perspektiven .... 38

7. Textabweichungen dieser Ausgabe von früheren $\ldots \ldots \ldots . \ldots 43$

\section{B. Text, Übersetzung und Anmerkungen}

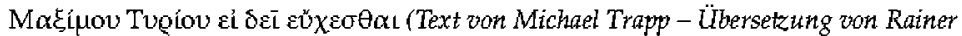
Hirsch-Luipold . . . . . . . . . . . . . . . . . 46 Anmerkungen zur Übersetzung (Rainer Hirsch-Luipold / Michael Trapp /

Simone Seibert [SBJ]

\section{Essays}

Philosophie als wahres Gebet. Platonische Elemente in der fünften Oratio des Maximos von Tyros (Franco Ferrari) . . . . . . . . . . 75

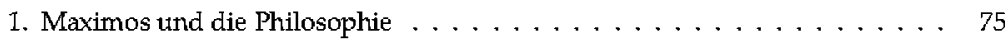

2. Der Platonismus und andere philosophische Richtungen . . . . . . . . . 77 
3. Die Unkenıntris des Menschen im Blick atf die Natur des Guten und dessen göttlichen Ursprung . . . . . . . . . . . . . . . . . . 80

4. Die Unveränderlichkeit des Gottes und seine Unzugänglichkeit für das Beten 84

5. Die Vorsehung: Das Ganze und die Teile . . . . . . . . . . . . . 86

6. Die anderen Kausalfaktoren: Schicksal, Zufall, Sachverstand . . . . . . . 88

7. Philosophie als authentisches Beten und Anträherung an Gott . . . . . . . 90

Würdigkeit versus Hartnäckigkeit. Gebetstheorie und -praxis bei Maximos von Tyros im Vergleich mit Lukas, Joseph und Aseneth und Plutarch (Rainer Hirsch-Luipold) . . . . . . . . . . . . . . . 93

1. Das Gebet bei Maximos . . . . . . . . . . . . . . . . . . . . 9 96

1.1. Platonisches und Stoisches ... . . . . . . . . . . . . 96

1.2. Gotteslehre als wesentliches Thema des Nachdenkens über das Gebet . . 97

1.3. Das philosophische Gebet als die aus dem Gottesgedanken sich ergebende Frömmigkeitspraxis . . . . . . . . . . . . 97

1.4. Das Bittgebet als verfehltes Gebet . . . . . . . . . . . . . . 97

1.5. Zwei Voraussetzungen für den Empfang des Gewünschten von der Gottheit: Würdigkeit und Zuträglichkeit . . . . . . . . . . . . . 99

2. Umstrittene Würdigkeit . . . . . . . . . . . . . . . . . . . . 100

3. Würdigkeit als Voraussetzung des Empfangens? Der Einspruch des Lukas . . 101

3.1. Nicht Qualität oder Leistung des Menschen, sondern gnädige Zuwendung Gottes . . . . . . . . . . . . . . . . 101

3.2. Das fortwährende Gebet . . . . . . . . . . . . . 105

3.3. Drängen als geforderte Gebetshaltung . . . . . . . . . . 107

3.4. Gebet als Beziehungspflege . . . . . . . . . . . . 108

3.5. Zum Vergleich von Maximos und Lukas . . . . . . . . . . . 109

4. Das Gebet im hellenistisch-jüdischen Bekehrungsroman Joseph und Aseneth . 110

5. Das Gebet bei Plutarch . . . . . . . . . . . . . . . . 113

6. Schlussgedanken ....................... 114

Beten als Akt der Freiheit. $\mathrm{Zu}$ den philosophischen Aspekten der Gebetsschrift des Origenes (Affons Fïrst) . . . . . . . . . 117

1. Philosophie des Betens . . . . . . . . . . . . . . . 117

2. Ist Beten möglich? . . . . . . . . . . . . . . . . 120

3. Ist Beten sinnvoll? . . . . . . . . . . . . . . . . . . 128

4. Das Gebet als Gespräch mit Gott und die Praxis des Betens . . . . . . . 140

Ikonographie des Betens (Barbara E. Borg) . . . . . . . . . . . . 147

1. Ursprung des römischen Gebetsmotivs . . . . . . . . . . . 148

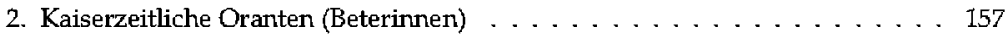

3. Christliche Oranten (Beterinnen) . . . . . . . . . . . . . 168

4. Fazit . . . . . . . . . . . . . . . . . . . . . 175

Religionsphilosophische Meditationen über Ödipus und Jesus im Gebet (Vincenzo Vitiello) . . . . . . . . . . . . . 177

1. Vorbemerkung . . . . . . . . . . . . . . . . . . . 177

2. Die Sprache des Gebets . . . . . . . . . . . . . . . . . . . . . . . . . . . . . . . . . . . . . .

3. Das pagane Gebet . . . . . . . . . . . . . . . . . . . . . 180

3.1. Der Ödipus auf Kolonos von Sophokles . . . . . . . . . . . . . 181 
4. Das christliche Gebet $\ldots \ldots \ldots \ldots \ldots \ldots$. . . . . . . . . . . . .

\section{Anhang}

I. Literaturverzeichnis . . . . . . . . . . . . . . . . . . . . 191

I. Abkürzungen . . . . . . . . . . . . . . . . . 191

2. Ausgaben, Kommentare und Übersetzungen . . . . . . . . . . . . . . 191

3. Sekutndärliteratur (und Ausgaben anderer Autoren) . . . . . . . . 192

4. Abbildungsnachweis . . . . . . . . . . . . . . 196

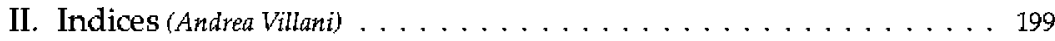

1. Stellenregister (in Auswahl) . . . . . . . . . . . . . . . . . . 199

2. Namens- und Sachregister . . . . . . . . . . . . . 205

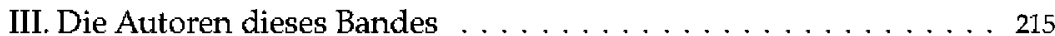



A. Einführung 



\title{
Einführung
}

\author{
Rainer Hirsch-Luipold / Michael Trapp
}

\section{Zum Gegenstand: Das Gebet}

\subsection{Einleitung}

Beten gehört zu den universalen religiösen Ausdrucksformen der Menschheit. ${ }^{1}$ Der Mensch versucht mit dem Göttlichen in Kontakt zu treten oder sich seiner Gegenwart zu versichern, schutzsuchend, feiernd und lobend, klagend und bisweilen auch anklagend. ${ }^{2}$ In seinen Bitten erfleht er den Beistand des Göttlichen für das, worïber er selbst nicht verfügen kann, individuell, aber auch gemeinschaftlich und öffentlich im Rahmen von Opferhandlungen und Festen. Die vielfältigen Formen von Gebeten können mit einer breitgefächerten Terminologie bezeichnet werden: Bitte, Dank, hymnischer Preis, Klage.

Ebenso alt wie das Gebet selbst ist die Frage, wie ein Gebet wirkungsvoll zu vollziehen ist. Welche Worte, Haltungen, Rituale sind nötig und sinnvoll? Mit welchen Namen ist die Gottheit anzureden? Hört Gott überhaupt und wenn ja, wie hört er? Müssen wir dazu vielleicht möglichst nahe ans Ohr der Statue? ? $^{3}$ Und lässt Gott sich durch Gebete bewegen oder weiß er nicht viel besser, wessen Mensch und Welt bedürfen?

Mit diesen Überlegungen bewegen wir uns bereits von den Vollzügen der religiösen Praxis hin zu dem dahinter stehenden Gottesbegriff, auf den es dem philosophischen Denker und Lehrer ankommt. Welches Gottes-

\footnotetext{
${ }^{1}$ Vgl. S. Pulleyn, Prayer in Greek Religion (Oxford 1997); T. S. Schebr, "Die Götter anrufen. Die Kontaktaufnahme zwischen Mensch und Gottheit in der griechischen Antike", in: K. BRodersen (Hg), Gebet und Fluch, Zeichen und Traum. Aspekte religiöser Kommunikation in der Antike. Antike Kultur und Geschichte 1 (Münster u.a. 2001) 31-56.

${ }^{2}$ Auch Plutarch behandelt das Gebet wie die Religiosität an sich als eine Universalie: "Auf Reisen mag man wohl Städte finden, die keine Mauern, keine Schrift, keine Könige, keine Häuser, keinen Geldverkehr und keine Münzen kennen, die unbeleckt sind von Theatern und Wettkampfstätten; einer Stadt ohne Tempel und Gott aber, die keine Gebete, Eide und Weissagungen, keine Opfer für Gutes oder zur Abwehr von Übeln vollzieht, ist noch kein Mensch je ansichtig geworden oder wird es je werden." (Plut. Adv. Col. 31, 1125D-E).

${ }^{3}$ Sen. ep. 41,1. Die Vorstellung, man müsse zum Gebet in den Tempel gehen, kritisiert Demonax in Lukians gleichnamiger Schrift: "Hältst du denn den Asklepios für so taub, dass er uns nicht auch dann hören könnte, wenn wir hier beten?" (Dem. 27).
} 
bild implizieren und transportieren unsere religiösen Vollzüge: Impliziert die Bitte nicht, dass mit ihr die Haltung Gottes beeinflusst werden kann? Wenn wir aber von der Allmacht, Güte und Gerechtigkeit Gottes ausgehen, kann dann der Bitte überhaupt eine sinnvolle Funktion zugewiesen werden? Müssen wir uns durch Gebete und Opfer, durch Worte und Geschenke der Gewogenheit Gottes versichern? Oder ist dieser Gedanke geradezu anstößig? Macht sich ein solcher Gott nicht der Bestechlichkeit verdächtig? Die Überlegungen zur Theologie hinter den Gebeten hat freilich wiederum Rückwirkung auf die religiöse Praxis: Was tun wir eigentlich, wenn wir beten? ${ }^{4}$ Welcher theologischen Logik folgt das Gebet? Richtet es sich nach außen oder doch eigentlich nach innen?

Insbesondere das Bittgebet wurde Ziel des Spotts und Anstoß des Denkens. ${ }^{5}$ Wenn der allwissende Gott ohnedies weiß, wessen wir bedürfen, dann ist es wenig sinnvoll, ihn im Gebet um etwas zu bitten. Wenn Gott ein guter und gerechter, den Menschen zugewandter Gott ist, wird er das Nötige den Bedürftigen und Würdigen in jedem Fall zuteil werden lassen. Wer betet, so die Argumentation, der handelt nicht nur überflüssig, sondern er stellt zudem implizit diese Gottesprädikate in Frage. Überdies: Stellt man sich die Implikationen eines anthropomorph gedachten Geschehens im Zusammenhang des Gebets konkret vor Augen und durchdenkt sie im Blick auf den Gottesgedanken, so gerät man unmittelbar in eine Reihe von Schwierigkeiten und Paradoxien, die sich - wie in Lukians Ikaromenipp ${ }^{6}$ oder in dem Hollywood-Film Bruce Almighty - amüsant inszenieren lassen. ${ }^{7}$ In gewohnt launigem Ton nimmt Lukian einige systematische Probleme im Zusammenhang des Gebets ins Visier, andere werden bei Maximos und anderen diskutiert. Zetus gibt sich alle Mühe, den unterschiedlichen Bedürfnissen und bisweilen widersprüchlichen Gebeten gerecht zu

${ }^{4}$ V. BRÜMMRR, "Was tun wir, wenn wir beten? Eine philosophische Untersuchung", Marburg 1985; W. ScrüssLER, "Das Gebet. Versuch einer philosophisch-theologischen Grundlegung", in: Ders. / A. J. Rermers (Hg.), Das Gebet als Grundakt des Glaubens. Philosophisch-theologische Überlegungen zum Gebetsverständnis bei Paul Tillich (Münster 2004) 11-28. Schüßler (13) sieht die philosophische Auseinandersetzung mit dem Gebet klassischerweise durch Gebetskritik bestimmt; nach Kant liegt das "abergläubische Wesen" des Gebets darin, dass der Mensch versucht, auf Gott Einfluss zu nehmen (I. KanT, Werke in zehn Bänden, hg. V. W. WeIschedel, Bd. VII [Darmstadt 1975] 87If.; vgl. ebd. 13). Gerade das Zeugnis des Maximos (or. 5,8) erweist diese Aussage indes als zu pauschal: das Anliegen des Maximos ist nicht einfach Gebetskritik (die Position wirkt auch bei FöRsTRR 2007, 286-291, nach, wenngleich er klarmacht, dass sich Maximos insbesondere gegen das Bittgebet wendet), sondern - wie sich in dem abschließenden $\$ 8$ zeigt - der Versuch einer philosophischen Reinigung des Gebetsverständnisses.

${ }^{5}$ Ahrliches gilt für die Frage, ob Gottesbilder siruvvoll sind, die Maximos in or. 2 behandelt.

${ }^{6} \mathrm{Vgl}$. auch die Darstellung des Zeus in Lukians Timon.

7 Auch die lateinische Satire widmet sich dem Thema. Zur Kritik der üblichen Gebetspraxis bei Juvenal vgl. die Anm. zur Übers. 6, 32, 88 von Simone Seibert sowie den Beitrag von Alfons Fürst, S. 117 Anm. 2 und S. 132-133. 
werden, die von überall auf ihn einströmen. Ikaromenipp wird bei seinem Ausflug in den Himmel Zeuge dieses Unterfangens:

\begin{abstract}
Während dieses Gesprächs langten wir an dem Orte an, wo Jupiter sich setzen und den Menschen Audienz geben musste. Es waren da der Ordnung nach eine Anzahl von Öffnungen, der Mündung eines Brunnens ähnlich, angebracht, die mit Deckeln verseherı waren, und neben jeder stand ein goldener Lehnstuhl. Jupiter setzte sich nun auf den ersten Stuhl, hob den Deckel auf und gab den Betenden Gehör. Nun stiegen aus allen Gegenden der Erde unterschiedliche Gebete zu vielfältigen Themen empor, die zum Teil unmöglich zugleich gewährt werden konnten. Ich bückte mich ebenfalls von der Seite nach der Öffnung hin, und da hörte ich: "O Jupiter, lass mich König werden!" "O Jupiter, lass meine Zwiebeln und Knoblauch gedeihen!" - "O Jupiter, lass meinen Vater bald von hinnen fahren!" Ein andrer rief: "Lass mich doch meine Frau beerben!" Noch ein anderer: "Möge mein Anschlag gegen meinen Bruder unentdeckt vonstatten gehen!" Ein dritter bat um einen glücklichen Ausgang seines Rechtshandels, ein vierter wollte zu Olympia gekrönt werden. Ein Seemann bat um Nordwind, ein anderer um Südwind; ein Bauer um Regen, ein Walker um Sorunenschein. - Jupiter hörte alles an, und nachdem er jede Bitte genat geprüft hatte, sprach der Vater zu einigen ja, und winkte nein zu den andern. Die gerechten Bitten wurden durch die Öffnung eingelassen und zur rechten Hand abgelegt die ungerechten aber blies er unerfüllt zurück, ehe sie den Himmel noch erreicht hatten.

Nur bei einer einzigen Bitte sah ich ihn ernsthaft in Schwierigkeiten. Zwei Parteien verlangten zu gleicher Zeit widersprechende Dinge und versprachen beide ein gleichwertiges Opfer. Da es ihm also an einem Bestimmungsgrunde fehlte, warum er den einen oder den andern hätte erhören sollen, so ging es ihm wie den Akademikern: er wusste nicht, wozu er ja sagen sollte und war genötigt, wie Pyrrhon sich skeptisch des Urteils zu enthalten. ${ }^{8}$
\end{abstract}

Das Bemühen des Zeus, den Gebeten gerecht zu werden, ist letztlich doch zum Scheitern verurteilt - weil ihm zwei Beter bei einer gegensätzlichen Bitte ein gleichwertiges Opfer anbieten und ihm so jede Entscheidungsgrundlage nehmen. In dieser Situation weißs auch der lukianische Zeus

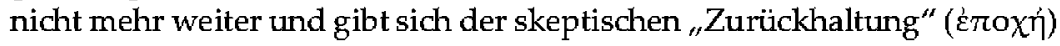
hin. Rhetorisch brilliant platziert Lukian die Pointe, die alle vorausgehende Gebetserfüllung des Zeus desavouiert - offenbar waren die versprochenen Geschenke auch schon vorher sein Bemessungsmaisstab gewesen! Lukian führt uns einen überaus bestechlichen Jupiter vor und macht deutlich, wie problematisch die Vorstellung ist, die Opfer und Gebete könnten einen Einfluss auf die Gebetserfüllung haben. ${ }^{9}$ Und Epikur sekundiert: würde Gott die Gebete der Menschen tatsächlich erhören, dann hätten die sich schon längst gegenseitig umgebracht. ${ }^{10}$ In der Hollywood-Version ist es Bruce, der eine Woche lang Gottes Aufgaben zu übernehmen hat und zur Erfüllung auch Gottes Fähigkeiten zur Verfügung gestellt bekommt. Nun versucht er, nachdem er sich zunächst ein wenig an den Freuden der

\footnotetext{
${ }^{8}$ Luk. Icarom. 25 (Übers. Wieland mit einigen Änderungen); im Anschluss behandelt Jupiter nach dem Bittgebet eine Reihe anderer Gebetsformen, die ats anderen Öffnungen zu ihm dringen.

${ }^{9}$ Vgl. Ps.-Plat. Alk. $2149 \mathrm{~d}-150 \mathrm{a}$.

${ }^{10}$ Epikur, fr. 66 .
} 
Allmacht ergötzt hat, den auf ihn einströmenden Gebeten beizukommen, indem er sie mal direkt beantwortet, mal en gros bewilligt, mal archiviert mit jeweils chaotischen Folgen.

\subsection{Das Gebet als Thema philosophischer Diskussion}

Wie die hier zur Diskussion stehende Schrift des Rhetors und philosophischen Lehrers Maximos von Tyros besonders deutlich zeigt, war das Gebet durchaus nicht nur eine zentrale Form des Vollzugs gemeinschaftlichen Lebens in der Antike, sondern auch Thema philosophischer und theologischer Reflexion. ${ }^{11}$ Die or. 5 des Maximos bietet das ausführlichste erhaltene Zeugnis im paganen Bereich zu diesem Thema. Hier werden einige mit der Theorie des Gebets verknüpfte theologische Probleme angesprochen und teilweise entfaltet. Dabei geht es insbesondere um Fragen der Gotteslehre (Unwandelbarkeit, Gerechtigkeit, Güte Gottes). Indes ist Maximos keineswegs der erste philosophische Autor, der sich des Themas annimmt. Maximos kann auf Ausführungen Platons (Euthyphron, Leges) und des Aristoteles sowie der platonischen Tradition (Alkibiades 2) zurückgreifen. ${ }^{12}$ Ein entscheidender Impuls für Diskussionen über Sinn und Inhalt des Gebets dürfte von Aristoteles' Schrift Über das Gebet ausgegangen sein. ${ }^{13}$ Leider ist uns nur ein Fragment der Schrift bei dem neuplatonischen AristotelesKommentator Simplikios erhalten geblieben ("Gott ist entweder Denken oder noch etwas jenseits des Denkens"). Flashars Bewertung des Fragments führt ungewollt in die entscheidende Richtung: „Der Neuplatoniker Simplikios (ca. $500 \mathrm{n}$. Chr.) war überhaupt nicht an der Problematik des Dialoges, sondern nur an dem Gottesbegriff interessiert. "14 Flashars Bemerkung wirft nämlich die Frage auf, was eigentlich zur Diskussion stand, wenn man philosophisch über das Gebet nachdachte. Dass auch Maximos die Frage des Gottesbegriffs ins Zentrum seiner Erörterung stellt, könnte durchaus ein Indiz dafür sein, dass Simplikios den Skopus der Schrift des Aristoteles treffend wiedergibt: schon bei Aristoteles wird weniger die Theorie und Praxis des Gebets die entscheidende Hinsicht gewesen sein, unter der die Problematik des Gebets diskutiert wurde, als vielmehr der in

\footnotetext{
${ }^{11}$ Wie unten ausgeführt (vgl. S. 10-11) bereitet Maximos das Material für einen philosophischen Elementarunterricht auf. Das bedeutet auch, class er bei seiner Hörerschaft ein besonderes Interesse an den behandelten Themen voraussetzt.

${ }^{12}$ Gebete finden sich in den Schriften Platons an zentralen Stellen: Phaedr. 279b-c; Tim. $27 \mathrm{c}$ i Leg. VII 801a-b. Zum "philosophischen Gebet" vgl. A. Trmotrs, La Prière dans la tradition platonicienne, de Platon à Proclus. Recherches sur les Rhétoriques Religieuses 22 (Turnhout 2018); C. OBribn, "Prayer in Maximus of Tyre", in: Dillon / Timotin 2016, 58-72; Timotin 2016; Dillon 2016; Clay 1979; Difle 1999.

${ }^{13}$ So Hellmut FLASHar jetzt wieder in seiner kurzen Darstellung: Aristoteles. Lehrer des Abendlandes, München 2013,29.

${ }^{14}$ Flashar 2006, 167.
} 
dem jeweiligen Gebetsverständnis sich ausdrückende Gottesbegriff. Auch Origenes wird etwas später als Maximos seine Schrift Über das Gebet mit Reflexionen über Gotteserkenntnis und Gottesbegriff beginnen. ${ }^{15}$

Ausführlich diskutiert der ps.-platonische Dialog Alkibiades $2^{16}$ in einer typisch platonischen Dialogszene die Frage, ob und unter welchen Umständen ein Gebet sinnvoll ist. Im Begriff, sich zu einem Gebet zu begeben, wird Alkibiades von Sokrates über die ratio des Betens befragt und insbesondere mit zwei Problemen konfrontiert: erstens, dass der Gott das Gebet erfüllen könnte, auch wenn es für den Betenden überhaupt nicht zuträglich wäre, und zweitens, damit zusammenhängend, dass der Mensch im Gegensatz zu Gott jeweils nur das partikulare, nie das ganze Gute in den Blick bekommt. Weiter fügt Sokrates die wahren Entscheidungsgründe der Götter an, wem etwas zuzugestehen ist, nämlich Würdigkeit und Gerechtigkeit. Da Alkibiades auf die von Sokrates aufgeworfenen Probleme nicht hinreichend $z \mathrm{tu}$ antworten in der Lage ist, lässt er schließlich von seinem Vorhaben $\mathrm{ab}$, bevor er nicht zu einer solchen Gotteserkenntnis vorgestoßen ist, die es ihm erlaubt, Gut und Böse klar zu unterscheiden (150d) und damit die richtigen, frommen Gebete zu sprechen. Seinen Ausgangspunkt nimmt der Dialog also von menschlicher Frömmigkeit und ihren anthropologischen wie erkenntnistheoretischen Voraussetzungen. Er entwirft nicht eine Gotteskonzeption, sondern bleibt an den beschränkten Erkenntnismöglichkeiten des Menschen orientiert. Dass das Gebet erst wieder aufgenommen werden soll, wenn die Götter den Schleier über der Gotteserkenntnis des Alkibiades gelüftet haben, könnte man entweder so interpretieren, dass die Einsicht in den kategorialen Unterschied zwischen dem wahrhaft seienden Gottund den sterblichen Menschen die Grundvoratussetzung eines echten, philosophischen Gebetes ist (150d). Dann stünde die Gebetsauffassung des Alkibiades 2 derjenigen des Ammonios in Plutarchs De E apud Delphos nahe, der die Erkenntnis und Anerkenntnis Gottes als einzig wahres Sein gegenüber der Nichtigkeit des Menschen, eine Erkenntnis, die sich in der Anrede "du bist" ( ${ }^{\prime 2}$ ) verdichtet $(17,392 \mathrm{~A})$, zur Grundvoraussetzung der homoiosis theo macht. Oder aber Sokrates formuliert einen eschatologischen Vorbehalt, der demjenigen des Paulus in 1 Kor

\footnotetext{
${ }^{15}$ Vgl. jetzt von Stritzky 2014 (bes. 12-39), sowie A. Fürst, S. 120-126 in diesem Band. Mit der Frage nach der Gotteserkenntnis geht Origenes gewissermaßen einen Schritt weiter. Setzt das rechte Gebet die richtige Gottesvorstellung voraus, so bedarf es für die richtige Gottesvorstellung der Möglichkeit der Gotteserkenntnis. Hier knüpft Origenes im Gespräch mit skeptischen Positionen an die positive Hermeneutik des frühkaiserzeitlichen Platonismus an, der der körperlichen Welt eine eigene Erkenntnisfunktion im Blick auf das Transzendent-Göttliche zuweist. Origenes spitzt diese erkenntrisleitende Funktion des Immanent-Körperlichen in der Folge des Johannesevangeliums allein auf den fleischgewordenen Logos zu.

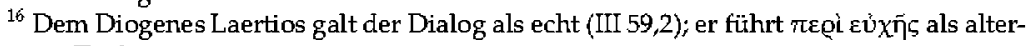
nativen Titel an.
} 
13,12 nahekommt: wirklich erkennen können wir Gott erst, wenn wir ihn von Angesicht zu Angesicht sehen. ${ }^{17}$

Die Aporien des klassischen Bittgebets führten in philosophischen Texten verschiedentlich dazu, dass Mustergebete formuliert wurden wie etwa das von Sokrates im Alkibiades mit Bezug auf die Tradition vorgeschlagene Gebet eines Dichters: „Zeus, Herrscher, das Gute gib uns, ob wir es uns erflehen oder nicht, das Schlimme aber mögest du uns verweigern, atuch wenn wir drum bitten", 18 oder das Gebet des Kaisers Mark Aurel, unter dessen Herrschaft Maximos gewirkt hat: "Ein altes Gebet: Regne, lieber Zeus, regne auf die Felder und Fluren der Athener - entweder soll man gar nicht beten oder so naiv und ungeniert" (Selbstbetrachtungen V 7). Gegenüber solchen Mustergebeten beschreibt Maximos eher eine exemplarische Gebetshaltung am Ende seiner 5. Dialexis: das Gebet des Philosophen. ${ }^{19}$

\section{Der Autor}

\subsection{Leben und Kontext}

Über das Leben des Maximos von Tyros wissen wir kaum etwas. Es heißßt, er sei in den Jahren 149-152 n. Chr. erstmals öffentlich aufgetreten und habe unter Kaiser Commodus (180-192) Vorlesungen in Rom gehalten. Er dürfte also irgendwann im 2. Jahrzehnt des 2 . Jh.s n. Chr. geboren worden sein. Die byzantinische Handschrift aus dem 9. Jh. $\mathrm{n}$. Chr., die seine heute erhaltenen Werke überliefert, bezeichnet diese als "Reden, die in Rom anlässlich seines ersten Besuches gehalten wurden" - womit vermutlich der Besuch zur Zeit des Commodus gemeint ist, auch wenn sich das nicht sicher erweisen lässt. ${ }^{20}$ Was wir aus externen Quellen gewinnen können, ist

\footnotetext{
${ }^{17}$ So wird es bei Maximos explizit gesagt in or. 11,11 (vgl. unten, S. 34). Zum Gebet bei Plutarch siehe den Beitrag von Rainer Hirsch-Luipold, S. 113-114 in diesem Band.

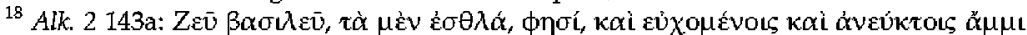

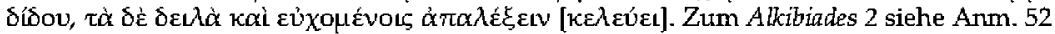
zur Übersetzung sowie die Beiträge von Franco Ferrari, S. 81, Alfons Fürst, S. 122-123 und Rainer Hirsch-Luipold, S. $96 \mathrm{Anm}$. 16 in diesem Band.

${ }^{19}$ Ganz ähnlich in or. 22,7 (unter Aufnahme des homerischen Materials aus or. 5): man solle sich an die Götter nicht wegen Alltäglichkeiten wenden und um einen Orakelspruch bitten, und nicht Kriege, Schlachten und. Seuchen thematisieren, sondern allein im alltägli-

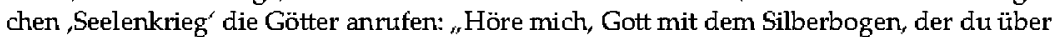
Chryse waltest, höre mich, Apollon, und Zeus und wenn es sonst noch einen Gott gibt, der eine kranke Seele heilt, Wenn ich je dir zum Wohlgefallen einen Tempel erbaute, Wenn ich je dir fette Schenkelstücke verbrannte." (Übers. Schönberger). Wenn er so bete, werde Apollon den Beter noch eher erhören als Chryses.

${ }^{20}$ Die Chronik Eusebs datierte anscheinend das erste Auftreten des Maximos

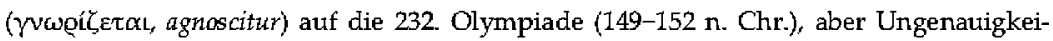
ten und Widersprüche in den Quellentexten, aus denen die Chronik rekonstruiert wercen muss, lassen Zweifel an der Verlässlichkeit dieser Angaben aufkommen. Dass er „in Rom
} 
also wenig mehr als das Bild eines griechischen Gelehrten atus der hellenisierten Levante - vormals dem Herrschaftsbereich der Seletziden, jetzt der römischen Provinz Syrien -, der sich vor allem als Philosoph, Redner und Lehrer in der zweiten Hälfte des 2. Jh.s einen Namen gemacht hat.

Dieses Profil ist vollkommen plausibel, so frustrierend bruchstückhaft es auch sein mag. Die zweite Hälfte des 2. Jh.s n. Chr. war eine Zeit großer Stabilität und finanzieller Blüte in der mediterranen Welt unter römischer Herrschaft. Dies gilt atıch für die Griechisch sprechende östliche Hälfte des Reiches. Eine ausgesprochene kulturelle und intellektuelle Vitalität war die Folge. Der wirtschaftliche Aufschwung nach der Talsohle infolge der römischen Eroberung und mithridatischen Kriege des 2./1. Jh.s v. Chr. hatte dazu geführt, dass unter der gebildeten Elite eine zunehmend selbstbewusste Kreativität erblühte. Dass sogar die Römer sich an den kulturellen Errungenschaften der Griechen orientierten - der sogenannte Graecia capta-Komplex -, sorgte darüber hinaus dafür, dass (neben der östlichen) auch die römische bürgerliche und politische Elite, die jetzt üblicherweise zweisprachig Griechisch und Latein beherrschte, ztum Publikum der Kulturschaffenden zählte. Ging es tum Sehen und Gesehen-Werden für griechische Intellektuelle, so stand Rom unmittelbat neben Athen, Ephesos oder Smyrna. Die sogenannte Zweite Sophistik führte in dieser Zeit zu einer nie dagewesenen Popularität der Rhetorik als einer niveauvollen Art von Unterhaltung, vorgetragen von Virtuosen, die zu den Führungsfiguren auch des kulturell-politischen Lebens ihrer Städte gehörten. ${ }^{21}$ Es blühten aber

zur Zeit der Herrschaft des Commodus Vorlesungen gehalten hat", ist in der Suda, dem mittelalterlichen Lexikon belegt, das ihn auch als "platonischen Philosophen" bezeichnet und sein Werk "philosophische Untersuchungen" ( nuskript, das seine erhaltenen Werke mit einem "ersten Aufenthalt" in Rom in Verbindung bringt, ist der Parisinus graecus 1962, der, als er im 9. Jh. zusammengestellt wurde, Albinos' Einfuhrung in die platonischen Lehren nach den Vorlesungen des Gains und Über die platonischen Lehren sowie die Dialexeis des Maximos und den Didaskalikos des Alkinoos enthalten hatte, aber jetzt nur noch die letzten beiden Werke enthält. Tyros als Herkunftsort ist durchaus glaubhaft für einen griechischen Intellektuellen dieser Zeit, wie die Beispiele des Sophisten Hadrian (ca. 113-193 n. Chr.) und des Philosophen Porphyrios (ca. 234-305 n. Chr.) belegen. Ob er allerdings den Beinamen "von Tyros" trug, weil er dort geboren wurde, oder ab er erst später dorthin gezogen ist, lässt sich tricht mit Sicherheit sagen. Weitere historische Belege neben Euseb und der Suda existieren nicht. Es ist verlockend, ihn mit jenem Cassius Maximus zu identifizieren, dem Artemidor die ersten drei Bücher seiner Darlegung zur Trauminterpretation gewidmet hat und den er als Phönizier, Schriftsteller und Philosophen preist (Oneirocritica 2 proem., 2,70 und 3,66). Dies bleibt indes unsicher sowohl aufgrund der Chronologie als auch, weil Maximos in dieser Zeit ein auch unter Philosophen ausgesprochen verbreiteter Name war. Für eine ausführliche Darstellung des Lebens und der Karriere des Maximos vgl. Trapp 1997a, xi-xii. Zum Inhalt und der Bedeutung der Pariser Handschrift s. WhitTakBr 1974, Trapp 1998; die ganze Handschrift ist online zugänglich: http://gallica.bnf.fr/ark/12148/btv1b8470113z.

${ }^{21}$ Zu den kulturell-politischen Aspekten der sog. Zweiten Sophistik vgl. G. W. BowBrsock, Greek Sophists in the Roman Empire (Oxford 1969); T. SchmrTz, Bildung und Macht. Zur sozialen und politischen Funktion der zweiten Sophistik in der griechischen Welt der Kaiserzeit. 
auch andere Formen literarischer und intellektueller Betätigung in dieser Zeit: Geschichtsschreibung, Biographie, der Roman und - für den vorliegenden Zusammenhang von besonderer Bedeutung - die Philosophie. ${ }^{22}$ $\mathrm{Zu}$ den philosophischen Schulen des Hellenismus - Stoa, Epikureismus und Skeptizismus - war ein neues Interesse an Aristoteles getreten, sowie, nach der langen skeptischen Zwischenphase, die die Akademie vom 3.-1. Th. beschäftigt hatte, eine neue Form eines dogmatisch-positiven Platonismus. Philosophischer Unterricht wurde öffentlich unterstützt, indem nun auch Philosophen die Steuervergünstigungen erhielten, die ursprünglich für Grammatik- und Rhetoriklehrer gedacht waren. Zudem wurden unter Mark Aurel in Athen im Jahr 176 n. Chr. vier kaiserliche Professuren für stoische, platonische, epikureische und peripatetische Philosophie eingerichtet. $^{23}$ Folglich gab es in den meisten größeren Städten des östlichen Reiches Lehrer und Lehrprogramme in einzelnen oder allen der gängigen philosophischen Richtungen; professionelle philosophische Lehrer sorgten für die Produktion einer großen Palette an schriftlichen Darlegungen für den Schulbetrieb, für philosophische Kollegen oder auch für die weitere gebildete Öffentlichkeit. ${ }^{24}$

Um Maximos und den Kontext seines Wirkens zu verstehen, ist dieser letzte Punkt von besonderer Bedeutung: die Philosophie in dieser Zeit richtete sich an eine breitere Hörerschaft. Philosophie war nicht mehr die Übung einiger exzentrischer Spezialisten, wie es zur Zeit des Sokrates und Platons noch der Fall gewesen war. Sie gehörte zur intellektuellen Grundausstattung und zum Selbstbewusstsein eines jeden pepaideumenos, also von jedem, der als gebildeter und kultivierter Mensch gelten wollte. Philosophie im Sinne eines gedanklichen Systems, aber auch im Sinne eines Korpus von Schriften (unter denen das Werk Platons eine herausragende Rolle spielte), galt nun als integraler Bestandteil des Hellenismus als der gesammelten Kulturtradition der Griechen, in die man eingeweiht sein musste, um als gebildete Person akzeptiert zu sein. Städte schmückten sich mit Philosophen aus Vergangenheit und Gegenwart, die aus ihnen hervorgegan-

Zetemata 97 (München 1997); eine jüngere Zusammenfassung seines literarischen Werkes bietet T. WhitMarsh, The Second Sophistic (Oxford 2005).

${ }^{22}$ Den umfassendsten Überblick über die Literatur dieser Zeit bietet immer noch B. P. Reardon, Courants littéraires grecs des IIe et IIIe siècles après J.-C. (Paris 1971).

${ }^{23}$ Einen Überblick über philosophisches Denken und Schreiben in dieser Zeit bieten $R$. Sharples / R. Sorabju (Hg.), Greek and Roman Philosophy 100BC-200 AD (London 2007); die Art des philosophischen Unterrichts und seine Institutionen untersucht J. GLUCKER, Antiochus and the Late Academy. Hypomnemata 56 (Göttingen 1978); die Rolle der philosophia in der Gesellschaft in dieser Zeit diskutieren J. HAHN, Der Philosoph und die Gesellschaft. Selbstverständnis, öfentliches Auftreten und populäre Erwartungen in der hohen Kaiserzeit (Stuttgart 1989) und Trapp 2007, 18-27.211-257.

${ }^{24}$ Vgl. B. WYss / R. Hirsch-Luipold u.a. (Hg.), Sophisten in Hellenismus und Kaiserzeit. Orte, Methoden und Personen der Bildungsvermittlung. STAC 101 (Tübingen 2017); B. BoRG (Hg.), Paideia. The world of the Second Sophistic (Berlin 2004). 
gen waren oder in ihnen gewirkt hatten. Zudem gab es ein breites Bedürfnis nicht nur nach formal philosophischem Unterricht und der entsprechenden technischen Schullektüre, sondern auch nach solchen Diskursformen und literarische Darstellungen, die philosophische Vorstellungen einem breiteren Publikum näherzubringen in der Lage waren. Entsprechend entstand eine bemerkenswerte Bandbreite philosophischer Darstellungsformen in griechischer Sprache in den ersten Jahrhunderten nach Christus, von technisch-philosophischen Traktaten und Kommentaren über Handbücher und doxographische Überblicksdarstellungen bis hin zu öffentlichen Vorträgen, schmuckvollen literarischen Dialogen und der geschickten Selbstinszenierung großer Redner auf einer breiten Bühne. Diese vielfältigen Erwartungen an den philosophischen Lehrer bilden auch den wesentlichen Hintergrund zur Figur des Maximos und dem Inhalt seines erhaltenen Werks. Seine Reden wollen philosophisches Denken und philosophische Werte einem breiteren interessierten Publikum vermitteln und dabei philosophische Substanz bieten, ohne in die trockene Systematik wissenschaftlicher Traktate und Kommentarwerke zu verfallen, literarisch eleganter und gefälliger aufbereitet als in einem Handbuch oder in einem doxographischen Überblick. Wenn wir im Folgenden versuchen, Maximos und seine Werke vor dem skizzierten Hintergrund zu verorten, so wird es auch darum gehen zu schaten, inwiefern sich die spezifische Gestalt und der Inhalt von oratio 5 als typisch innerhalb des Gesamtbilds von Maximos' Interessen und Darstellungsform erweisen oder gerade nicht.

\subsection{Das Werk: Die Dialexeis und ihr Publikum im Überblick}

\subsubsection{Die Dialexeis}

41 kurze philosophische Darlegungen sind uns von Maximos überliefert; in der wichtigsten Handschrift werden sie kollektiv als "Reden"

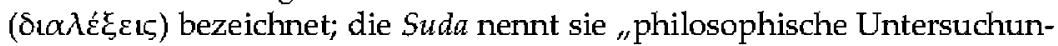

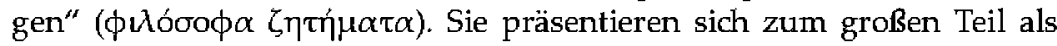
unabhängige Stücke mit einem je eigenen Thema oder einer Fragestellung, bisweilen aber auch als antithetische Paare oder als Folgen von zwei, vier oder fünf Stücken. Die Darlegungen beschäftigen sich mit einer Vielzahl von Themen aus den Bereichen der Theologie, Psychologie, Erkenntnistheorie, Politik und Ethik, vermeiden aber bewusst alle Themen, die unmittelbar mit Logik oder Sprachtheorie zu tun haben. Sie beantworten spezifische Einzelthemen, so als handelte es sich um die Antwort auf ein philosophisches Einzelproblem, das vom Publikum gestellt wurde oder werden könnte und ihm jedenfalls am Herzen liegen sollte. Immer aber werden die Fragen mit einem ethischen Unterton behandelt, indem die Aufmerksamkeit jeweils auf die Konsequenzen gelenkt wird, die sich aus 
einem richtigen Verständnis der jeweiligen Fragestellung für die Lebensführung ergeben (ein glückliches Leben aufgrund eines ehrbaren Charakters und eines tugendhaften Handelns).

Alle Abhandlungen, seien sie nun Einzelstudien, Paare oder ganze Reihen, sind als schriftliche Versionen von mündlichen Vorträgen gestaltet. Wenn man dem Titel der Pariser Handschrift trauen darf, wurden die Vorträge ursprünglich in Rom gehalten während eines Aufenthalts, der auch in der Suda erwähnt wird. Allerdings findet sich nichts im Text, das auf einen speziell römischen Kontext oder ein römisches Publikum hindeuten würde. Es ist deshalb ebenso gut vorstellbar, dass Maximos diese oder ähnliche Reden auch in der griechischen Hälfte des Römischen Reiches gehalten hat. Das genatue Verhältnis zwischen dem Text, den wir heute lesen, und den möglicherweise zugrunde liegenden Vorträgen ist indes unklar. Vor dem Hintergrund dessen, was wir über die üblichen Formen von öffentlichen Reden und philosophischen Lehrvorträgen in dieser Zeit wissen, lässt sich kaum ein gesicherter Kontext für den Vortrag der Stücke des Maximos angeben. Ihre Benennung in der Pariser Handschrift als Dialexeis ebenso wie ihre durchschnittliche Länge legt eine Verbindung zur rhetorischen Form der prolalia nahe. Aber die prolalia diente als Auftakt eines längeren Redeauftritts, einer "Deklamation" $(\mu \varepsilon \lambda \varepsilon \tau \tau\}) .{ }^{25}$ Welche längeren Stücke aber sollen wir uns vorstellen, die Maximos nach seinen Dialexeis vorgetragen haben könnte, und wie lassen sich die Paare und die Zusammenhänge von vier oder fünf Stücken in diese These integrieren? Freilich lässt sich atuch tungekehrt fragen: wenn jede Dialexis als eine eigenständige Rede zu gelten hat, ist es wirklich plausibel, dass Maximos für die kurze Zeit, die zum Halten einer solchen Rede notwendig wäre, eigens ein Publikum versammelt haben sollte? Solcherlei Schwierigkeiten führen zu Erwägungen, der Zusammenhang zwischen dem uns vorliegenden schriftlichen Text und der diesem Text zugrundeliegenden Vortragstätigkeit könnte wesentlich lockerer gewesen sein. Bisweilen, wie gerade auch bei or. 5, kann man den Eindruck bekommen, dass es sich eher um Vorlesungsskizzen handelt, die Grundlage einer mündlichen Darlegung waren, als um sorgfältig literarisch durchgeformte Redemanuskripte oder Redenachschriften. Die Nähe zu den prolaliai könnte auf eine solche Funktion ebenso hinweisen wie die Tatsache, dass die orationes keine Hinweise auf ein konkretes Publikum oder einen Anlass liefern. Freilich ließe sich für solche Vorlesungsskizzen keine antike Parallele anführen. Es gibt auch Überlegungen, es könnte gar keinen ursprünglich mündlichen Vortrag gegeben haben und die orationes wären von Anfang an als eine Sammlung schriftlicher Texte konzipiert und im Umlauf gewesen, die eine mündliche Entstehungsform lediglich als ein belebendes Moment evoziert.

\footnotetext{
${ }^{25}$ Zur Gattung der prolalia und zu ihrer Bedeutung für das Werk des Maximos vgl. RusSELL 1983, 77-79; TrapP 1997a, xlf.; 1997b, $1973 \mathrm{f}$.
} 
2.2.2. Das Publikum, sein Bildungshintergrund und das Bildungsziel der Dissertationes

Die ausführlichsten Informationen über das angezielte, gewissermaisen das ideale Publikum liefert uns oratio $1 .{ }^{26}$ Hier entwirft Maximos auch ein Bild seiner Rolle, seiner Ziele und Kompetenzen. In der handschriftlichen Überlieferung trägt die oratio den Titel: "Dass die Darlegungsform des Philosophen zu jedem Gegenstand passt". Dieser Titel gibt durchaus einen Teil des Inhalts wieder, trifft aber nicht die ebenso wichtige einführende und programmatische Funktion der oratio. ${ }^{27}$ Sie zielt darauf, einem neuen Publikum die folgenden drei Dinge nahezubringen:

1. Jeder braucht Philosophie, weshalb es sich lohnt, philosophische Darlegungen anzuhören; 2. das Publikum ist in der Lage, philosophischen Darlegungen zu folgen, und 3. Maximos ist der Richtige, um solche Darlegungen zu präsentieren.

Philosophische Protreptik (also eine ermutigende Beschreibung der fundamentalen Bedeutung der Beschäftigung mit der Philosophie auf der Suche nach einem glücklichen und erfolgreichen Leben und den fatalen Konsequenzen für den, der solche Beschäftigung vernachlässigt) verbindet sich hier mit Eigenwerbung und der Wahrnehmung der besonderen Umstände seiner Hörer.

Philosophie erschöpft sich für diesen Redner und seine Hörer gerade nicht in pedantischem Argumentieren (,Begriffe und Definitionen oder Argumentationstechniken oder Widerlegungen, Wortklaubereien und Sophistereien" ${ }^{\prime \prime}$ or. 1,8 ), sondern sie ist verstanden als eine grundlegende Lebensschule, die den Eigensinn der Menschen bändigen hilft $(1,3)$ und deren Ziel es ist, die menschlichen Seelen zur Tugend zu führen (1,8). Wird dieses Licht der Orientierung außer Acht gelassen, so läuft das Leben Gefahr abzurutschen in den dunklen Abgrund der Sittenlosigkeit $(1,3)$. Trotz dieser großen Bedeutung der Philosophie braucht der Neuankömmling sich aber keine Gedanken darüber zu machen, ob er der Aufgabe gewachsen ist: in or. 1 wird die Hörerschaft dessen versichert, dass anders als beim Sport, wo bestimmte körperliche Voraussetzungen für den Erfolg gege-

\footnotetext{
${ }^{26} \mathrm{Or} .1$ wird ausfïhrlich diskutiert bei H. HoвEIN, ,Zweck und. Bedeutung der ersten Rede des Maximus Tyrius", in: XAPITE $\Sigma$. Friedrich Leo zum sechzigsten Geburtstag dargebracht, Berlin 1911, 188-219; Kontar is 1982; J. Lauwers, „T The Rhetoric of Pedagogical Narcissism: Philosophy, Philotimia and Self-Display in Maximus of Tyre's First Oration", Classical Quarterly 59/2 (2009) 593-607; Trapp 1997a, xx-xxi. xli-xliii. 3-15.

${ }^{27}$ Die Überschriften, die den Dialexeis in der maßgeblichen Handschrift zugewiesen werden (Paris. gr. 1962), geben an vielen Stellen den Inhalt des Gedankengangs nur unzureichend wieder; manchmal widersprechen sie ihm sogar. Sie sind also deutlich der Nachtrag eines Herausgebers und. stammen nicht aus der Feder des Maximos; vgl. Trapp 1997a, lviii, in der Folge von H. Hobern, Maximi Tyrii Philosophoumena (Leipzig 1910) liv-lv; KoNLARIs 1982, 102-110 bietet einen interessanten, aber wenig überzeugenden Versuch, ihre Authentizität zu verteidigen.
} 
ben sein müssen, fast alle Menschen die nötige geistige (psychische) Kapazität für die Philosophie und ein tugendhaftes Leben mitbringen $(1,5)$. Angesichts dieser natürlichen Affinität des Menschen zu Philosophie und Tugend erreicht die richtige Form philosophischer Unterweisung die Seelen auf so natürliche und mühelose Weise, wie das bloße wiederholte Hören bestimmter Flötenmelodien von einer Schar Singvögel aufgenommen wird $(1,7)$.

Offensichtlich setzt der philosophische Lehrer die Notwendigkeit voraus, den Schülern erst einmal den übergroßen Respekt vor der Aufgabe zu nehmen. Dies erklärt sich daraus, dass es sich um junge Menschen handelt: in 1,7 werden sie als véol (,junge Männer") angesprochen, und das wird in 1,8 aufgenommen, wo die Aufgabe des philosophischen Lehrers folgendermaßen definiert wird: "die Seelen der jungen Männer ( $\tau \dot{\alpha} \zeta \tau \tilde{\omega} v$ vé $\omega v$ $\psi v \chi \alpha \alpha ́ \varsigma)$ wachrütteln und sie zur Tugend führen." Nḱoৎ (neos) bezeichnet als terminus technicus in der politischen Sphäre einen jungen Mann aus der Gruppe derjenigen, die die Ephebenzeit abgeschlossen haben, der also am Ende des zweiten oder am Beginn des dritten Lebensjahrzehnts steht. In der vorliegenden Rede ist der Begriff aber wohl untechnisch verwendet und allgemeiner gemeint. Auf jeden Fall setzen die orationes junge Menschen voraus, die ihre Karriere noch vor sich haben. Sie konnten sich noch nicht auszeichnen in ihrem Leben, sondern suchen gerade nach Wegen, sich zu profilieren. Zwar empfiehlt Maximos seine geschliffen vorgetragenen Lehren vornehmlich als Philosophie, macht aber zugleich klar, dass sie auch jenen nützlich sein können, die eine Laufbahn als Dichter, Redner oder Politiker anstreben $(1,7)$. Es sind eher Mitglieder der sozialen und politischen Elite - also honestiores eher als humiliores - bei denen man solche Ambitionen erwartet. Auf Reichtum und privilegierte soziale Stelltung des Redners wie seines Publikums weisen noch weitere Aspekte in dieser Rede hin: Maximos unterstreicht mit Nachdruck, dass Sokrates, der als das Paradigma philosophischen Unterrichts gelten kann, seine Botschaft an reiche und berühmte Menschen aus gutem Hatuse (wie etwa Alkibiades, Kritias oder Kallias) ebenso gerichtet hat wie an ärmere Hörer (wie Aischines und Antisthenes). Unter seinen Schülern und Nachfolgern war der Plutokrat Aristippos als Philosoph ebenso wahrhaftig und erfolgreich wie der Asket Diogenes $(1,9)$.

Oratio 1 setzt wie die Sammlung insgesamt eine kulturelle Kompetenz beim Publikum voraus, die sich nahtlos in diesen Referenzrahmen einfügt: ${ }^{28}$ ein Standardrepertoire griechischer Bildung (paideia) vorausgesetzt. Es wird erwartet, dass sie Anspielungen auf verschiedene historische Ereignisse, von den Tyrannen des archaischen Griechenland über die Perserzeit und den Peloponnesischen Krieg bis hin zu Demosthenes und Alex-

\footnotetext{
${ }^{28}$ S. weiter Trapp 1997a, xxxv-xl; 1997b, 1966-1970; Ders., Studies in Maximus of Tyre: $a$ second century philosopher and his Nachleben, AD 200-1850 (Diss. Oxford 1986) 228-325.
} 
ander dem Großen, erkennen und goutieren können - historisches Spezialwissen wird hingegen nicht vorausgesetzt. ${ }^{29}$ Auch im Bereich der Literatur bewegen sich die zitierten Autoren im Rahmen des Erwartbaren. Mit großem Abstand am meisten zitiert wird der unverzichtbare Homer (weit mehr als alle anderen zusammen) - jeder Schüler, der die Schule dieses grammatikos durchlaufen hatte, wird Homer kennen und lieben gelernt haben (oder jedenfalls gelernt haben, dass man diesen Autor lieben sollte!) ${ }^{30}$ Auch im Bereich der Philosophie wird Vertrautheit mit einer umfangreichen, aber wiederum wenig ausgefallenen Liste von Namen vorausgesetzt (Thales, Anaximenes, Xenophanes, Heraklit, Pythagoras, Parmenides, Empedokles, Leukipp, Demokrit, Anaxagoras, Diogenes von Apollonia, Sokrates, Platon, Xenophon, Aischines, Antisthenes, Aristippos, Diogenes von Sinope, Aristoteles, Epikur, Zenon, Chrysipp, Straton, Kleitomachos und Karneades) ebenso wie mit den Themen, mit denen man diese Namen für gewöhnlich verbindet (z.B. Thales mit dem Wasser oder Karneades mit der Skepsis). Ein tieferes Verständnis ihrer Lehren und Argumentationsgänge und der technischen Begrifflichkeit der Philosophie scheint dagegen nicht vorausgesetzt $\mathrm{zu}$ sein. Maximos geht zum Beispiel nicht davon aus, dass seine Schüler mit der platonischen Anamnesislehre vertratut sind (or. 10) oder mit der platonisch-pythagoreisch-aristotelischen Zweiteilung der Seele in einen rationalen und einen irrationalen Teil (or. 27,5). All dies legt nahe, dass Maximos mit seinem Unterricht einen allgemein gebildeten jungen Menschen seiner Zeit anzusprechen versuchte. Es ergibt sich das Bild eines Publikums, das sich vor allem aus jungen Leuten zusammensetzt, die eine ordentliche, aber keineswegs außergewöhnliche grammatisch-rhetorische Ausbildung hinter sich gebracht haben. Andererseits passt das, was hier präsentiert wird, durchaus auch zu einem älteren Publikum, das mit ähnlichen Bildungsvoraussetzungen kommt und nun daran interessiert ist, seine Kenntnisse zu ernetern und durch eine Dosis elegant verpackter Philosophie zu erweitern. Was uns in den orationes als das primäre Publikum präsentiert wird, muss also keineswegs das einzige Zielpublikum sein, das Maximos im Blick hat.

\footnotetext{
${ }^{29}$ Der chronologische Umfang der von Maximos zitierten historischen Beispiele stimmt genau mit dem überein, was in den zeitgenössischen sophistischen Reden gängig war; vgl. R. KонL, De scholasticarum declamationum argumentis ex historia petitis, Paderborn 1915; E. L. BowIr, "Greeks and their Past in the Second Sophistic", Past \& Present 46 (1970) 3-41 [revidierte Fassung publiziert in: M. I. FinLer (Hg.), Studies in Ancient Society (London / Boston 1974) 166-209]; RussBll 1983, 106-128.

${ }^{30}$ Für eine umfassende Liste der von Maximos zitierten Autoren s. Trapp 1997b, 1969-1970; für Homer: J. F. KindsTrand, Homer in der Zweiten Sophistik. Studien zu der Homerlektüre und dem Homerbild bei Dion von Prusa, Maximus von Tyros und Ailios Aristeides. Acta Universitatis Upsaliensia. Studia Graeca Upsaliensis 7 (Uppsala 1973).
} 


\subsubsection{Rhetorische Form und Kommunikationsstrategien}

Wie sehr die Rhetorik zur Vermittlungsform philosophischer Überlegungen geworden ist, lässt sich an or. 5 exemplarisch aufzeigen.

Im Anschluss an einige einleitende mythologische Exempla (Midas, Kroisos und der Apollonpriester Chryses) werden die philosophischtheologischen Argumente vorgestellt und entfaltet. Den Abschluss bildet eine Applikation auf das individuelle Leben, die an den Größen der philosophischen Vergangenheit (Sokrates, Pythagoras, Platon) vorgeführt wird. Dieser Fortschritt von einer untechnischen, zugänglichen Einleitung, die auf die eigentliche Frage in ein paar Paragraphen hinführt, über eine stärker systematische Durchführung hin zu einem ethisierenden Abschluss, könnte geradezu als das Standardschema des Maximos in den orationes bezeichnet werden. Manche von ihnen beginnen zwar durchaus mit dem Formulieren einer Fragestellung oder einer These, die im Folgenden erörtert werden soll (oratio 27 zum Beispiel beginnt mit der ungehaltenen Frage: "Wie sollte jemand einem Philosophen Glauben schenken, der behauptet, Tugend sei keine Wissenschaft [technê], sondern etwas anderes?"), die überwiegende Mehrheit aber wählt den Zugang zu ihrem jeweiligen Thema über ein ansprechendes Bild oder eine Geschichte oder eine Episode aus der Literatur. Oratio 22 setzt mit einer Zusammenfassung der Irrfahrten ein, die Odysseus an den Hof des Königs Alkinoos brachten; orr. 18-21 Über die sokratische Liebe beginnen mit einer Reihe erotischer Anekdoten, die von dem attraktiven Aktaion aus Korinth, dem korinthischen Tyrannen Periander und den Tyrannenmördern Harmodios und Aristogeiton handeln; or. 10 Über Lernen und Erinnerung beginnt mit Geschichten von Epimenides, Pythagoras und Aristeas von Prokonnesos, or. 12 mit einem berühmten Pindarzitat über Gerechtigkeit, or. 13 Über Prophetie und menschliches Gericht mit der Invasion des Xerxes und dem Orakel an Athen, das besagte, man solle sich gegen die Perser mit hölzernen Mauern verteidigen. Das Hauptthema leitet sich jeweils als Frage aus der einleitenden Geschichte oder dem Zitat ab bzw. ergibt sich als Wahrheit daraus. Bisweilen ist es auch ein Faden, der mehrere zitierte Geschichten durchzieht. Ist das Thema auf diese Weise etabliert, so entwickelt der Hauptteil der oratio den Gedankengang. Maximos bemüht sich, den Zusammenhang organisch und wohldisponiert erscheinen zu lassen, aber die Verbindungen, die die unterschiedlichen Teile zusammenhalten, sind nicht weniger rhetorisch als argumentativ-logisch. Or. 5 kann zu den stärker logisch durchstrukturierten Stücken im Werk des Maximos gezählt werden. ${ }^{31}$ Immer aber gewinnt man den Eindruck eines Redners, der sich als souveräner Kenner der jeweiligen Thematik präsentieren will, ohne dabei in eine pedantische oder zu detaillierte Darstellungsform zu verfallen.

\footnotetext{
${ }^{31}$ Für einige weitere Analysen vgl. Trapp 1997b, 1956-1957.
} 
Maximos will das Publikum interessieren und inspirieren. Von diesem Ziel spricht er explizit in seinen theoretischen Reflexionen über eine gute philosophische Redekunst in orr. 1,8 und 25,7. Als ideal beschreibt er in 1,8 eine Rede, „die ihr Publikum dazu drängt aufzustehen und ihre Leidenschaft zu teilen, so wie der Klang einer Trompete, der mal Angriff, mal Rückzug anzeigt"; nach 25,7 darf philosophischer Unterricht durchaus Vergnügen bereiten, allerdings nur, wenn es jenem Vergnügen entspricht, "das sich durch den Klang der Trompete einstellt, die inmitten einer Armee von Hopliten deren Seelen durch ihren Ruf anstachelt". Dieses Bestreben zu inspirieren und zu begeistern kommt am offensichtlichsten zum Tragen in den moralisierenden Ausrufezeichen, die den Abschluss nicht weniger orationes bilden. Or. 1 beispielsweise schließt mit Worten, die die Hörer nicht nur durch die philosophischen Gedanken aufzurütteln, sondern auch durch die küinstlerische Form, in der diese hier vorgetragen werden: "Glücklich sind die Darsteller dieses Dramas [sc. das von den großen philosophischen Lehrern aufgeführt wird], glücklich auch die Zuschatuer, die ihm beiwohnen! Sollten wir nicht auch, gerade jetzt, einen Dichter und Schauspieler finden können, der es aufgrund seiner Anmut und Beredsamkeit wert ist, die Theater Griechenlands zu bespielen? Vielleicht tritt er bald auf, und wenn er es tut, wird er nicht geringgeachtet werden!" Or. 2 beendet die Diskussion über die Legitimität der Verehrung von Götterbildern mit einer klangvollen Proklamation dessen, worauf es wirklich ankommt: "Lasst die Menschen das Geschlecht der Götter kennen, nur die Götter sollen sie kennen! Wenn es die Kunst des Phidias ist, die bei den Griechen eine Erinnerung an die Götter wachruft, während es bei den Ägyptern die Verehrung von Tieren ist, bei anderen wieder ein Fluss oder das Feuer, dann habe ich gegen eine solche Vielfalt nichts einzuwenden. Nur lasst sie Gott kennen, lasst sie nach ihm verlangen, sich an ihn erinnern!" Und am Ende von or. 16, als Maximos für ein Leben in philosophischer Kontemplation plädiert, zeichnet er ein solches Leben als eine Reise der Seele durch die gesamte physische Welt: „Was für eine wirklich gesegnete Reise! Was für ein wundervolles Schauspiel! Was für wahrhafte Träume!“ Der Abschluss der or. 5 mit ihrer Anrufung an die Götter der Philosophie und ihrer Reihe von Bildern für den belebenden Effekt des Geschenks, das sie darbieten, fügt sich wunderbar zum allgemeinen Schema.

Ebenso typisch ist die umfangreiche Verwendung von Illustrationsmaterial aus den Bereichen der Geschichte, des Mythos und der Dichtung innerhalb der or. 5 für das durchgängige Streben des Maximos, Zugänglichkeit, Erbaulichkeit und literarische Eleganz miteinander zu verbinden. Werfen wir zunächst einen Blick auf das mythologische Material. Ein falsches Verständnis des Gebets wird in or. 5,2f.7 mit Beispielen aus der Ilias illustriert: griechische Fürsten beten, es möge das Los eines anderen aus dem Helm gezogen werden, um ihn zum Gegner im Zweikampf mit Hek- 
tor zu bestimmen (Il. VII 175-184), der Priester Chryses fleht Apollon um Hilfe gegen Agamemnon an (Il. I 35-42), die Gebete von Agamemnon und Priamos erzielen ein vollkommen gegensätzliches Ergebnis (Il. II 112f. und IV 31-49), schließlich zitiert Maximos die Bemerkung des Phoenix gegenüber Achilles, selbst die Götter könnten aufgrund von flehentlichen Bitten ins Wanken gebracht werden (Il. LX 497). Etwas später wird in $\$ 5$ die Unerbittlichkeit des Schicksals durch das Beispiel des Trojaners Adrestos illustriert, der Menelaos im Kampf um Gnade anfleht (ll. VI 46), und durch Zeus und Thetis, die den bevorstehenden Tod ihrer Kinder Sarpedon und Achilles beklagen (Il. XVI 43f.; XVIII 54). Jedes dieser Beispiele wird mit einem direkten Homerzitat oder der Paraphrase einer Homerpassage eingeführt. Dabei ist eine der pädagogischen Wirkung verpflichtete, gefällige sprachliche Gestaltung ebenso wichtig wie die jeweilige inhaltliche Aussage. Neben Homer führt Maximos auch Menander als Gewährsmann für die Überzeugung an, dass man atßer dem Gebet noch andere Dinge bratucht, um Geld zu verdienen (or. 5,7), indem er zwei Zeilen aus dessen Komödie Hymnis zitiert ( $f r .363 \mathrm{~K}$-A.). Flankierend tritt historisches Material zu diesen mythologischen und poetischen Illustrationen: Maximos fügt den am Anfang stehenden Beispielen für falsche Erwartungen an das Gebet den Fall des Kroisos und seiner Opfergaben für Apollon in Delphi hinzu (or. 5,2; Herodot I 50-53), und auch eine Reihe von bekannten Naturkatastrophen, die sich im 5. Jh. v. Chr. ereignet haben und die er im Wesentlichen Herodot und Thukydides entnimmt. Diese Beispiele sollen erklären, dass die Vorsehung die Interessen des Einzelnen dem Wohl des Ganzen unterordnet. Weiter bringt Maximos einen Katalog bekannter Tyrannen (Dionysios, Peisistratos, Periander und Thrasybulos), der den Zwangscharakter der Macht des Schicksals atufweisen soll, und schließlich eine Liste von bekannten Schurken aus dem 5. Jh., die untermatern soll, dass sich Erfolg in irdischen Dingen, den man für wünschenswert erachten könnte, oft genug gerade moralischer Verworfenheit verdankt.

Auch durch die Verwendung von Dichterzitaten (mit einer besonderen Vorliebe für Homer) und historischen Bezügen (insbesondere zu den ruhmreichen Tagen eines freien Griechenland, zwischen der archaischen Zeit und den Tagen Alexanders des Großen, zu den Perserkriegen und dem Peloponnesischen Krieg, wie sie von Herodot und Thukydides aufgezeichnet wurden) ist die or. 5 repräsentativ für die orationes insgesamt. Die wohlüberlegte Art, wie das illustrative Material die Argumentation unterstützt, dient dazu, beim Publikum für die Philosophie zu werben und ihm gleichzeitig die Scheu davor zu nehmen. Maximos greift in seinem Illustrationsmaterial auf das Standardrepertoire antiker paideia zurück, um den Hörerinnen und Hörern auf diese Weise das Gefühl zu vermitteln, dass der Redner, dem sie zuhören, ihre Kultur und ihre Werte teilt, und dass die Philosophie, für die er steht, nicht ein vollkommen neues, fremdes Gebiet 
ist, sondern Teil dieses gemeinsamen Wertesystems. Außergewöhnlich an or. 5 ist allenfalls die Art und Weise, wie Homer behandelt wird. Anderswo in der Sammlung nämlich erscheint Homer als bedeutender Philosoph, seine Dichtung formuliert in allegorischer Weise die wesentlichen Wahrheiten der Philosophie (orr. 4 und 26); wo immer sein Werk etwas scheinbar Skandalöses enthält, wenn etwa Odysseus ein hedonistisches Lebensziel gutzuheißen scheint, da ist es nach Maximos die Aufgabe des Auslegers, die verborgene Wahrheit aufzustöbern, die sich unter der scheinbar verstörenden Oberfläche verbirgt (or. 22). Anders werden homerische Aussagen in or. 5 bewertet: hier äußern Homers Charaktere tatsächlich falsche Meinungen bezüglich des Gebets. Der philosophische Lehrer widerspricht Homer am Beginn von $\$ 3$ sogar direkt, ohne dass atuch nur der Versuch unternommen würde, das Ansehen des Dichters dadurch zu retten, dass erklärt würde, die geäußerten Gedanken seien nicht seine eigenen, sondern die der von ihm geschaffenen Figuren, oder aber ihre Worte bedeuteten etwas anderes als das, was man auf den ersten Blick annehmen würde. Wir müssen also wohl die Erklärungen anwenden, die Maximos selbst an anderer Stelle bietet: Homer habe, so sagt er etwa in or. 26,5f., mit Absicht neben guten auch moralisch problematische Beispiele in seine Dichtung aufgenommen, um die Unterscheidung zwischen beidem deutlich zu machen.

Die sorgfältige rhetorische Ausgestaltung, die manchmal sogar wichtiger als eine akribisch durchgeführte Argumentation erscheint, hat dem Maximos vielfach den Vorwurf der Oberflächlichkeit eingebracht. ${ }^{32} \mathrm{Er}$ wurde als "Sophist" und "Halbphilosoph" bezeichnet, der mehr mit Atutoren wie Apuleitus und Dion Chrysostomos gemein habe als mit den ernsthaften philosophischen Lehrern wie etwa Alkinoos oder Kalbenos Tauros. ${ }^{33}$ Maximos in dieser Weise den Rang eines „echten" Philosophen $z u$ verweigern, ist indes nicht unproblematisch, weil es sowohl an seinem Philosophieverständnis als auch an dem seines Publikums vorbeigeht, wie sich schon in der obenstehenden Analyse von or. 1 gezeigt hat. Der nun folgende Überblick über den philosophischen Gehalt der orationes wird das Bild vervollständigen.

\footnotetext{
${ }^{32}$ H. Dörrie nannte den Inhalt der Dialexeis "Philosophisches in ... Verflachung” („Maximus II.I*, Der Kleine Pauly 3, 1115).

${ }^{33}$ Z.B. G. Annerson, Lucian. Theme and Variation in the Second Sophistic (Leiden 1976) 4; C. S. O'Brien, The Demiurge in Ancient Thought (Cambridge 2015) 117. Auch die Unterscheidung von Dion und Apuleius von den, wirklichen' oder, ernsthaften' Philosophien ist durchaus problematisch: vgl. Trapp 2007, 23-27, und jüngst C. Moreschini, Apuleius and the Metamorphoses of Platonism (Tumhout 2016) sowie R. FleTcHer, Apuleius' Platonism. The Impersonation of Philosophy (Cambridge 2014).
} 


\subsubsection{Maximos als philosophischer Lehrer und das Bild der Philosophie in den Dialexeis}

Inhaltlich liegt der Schwerpunkt der orationes, wie bereits gesagt wurde, auf der Philosophie im Sinne der Förderung eines guten Charakters und damit einer Anleitung zu einem tugendhaften und folglich glücklichen Leben. Der Gewinn der Philosophie besteht Maximos zufolge darin, den Geist durch die Kontemplation höherer Wahrheiten zu üben (so etwa in orr. 10, 11 und 16). Diesen kontemplativen Aspekt der Philosophie deutet Maximos regelmäßig im Sinn eines Kontakts mit dem Göttlichen. Ebenso entscheidend ist ihm die ethische Perspektive der Philosophie. Um auch Homer unter die groß́en Philosophen zählen zu können, bezeichnet er dessen Dichtung unter Anwendung dieses Philosophiebegriffs als "genaue Kenntnis der göttlichen und menschlichen Dinge" und zugleich als "die Quelle der Tugend und nobler Gesinnung und eines harmonischen Daseins und eines praktischen savoir-faire" (or. 26,1).

Die zweifache Definition des philosophischen Gebets im Rahmen von or. 5 - einerseits als "Umgang mit dem Göttlichen" und andererseits als ein "Aufzeigen von Tugend" bei denen, die Philosophie pflegen und sie dazu

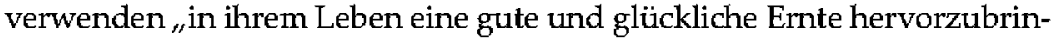
gen" - stimmt genau zu diesem Verständnis von Philosophie innerhalb der orationes. Indem Maximos eine wahrhaft philosophische Einstellung, aus der allein ein sinnvolles Gebet hervorgehen kann, als essentiell für erfülltes Leben und zugleich ausgesprochen selten bezeichnet („Es bedarf aber dieses seltenen und kleinen Flämmchens für das Leben, ... wie man in der dunkelsten Nacht nur eines schwachen Lichtes bedarf ... durch dieses Wenige pflegt sich aber das Ganze zum Heil zu wenden"), nimmt die or. 5 die pessimistisch-moralisierende Sicht der orationes insgesamt auf, in denen auch andernorts die Welt bisweilen als trübe, verdreht und böse erscheint, so dass jede menschliche Bewegung auf das Gute hin sich gegen die allgegenwärtigen Kräfte der Unordnung durchsetzen muss. Das menschliche Leben unterliegt, körperlich wie bezüglich der Beschaffenheit der Seele, der Anfälligkeit alles Materiellen (or. 41): echte Freundschaft ist in menschlichen Beziehungen eine Seltenheit, und die düstere Logik der Rache überwindet vernünftige Zurückhaltung mit einer erschütternden Regelmäßigkeit (orr. 35 und 12); die Gefahr eines Abstiegs in die Barbarei ist allgegenwärtig (or. 1,3). Gott mag wohl "den Funken der Erwartung des Guten in das Menschengeschlecht gepflanzt haben", aber er sorgte auch dafür, dass das Gute selbst schwer zu finden ist (or. 29,6). Gleichwohl kann durch eine philosophische Haltung Tugend erblühen: der Funke der göttlichen Vernunft ist in der Menschheit vorhanden, ein natürlicher Antrieb auf Gott und das Gute hin (orr. 10,9; 11,11; 29,6); und Gott hat die Welt so eingerichtet, dass selbst aus den widrigsten äußeren Umständen die 
Möglichkeit zu einem tugendhaften Leben geschaffen werden kann (orr. 34 und 38). Das umzusetzen ist die Aufgabe und Herausforderung eines philosophischen Lebens, es glückt indes nur wenigen Glücklichen, während die ungebildete Masse diese Möglichkeit ungenutzt lässt. In solchen Aussagen lässt sich eine sorgfältig kalkulierte protreptische Strategie des Maximos erkennen. Das Publikum der orationes soll sich selbst als zu dieser philosophisch-tugendhaften Minderheit gehörend betrachten. Sie können sich auf die Schulter klopfen, weil sie erreicht haben, was nur ganz wenigen Menschen möglich ist: sie sind Teil einer Elite von Tugendhaften geworden.

Philosophie baut für den philosophischen Lehrer selbstverständlich atuf einem Set von Lehren, einer bestimmten Terminologie und Argumentationstechnik auf. Man mag als Beispiele die Diskussion der Daimonologie in or. 9 oder diejenige der zweiteiligen Natur der menschlichen Seelen in or. 26,5 heranziehen; auch die sorgfältige Erläuterung der Unterscheidung

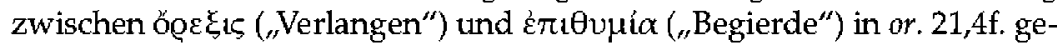
hört hierher. Aber Philosophie kommt in den orationes nicht nur theoretisch als eine Reihe von Lehrmeinungen und Werten zur Darstellung; sie ist verkörpert in einem Pantheon großer philosophischer Köpfe der Vergangenheit. Die Auswahl von Sokrates, Platon und Pythagoras als paradigmatischen Vertretern eines wahrhaft philosophischen Gebets in or. 5,8 ist typisch, denn diese drei sind (neben dem Kyniker Diogenes) innerhalb der Sammlung der orationes die am meisten zitierten Philosophen, die sowohl für ihren philosophischen Unterricht als auch für ihr beispielgebendes Leben gepriesen werden. Pythagoras wird nicht nur aufgrund seiner Vorstellungen bezüglich der Untersterblichkeit der Seele und bezüglich der Harmonie rezipiert (orr. 10,2; 29,5.7; 37,5), sondern atuch wegen dem ihm eigenen pädagogischen Stil: der an Gesetzesdefinitionen erinnernden Knappheit seiner berühmten akusmata $(25,2)$ und der mitreißenden Wirkung seines königlichen Auftretens $(1,10)$. Platon ist selbstverständlich in den orationes insgesamt ein herausragender Bezugspunkt, dessen Position bei philosophischen Schlüsselthemen wie der Frage nach dem Wesen Gottes (or. 11), nach dem Aufbau und den Wahrnehmungen der Seele (orr. 10; 27,5) ebenso wie zum Schicksal als unmittelbar autoritativ herangezogen wird (or. 13,7). Auch seine ethische Einstellung, die er auf den Sizilienexpeditionen an den Tag legte, indem er die Tyrannei als verfehltes politisches System anprangerte und den Wert der Philosophie verteidigte, wird in den höchsten Tönen gepriesen (orr. 15,8; 16,5;34,9). Nur hinter seinem Lehrer Sokrates muss Platon in seiner Bedeutung als philosophische Ikone in den orationes zurickstehen. Sokrates wird nicht nur als inspirierendes Beispiel präsentiert, als äußerste Verkörperung philosophischer Tugenden, sondern auch als Quelle jener Lehren, die im späteren Platonismus zentrale Geltung erlangen. In diesem Sinne hören wir von seiner beispiel- 
haften Weigerung, seine philosophischen Prinzipien zu verraten, indem er sich vor Gericht verteidigt (or. 3) oder gar seinen Anklägern ihre Bosheit heimzuzahlen versucht hätte (or. 12,8), und von dem göttlichen Wohlwollen, durch das er ein eigenes daimonion als Berater erhielt (or. 8,1-6). Und als sich Maximos dann in orr. 18-21 der scheinbar skandalösen Beziehung des Sokrates zu einem schönen Jüngling in Athen zuwendet, rechnet er dem Sokrates sowohl die Haltung des philosophisch inspirierten Geliebten als auch die zugrundeliegende Theorie des erôs und der Schönheit zugute. ${ }^{34}$ Die Wahl dieser drei Philosophen (Pythagoras, Sokrates, Platon) als einer einheitlichen Gruppe in or. 5,8 und atuch die Tatsache, dass Sokrates der erste Rang unter ihnen eingeräumt wird, entspricht also der üblichen Praxis des Maximos. ${ }^{35}$

Die Frage, welcher philosophischen Schule Maximos auf der Grundlage des skizzierten Philosophieverständnisses und der genannten Schwerpunkte zuzuordnen ist, wurde in der Forschung unterschiedlich beantwortet. Während Guy Sotry tund George Koniaris ihn als Eklektiker verstanden (wenn auch mit durchaus unterschiedlichen Schwerpunktsetzungen) ${ }^{36}$ behandelt ihn John Dillon als Platoniker. Dillon zufolge bietet Maximos, was in gebildeten Kreisen als "Allgemeingut platonischer Philosophie" in der zweiten Hälfte des 2. Jh.s n. Chr. gelten konnte. ${ }^{37}$ Dillon liegt hier zweifelsohne richtig. Man kann davon ausgehen, dass bereits die Wahl der platonischen Themen einen Hinweis auf die philosophische Grundausrichtung des Autors gibt. ${ }^{38}$ Genatuer sind es die Themen des religiös gewendeten Platonismus der frühen Kaiserzeit, ${ }^{39}$ die Maximos aufnimmt: "Wer ist Gott nach Platon"; oder: "Wenn Gott Gutes schafft, woher kommt das Schlechte?" Platon ist offensichtlich die zentrale Autorität (neben Homer). Und doch handelt es sich nicht im klassischen Sinne um Schtulphilosophie. Die Argumentationen sind, wie wir das in Texten des 1 . und 2. Jh.s n. Chr. üblicherweise finden, auch mit Gedankenfiguren stoischer Provenienz durchsetzt, die aber in Maximos' platonisches Weltbild integriert sind. Gerade die hier zur Diskussion stehende or. $5 \mathrm{zum}$ Gebet ist nach

\footnotetext{
${ }^{34} \mathrm{Vgl}$ or. 21,7: „, soll ich dir sagen, was Schönheit nach der Überzeugung des Sokrates ist und auf welche Weise sie wirksam wird?"

${ }^{35}$ Zur Genealogie der Weisen siehe den Beitrag von Franco Ferrari, S. 90-91 in diesem Band.

${ }^{36}$ Soury $1942 \mathrm{im}$ Titel seiner Monographie (Maxime de Tyr, platonicien éclectique); KonLARIS 1983.

${ }^{37}$ Dillon 1996, 400.

${ }^{38}$ Während Franco Ferrari im vorliegenden Band, S. 77-80 dafür votiert, dass Maximos sich als Platoniker verstand, hat Michael Trapp sich bereits in früheren Putblikationen dagegen ausgesprochen, dass Maximos sich selbst hätte als Platoniker bezeichnen wollen (TrapP 1997a, xxii-xxx, bes, xxiv-xxvi).

${ }^{39}$ Vgl. Hirsch-Luipold / Görgemanns / von Albrecht 2009.
} 
dem Urteil von G. Soury stoisch gefärbt; ${ }^{40}$ mit der Frage der Vorsehung steht ein dezidiert stoischer Aspekt im Vordergrund. ${ }^{41}$ Heute weicht das Verdikt eines philosophischen Synkretismus oder Eklektizismus für diese für die Kaiserzeit charakteristische Aufnahme stoischer Philosopheme in die grundsätzlich platonische Position des Autors in den letzten Jahren zunehmend einer differenzierteren Sicht, die mit Begriffen wie "subordinating appropriation" (Boys-Stones 2001) das Phänomen zu beschreiben versucht, dass die Autoren der frühen Kaiserzeit nicht mehr starr einer philosophischen Schule folgen, sondern sich bei Gedanken und Terminologie unterschiedlicher Schultraditionen bedienen, um ihre eigenen philosophischen Gedanken zu formen. ${ }^{42}$

Dass die Ideenlehre bei Maximos als wesentliches Element platonischen Denkens keine Erwähnung findet, muss man nicht überbewerten, wenn man in Rechnung stellt, dass auch Plutarch als der bedeutendste und einflussreichste Platoniker des 1./2. Jh.s n. Chr. nur an jenen Stellen von Ideen redet, wo er unmittelbar Platon interpretiert, ansonsten aber die Rede von den Ideen durch den Gottesgedanken ersetzt. ${ }^{43}$ Maximos lässt sich auch in dieser Hinsicht dem religiösen Platonismus der frühen Kaiserzeit ztuordnen.

Freilich ist zu beachten, dass sich Maximos nirgendwo explizit als Platoniker bezeichnet. Er vermeidet Grenzziehungen und stellt sich anstatt dessen als Repräsentanten einer breiten, altehrwürdigen Bildungs- und Weisheitstradition dar, der es um die essentiellen Wahtheiten von Welt, Gott und Mensch und um die Grundregeln eines guten Lebens zu tun ist. Entsprechend vermeidet er jegliche terminologische Kennzeichnung philosophischer Schuldifferenzen; das Wort hairesis (Sekte, Schule) erscheint bei ihm ebenso wenig wie der Name einer der gängigen Schulen. Zeitgenössisches philosophisches Denken ist s.E. nichts anderes als eine pedan-

\footnotetext{
${ }^{40}$ Ebenso wie or. 13 (Prophetie) und or. 41 (Quelle des Übels), die Soury 1942 neben or. 5 untersucht.

${ }^{41}$ Demgegenüber unterstreicht TrмoтiN 2016, 166-168, den platonischen Charakter der Argumentationen in den Anfangskapiteln, insbesondere der Kritik an der Vorstellung, das Göttliche könnte durch Geschenke beeinflussbar sein.

${ }^{42}$ Die Frage, wie sich die Grenze zwischen Platorismus und Stoa in der Kaiserzeit bestimmen lässt, wird jüngst an einzelnen Autoren ebenso wie im Blick auf das Gesamtbild wieder intensiv diskutiert (vgl. etwa M. BonazzI / C. HelmIG [Hg.], Platonic Stoicism-Stoic Platonism. The Dialogue between Platonism and Stoicism in Antiguity [Letven 2007]). Dabei geht es auch darum, treffendere Konzepte für das Phänomen zu finden als "Synkretismus" oder "Eklektizismus". T. EnGRerg-Pedersen spricht von einer "transitional period" ("Setting the Scene. Stoicism and Platonism in the Transitional Period in Ancient Philosophy" in: T. Rasimus / T. Engberg-Pedersen / I. Dundergerg (Hg.), Stoicism in Early Christianity [Grand Rapids (MI) 2010] 1-14; T. Engberg-Pedersen (Hg.), From Stoicism to Platonism. The Development of Philosophy, 100BCE-100CE [Cambridge 2017]).

${ }^{43}$ In ähnlicher Weise erinnert bei Maximos die Rede über eine transzendente Form des

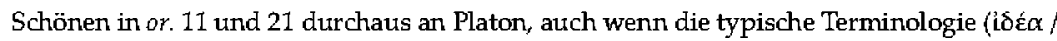
ETós) fehlt.
} 
tischere Reformulierung der umfassenden Weisheit, die sich bereits in der frühesten Dichtung aufbewahrt findet (orr. 4; 26). An manchen Stellen thematisiert Maximos die Tendenz der Philosophie, sich in scheinbar gegensätzliche Schultraditionen aufzuspalten (orr. 4,3;26,2;29,7), aber wenn er das tut, dann nur, um solche Entwicklungen als ein Zeichen der Degeneration in der modernen Welt und als Verrat am eigentlichen Wesen der Philosophie zurückzuweisen. Wie die Wahrheit eins und unteilbar ist, so sollte auch das Streben nach der Erkenntnis dieser Wahtheit (philo-sophia) ihre Vertreter einen, anstatt sie zu spalten. Der Einzige, der aus dieser vielfältigen Kirche von Erleuchteten ausgeschlossen bleibt, ist Epikur, der in den orationes regelmäßig als Atheist (orr. 4,9;25,4;41,2) oder als Hedonist (orr. 29-33; vgl. 15,8; 19,3) beschimpft wird und deshalb auch der Benennung als "Philosoph" (orr. 4,4;33,3) unwürdig ist. Davon abgesehen aber arbeiten alle Philosophen zusammen, weil sie über die grundlegenden Wahrheiten einer Meinung sind: Platon, Aristoteles und Pythagoras sind derselben Ansicht über die Seele (or. 27,5); Aristoteles, Chrysipp und Kleitomachos bringen das gemeinsame Erbe, das sie von Homer, Hesiod und Orpheus übernommen haben, in ihre je eigenen Worte (or. 4,3); Platon ist Homer ebenso verpflichtet wie seinem unmittelbaren Lehrer Sokrates, sowohl was seine philosophischen Vorstellungen als auch was die gehobene philosophische Redeform anbelangt (or. 26,3). Auch hier fügt sich die Verbindung von Platon, Sokrates und Pythagoras in or. 5,8 in ein allgemeineres gedankliches Muster ein.

Die vorsichtige Mischtung aus philosophischem Inhalt tund rhetorischer Darstellungsform in den orationes bringt Maximos in einige Nähe zu Dion Chrysostomos und Apuleius. Diese Verwandtschaft disqualifiziert Maximos keineswegs als Philosophen, sondern unterstreicht seinen Anspruch eher. In der Meinung der Zeitgenossen nämlich hatten die beiden Genannten Anspruch auf diesen Titel. ${ }^{44}$ Die Nähe zu Plutarch, im Blick auf die Verwendung von quaestiones oder problemata (Platonicae Quaestiones, Symposiaca) und unterschiedliche Formen bildhafter Sprache ${ }^{45}$ ebenso wie durch sein durchgängiges Bemühen, philosophisch-ethische Bildung mit einer angenehmen literarischen Darstellung zu verknüpfen (Eheratschläge, Tischgespräche), unterstreicht diesen Anspruch noch weiter.

Man sollte angesichts der ztu beobachtenden Nähe zu den genannten Autoren indes die individuellen Akzente in den eigenen Beiträgen des Maximos zur Ausgestaltung der Tradition nicht unterschätzen. Wie aus der vorausgegangenen Diskussion klar geworden sein sollte, lassen sich die Reden des Maximos, auch wenn sie in manchen Zügen Ähnlichkeiten gerade zu Dion, Apuleitus und Plutarch aufweisen, nicht ohne weiteres mit irgendeinem anderen Werk des 2. Jh.s n. Chr. vergleichen. Einen

\footnotetext{
${ }^{44}$ Vgl. Trapr 2007, 23-27; Apuleits, A pol. 1-I6 und ILA 2115.

${ }^{45}$ Vgl. Hirsch-Luipold 2002.
} 
entscheidenden Punkt könnte man die "kulturelle Verortung" der Philosophie nennen, der sich besonders klar in der programmatischen or. 1, aber durchaus auch anderswo, ausgedrückt findet: Maximos betont den Wert und die Stellung der Philosophie im Konzert der übrigen Bestandteile griechischer paideia. So ist oratio 1 voll von Bildern, die einerseits einen attoritativen (philosophischen) Lehrer vor seinen aufmerksamen Schülern evozieren, andererseits einen Starredner vor seinem begeisterten Publikum: den Aulos-Spieler und seine Vögel $(1,7)$, aber ebenso den vielseitigen Kithara-Spieler (1,1f.), den Athleten im Stadion (1,4-6), den Schauspieler $(1,1.10)$. Dass sich diese beiden Paradigmen überlagern, spiegelt die Verbindung philosophischer Unterrichtsgegenstände mit einer gelehrten rhetorischen Darstellungsform, die das Werk des Maximos selbst charakterisiert. Damit will Maximos aber die Philosophie zugleich verorten in einer Zeit, in der paideia ganz allgemein Aufführungscharakter hat. Für die Philosophie ergab sich darats die Herausforderung, sich dieser Dimension nicht $\mathrm{zu}$ entziehen, und doch nicht aus dem Blick $\mathrm{zt}$ verlieren, dass sie nicht nur zur Unterhaltung dienen soll, sondern Hilfe zu einem reflektierten und verantwortlichen Leben sein will. Etwas von dieser Problematik kann man in orr. 22 und 25 sehen. Beide setzen pointiert den philosophischen Diskurs von konkurrierenden zeitgenössischen Formen ab. Nach or. 22 kann nur die philosophische Rede die Seele wirklich nähren, und nur sie zeigt wirksam den inneren "Krieg" zwischen Vernunft und den unberechenbaren Leidenschaften auf, von dem die Unterscheidung zwischen einem Leben in tugendhafter Selbstkontrolle und einem Leben in lasterhafter Selbstvergessenheit abhängt. Gerichtsrhetorik, sophistische Redekunst und Geschichtsdarstellung haben nichts Gleichwertiges anzubieten. Or. 25 behauptet in ähnlicher Weise, dass wirkliche Schönheit der Worte nur in philosophischer Rede zu finden ist; denn sie regt zur Tugend an, anstatt atuf den niederen Impuls sinnlicher Befriedigung abzuzielen. Bloßer Wortglanz, wie er wiederum durch die sophistische Redekunst repräsentiert wird, droht das Publikum eher zu verführen und zu korrumpieren als es zu informieren und zu erleuchten. ${ }^{46}$ Nach or. 37 besteht der eigentliche Wert jeglicher intellektuellen Übungen, etwa von Musik und Geometrie, die hier für das gesamte Spektrum der freien Künste (enkyklia mathêmata) stehen, weniger in ihrem je eigenen Beitrag als vielmehr darin, dass sie den Geist für die Philosophie vorbereiten.

\footnotetext{
${ }^{46}$ Sophistische Redekunst, so sagt Maximos polemisch, sei entweder dem Preis von längst verblichenen Heroen aus Geschichte und Mythologie gewidmet oder diene der Verurteilung von ummoralischen Verhaltensweisen, deren sich der Sprecher selbst schuldig mache. Er zielt damit auf die beiden Hauptredeformen der Zeit, nämlich historische oder erfundene Themen der Gerichtsrede; vgl. Russell 1983, 9-15. 21-39. 106-128.
} 


\section{Die Schrift "Ist beten sinnvoll?“ - Thema, Stil und Aufbau}

Als Haupthese der Schrift kann gelten: Beten ist sinnlos im Sinne eines Bittgebetes um etwas. Bittet der Mensch nämlich um etwas Gutes und Sinnvolles, wird ihm die gute Gottheit dies auch ohne Gebet zuteilwerden lassen, wenn er des Erbetenen würdig ist; bittet er indes um etwas Schlechtes oder Schädliches, wird er es nicht erhalten, selbst wenn er darum bittet. Anstatt aber das Thema unmittelbar systematisch anzusteuern, wählt Maximos in der für ihn charakteristischen Weise einen gefälligeren Einstieg über eine fesselnde Geschichte: die Geschichte von Midas, dem Satyr und der Berührung, die alles zu Gold werden lässt. Dann folgen ein mythisches und ein historisches Exemplum (\$\$1f.). Über seine Kommentare verhilft Maximos den Zuhörern dazu, diese Geschichten als Beispiele von verfehlten Gebeten zu interpretieren.

Erst in $\$ 3$ beginnt Maximos die Hauptthese der Schrift zu entfalten: aus den Worten des Phoenix aus Ilias IX 497 entwickeln sich die beiden Fragen, ob nämlich der Gedanke angemessen ist, dass das Göttliche seine Meinung ändern könnte, und welche Rolle die Würdigkeit des Betenden bei der Erfülltung des Gebets spielt. Das Argument ergibt sich aus einem Gottesbegriff, der Gott als allwissend, allmächtig und vor allem gütig den Menschen zugewandt versteht. Die Gottheit weiß auch ohne das Gebet besser als der Mensch selbst, was für ihn zuträglich ist und ob er des Erbetenen würdig ist. ${ }^{47}$ Maximos zieht zur Erlätuterung das Wirken des Arztes vergleichend heran. Auch der Arzt lässt sich nicht von den Wünschen des Patienten leiten und beeinflussen, sondern richtet seine Verschreibung von Medikamenten einzig und allein daran aus, was für den jeweiligen Menschen zuträglich ist (\$ 4). Die Grundlinien der Problematik zeichnet Maximos also in den ersten drei Kapiteln (I). Ein systematischer Teil (II) schließst sich an. Von der Frage nach der Würdigkeit (schon hier verbunden mit Gottes übergeordneter Sorge um die gute Gesamtordnung und die richtige Reihenfolge in der Verfolgung der Bedürfnisse im Rahmen dieser Ordnung) schreitet Maximos zu einer Untersuchung der Faktoren, unter deren Aufsicht alles Geschehen in der Welt steht (Vorsehung, Schicksal, Zufall und Sachverstand). Worum Menschen bitten könnten, das steht Maximos zufolge unter dem Einfluss dieser vier Faktoren (\$4). Die ersten drei sind nicht beeinflussbar, der letzte steht in der Verfügung des Menschen und ist

\footnotetext{
${ }^{47}$ In diesem Zusammenhang kritisiert Maximos auch den für das Gebet an sich gattungsgerechten Hinweis auf frühere Wohltaten, die der Beter der Gottheit erwiesen habe, da ein solcher Hinweis eine Bestechlichkeit des Göttlichen zu implizieren scheint (vgl. die oben erwähnte Kritik Lukians). Zur Würdigkeit des Beters siehe đie Anm. zur Übers. 32-38 und 81, die Beiträge von Franco Ferrari, S. 85, Alfons Fürst, S. 123, 135 und. 138 Anm. 76 sowie Rainer Hirsch-Luipold in diesem Band.
} 
also unabhängig von der Gunst des Göttlichen: in allen Fällen ist deshalb ein Gebet sinnlos. Diese vier Aspekte werden in der Rede nacheinander behandelt ( $\$ 4-6)$, bevor in einer Art Ergebnissicherung das Erhobene an einigen Einzelbeispielen durchgeführt wird (\$7).

Alle diese Beispiele widersprechen auf ihre je eigene Weise einer sinnvollen Rolle des Bittgebets. Als Coda ( $\$ 7$ ), die zu den Eingangsbeispielen von Kroisos und Chryses zurückführt, macht Maximos klar, dass diese Form des Gebets selbst im Zusammenhang der niedrigsten, materialistischsten menschlichen Ambitionen (nach Reichtum, Sieg oder Erfolg bei Handelsunternehmungen) sinnlos ist. Nachdem die falsche Gebetspraxis auf diese Weise zu den Akten gelegt worden ist, kommt die Rede in einem abschließenden Kapitel (III) mit der einzig sinnvollen Form des Gebets, dem Gebet des Philosophen, das an den drei klassischen Vorbildern Sokrates, Pythagoras und Platon exemplifiziert wird, zu ihrem Höhepunkt. Der Philosoph habe das Gebet nicht als Bitte um etwas zu verstehen, das nicht vorhanden wäre, sondern als Gespräch der Seele mit Gott und als Aufweis ( $\dot{\varepsilon} \pi \hat{\delta} \delta \varepsilon\llcorner\xi \zeta)$ der ethischen Tugend des Betenden (\$8). Nun nimmt Maximos auch formal im Sprechakt des Gebets das Thema der Schrift auf: Am Ende der Darlegung steht bemerkenswerterweise ein Gebet an Zeus, Athena und Apollon. Es mündet in die Aussage ein, die Philosophie sei als Lebensfunke zu betrachten, weil sie jenes Organ im Menschen darstelle, das sich aufs Beten versteht (",es bedarf aber dieses seltenen und kleinen Flämmchens für das Leben, das bald in diesem, bald in jenem Körper aufleuchtet... Wenn du ats dem Leben die Philosophie herausnimmst, dann hast du ihm den Lebensfunken genommen, den Atem, die Lebenskraft, dasjenige nämlich, das sich allein aufs Beten versteht", \$8). Damit wird zuletzt die Philosophie zur Voraussetzung des Gebets als einer Grundfunktion menschlichen Lebens.

Formal ergibt sich also eine Dreigliederung: ${ }^{48}$

I. Hinführung mit mythischen Exempla und Grundlinien: Die Unsinnigkeit bestimmter Formen des Bittgebets

II. Systematischer Durchgang:

1. Die Würdigkeit des Betenden als entscheidende Kategorie

2. Die vier Kräfte, die menschliches Leben beeinflussen III. Schluss: Das philosophische Gebet

Inhaltlich zielt die Schrift über das Gebet nicht allein auf menschliche Frömmigkeit und ein heilsames Gottesverhältnis, sondern zugleich auf den der Gebetsfrömmigkeit zugrundeliegenden Gottesgedanken. Wenngleich von dort her die Gebetspraxis kritisch beleuchtet wird, ist die Schrift nicht einfach gebetskritisch. Maximos begreift wie die übrigen Vertreter

\footnotetext{
${ }^{48} \mathrm{Vgl}$. Trmotin 2016, 164, der allerdings die mythische Darstellung und Auswertung in \$1-3 einmal untergliedert.
} 
des religiösen Platonismus der Kaiserzeit Philosophie nicht nur allgemein als religiöse Übung, sondern füllt dies im Gespräch mit der gelebten religiösen Tradition aus.

\section{Götter und Religion im pädagogisch-philosophischen Werk des Maximos von Tyros}

In or. 5 wie in den übrigen Dialexeis widmet sich Maximos gern philosophischen Themen mit theologischem Einschlag: "Wer hat die zutreffendere Gottesauffassung: Dichter oder Philosophen?" (or. 4), "Wer ist Gott gemäß der Philosophie Platons?" (or. 11), "Wenn Gott das Gute tut, woher kommt das Übel?" (or. 41). Bisweilen behandelt er auch, wie im vorliegenden Fall der or. 5 oder in or. 2 ("Soll man den Göttern Standbilder aufstellen?"), Themen der religiösen Tradition und Praxis, die er auf ihren philosophischen und genauer theologischen Gehalt hin ausleuchtet. Mit der Frage nach dem Kontakt zwischen Gott und den Menschen, der in diesen Schriften angesprochen ist, befassen sich auch zwei Schriften über das Daimonion des Sokrates (orr. 8-9) und vier über den Eros bzw. die sokratische Liebe (orr. 18-21). Gemeinhin bezeichnet man sechs bis acht der genannten Dialexeis als religiös-philosophische Schriften. ${ }^{49}$

Das Phänomen greift aber über diese üblicherweise als religiös-philosophisch bezeichneten Dialexeis hinaus. ${ }^{50}$ Sichten wir die übrigen Dialexeis, so wird schnell deutlich, dass eine ganze Reihe von ihnen entweder ihren Ausgang von Aspekten der gelebten Religion nimmt oder dezidiert theologische Probleme diskutiert, auch dort, wo der (sekundäre) Titel dies - anders als in or. 38 ,ob jemand durch göttliche Zuteilung ${ }^{51}$ ein guter Mensch wird $^{\prime \prime}$ - nicht unbedingt vermuten lässt. Auch Gebete kommen verschiedentlich vor und werden sogar explizit zum Thema (orr. 7,1.5; 22,7). Angesichts der breiten Präsenz der religiösen Thematik in den Dialexeis hat das Thema bislang überraschenderweise - mit Ausnahme der Dissertation von Rohdich ${ }^{52}$ und der erwähnten Studie von Soury - nicht die gebüh-

\footnotetext{
${ }^{49}$ B. Pérez-Jean / F. Fauquibr (Hg.), Maxime de Tyr. Choix de conférences: religion et philosophie. La route à livres 70 (Paris 2014), wählen neben der einleitenden or. I folgetıde Dialexeis aus: or. 2 (Götterbilder); or. 4 (Dichter oder Philosophen), or. 5 (Beten); orr. 8-9 (Daimonion des Sokrates); or. 11 (Gott nach Platon); or. 38 (Wie jemand gut wirc); or. 41 (das Böse); ihre knappe Einleitung behandelt Maximos aber überwiegend als rhetorischen Autor und Vertreter der Zweiten Sophistik; das Thema Religion und Theologie wird abschließend lediglich bei der Begründung der Auswahl erwähtnt.

${ }^{50}$ Interessanterweise stammt auch eine der drei religiös-philosophischen Schriftetı, die Soury 1942 exemplarisch diskutiert, aus dem Kreis der übrigen Dialexeis: or. 13 über Divination und Freiheit, die Soury neben or. 5 und or. 41 behandelt.

${ }^{51}$ uoīpa. Vgl. Platon, Men. 100a.

${ }^{52}$ RohDIch 1879. Zur Theologie s. immerhin die Dissertation von M. DePRÉ, La connaissance de Dieu chez Maxime de Tyr, Diss. Louvain 1940.
} 
rende Aufmerksamkeit in der Forschung erhalten. ${ }^{53}$ Deshalb wollen wir im Folgenden in einem Durchgang die Vielzahl der Stellen mit religiöstheologischer Thematik im Gesamtwerk des Maximos herausarbeiten. Dabei zeichnen wir einige systematische Linien, die das Werk des Maximos durchziehen. Die Zwischenüberschriften, unter die jeweils eine Reihe von orationes zusammengestellt werden, formulieren dabei Einzelaspekte des Themas, die in diesen Schriften besonders präsent sind, aber sich durchaus auch in anderen Schriften finden.

\subsection{Philosophie und religiös-künstlerische Tradition im Dienst der Gotteserkenntnis und einer Kommunikation mit dem Göttlichen}

Gotteserkenntnis und Kommunikation mit dem Göttlichen treten als Thema in or. 5 in besonderer Weise in den Vordergrund, prägen aber einige gerade der ersten Dialexeis. Bereits die programmatische erste Dialexis (or. 1) vergleicht das Leben mit einem Theaterstück, dessen Autor und Regisseur Gott ist. Or. 2 fragt danach, ob Kultbilder der Götter (agalmata) für religiöse Götterverehrung unabdingbar sind, und gibt eine sorgfältig ausbalancierte Antwort: zwar braucht Gott keine Götterbilder, weshalb auch keines der vielen Bilder, die bei den Völkern der Welt in Verwendung sind, für sich eine besondere Autorität beanspruchen kann. Bilder sind aber dennoch aus der Sicht der Menschen nützlich, denn sie helfen dem schwachen menschlichen Geist dabei, sich auf das Göttliche zu konzentrieren (so wie die Linien, die Lehrer ihren Schülern in die Übungsbücher zeichnen, dabei helfen, sorgfältig zu schreiben). ${ }^{54}$ Die oratio nimmt mit der Frage der Legitimität der Repräsentation und Verehrung des Göttlichen in küinstlerischen und mythologischen Bildern eine klassische Debatte zu den Grundlagen und Ausdrucksformen der Theologie auf. ${ }^{55}$ Behandelt werden Statuen und andere Repräsentationen des Göttlichen in einem religionsgeschichtlichen Überblick über die unterschiedlichen Formen von Götterbildern und ihre regionalen Ausprägungen $(2,1){ }^{56}$ Dem stellt Maximos die Universalität der Rede gegenüber, die keiner Bilder bedürfe. Indes sei eben ein abstrakter Gottesbegriff nur einer kleinen Minderheit zugänglich - die Legitimität der Bilder liegt also in ihrem Vermittlungscharakter $(2,2)$. Nach diesen einleitenden Überlegungen geht Maximos die einzelnen Regionen mit ihren

\footnotetext{
${ }^{53}$ Einen Artikel im RAC etwa gibt es nicht.

${ }^{54} \mathrm{Zu}$ or. $2 \mathrm{vgl}$. U. von WILAm OWITZ-MokLlEndorfF, Griechisches Lesebuch, Bd. I/2 (Berlin 1902) 338-342; Trapr 1997a, 15-24.

${ }^{55} \mathrm{Vgl}$. V. FAzzo, La giustificazione delle imagini religiose dalla tarda antichità al cristianesimo (Napoli 1977) 137-150 (zu Maximos).

${ }^{56}$ Manches, das auch aus Plutarchs De superstitione und De Iside et Osiride geläufig ist, wird hier aufgegriffen.
} 
jeweiligen Bildern durch: Griechen mit ihrer anthropomorphen Gottesverehrung (2,3), Perser (2,4: Feuer), Ägypter (2,5: Tierverehrung, die wie von den meisten Autoren auch von Maximos hier kritisch beurteilt wird), Inder, Libyer und Kelten (2,6-8). Die Diskussion gelebter Religion steht also im Zentrum der Schrift. Den Schluss bildet eine Klassifizierung von Götterbildern und Gründen der Verehrung sowie die These, dass kein Volk ohne Götterbilder auskomme $(2,9)$, und schließlich ein theologisches Fazit: Der "Vater und Schöpfer aller Dinge ${ }^{\prime 57}$ ist für den Menschen nicht zu fassen, aber die Bilder erinnern uns an ihn, so wie sie das bei Verliebten tun. Diese Einsicht hat Implikationen für die Gottesverehrung, die nun auch eine größere Offenheit gegenüber der zuvor heftig kritisierten Gottesverehrung der Ägypter zeitigen: "Warum soll ich also noch den Gebrauch von Götterbildern untersuchen und Vorschriften darüber machen? Alle Menschen sollen um das Göttliche wissen, nur um solches Wissen geht es. Wenn aber die Kunst des Phidias die Griechen zur Erinnerung an Gott aufruft, die Ägypter andererseits Tierverehrung, noch andere ein Fluss oder das Feuer, tadle ich diese Vielstimmigkeit nicht. Man soll nur (um die Götter) wissen, soll (sie) nur lieben, soll (ihrer) gedenken" (2,10). Am Ende wird hier das Dass der Gottesverehrung der theologischen Erkenntnis sogar vorgeordnet! Gleichwohl bleibt freilich der Gottesbegriff zentral für die Schrift. ${ }^{58}$

Im Verlauf seiner Darlegung entwirft Maximos ein Idealbild von Menschen, die mit einer starken Erinnerungsfähigkeit gesegnet und deshalb in der Lage sind, "sich mit ihren Seelen unmittelbar nach dem Himmel auszustrecken, um dort auf das Göttliche zu treffen". Weil die wenigen, denen das gelingt, aber nicht für die Menschheit insgesamt repräsentativ sind, und deshalb auch nicht als Grundlage dafür dienen können, was als gute Religionsausuibung zu gelten hat, verwirft Maximos dieses Ziel sofort wieder. Man wird diese wenigen, nicht-repräsentativen Glücklichen wohl nicht zu tunrecht in die Nähe jener philosophischen Schüler rücken, die sich Maximos in or. 5,8 wünscht, die nämlich in ihre "starken Seelen" die Lehren des Zeus, der Athena und Apollons aufzunehmen in der Lage sind und "in ihrem Leben eine gute und glickliche Ente hervorbringen".

Das Thema der Legitimität von Bildhaftigkeit in der Rede über Gott und das Thema der (Gottes-)Erkenntnis wird in or. 4 fortgeführt mit dem Vergleich von Dichtung (Homer) und Philosophie (Platon) im Blick auf ihre Fähigkeit, theologische Erkenntnis und Kommunikation tiber das Göttliche und mit dem Göttlichen zu ermöglichen. Homer wird bei Maximos als

\footnotetext{
${ }^{57}$ Vgl. Plat. Tim. 28c.

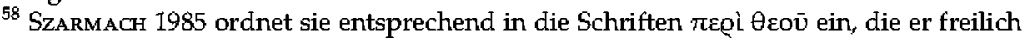
primär in rhetorischer Tradition sieht.
} 
„Bibel der Griechen ${ }^{459}$ (neben Platon) in seinem ganzen Werk ausführlich und in der Regel zustimmend zitiert. ${ }^{60}$ Daraus ergibt sich nahezu zwangsläufig die Frage, wem der Vorrang zukommt, ja, von Platons Homerkritik herkommend zunächst einmal die Frage, ob den Dichtern überhaupt etwas Sinnvolles im Blick auf die Wahrheit entnommen werden könne. Maximos kommt letztlich zum selben Ergebnis wie in or. 2: Dichter wie Philosophen arbeiten (legitimerweise) mit Bildern, denn der Mensch versucht, das Unsichtbare zu entschlüsseln und sich vom Göttlichen eine Vorstellung zu machen: "Alles ist voll bildhafter Rätselrede ( $\alpha$ iví $\gamma \mu \alpha \tau \alpha)$, sowohl bei Dichtern wie bei Philosophen" $(4,5) \cdot{ }^{61}$ Dies ist in eine Kulturgeschichte eingebunden: früher gab es aufgrund der Einfachheit der Seele eine poetischere Philosophie; wenn dies auch in jüngerer Zeit einer Philosophie des bloßen Wortes gewichen ist, so war doch von Anfang an die Lehre von den Göttern immer schon Teil der Philosophie $(4,3)$. Dem schließt sich eine Theologie der mythischen Bilder an, die an das Compendium des Cornutus erinnert $(4,8)$. Diese Theologie mündet schließlich in eine Reihe traditioneller Götterbilder für die göttliche Weltenlenkung (Großkönig, Steuermann, Heerführer, Verwalter, Landwirt). Die Vorstellung einer guten Lenkung der Welt durch die Götter wird als Kritik an der epikureischen Vorstellung von der glückseligen Ruhe der Götter zugespitzt. Die Dialexis stellt also die traditionellen poetischen Gottesbilder mit der sich aus ihnen jeweils ergebenden Gottesvorstellung neben philosophische Gottesbilder.

\subsection{Zur Verbindung von Gott und Mensch: Geschichtstheologie, Ethik, Anthropologie, Daimonologie und Seelenlehre}

Or. 3 handelt von der (mangelhaften) Verteidigung des Sokrates gegen die Anklage, die Jugend zu verführen und netue Götter einzuführen, was am Ende zu Aussagen über das Wesen Gottes führt. Es wäre, so sagt Maximos, für Sokrates ein Leichtes gewesen zu zeigen, dass "die Beschäftigung mit der Tugend die Jugend nicht verdirbt und die Erkenntnis Gottes kein Vergehen gegen die Götter" darstellt (or. 3,6). Den Abschluss der Dialexis

\footnotetext{
${ }^{59}$ So schon F. A. Wolf, Vorlesung ïber die vier ersten Gesünge von Homer's Illias, herausgegeben und mit Bemerkungen und Zusätzen begleitet von L. UstrRI, Bd. I (Bern 1930) 7.

${ }^{60}$ Eine Ausnahme bildet, wie schon gesagt, die hier zur Diskussion stehende or. 5, wo er Äußerungen der homerischen Helden zum Gebet kritisiert.

${ }^{61}$ Übers. Schönberger. In or. 4 finden sich eirige Überlegungen zu bildhaften Darlegungsformen, die er entsprechend ihrer Wahrscheinlichkeit auf eine Skala diskursive

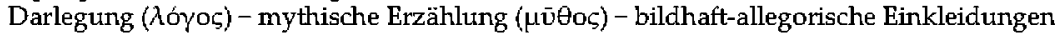

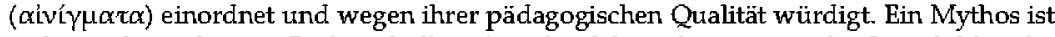
nichts anderes als „eine Rede, gehüllt in fremđen Schmuck, ganz wie die Götterbilder, denen ihre Verehrer Gold, Silber und Gewänder umhängten, um die Vorstellung von ihnen majestätischer zu machen" (Übers. Schönberger).
} 
bildet eine geschichtstheologische Darlegung des zeugnishaften Sterbens des Sokrates sowie seiner besonderen Gottesbeziehung, eine Darlegung, die durchaus Ähnlichkeiten zur christlichen Darstellung des Todes Jesu aufweist. Denn Maximos dreht die Anklage um: an vielen Beispielen in der Geschichte zeigt sich, dass das Volk der Athener sich genau der Punkte schuldig macht, die es dem Sokrates zu Unrecht zur Last legt. Mit der Bezeichnung des Perikles als "Olympier" führt es einen seltsamen netuen Gott ein, und wie sehr es die Jugend verdirbt, lässt sich an den Beispielen des Alkibiades, Hipponikos, Kritias und vieler anderer aufweisen. Als göttliche Strafe für dieses frevelhafte Verhalten der Athener, das die Geschichte durchzieht, schickt Zeus die Pest, den Peloponnesischen Krieg und weitere Ủbel. „So richtet Gott, so setzt er das Urteil um", mit diesem Satz schließt die Dialexis $(3,8)$. Nach der Diskussion des Gebets (or. 5) folgt in or. 6 eine Diskussion darüber, was als Wissenschaft zu gelten habe. Auch diese Frage zeichnet Maximos von Anfang an in eine theologische Dimension ein, insofern er zunächst Klassen von Wesen (Tier-Mensch - Gott) im Blick auf ihre Erkenntnisfähigkeit einander gegenüberstellt. Gottes Weisheit ist aufgrund seiner Ewigkeit umfassend, ${ }^{62}$ er repräsentiert als Gesetzgeber das ungeschriebene Weltgesetz, an dem sich auch der menschliche Geist zu orientieren hat (or. 6,5-7). Damit ist die anthropologische Frage nach der Fähigkeit des Menschen zu gottgleichem Leben ${ }^{63}$ gestellt, die daher rührt, dass der Mensch Anteil an der göttlichen Verntunft hat. An verschiedenen anderen Stellen setzt sich Maximos mit dem Attribut "gottgleich" auseinander $(35,1 ; 38,1$; vgl. 23,1-2). Die Gottheit ist ethisches Vorbild, wie or. 6 deutlich macht: Gottes Eigenschaften, die ähnlich wie in Dions or. 12 axiomatisch vorausgesetzt werden, ${ }^{64}$ gilt es für den Menschen nachzuahmen, um gottgleich zu werden (or. 35,2). Zu diesen Eigenschaften Gottes gehören insbesondere seine Vollkommenheit und Güte (or. 38,5-8), die Grundlage alles Guten ist (orr. 39-41).

Die folgenden Dialexeis führen die Thematik der Verbindung von göttlicher und menschlicher Sphäre fort, zunächst in or. 7 noch in anthropologischer, ${ }^{65}$ dann in orr. 8-9 in daimonologischer Hinsicht. Die beiden orationes erklären verschiedene Aspekte der platonischen Theorie der daimones, wie sie - ausgehend vom Anstoß im Symposion (202d-203a) und der pseudo-platonischen Epinomis $(984 \mathrm{~b}-\mathrm{d})$ - innerhalb der platonischen Tra-

\footnotetext{
${ }^{62}$ Vgl. Plut. De Is. 1, 351C-D.

${ }^{63}$ Zur Gottgleichheit vergleiche die emphatisch ans Ende gestellte Formulierung itr or. 26,9 .

${ }^{64}$ Interessanterweise geht Maximos abschließend auch auf die Götterfeste in Olympia sowie Nemea, Athen und Sparta ein (or. 35,8).

${ }^{65}$ Jedenfalls kann man die einleitende Gebetsbitte um Gesundheit der Seele so verstehen, dass sie den Kontakt mit dem Göttlichen erlaubt.
} 
dition über mehrere Generationen entwickelt worden war. ${ }^{66} \mathrm{Im}$ Geiste dieser Lehrtradition legen diese Vorträge die Bedeutung der dainones als Zwischenwesen dar, die verhindern, dass sich in der großen Kette des Seins eine Lücke auftut, die den Kosmos auseinander fallen lassen würde, und die zudem die Kommunikation zwischen Gott und Mensch sicherstellen. Maximos stellt das Daimonion (des Sokrates) in den Kontext anderer divinatorischer Phänomene wie der Orakel in Delphi und Klaros oder der Höhle des Trophonios. Diese Institutionen der Divination begreift er insgesamt als ein Instrument Gottes, um Kontakt zu den ihm zugewandten Menschen herzustellen und für sie zu sorgen $(8,7)$, während er selbst an einem festen Ort im Himmel verbleibt $(8,8)$. Nicht nur kommunizieren die daimones Botschaften von Gott zu den Menschen in Gestalt von ominösen Zeichen und Orakeln und überführen die göttliche Vorsehung in unmittelbare praktische Hilfestellungen für Menschen, ${ }^{67}$ sondern sie überbringen auch Botschaften in der anderen Richtung, von Mensch zu Gott. Um es mit den Worten von or. 8,8 zu sagen: sie sind „Übersetzer, die aufnehmen, was jede Seite zu sagen hat, und setzen es hinüber auf die andere Seite" ${ }^{68}$ Das Thema des Kontakts zwischen Gott und den Menschen bringt die Reden in die Nähe von or. 5 . Denn die Pointe des philosophischen Gebets, wie es in or. 5,8 definiert wird, ist der Kontakt zum Göttlichen.

Das platonische Thema, ob Lernen Erinnerung ist (or. 10), führt mit der Seelenlehre (or. 7 thematisch aufnehmend und mit orr. 8-9 verbindend) die Frage nach dem Verhältnis von Gott und Mensch weiter: eine Seele, die einen starken Daimon erhalten hat, bleibt auch im Körper unerschüittert $(10,9)$.

\subsection{Gottes machtvolle Gerechtigkeit und die menschliche Freiheit}

Von den folgenden Dialexeis (or. 11: Gottesbegriff Platons; or. 12: Gerechtigkeit; or. 13: Divination und menschliche Vernunft $)^{69}$ kommt interessanterweise gerade or. 12 zur Gerechtigkeit ohne theologische Argumentation aus, obwohl Maximos bereits in or. 6 Gott als Weltvernunft und insbesondere als Urheber des Rechts vorgestellt hatte. Das Thema der or. 11 ("Der Gottesbegriff Platons") ist umfassender als der Titel vermuten lässt, und greift über Philosophiegeschichte hinaus auf Epistemologie und Bildtheologie: Wie können wir uns einen Begriff von dem Göttlichen machen,

\footnotetext{
${ }^{66}$ Zur mittelplatonischen Daimonologie vgl. Dillon 1996, 31f. 46f.; J. Ditlon, „Dämonologie im frühen Platonismus" ${ }^{\prime \prime}$ in: BaLTHBs 2004, [123-141] 135-141; TIMOTIN 2012; TRAPP 1997a, 67-83; zum Daimonion des Sokrates P. DonINI, "Sokrates und sein Dämon im Platonismus des 1. und 2. Jahrhunderts n. Chr." , in: BaLtHBs 2004, 142-161.

${ }^{67}$ Or. 8,7 .

${ }^{68}$ Vgl. Platon, Symp. 202e; Ps.-Platon, Epin. 984e; Plutarch, De defectu 416F; De Is. 361C.

${ }^{69}$ Vgl. Trapp 1997a, 115f.
} 
wenn es mit den Sinnen nicht wahrnehmbar ist? ${ }^{70}$ Wie lässt sich folglich angemessen über Gott reden? Der Ausgang spunkt, so die These, ist Platons Gottesverständnis, das als Maßstab zu gelten hat. Weil es aber den meisten ohne Vermittlung schwer verständlich ist, wird es ins Verhältnis zu den zugänglicheren Gottesbildern der Künstler gesetzt. ${ }^{71}$ Natürlich ist ein anthropomorphes Gottesbild, wie man es bei Dichtern und Künstlern findet, wörtlich verstanden lächerlich $(11,3)$; es handelt sich bei solchen Darstellungen aber um Bilder, in denen man der Gottheit begegnen kann $(11,6)$. In der Vielzahl der Meinungen, die sich aus den unterschiedlichen Götterbildern ergeben, gebe es nur eine communis opinio (die nach Maximos selbst notorische Atheisten einschließt): ${ }^{72}$ Gott, der König und Vater aller ist, ist einer, die vielen Götter aber sind Kinder Gottes (or. 11,5.9.12). Die Schau des Vaters und Schöpfers wird erst möglich, wenn er uns zu sich ruft $(11,11)$ - bis dahin müssen wir uns mit der Schau dessen begnügen, was sich von ihm in der Welt abbildet. Dabei rückt Maximos Gott ganz in die Nähe der platonischen Idee des Guten (vgl. das Ende von or. 21) und in die Nähe des Großkönigs, als den die ps.-aristotelische Schrift Über die Welt Gott in ihrer Kosmotheologie darstellt. ${ }^{73}$

In ihrem Interesse am Zusammenspiel des Göttlichen mit anderen katsalen Faktoren und in der Betonung der Vorsehung sind orr. 13 und 41 am engsten mit or. 5 verwandt. ${ }^{74} O r .13$, die in der handschriftlichen Überlieferung fälschlicherweise als Diskussion über die Vereinbarkeit von menschlicher Freiheit mit Prophetie überschrieben ist ${ }^{75}$ handelt in Wirklichkeit davon, dass die Organisation des Weltganzen Raum für menschliche Meinungen (gnôme) wie für prophetische Vorhersagen lässt. Der Argumentationsgang, der zu dieser Schlussfolgerung fühtt, beruht in einer Weise, die mit der Argumentation in or. 5 verwandt, aber doch nicht mit ihr identisch ist, auf der Voraussetzung, dass das gesamte Weltgeschehen durch eine Reihe von Kräften bestimmt wird, die den Zufall und menschlichen Sachverstand (technê) ebenso einschließen wie Schicksal und Notwendigkeit. Sie alle arbeiten harmonisch ineinander wie die unterschiedlichen Teile

\footnotetext{
${ }^{70}$ Or. 11,7-12. Das Thema beschäftigt innerhalb des Neuen Testaments insb. die johanneische Literatur (Joh 1,18; 1 Joh 4,12; vgl. 1 Tim 6,16).

${ }^{71} \mathrm{Vgl}$. orr. 2 und 4 . Wie ein Goldschatz müsse das bei der ersten Lektüre Platons Erhobene zunächst geprüft werden $(11,2)$. Maximos detutet eine Gerichtsverhandlung an, in der Künstler, Dichter und Philosophen über ihre Meinung Rechnung ablegen müssen - eine deutliche Reminiszenz an Dions Olympische Rede (or. 12).

${ }^{72}$ Genannt werden ats unterschiedlichen Gründen die Atomisten Letkipp und Demokrit, dazu Straton, Epikur, Diagoras und. Protagoras.

${ }^{73} \mathrm{Vgl}$. J. Thom, "The Cosmotheology of De mundo", in: ders. (Hg.), Cosmic Order and Divine Power. Pseudo-Aristotle, On the Cosmos. SAPERE 23 (Tübingen 2014) 107-120.

${ }_{74}^{74}$ Diese beiden Dialexeis untersucht Soury 1942 gemeinsam mit or. 5.

75 "Ob irgendetwas in unserer Macht steht, wenn es Prophetie wirklich gibt" ( $\varepsilon \mathrm{i}$

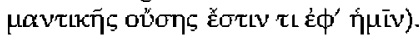


einer ausgeklügelten Maschine, um ein gemeinsames Ziel zu erreichen. ${ }^{76}$ Auch or. 41 tariert göttliches und menschliches Wirken in der Welt als katusale Faktoren aus, diesmal allerdings in einer Diskussion der Frage nach dem Bösen. Maximos verteidigt hier die Geltung der göttlichen Vorsehung mit der Behauptung, alles Übel, sei es nun wirklich oder nur scheinbar, sei nicht das Ergebnis eines göttlichen Wollens (das immer gut ist), sondern fließe aus zwei Quellen: entweder sei es ein Nebenprodukt des Wirkens der göttlichen Vorsehung, das um des erwünschten Effekts willen notwendig, aber nicht in sich selbst gewollt sei, oder aber es beruhe auf menschlicher Wahl, die von widerstreitenden Leidenschaften dazu gebracht wurde, das Gebot der Vernunft zu missachten. ${ }^{77}$ Die Verantwortlichkeit des Göttlichen für die Struktur und Ordnung der Welt ist auch Thema in orr. 11 (bes. $\$ \$ 11$.) und 4 (\$8), wird aber dort in einer Art und Weise behandelt, die mit derjenigen in or. 5 weniger eng verwandt ist. Am Ende von or. 11 erscheint Gott zunächst als entfernte Quelle, aus der Schönheit "herabfließt" durch die Himmel und die Himmelsgötter auf die Wiesen, Flüsse und Körper auf unserer Erde $(11,11),{ }^{78}$ und später (ganz ähnlich wie in der ps.-aristotelischen Schrift De mundo) als der Großkönig, der an der Spitze des Weltganzen thront und seine Macht durch eine komplexe Hierarchie von niederen göttlichen Kräften ausübt $(11,12) .{ }^{79}$ Or. 4 deckt auf, dass das Nicken des Zeus bei Homer als Allegorie für Gottes Einrichtung der Struktur der körperlichen Welt und aller Vorgänge in ihr ztu verstehen ist. ${ }^{80}$

Das gesamte erste Drittel der Dialexeis, bis zu or. 13, ist also von religiöstheologischen Themen und Argumentationen durchzogen. So auffällig diese Hätufung ist, es finden sich durchatus auch in den übrigen Dialexeis bisweilen fundamentale theologische Überlegungen, wie etwa in or. $26 \mathrm{zur}$ homerischen Theologie, die mit einer Definition der Philosophie als „Wissenschaft von Göttern und Menschen" einsetzt, oder or. 27, wo das Göttliche als entscheidender Referenzpunkt menschlicher Tugend und menschlichen Könnens erscheint. Freilich gibt es auch eine ganze Reihe von Dialexeis, die ethische Themen behandeln, ohne auf religiöse oder theologische Sprache zurückzugreifen (z.B. orr. 29-33 zum Thema der Lust). Interessanterweise spielen auch bei or. 18-21 über die Liebe die Götter eine untergeordnete Rolle (dafür tritt unter Berufung auf Platon das Streben nach dem die Welt des Körperlichen übersteigenden Schönen als Wesen wahrer Lie-

\footnotetext{
${ }^{76}$ S. auch Soury 1942, 39-56; Dillon 1996, 400; Trapr 1997a, 115-124.

${ }^{77}$ Soury 1942, 57-76; Trapr 1997a, 321-330. Zur Theodizee siehe die Anm. 16, 44 und 50 zur Übers. sowie den Beitrag von Franco Ferrari, S. 80-85 in diesem Band.

${ }^{78} \mathrm{Vgl}$. auch or. 21,7f., wo körperliche Schönheit erneut als Herabfließen aus seiner höheren, transzendenten Quelle erklärt wird. Diese erscheint als das letzte Ziel der Liebe, wird aber diesmal nicht explizit Gott genannt.

${ }^{79} \mathrm{Vgl}$. De mundo $400 \mathrm{~b} 12 \mathrm{ff}$.

${ }^{80}$ Or. 4,8; vgl. auch 41,2; und H. SchwabL, "Zeus nickt (zu lias I, 524-530 und seine Nachwirkung)", Wiener Studien 89, N.F. 10 (1976) 22-30.
} 
be in den Vordergrund, ${ }^{81}$ das in or. 11 mit Gott identifiziert wird). Selbst in diesen nicht unmittelbar mit religiöser Sprache ausformulierten Dialexeis finden sich immer wieder Gebete (or. 22,7) oder Bezüge auf das Gebet (or. 36,2 mit einer kurzen Geschichte des Gebets) und zentrale theologische Aussagen (wie in 39,5 über die Einheit des Göttlichen und des Guten: "sie haben nur ein Wesen, aber viele Namen"). Einen wesentlichen Teil der Dialexeis beschäftigt das ethische Thema, wie man zu einem glücklichen und selbstbestimmten Leben findet. Die Antwort lässt sich je nachdem ethisch, epistemologisch oder theologisch geben: ein glückliches und gutes Leben ist die Frucht der Tugend, die wiederum aus der Erkenntnis des Wahren und Guten erwächst, über die man sich zum Guten - oder zu Gott - in Beziehung setzt.

\section{Maximos, der philosophische Lehrer, und die religiös-philosophische Literatur der Kaiserzeit}

Neben dem Verhältnis von philosophischem Vermittlungsinteresse und kunstvoller rhetorischer Ausgestaltung sowie der Frage, inwieweit sich der Autor einer bestimmten philosophischen Schule zuordnen lässt und lassen will, rückt or. 5 noch eine weitere entscheidende Frage zum Verständnis seines Werks und der Philosophie der Zeit ins Zentrum: wie nämlich die Verbindung zwischen Philosophischem und Religiösem in seinem Denken zu verstehen ist, und wie dieses Verständnis auch die religiöse und philosophische Kultur in der Zeit der römischen Kaiserzeit allgemein besser erschließen hilft.

Insbesondere hat sich in der Forschung eine Abgrenzung als problematisch erwiesen, die als der religion-philosophy-divide bezeichnet werden kann. Sie trennt philosophische von "religiösen" Themen und Argumentationen, wie sie sich am deutlichsten in der Aufnahme und Diskussion religiöser Tradition (Gebet, Divination, Ikonographie, Riten und Mythen usw.) niederschlagen. Diese sind indes nicht scharf abgrenzbar von theologischen Fragestellungen, die ihrerseits als Teil der originär philosophischen Frage nach den Prinzipien gelten können, im Rahmen der religiösen Philosophie der Kaiserzeit aber vielfach gerade atus der philosophischen Interpretation religiöser Tradition gewonnen werden. Die religiöse Philosophie der frühen Kaiserzeit gründet in den Traditionen der gelebten Religion, die auf ihre Implikationen für die "Theologie", also einen philosophischen Gottesbegriff, hin befragt werden. ${ }^{82}$ Maximos ist ein Zetuge die-

\footnotetext{
${ }^{81} \mathrm{Vgl}$. or. 21,4.7.

${ }^{82}$ Vgl. Hirsch-Luipold 2009; ders. 2013.
} 
ser sich zunehmend religiösen Fragen öffnenden Philosophie. ${ }^{83}$ Völlig zu Recht sieht Rohdich den Autor deshalb in den Spuren Plutarchs wandeln, 84 der diese Verbindung von religiöser Tradition und philosophischer Auslegung neben Philon von Alexandria am umfassendsten vollzogen hat. Man könnte zudem auf den Einfluss von Dion von Prusa auf die philosophischtheologischen Aspekte, insbesondere durch die Olympische Rede or. 12 und die Borysthenes-Rede or. 36, hinweisen. Zudem dürten die Diogenesreden (orr. 6-10) für die or. 36 des Maximos prägend gewesen sein.

Die Rede von "philosophical sermons ${ }^{\prime 85}$ trägt diesem religiös-ethischen und zugleich pädagogischen Impetus der Dialexeis Rechnung. Vielleicht kann man sogar noch weiter gehen. Anhand der vorliegenden Behandlung des Themas des Gebets können wir erörtern, ob das Religiöse hier nicht als originärer Gegenstand philosophischen Nachdenkens ins Blickfeld tritt und gerade darin der Kern des religious turn der platonischen Philosophie der Kaiserzeit exemplarisch erkennbar wird.

Der Definition von Philosophie, die Maximos am Anfang der 26. Dialexis liefert, wäre dann mehr Gewicht beizumessen, als dies üblicherweise geschieht. Im Zusammenhang des Preises Homers als Grundlage der Philosophie definiert Maximos folgendermaßen:

Was anderes könnte das [sc. Homers Dichtung] sein als Philosophie? Wie sollten wir Philosophie verstehen, wenn nicht als genaue Kentrtnis göttlicher tund menschlicher Dinge, als Quelle der Tugend und von hohen Gedarken, und eines harmonischen Lebens mit kultivierten Gewohnheiten ${ }^{86}$

Die Definition von Philosophie als "Kenntnis der göttlichen und menschlichen Dinge" (or. 26,1), die zunächst wie eine Standarddefinition erscheint, ${ }^{87}$ umreißst den Inhalt des von Maximos Behandelten präzise.

Als philosophischer Lehrer, so hatten wir gesagt, eröffnet uns Maximos mit seinen philosophischen Interessen den Blick atuf das intellektuellreligiöse Milieu, das für die philosophische Landschaft der frühen Kaiserzeit charakteristisch scheint. Ist Dillons zitiertes Urteil zutreffend, dass wir

${ }^{83}$ Zut Plutarch als Lehrer einer religiösen Philosophie vgl. R. HirsCH-LurroLd, "Plutarch. Religiöse Philosophie als Bildung zum Leben", in: I. TANASEANu-DöbLER / T. GEorges / J. Schringr $(\mathrm{Hg}$ ) , "Die Lehre des Weisen ist eine Quelle des Lebens" (Spr 13,14) - bedeutende Lehrer in der Tradition der Antike und der monotheistischen Religionen (Tübingen 2015) 96-122. Wie dort anhand von Plutarchs Pythischen Dialogen gezeigt wird, verortet Plutarch seinen philosophischen Unterricht im Heiligtum des A pollon in Delphi und lässt seine Unterweisung von religiös-symbolischen Gegenständen aus dem Orakelheiligtum ausgehen.

${ }^{84}$ RoHDich 1879, If. Einen Unterschied erkennt er darin, class Maximos eher den thetorischen, Plutarch eher den philosophischen Zugang wählt.

85 Trapp 1997b; vgl. schon H. MutschmanN, "Das erste Auftreten des Maximus von Tyrus in Rom", Sokrates. Zeitschrift fiur das Gymnasialwesen N.F. 5 (1917) 185-197: "ButBpredi$\operatorname{ger}^{\prime \prime}(185) ;$, seine Reden - man kann sie ruhig Predigten nennen ${ }^{\prime \prime}$ (185); ,im Stile unserer Kanzelredner" (188).

${ }^{86}$ Or. 26, I; vgl. Alkinoos, Did. 1,1.

${ }^{87}$ Vgl. Alkin. Did. 1,152,5-6; Apul. De Plat. 2,6,228 und oben, S. 20. 
bei ihm die "common currency", also einen gängigen Grundbestand philosophischer Themen vorfinden, so sind dazu, wie die vorliegende Dialexis (und natürlich auch der ihr zugrundeliegende ps.-platonische Alkibiades 2) zeigt, eben auch Problemstellungen zu rechnen, die sich aus der religiösen Tradition ergeben. Das ist an sich wenig erstaunlich zu einer Zeit, als die Philosophie als ars vitae in durchaus lebenspraktischer Hinsicht Antworten auf die Grundfragen des Lebens zu geben versuchte: Was ist die Liebe? Woher kommt die Welt und wer bestimmt den Lauf der Geschichte? Was ist der Tod und gibt es eine Perspektive darüber hinaus? Gibt es Freiheit im menschlichen Leben und wie lässt sich ihr Wesen bestimmen? Diese Fragen sind nicht nur die Fragen eines gebildeten Schulpublikums, sondern sie rücken in der philosophischen Debatte zunehmend ins Zentrum. ${ }^{88}$

Als Gottesfrage, das heißt als Frage nach der Existenz, Macht und Gerechtigkeit eines hinter der körperlichen Welt stehenden Prinzips sowie nach dessen Umgang mit der Welt und den Menschen (und damit auch nach der Rolle der Kommunikation zwischen Mensch und Gott durch die Elemente der religiösen Tradition - Gebet, Opfer, Symbolik, Ikonographie) artikuliert sich diese Frage gerade in derjenigen Sparte des philosophischen Diskurses, die den platonischen Ideenhimmel insbesondere im Anschluss an Platons Timaios und Geseke religiös-theologisch als Sphäre des Göttlichen interpretiert. Offensichtlich beschäftigte die Frage der Rolle der gelebten Religion im Kontext der Philosophie das gelehrte Publikum des Maximos. Dem Charakter dieser religiösen Philosophie entspricht aber auch die am Gedanken der Philosophie als ars vitae orientiette pädagogische und zugleich literarisch gefällige Darstellungsweise des Maximos.

\section{Die Bedeutung der orationes - Wirkungsgeschichtliche Perspektiven}

Die orationes des Maximos sind deshalb für die Betrachtung des religiösphilosophischen Denkens in der frïhen Kaiserzeit von Bedeutung, weil kein anderer erhaltener griechischer oder lateinischer Text aus dieser Zeit in dieser Weise philosophische Themen mit rhetorischer Formung verbindet und dabei eine Vielzahl ethischer, religiös-theologischer und kultureller Anliegen zusammenführt. Deshalb kann die Auseinandersetzung mit den orationes unser Verständnis der vielfältigen Denkformen, die der Platonismus in dieser Zeit zwischen der Rückkehr der Akademie ztu dogmatischem Denken im 1. Jh. v. Chr. und dem Aufkommen des üblicherweise so genannten Neuplatonismus im 3. Jh. n. Chr. annehmen konnte, erheblich erweitern und vertiefen. Der philosophische Diskurs und die Wertediskus-

\footnotetext{
${ }^{88}$ Von dieser Tendenz legen eine ganze Reihe von SAPERE-Bänden zut Autoren unterschiedlicher religiöser Herkunft und philosophischer Ausrichtung Zeugnis ab.
} 
sion unter den Bildungseliten in den griechischsprachigen Teilen des Römischen Reiches mussten austariert werden, und der Platz der philosophia im Leben und in der Welt des pepaideumenos war immer neu zu bestimmen.

Ein weiterer, rezeptionsgeschichtlicher Aspekt kommt hinzu. Wenngleich die Zeiten schon länger vorbei sind, in denen die orationes eine gröBere Leserschaft anziehen konnten, die sich erhoffte, dort Erkenntnis oder gar Weisheit zu finden - es gab solche Zeiten durchaus. Das späte 18. Jahrhundert scheint der Wendepunkt in dieser Hinsicht gewesen zu sein. ${ }^{89}$ Es mag auch manchem modernen Betrachter schwer nachvollziehbar sein, aber die byzantinischen Gelehrten des 9 . und 10. Jahrhunderts und ihre Kollegen im Florenz des ausgehenden 15. Jahrhunderts haben die orationes als das Werk eines ernstzunehmenden, unabhängigen Denkers gelesen und rezipiert, dem hilfreiche Informationen und wertvolle Einsichten zu entnehmen sind. ${ }^{90}$ In diesen beiden Perioden einer verstärkten Atufmerksamkeit wurde Maximos für die unmittelbar folgende Generation auf die Tagesordnung gehoben: das 9. und 10. Jahrhundert erschloss den Autor für die folgenden byzantinischen Denker, von Theodoros Metochites und Nikephoros Gregoras bis zur Generation der Auswanderer, die die griechische Kultur zurück ins Italien der Renaissance brachten, und Gelehrte in Florenz bis hin zur Aufklärung erschlossen ihn für Literaten, Historiker und Theologen. ${ }^{91}$ Als Folge dieser Entwicklungen finden wir überraschend vielfältige Spuren der Auseinandersetzung mit den orationes, die über eine faszinierende Breite von Autoren und Kontexten verteilt sind sei es als Quelle für eher zufällige Einzelinformationen oder für ganze Argumentationszusammenhänge. Man lemte davon, zitierte sie als Unterstützung oder lehnte sie kritisch ab.

Oratio 5 stellt einen ausgesprochen interessanten Beleg für diese Entwicklung dar. Spätere Leser setzen sich mit der Gesamtthematik der Vorlestung auseinander, schlachten aber auch einzelne Details der Argumentation aus. Die ersten Belege für eine Auseinandersetzung mit dem Inhalt der oratio finden sich bereits in der frühesten erhaltenen Handschrift aus dem 9. Jh. (Parisinus graecus 1962), von der man mit guten Gründen annehmen kann, dass sie für einen der bedeutenden Denker der Zeit hergestellt wur-

\footnotetext{
${ }^{89}$ Was die Texteditionen anbelangt, scheint der Umbruch zwischen John Davies' zweiter Auflage und Johann Jakob Reiskes Edition gelegen zu haben. Davies' posthum herausgegebene zweite Auflage von 1740 markierte die Inauguration der Society for the Encouragement of Learning, die von dem Gelehrten Dr. Richard Mead vorgeschlagen worden war. Reiske verwirft den Autor im Vorwort seiner Leipziger Ausgabe von 1774-1775 als einen kindischen Sophisten dessen atfgeregter und enervierender Stil regelmäßig die Emsthaftigkeit des Gegenstandes verfehlt: Argumenta cum tractanda sibi stmsisset gravissima quaeque atque sanctissima, tum maiestatem eorum disputationis levitate, et paene dixerim, puerilitate saepe numero elevat atque corrumpit (v).

${ }^{90}$ Trapp 1997a, lv-lxxviii.

${ }^{91}$ Für einen knappen Überblick vgl. Trapp 1997a, lxxix-xci.
} 
de. ${ }^{92}$ Or. 5 ist eine der wenigen Vorlesungen in dieser Handschrift, die am oberen und unteren Rand mit Anmerkungen versehen ist, die Kernpunkte der Argumentation schematisierend zusammenfassen. ${ }^{93}$ Die Diskussion über das Verhältnis von Würdigkeit und Gebetserhörung in $\S 3$ wird hier in vertikale und diagonale Linien angeordnet, wobei die Vorausset ungen "betend" / "nicht betend" und „würdig" / "nicht würdig" um die Scheitelpunkte herum angeordnet sind, und das jeweilige Ergebnis „erfolgreich"/ "nicht erfolgreich" an den Verbindungslinien steht. ${ }^{94}$

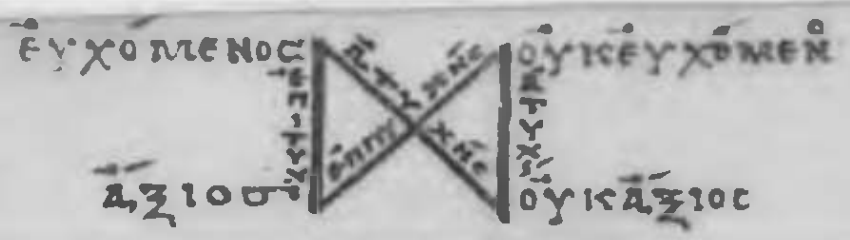

Abb. 1: BnF, Paris. gr. 1962, f. 36r, oberer Rand.

Noch ausgefeilter ist die Darstellung der vier Kräfte in $\S 4$, die auf das menschliche Leben einwirken. Sie sind in Form eines Baumdiagramms angeordnet, das den Bereich „all jener Dinge, für die Menschen beten, dass sie eintreffen mögen" unterteilt nach "was die Vorsehung beaufsichtigt", "was das Schicksal erzwingt", „was der Zufall verändert" und „wofür die eigene Fähigkeit verantwortlich ist". Ein weiteres Label erklärt jeweils, dass diese Ereignisse "das Werk Gottes", "das Werk der Notwendigkeit", "das Werk des Zufalls" oder "das Werk des Menschen" sind

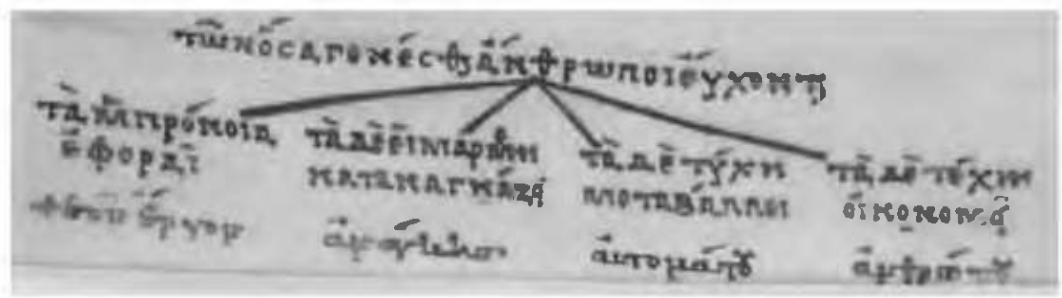

Abb. 2: BnF, Paris. gr. 1962, f. 36r, unterer Rand.

Es ist nicht ganz klar, ob diese Notizen von dem Schreiber des Manuskripts selbst erstellt oder aus einem ihm vorliegenden Exemplar kopiert wurden,

\footnotetext{
92 Über die Handschriftengruppe, zu der Paris. gr. 1962 gehört hat (die sogenannte collection philosophique) vgl. N. G. WuLson, Scholars of Byzantium (London 1983) 86-88; WHITTAKER 1974.

${ }^{93}$ Paris. gr. 1962, f. 36r, vgl. TRAPr 1994, 340; s. Abb. 1. Anmerkungen dieser Art finden sich auch bei den Vorlesungen über daimones (or. 9), Erinnerung (or. 10), und in or. 27 über die These, dass Tugend auch eine techné sei; vgl. TRAPP 1994, 341-343. 345.

94 Auch zitiert bei Timotin 2016, 170.
} 
das wohl aus dem 6. Jh. gestammt haben dürfte. In jedem Fall zeigen sie ein Bedürfnis der ersten Leser, sich über die Argumentationslogik des Maximos und über seine Vorstellung von Kräften, die den Lauf der Welt bestimmen, klar zu werden.

Eine weitere Spur der Beschäftigung mit der Argumentation des Maximos bei einem byzantinischen Leser finden wir in einer Handschrift, die Kardinal Bessarion gehörte (1403-1472). Der Kardinal selbst hat hier Randnotizen zu $\$ 8$ angebracht über die Frage, "was das Wesen des Gebetes ist und wie man beten sollte".95 Die klarsten Zeichen einer ernsthaften philosophischen und theologischen Auseinandersetzung sind indes in England und Frankreich im 18. Jh. zu finden. Der presbyterianische Theologe und Pastor George Benson (1699-1762) fügte seinem Brief an einen Freund bezüglich des Ziels und Aufbaus eines Gebets ... als Antwort auf die Einwürfe der modernen Ungläubigen, nicht nur eine Übersetzung der or. 5 als Anhang an, sondern kommentiert sie zudem durch zwölf kritische Anmerkungen. Sie wurden erstmals im Zusammenhang 1737 publiziert in Zwei Briefe an einen Freund, und dann wieder abgedruckt 1748 in Eine Sammlung von Traktaten. ${ }^{96}$ Für Voltaire war Maximos der erste Bezugspunkt in seinem Artikel über das Gebet ("Prières"), den er ursprünglich als $\$ 9$ seiner Questions sur l'Encyclopédie verfasst hatte und später in das Dictionnaire philosophique aufnahm. ${ }^{97}$ Wenig erstaunlich hoben die beiden Autoren sehr unterschiedliche Aspekte der Argumentation des Maximos hervor. Voltaire zitiert ihn als Modell einer Vernunftreligion. Maximos wolle die allzu verständliche, aber doch falsche Neigung der Menschen offenlegen, sich das Göttliche als einen Pascha oder Sultan vorzustellen, der verärgert und versöhnt werden könnte. Benson dagegen lobt Maximos zwar für seine aufgeklärte Sicht der göttlichen Vorsehung, unterstreicht aber zugleich nachdrüicklich, dass er darin fehlgeht, die Vorstellung des Gebets als Ausdruck einer demütigen und zugleich frohen Unterordnung unter den Willen Gottes atuszuschlieBen. Nur die Blindheit des Maximos gegenüber der christlichen Offenbarung halte ihn davon ab, den Wert in einem solchen Gebet zu erkennen. Benson's überraschend detaillierte Auseinandersetzung mit der Position des Maximos mag provoziert sein durch die zustimmende Zusammenfas-

\footnotetext{
${ }_{95}$ Marc. gr. Z 254 (757), f. 103v: die Handschrift wurde eigentlich für Papst Nikolaus V. von seinem Schreiber Johannes Skytariotes hergestellt, gelangte dann aber irgendwie in Bessarions Bibliothek.

${ }^{96}$ G. Benson, Two Letters to a Friend (London: R. Ford), 1-64; A Collection of Tracts (London: J. Waugh), 46-126 (Tracts 2-5).

${ }^{97}$ Voltaire, Questions sur l'Encyclopédie IX (Geneva: Cramer, 1772) 179-181; Oeuvres complètes de Voltaire [Kehl] Impr. de la Société littéraire-typographique 1785, Bd. 42 (Dict. phil., Bd. 6) 405. Der Artikel findet sich in keiner Ausgabe des Dictionnaire, die zu Voltaires Lebzeiten veröffentlicht wurde; in der Kehl-Ausgabe handelt es sich nur um die erste Hälfte, die vor allem Maximos gewidmet ist; dadurch ist die Betonung des Maximos im Dictionnaire stärker als in den Questions.
} 
sung und teilweise Zitation der Rede in einem Brief, der in der Januarausgabe 1737 des Gentleman's Magazine erschien und auf eine Anmerkung in der Ausgabe zum "Gebet als natürlicher Pflicht" vom Oktober 1736 reagierte. $^{98}$

Diese beiden Bezugnahmen auf die Vorlesung des Maximos über das Gebet, die sicher unabhängig voneinander entstanden sind, legen nahe, dass sie schon lange ihren Weg in die theologische Diskussion gefunden hatte, bevor Benson und Voltaire (oder der anonyme Beiträger zum Gentleman's Magazine) sie aufgegriffen haben. Dazu würde passen, dass die orationes allgemein von Theologen und Religionsgeschichtlen seit dem späten 16. Jh. verstärkt aufgenommen wurden. ${ }^{99}$ Bezüglich der or. 5 ist auch ein Hinweis im Werk des holländischen Theologen Herman Witsius aus dem 17. Jahrhundert (1636-1708) beachtenswert. In der zweiten seiner Heiligen Dissertationes über das Herrengebet von 1689 schreibt er: „atus Platons Schriften geht eindeutig hervor, dass Maximus Tyrius zu Recht gesagt hat, das Leben des Sokrates war voll von Gebet. "100 Jedenfalls erwies sich die or. 5, als sie es erst einmal ins Repertoire der antiken Texte zum Gebet geschafft hatte, als ausgesprochen langlebig: sie wird noch am 9. Juli 1881 in einem Artikel über "Gebet und Naturgesetz" im Sacramento Daily Union zitiert; freilich ist $\mathrm{zu}$ dieser Zeit die Kenntnis der Herkunft und der Details so verwischt, dass Maximos als ein Autor des 16. Jh.s [sic] bezeichnet werden kann, und die direkten Zitate des Werks nicht wirklich von Maximos selbst sind, sondern Voltaires Lexikonartikel entstammen. ${ }^{101}$ Damit sind aber noch nicht alle Bereiche der Verwendung der Rede bei späteren Autoren diskutiert. Der Mythos am Anfang nämlich, über Midas, Satyr und das unvernünftige Gebet des Königs, erwies sich als attraktiv für die Verfasser von Zusammenstellungen von Sprichwörtern und Darlegungen über antike Religion. Der spätbyzantinische Vertriebene Michael Apostoles (c. 1420-1474/86), ein Landsmann und Klient Bessarions, zitiert or. 5 in seinen Proverbia, um das Sprichwort "der Reichtum des Midas" (Midou chrêmata) zu erklären. ${ }^{102}$ Und in ihrer Chronik pagan-religiöser Kulte nehmen sowohl Giglio Gregorio Giraldi als auch Gerrit Vos im 16. und 17. Jh. die Geschichte als eine Illustration des typischen Handelns einer niederen Gottheit auf. ${ }^{103}$ So erinnert uns or. 5 daran, wie auch heute unterbewerte-

\footnotetext{
${ }^{98}$ Gentleman's Magazine VII (1737) 14-15; der Brief ist mit „W.C." unterschrieben.

${ }^{99}$ Trapp 1994, lxxxviii-luxxix.

${ }^{100} \mathrm{H}$. Wirsius, Exercitationes in orationem Dominicam (Franeker: J. Gyselaar, 1698) 43: exercitatio 2,19; engl. Übers. von W. Pringle tunter dem Titel Sacred Dissertations on the Lord's Prayer (Edirburgh: T. Clark, 1839).

${ }_{101}$ Sacramento Daily Union, Bd. 13, Nr. 119, 9 July 1881, 4.

${ }^{102}$ M. Apostolius, Proverbia 11,67 (E. von Leutsch / F. W. Schneidewin, Corpus Paroemiographorum Graecorum II [Göttingen 1851] 531-533).

${ }^{103}$ L. G. GrRaldr, De deis gentium (Basel: J. Oporinus, 1548) 612; G. J. Vos, De theologia gentili et physiologia christiana (Amsterdam: J. C. Blaeu, 1641) Bd. 1, \$21, 158.
} 
te antike Texte in unterschiedlicher Weise Einfluss auf die Gedanken und Vorstellungswelten späterer Phasen der europäischen Kultur ausgeübt haben.

\section{Textabweichungen dieser Ausgabe von früheren}

In der folgenden Übersicht sind textliche Abweichungen der hier vorgelegten Ausgabe von Trapp 1994 und von Koniaris 1995 zusammengestellt. Die Textversion der frühesten erhaltenen Handschrift (Paris. gr. 1962, siehe oben S. 39) zeigt einen textkritisch relativ unproblematischen Zustand, der nur geringe Korrekturen notwendig macht (es finden sich verstreut einige fehlende Silben und bestimmte Artikel sowie ein oder zwei eindeutige Fälle von Interpolationen). Lediglich eine Stelle ist unheilbar verderbt $(5,7)$. Selbst hier lässt sich jedoch der Sinnzusammenhang rekonstruieren (siehe Anm. 73 zur Übersetzung). Bei 5,4 wurde die Konjektur von Markland übernommen (aus dessen Beiträgen zur zweiten Edition von Davies 1740), bei 5,7 diejenige von Reiske 1774:

\begin{tabular}{|c|c|c|c|}
\hline Stelle & SAPERE & Koniaris (1995) & Trapp (1994) \\
\hline 5,4 & 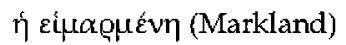 & 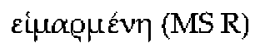 & $\langle\dot{\eta}>\varepsilon \dot{\mu} \mu \alpha Q \mu \varepsilon \dot{v} \nu \eta$ \\
\hline 5,4 & $\dot{\alpha} v u ́ \sigma u \mu o v(\mathrm{MS}$ I) & $\dot{\alpha} v u ́ \sigma \mu o v$ & óvútel \\
\hline 5,7 & 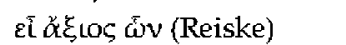 & $\varepsilon \dot{\alpha} \alpha \hat{\alpha} \cos \alpha$ w & $\varepsilon \dot{\alpha} \alpha \xi \cos \omega v$ \\
\hline
\end{tabular}

Jeder dieser Textvarianten ist im griechischen Text durch einen Asteriskos $(*)$ markiert. 

B. Text, Übersetzung und Anmerkungen 


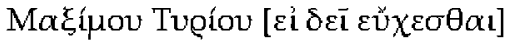

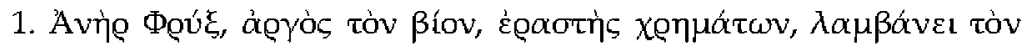

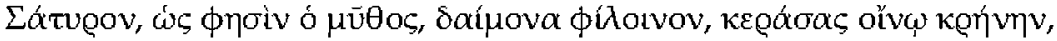

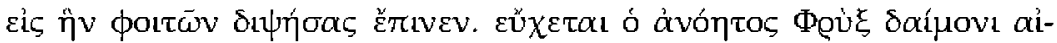

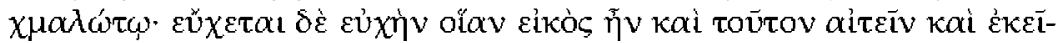

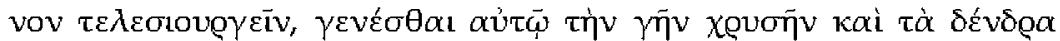

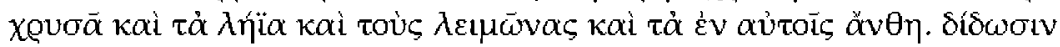

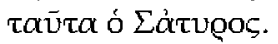

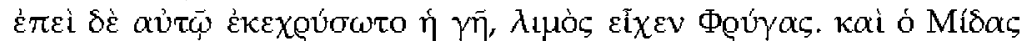

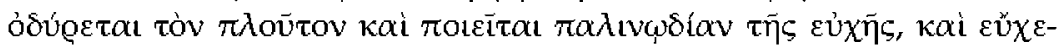

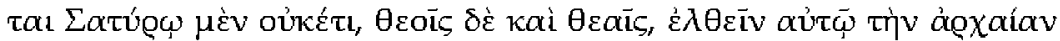

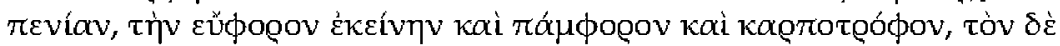

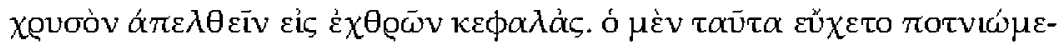

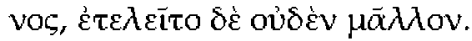

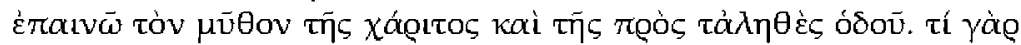

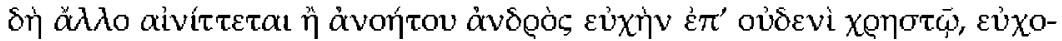

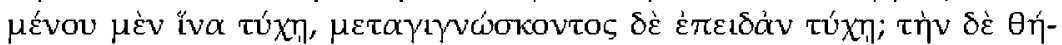

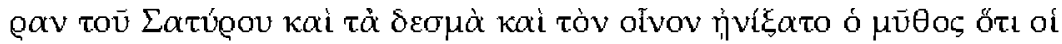

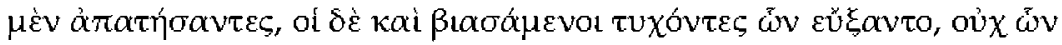

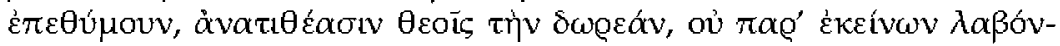

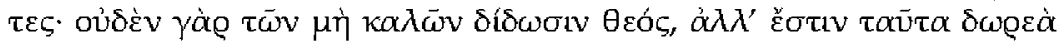

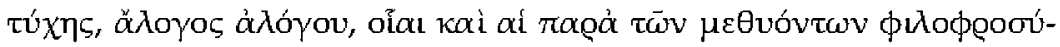
vat.

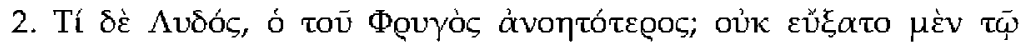

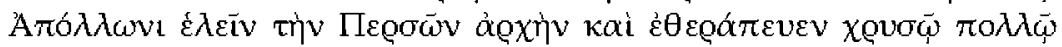

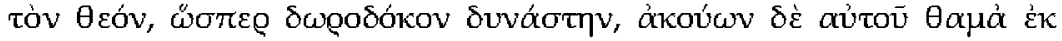
$\Delta \varepsilon \lambda \phi \bar{\omega} \nu \dot{\varepsilon} \pi ๘ \tau \tau \dot{\lambda} \lambda \lambda \circ \vee \tau \circ \varsigma$ 


\section{Maximos von Tyros, Ist beten sinnvoll? ${ }^{1}$}

\section{[Berühmte Beispiele unsinniger Gebete]}

1. Ein Phryger, ${ }^{2}$ der ein Leben im Müßiggang führte und das Geld liebte, nimmt, wie es der Mythos erzählt, Satyr, den weinliebenden Daimon, ${ }^{3}$ gefangen, ${ }^{4}$ indem er jener Quelle Wein beimischt, zu der dieser - wann immer ihn dürstete - hinzugehen und daraus zu trinken pflegte. Dieser unvernünftige Phryger richtet nun ein Bittgebet an den göttlichen Gefangenen; und zwar richtet er ein solches Bittgebet an ihn, wie man es von diesem $\mathrm{zu}$ erbitten und von jenem zu gewähren erwarten würde: es möge ihm sein Land zu Gold werden, die Bäume, die Felder und die Wiesen mit allen ihren Blumen - alles golden. Dies gewährt ihm Satyr.

Als jenem aber das Land zu Gold geworden war, ergriff eine Hungersnot die Phryger. ${ }^{5}$ Da hebt Midas eine Klage über seinen Reichtum $a^{j^{6}}$ er widerruft ${ }^{7}$ sein Gebet und betet nun nicht mehr zu Satyr, sondern zu Göttern und Göttinnen: es möge zu ihm die gute alte ${ }^{8}$ Armut kommen, jene Wohltragende, ${ }^{9}$ alles Hervorbringende, Nährerin der Früchte. ${ }^{10}$ Das Gold hingegen möge ihn verlassen und über die Häupter seiner Feinde kommen. Klagend stieß er das Gebet hervor, erfüllt wurde es ihm dadurch allerdings nicht eher. ${ }^{11}$

Diese Geschichte lobe ich nicht nur, weil sie hübsch ist, sondern auch aufgrund ihres wahren Kerns, auf den sie hinführt. Denn was sie offenbar versinnbildlicht, ${ }^{12}$ ist nichts anderes als das Gebet eines törichten Mannes ${ }^{13}$ um etwas völlig Nutzloses; zuerst bittet er, etwas zu erhalten, um dann reuig zu widerrufen, sobald es ihm zuteil geworden ist. ${ }^{14}$ Mit der Jagd und Gefangennahme Satyrs und mit dem Wein deutet die Geschichte an, dass - wenn die einen durch Täuschung, die anderen sogar durch Gewalt erreicht haben, worum sie gebetet haben (nicht aber, wonach es sie eigentlich verlangt) ${ }^{15}$ - sie dieses Geschenk den Göttern zuschreiben, obwohl sie es gar nicht von ihnen erhalten haben. Denn Gott schenkt nichts, wenn es nicht gut ist; ${ }^{16}$ alle diese Dinge sind die Gabe der Tyche (des Zufalls), ohne Vernunft erstrebt von einer Geberin ohne Vernunft ${ }^{17}$ - gleich den Aufmerksamkeiten, die man von Betrunkenen erhält.

2. Was aber ist mit dem Lyder, ${ }^{18}$ der noch unvernünftiger als der Phryger war? Hat er nicht zum Apollon gebetet, er möge das Reich der Perser erobern, und erwies dem Gott, als wäre der ein bestechlicher Herrscher, seine Reverenz mit viel Gold? Als er dann wiederholt hörte, wie der Gott aus Delphi verlauten ließ: 


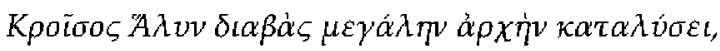

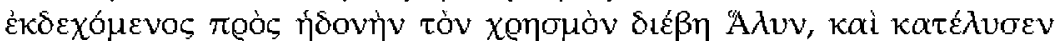

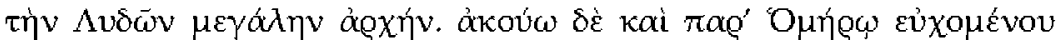

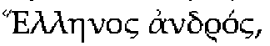

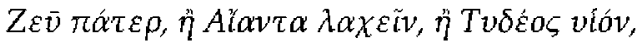

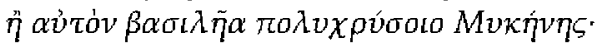

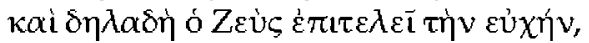

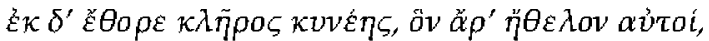

Alovios.

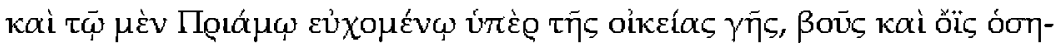

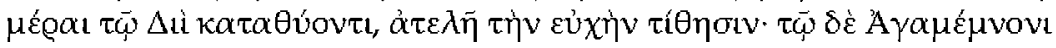

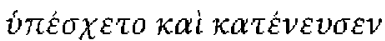

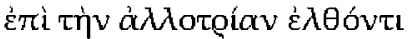

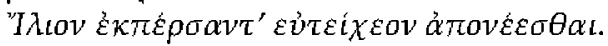

кaì ó A

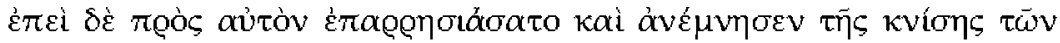

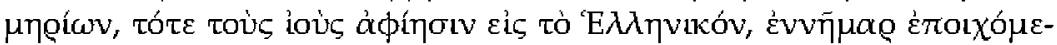

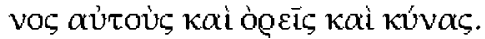

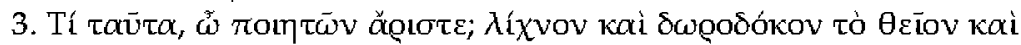

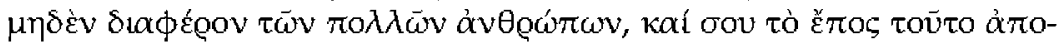
$\delta \varepsilon \xi o ́ \mu \varepsilon \theta \alpha$,

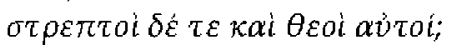

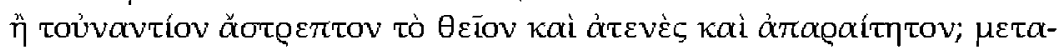

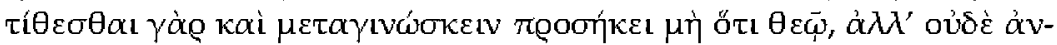

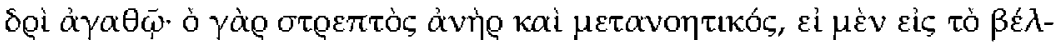

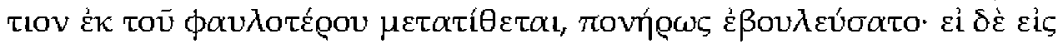

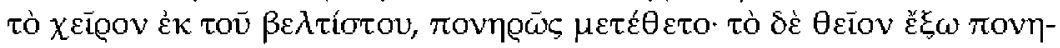
pías. 
Kroisos wird, wenn er den Halys überschreitet, ein großes Reich vermichten, ${ }^{19}$

nahm er den Spruch so auf, wie es ihm gelegen kam, überschritt den Halys - und vernichtete das große Reich der Lyder ${ }^{20}$ Selbst bei Homer ${ }^{21}$ höre ich, wie ein Grieche betet:

Vater Zeus, lass entweder Aias das Los ziehen, oder den Sohn des Tydeus

oder den König selbst des vielgoldenen Mykene.2

(Diomedes),

Und ganz offenbar ${ }^{23}$ erfüllte Zeus ihm die Bitte:

heraus aber sprang das Los, das sie sich selbst gewünscht hatten,

das des Aias. ${ }^{24}$

Dem Priamos andererseits, der für das eigene Land betete, wobei er Tag für Tag Rinder und Schafe dem Zeus opferte, ließ er das Gebet unerfüllt. Dem Agamemnon aber, versprach er's und nickte ihm Zustimmung,

ihm, der doch in ein fremdes Land einfiel,

nachdem er das wohl bewehrte Troja völlig zerstört hat, nach Hause $z u$

segeln. ${ }^{25}$

Und selbst Apollon kam dem Chryses, ${ }^{26}$ als diesem Unrecht widerfuhr, zunächst nicht zu Hilfe, als der ihn aber ganz offen an den Fettduft der Schenkel erinnerte, ${ }^{27}$ da schickte er seine Pfeile gegen das griechische Heer und attackierte sie neun Tage lang nebst ihren Lasttieren und Hunden. ${ }^{28}$

[Die problematischen Implikationen des Bittgebets für den Gottesbegriff]

3. Was soll das alles bedeuten, o Bester der Dichter? Ist das Göttliche etwa verfressen und bestechlich, ${ }^{29}$ ist es also nicht besser als die meisten Menschen? Sollen wir jenen Vers von dir gutheißen:

Biegsam sind selbst die Göter. ${ }^{30}$

Ist nicht im Gegenteil das Göttliche unbeugsam, unnachgiebig und auch durch Bitten nicht zu erweichen? Sinneswandel und Reue nämlich passen nicht zu einem guten Menschen, noch viel weniger aber zu Gott. Denn wenn sich ein wandelbarer und wankelmütiger Mensch vom Schlechteren zum Besseren umentscheidet, dann war er zuerst schlecht beraten; wenn aber von einer sehr guten Lösung $\mathbf{z u}$ einer schlechteren, dann war seine Meinungsänderung schlecht. ${ }^{31}$ Das Göttliche hingegen steht jenseits alles Schlechten. 


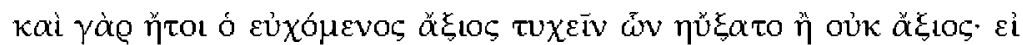

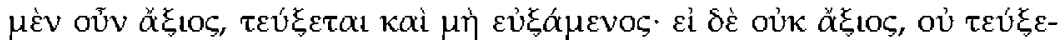

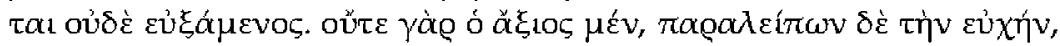

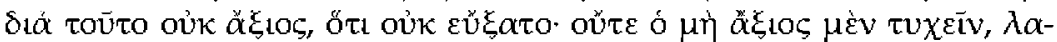

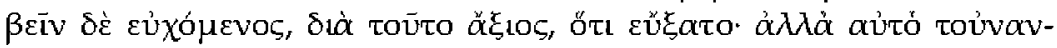

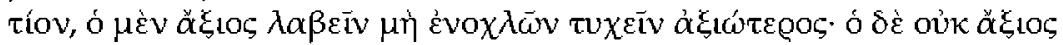

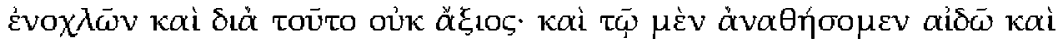

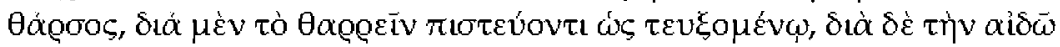

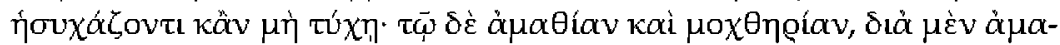

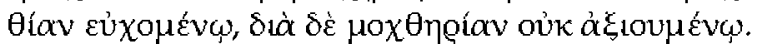

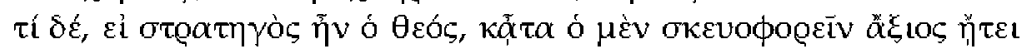

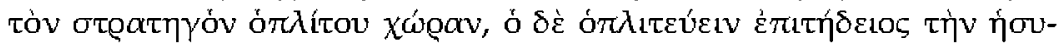

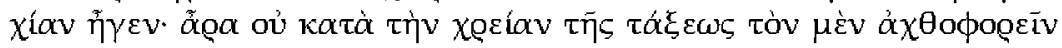

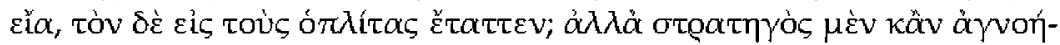

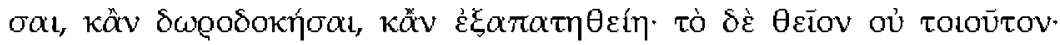

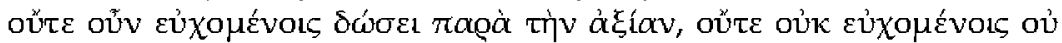

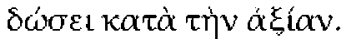

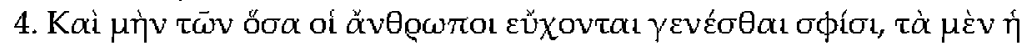

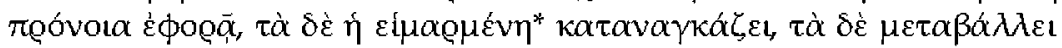

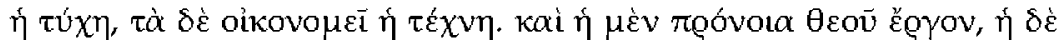

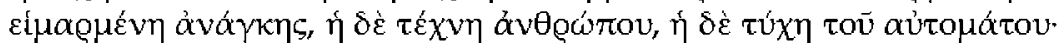

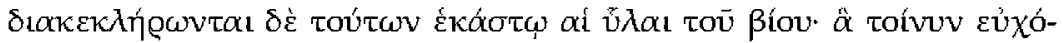

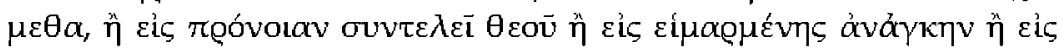

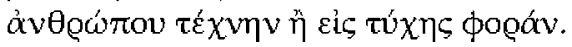


[Die Würdigkeit des Betenden als entscheidende Kategorie]

Im Übrigen: Jeder Betende ist doch entweder würdig, das zu erhalten, worum er gebeten hat, oder aber unwürdig. Wenn er also würdig ist, wird er das Erbetene erlangen, auch wenn er kein Gebet spricht. ${ }^{32}$ Wenn aber nicht würdig, wird er es nicht erlangen, selbst wenn er ein Gebet spricht. ${ }^{33}$ Denn weder wird der Würdige, der kein Gebet spricht, dadurch unwürdig, dass er es unterlässt zu beten, noch wird derjenige, der nicht würdig ist, etwas zu erhalten, aber ein Gebet spricht, dass er es erhalten möge, durch sein Gebet des Erbetenen würdig. ${ }^{34}$ Das genaue Gegenteil trifft vielmehr zu: wer würdig ist, etwas zu erhalten, wird dadurch noch würdiger, dass er nicht darauf drängt, es zu erlangen; wer aber auf etwas drängt, dessen er nicht würdig ist, erweist sich schon dadurch als unwürdig. Dem Einen erkennen wir Zurückhaltung und Zuversicht $\mathbf{z u}$, weil er zuversichtlich darauf vertraut, dass er erhalten wird, was ihm zusteht; weil er zurückhaltend stillschweigt, auch wenn er einmal nichts erhält. ${ }^{35}$ Dem Anderen aber erkennen wir Einfalt und Verdorbenheit zu; aufgrund seiner Einfalt betet er, aufgrund seiner Verdorbenheit wird er des Erbetenen nicht für würdig erachtet.

\section{[Gottes gute Zuteilung]}

Nehmen wir einmal an, Gott wäre ein Feldherr, und nun würde einer vom Status eines Lastknechts ${ }^{36}$ ihn bitten, den Platz eines Hopliten einnehmen zu dürfen, derjenige aber, der sich als schwerbewaffneter Fußsoldat eignet, Pause machen? Wird er nicht gemäß den Erfordernissen einer guten (Schlacht-)Ordnung den Lastknecht die Last tragen lassen und den anderen zu den Fußsoldaten stellen? Aber selbst wenn ein Feldherr einmal irren könnte, wenn er bestechlich sein oder auf eine Täuschung hereinfallen könnte - Gott ist nicht so ${ }^{37} \mathrm{Er}$ wird weder den Betenden etwas geben, obwohl es ihnen nicht zusteht, noch wird er denen, die nicht beten, etwas vorenthalten, das ihnen zusteht..$^{38}$

\section{[Vorsehung, Schicksal, Zufall, Sachverstand ${ }^{39}$ ]}

4. Und außerdem: Von allen Dingen, für die die Menschen beten, sie möchten ihnen zuteil werden, stehen manche unter der Aufsicht der Vorsehung, andere erzwingt das Schicksal, wieder andere lässt der $\mathbf{Z u}$ fall durcheinanderpurzeln und noch andere verwaltet der Sachverstand ${ }^{40}$ Die Vorsehung ist die Sache Gottes, ${ }^{41}$ das Schicksal die der Notwendigkeit, Sachverstand ist Sache des Menschen, der Zufall ist Geschehen ohne Grund. ${ }^{42}$ Die Dinge des Lebens sind jeweils einem von diesen vier zugeordnet. Worum wir also im Gebet bitten, das unterliegt ent- 


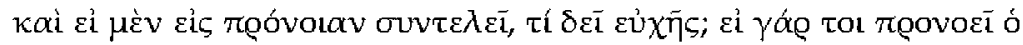

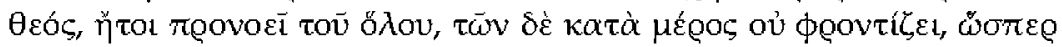

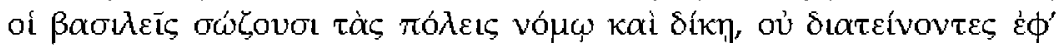

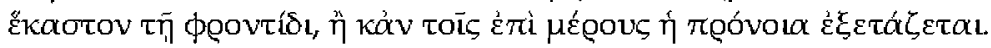

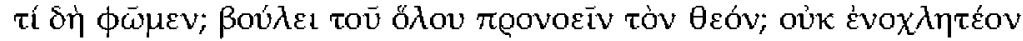

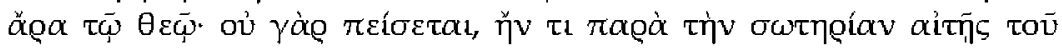

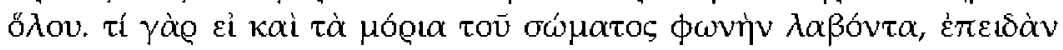

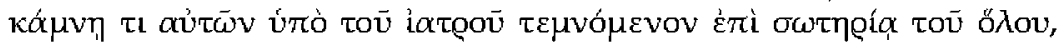

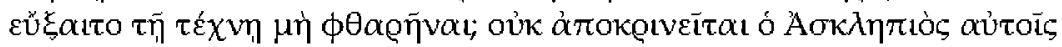

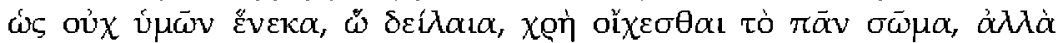

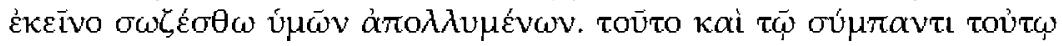

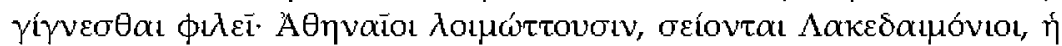

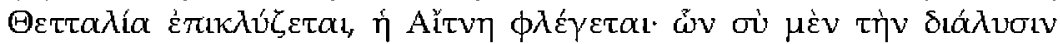

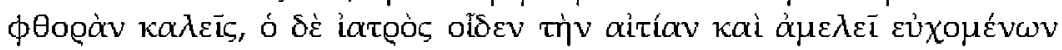

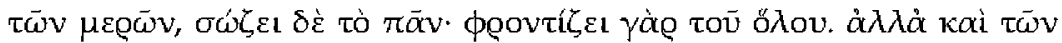

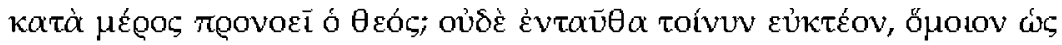

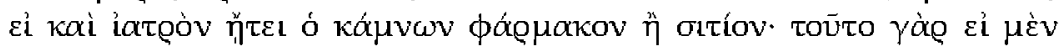

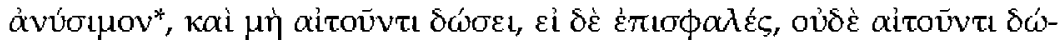

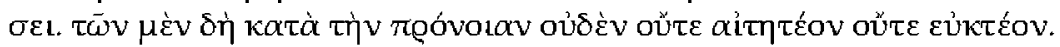

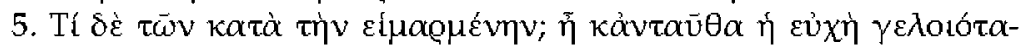

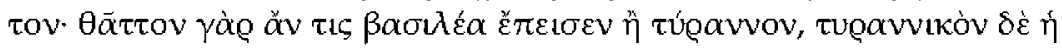


weder der Vorsehung Gottes, oder dem Zwang des Schicksals oder menschlichem Sachverstand oder den Wechselfällen des Zufalls. ${ }^{43}$

[Was von Gottes Vorsehung geleitet wird]

Wenn etwas nun der Vorsehung ${ }^{44}$ unterliegt, was bedarf es des Gebets? Wenn nämlich Gott sich mit seiner Vorsehung kümmert, dann kümmert er sich entweder um das Ganze, ohne sich um die Einzelbelange zu sorgen (wie Könige mit Recht und Gesetz das Heil der Städte bewahren, ihre Sorge aber nicht auf jeden Einzelnen ausdehnen), ${ }^{45}$ oder die Vorsehung lässt sich auch an den Einzelbelangen aufweisen. 46

Was sollen wir also sagen? Willst du, dass sich Gottes Vorsehung auf das Ganze erstreckt? Dann darf man Gott nicht belästigen. Er würde dir ja auch nicht folgen, falls du ihn um etwas bittest, das dem. Heil des Ganzen entgegensteht. Denn was wäre, wenn auch die Einzelteile des Körpers auf einmal eine Stimme bekämen und nun, wenn einmal eines von ihnen vom Arzt zum Heil des ganzen Körpers einem operativen Eingriff unterzogen würde, ${ }^{47}$ beten würden, es möge nicht der Arztkunst zum Opfer fallen? ${ }^{48}$ Wird nicht Asklepios den Gliedern folgendermaßen antworten: Es darf nicht sein, dass um euretwillen, ihr Feiglinge, der Körper als Ganzes dahinscheidet; vielmehr muss - durch euren Untergang - jener gerettet werden. Dasselbe gilt auch für das Weltganze insgesamt: Die Athener leiden unter der Pest, die Spartaner werden von Erdbeben geschüttelt, Thessalien wird überschwemmt und der Ätna spuckt Feuer. ${ }^{49}$ Ihre Zerstörung magst du als Untergang bezeichnen, der Arzt aber kennt den Grund dafür und kümmert sich deshalb nicht um das Bitten von einzelnen Teilen, sondern er sucht das Heil des Weltganzen zu bewahren. ${ }^{50}$ Seine Sorge gilt ja dem Ganzen. Gleichwohl dehnt Gott seine Vorsehung durchaus auch auf die einzelnen Dinge aus. Freilich braucht man auch hierum nicht $\mathbf{z u}$ bitten; das wäre, wie wenn ein Kranker den Arzt um Medikamente oder Speise bitten würde. Wenn es etwas hilft, ${ }^{51}$ wird sie der Arzt ihm verordnen, auch wenn er nicht darum bittet. Wenn ihm aber etwas zu schaden droht, wird der Arzt es ihm nicht zugestehen, selbst wenn er darum bittet. ${ }^{52}$ Also ist $\mathbf{u m}$ die Dinge der Vorsehung weder $\mathbf{z u}$ bitten noch $\mathbf{z u}$ beten.

[Was wom Schicksal regiert wird]

5. Was ist nun mit den Dingen, die dem Schicksal unterstehen? Auch hier wäre das Gebet vollkommen lächerlich. Denn leichter könnte wohl noch einer einen König als einen Tyrannen überzeugen. Das Schicksal53 


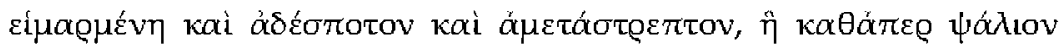

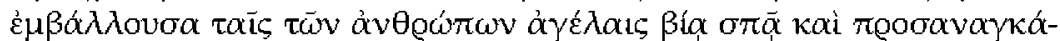

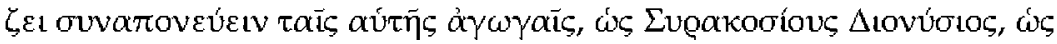

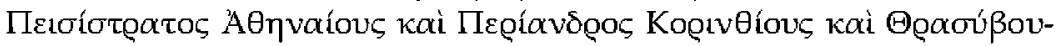

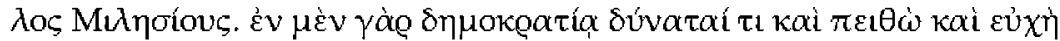

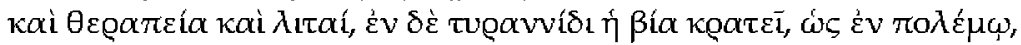

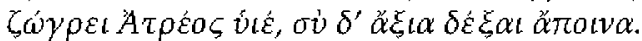

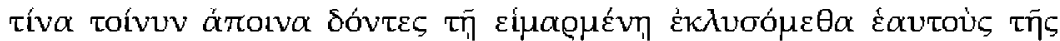

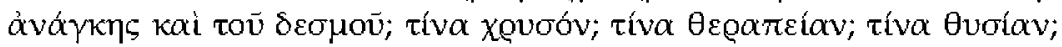

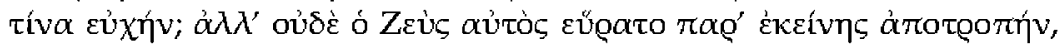

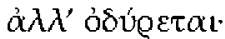

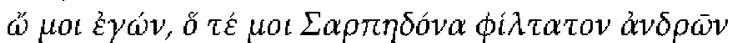

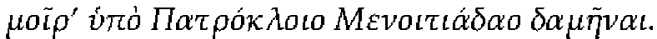

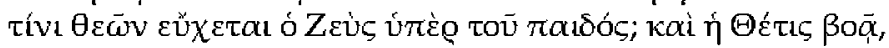

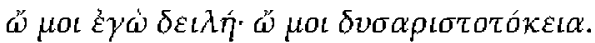

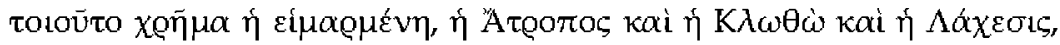

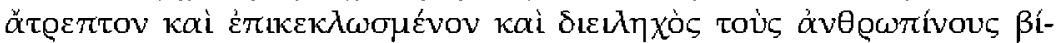

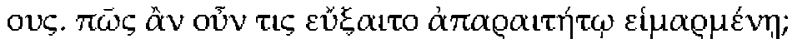

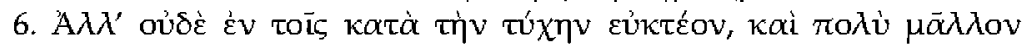

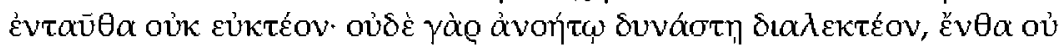

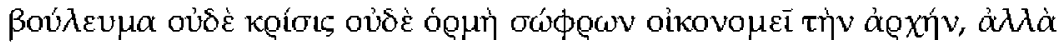

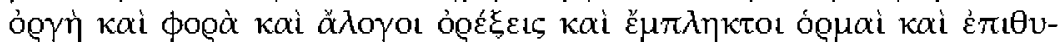

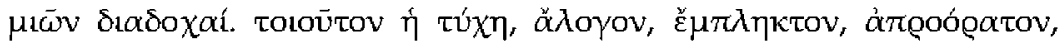

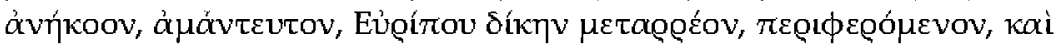

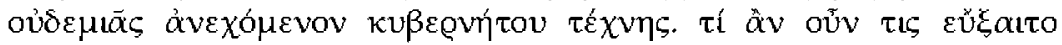

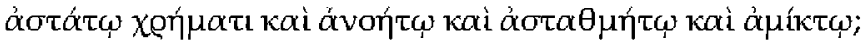


aber regiert nach der Art eines Tyrannnen, ${ }^{54}$ es ist unbeherrschbar und lässt sich nicht umstimmen. Den Menschenherden legt es gleichsam ein Trensengebiss an, zieht sie so gewaltsam mit sich und zwingt sie willfährig zu folgen, wohin auch immer es führt, ${ }^{55}$ so wie Dionysios die Syrakusaner (gezwungen hat), Peisistratos die Athener, Periander die Korinther und Thrasybulos die Milesier. ${ }^{56}$ Denn in einer Demokratie vermag die Überzeugungskraft ebenso etwas auszurichten wie Bitten, Huldigungen und flehentliche Gebete, in einer Tyrannenherrschaft dagegen herrscht gewaltsamer Zwang $^{57}$ wie im Krieg:

Nimm mich als Gefangenen, Atreussohn, und empfange ein stattliches

Lösegeld!58

Welches Lösegeld aber wollen wir dem Schicksal anbieten, um uns aus den Fesseln des Zwangs zu befreien? Welches Gold? Welche Huldigung? Welches Opfer? Welches Gebet? Nicht einmal Zeus selbst konnte eine Abwehr gegen sie finden, sondern klagt:

Oh ich Armer, dass mir das Schicksal bestimmt hat, Sarpedon, ${ }^{59}$ der liebste der Männer,

müsse durch die Hand des Menoitiossohnes Patroklos bezwungen werden. ${ }^{60}$

$\mathrm{Zu}$ welchem Gott soll Zeus für seinen Sohn beten? Und auch die Thetis ruft aus

Oh ich Arme, oh ich Unglücksgebärerin des edelsten Helden.

So ist das Schicksal, Atropos und Klotho und Lachesis: als unwandelbarer Lebensfaden hat es jedem menschlichen Leben das Los schon zugeteilt. ${ }^{61}$ Wie wollte da einer das unerbittliche Schicksal anrufen?

[Was dem Zufall untersteht]

6. Aber um die Dinge, die dem glücklichen Zufall unterstehen, soll man nicht beten, und gerade hier soll man nicht beten. Denn man kann sich auch mit einem unvernünftigen Despoten nicht vernünftig unterhalten - da leitet kein Abwägen, kein Urteil, keine vernünftige Herangehensweise die Herrschaft, sondern nur Zorn, Unbeherrschtheit, sinnlose Gier, unvernünftige Triebe und Kaskaden von Begierden. ${ }^{62}$ So ist die Tyche: ${ }^{63}$ vernunftlos, unberechenbar, planlos, taub, unvorhersehbar; wie der Euripos ${ }^{64}$ ändert sie unstet ihre Fließrichtung, nicht $\mathrm{zu}$ bezwingen durch die Kunst irgendeines Steuermanns. ${ }^{65}$ Warum aber sollte einer beten $z u$ einer Sache ohne festen Stand ${ }^{66}$ und ohne Vernunft, unberechenbar und beziehungslos? 


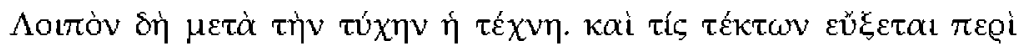

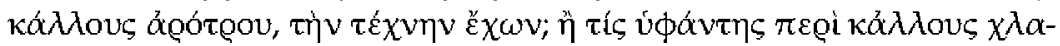

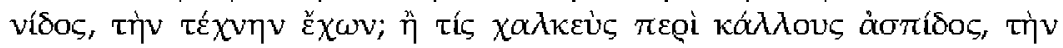

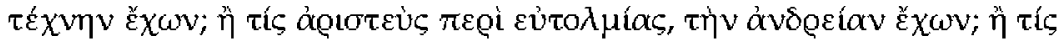

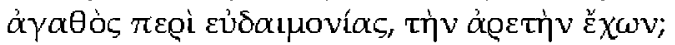

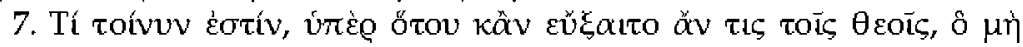

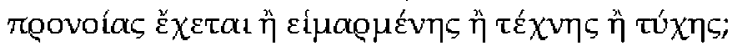

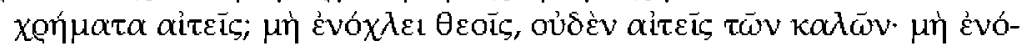

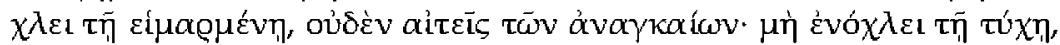

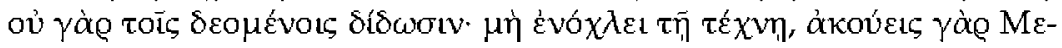

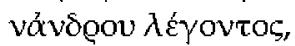

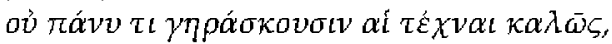

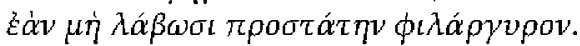

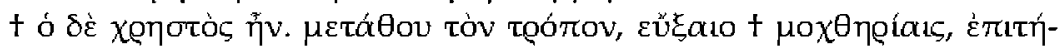

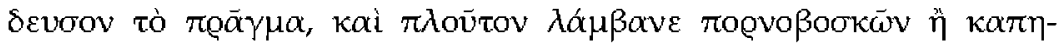

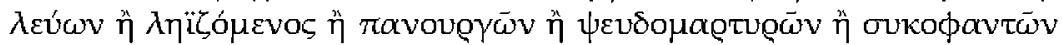

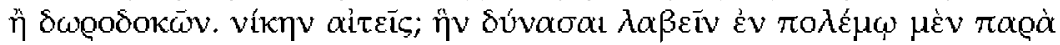

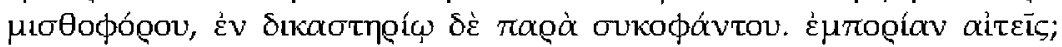

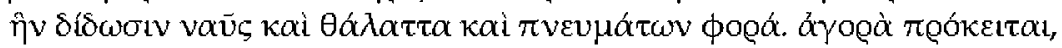

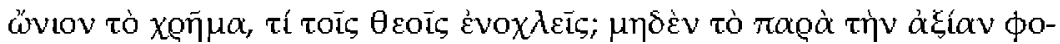

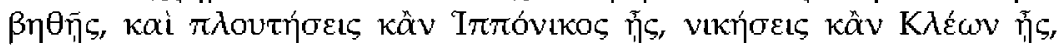

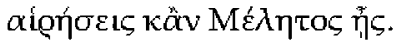

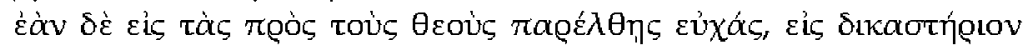

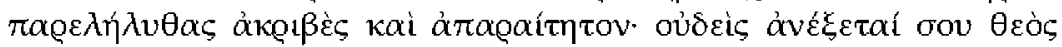

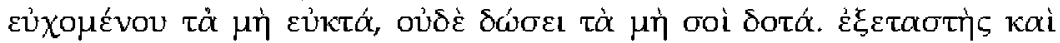


[Was durch menschlichen Sachverstand zu erreichen ist] ${ }^{67}$

Fehlt nach dem Zufall nur noch der menschliche Sachverstand.68 Welcher Handwerker würde um einen schönen Pflug beten, wenn er doch selbst den Sachverstand dafür besitzt? Oder welcher Weber um ein schönes Gewand, wenn er doch selbst den Sachverstand dafür besitzt? Oder welcher Schmied um einen schönen Schild, wenn er doch selbst den Sachverstand dafür besitzt? Oder welcher Held um Wagemut, wenn er doch selbst Tapferkeit besitzt? Oder welcher gute Mensch um Glückseligkeit, wenn er doch die Tugend besitzt (die ihn dort hinführen kann)? ${ }^{69}$

7. Was bleibt aber dann, für das jemand sinnvollerweise zu den Göttern beten könnte, das nicht von der Vorsehung abhängt ${ }^{70}$ oder vom Schicksal oder von menschlicher Kunstfertigkeit oder vom Zufall?

Betest du um Geld? Belästige nicht die Götter - es ist ja nichts Gutes, worum du bittest. ${ }^{71}$ Belästige auch nicht das Schicksal - es ist ja nichts Notwendiges, worum du bittest. Belästige auch nicht den Zufall - denn er gibt nichts, weil ihn jemand darum bittet. Belästige auch nicht den Sachverstand. Du hörst doch, was Menander sagt: ${ }^{72}$

Die Künste werden nicht in Ehren alt, wenn thnen keiner vorsteht, der das Geld verehrt.

Da war einer rechtschaffen $?^{73}$ Nun, ändere deine Lebensweise, bete um Niedertracht, und so verfolge dein Geschäft, und dann scheffle deinen Reichtum als Zuhälter oder mit allerlei Hökereien, als Plünderer oder Betrüger, indem du als falscher Zeuge auftrittst, Verleumdungen kolportierst oder dich bestechen lässt. ${ }^{74}$ Oder betest du um einen Sieg? Den kannst du haben - im Krieg mithilfe von Söldnern, im Gericht mit Hilfe von Denunzianten. Betest du um gewinnbringenden Handel? Den geben Schiff und Meer und günstige Winde. Der Markt steht dir offen, was du begehrst, ist käuflich, was also belästigst du die Götter? Fürchte in keiner Weise alles, was gegen Anstand verstößt, und du wirst reich werden, selbst wenn du ein Hipponikos wärst, du wirst Siege feiern, selbst wenn du ein Kleon wärst, du wirst deinen Prozess gewinnen, selbst wenn du ein Meletos wärst. ${ }^{75}$

[Von der Ernsthaftigkeit des echten Gebets, das das Leben in die Verantwortung vor dem göttlichen Gericht stellt]

$\left.{ }^{76}\right]$ Wenn du dich allerdings daranmachst, dich im Gebet an die Götter zu wenden, dann hast du dich an ein penibles, unbestechliches Gericht gewandt. ${ }^{77}$ Kein Gott wird es zulassen, dass du um etwas bittest, für das sich ein Gebet nicht schickt, oder wird dir geben, was dir nicht zusteht. Als harter Prüfer und Beurteilungsinstanz der Gebete jedes 


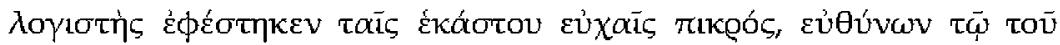

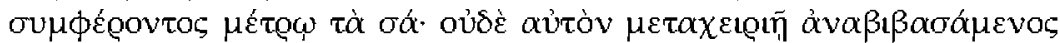

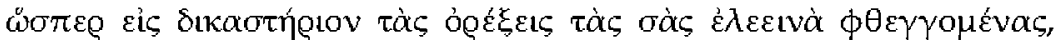

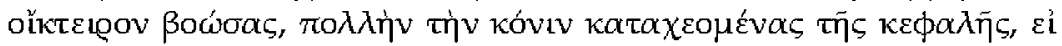

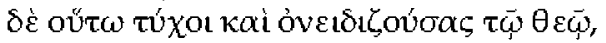

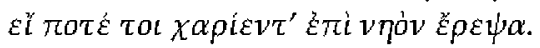

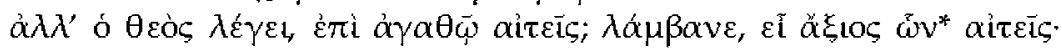

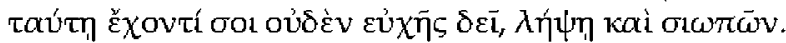

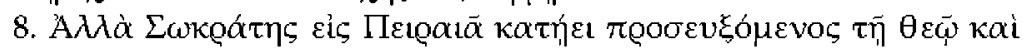

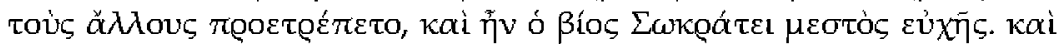

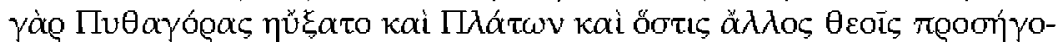

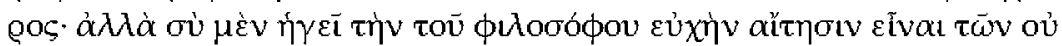

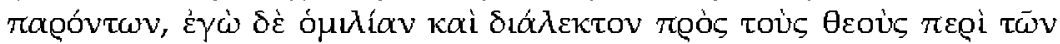

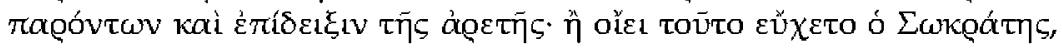

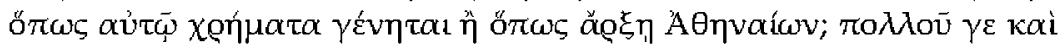

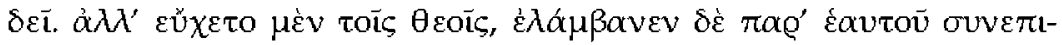

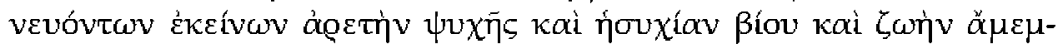

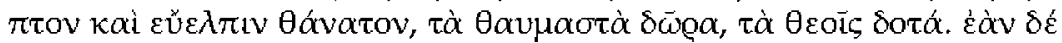

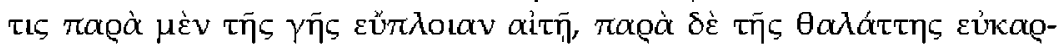

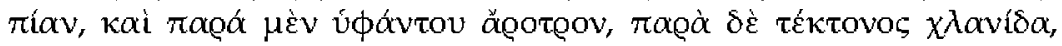

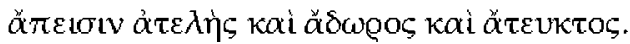

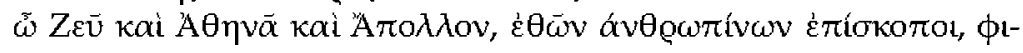

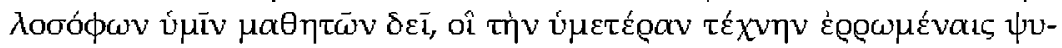

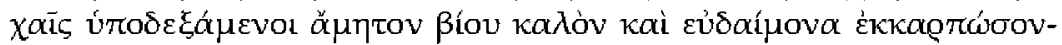

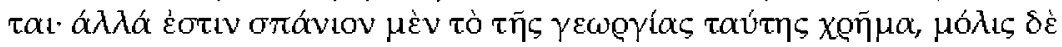

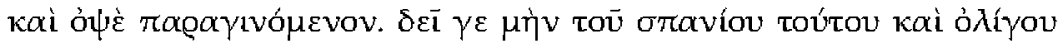

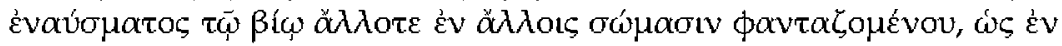


Einzelnen steht er da und spricht jedem das Seine nach dem Maß des für ihn Zuträglichen zu. Du wirst nicht mit ihm verhandeln können, indem du deine Bedürfnisse gleichsam in den Zeugenstand aufrufst, die erbarmungswürdig betteln, die "hab Erbarmen" rufen, die den Kopf mit viel Staub überschütten und vielleicht gar dem Gott tadelnd zurufen: ${ }^{78}$

Wenn ich je dir den strahlenden Tempel geschmückt. ${ }^{79}$

Aber Gott spricht: "Zielen deine Bitten auf etwas Gutes? Dann empfange, du bist dessen würdig, worum du bittest!" 80 Wenn es sich bei dir aber so verhält, bedarf es in keiner Hinsicht des Gebets: Du wirst empfangen, auch wenn du schweigst. ${ }^{81}$

[Das wahre, philosophische Gebet: nicht Bitte, sondern Gespräch]

8. "Aber" (so wendest du ein) ${ }^{82}$ "auch Sokrates ${ }^{83}$ ging hinunter zum Piräus, um zu der Göttin $z u$ beten, ${ }^{84}$ und ermunterte auch die anderen zum Beten, ja, das ganze Leben des Sokrates war des Gebetes voll. ${ }^{\star 85}$ Auch Pythagoras betete ja, ebenso wie Platon und jeder andere, der sich je im vertrauten Gespräch mit den Göttern befand. Aber du bist der Meinung, dass es sich bei dem Gebet des Philosophen um eine Bitte um Dinge handelt, die gegenwärtig nicht vorhanden sind, ich dagegen halte es für den Umgang ${ }^{86}$ und das Gespräch ${ }^{87}$ mit den Göttem über Dinge, die bereits vorhanden sind, und für einen Aufweis der Tugend. ${ }^{88}$ Oder glaubst du, dass Sokrates im Gebet um derlei Dinge bat, dass er zu Geld kommen möge oder dass er die Herrschaft über die Athener erlange? Weit gefehlt! Vielmehr: er pflegte zwar tatsächlich zu den Göttern zu beten, empfing aber von sich selbst - mit ihrer wohlwollenden Zustimmung - eine tugendhafte Seele und die Gelassenheit im Leben, eine untadelige Lebensführung und einen hoffnungsvollen Tod, ${ }^{89}$ wunderbare Geschenke, von den Göttern überreichte Gaben. Wenn aber einer vom Land eine gute Seefahrt erbittet, vom Meer eine reiche Ernte, und ebenso vom Weber einen Pflug, vom Zimmermann aber ein Gewand, der wird unverrichteter Dinge fortziehen, ohne Geschenke, ohne Erfüllung.90

\section{[Abschließ3endes Gebet $]^{91}$}

O Zeus, Athena und Apollon, ${ }^{92}$ Wächter über die Lebensweisen der Menschen, ihr braucht Philosophen als Schüler, die eure Lebenskunst in gestärkten Seelen aufnehmen und so eine gute, glückliche Ernte des Lebens einfahren. Aber diese Form des Ackerbaus ${ }^{93}$ kommt nur selten zum Einsatz, er findet nur unter Mühen und allenfalls spät statt. Es bedarf aber dieses seltenen und kleinen Flämmmchens für das Leben, das bald in diesem, bald in jenem Körper aufleuchtet, wie man in der 


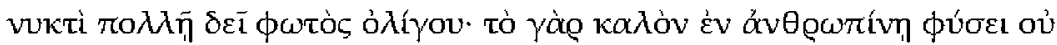

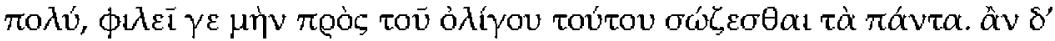

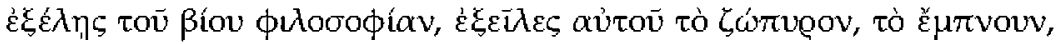

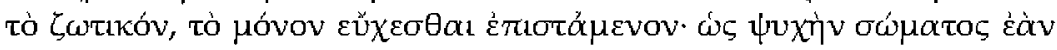

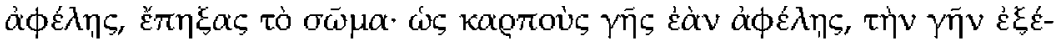

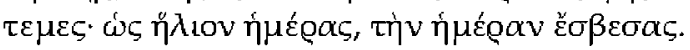


dunkelsten Nacht nur eines schwachen Lichtes bedarf. ${ }^{94}$ Denn was schön und gut ist in der menschlichen Natur, ist nicht viel, durch dieses Wenige pflegt sich aber das Ganze zum Heil zu wenden. Wenn du aus dem Leben die Philosophie herausnimmst, ${ }^{95}$ dann hast $\mathrm{du} \mathrm{ihm}$ den Lebensfunken genommen, den Atem, die Lebenskraft, dasjenige nämlich, das sich allein aufs Beten versteht. ${ }^{96}$ Es ist, wie wenn du dem Leib die Seele nimmst: dann lässt du ihn erstarren; wie wenn du der Erde die Früchte nimmst, dann machst du die Erde unfruchtbar; wie wenn (du) dem Tag die Sonne (nimmst): dann löschst du den Tag aus. 


\section{Anmerkungen zur Übersetzung}

* Der Asteriskos im griechischen Text bezieht sich auf die Liste der Textvarianten am Ende der Einführung.

I Wie bei den übrigen Dialexeis finclet sich der Titel zwar in den Handschriften, dürfte aber kaum von Maximos selbst stammen, sondern gehen eher auf einen Herausgeber zurück; vgl. Einführung, S. 13 Anm. 27.

2 Gemeint ist der (mythische) König Midas. Die Geschichte ist verschiedentlich überliefert: Xen. An. I 2,13; Paus. I 4,5; Ovid, Met. XI 85-145; Hygin, Fab. 191.

3 In der Überlieferung meistens Silen. Im paganen Griechisch meint das Wort "Daimon" nicht primär eine diabolische Macht, sondern allgemein ein göttliches Wesen oder ein Wesen zwischen Gott und Mensch (auch die hilfreichen oder schadenstiftenden Seelen Verstorbener können so genannt werden). In diesem Sinne sind Daimones Gegenstand von orr. 8-9.

4 Bei Ovid, Met. XI 90-93 sind es Bauern, die Silen gefangennehmen und zu Midas bringen.

5 Ovid schildert den Grund für die Hungersnot plastisch und detailreich: was immer der König berührt, wird tatsächlich zu Gold: auch das Brot und der Wein, die Ähren und Bäume.

6 Juvenal (geb. vermutl. unter Nero, gest. nach 127) hat sich in seiner zehnten Satire ebenfalls mit dem Beten befasst und nutzt teilweise dieselben Beispiele für seine Argumentation wie Maximos, wobei Juvenal seine Vorlagen eher der römischen Geschichte entlehnt. Beiden Autoren ist gemeinsam, dass sie das Beten um einzelne Güter ablehnen, weil der Mensch mit seiner begrenzten Einsichtsfähigkeit nicht entscheiden kötune, ob sie ihm, in einem größeren Zusammenhang gesehen, letztendlich wirklich zuträglich sind. Das Streben nach Besitz und Reichtum wird dabei sowohl von Maximos als auch von Juvenal als ein menschliches Grundübel entlarvt. Beide setzen es als abschreckendes Beispiel an prominente Stelle zu Beginn ihrer Ausführungen (Max. or. 5,1 bzw. Iuv. 10,12-27). [SB]

7 Das einleitende Exemplum bei Maximos illustriert, was Sokrates im ps.-plat. Alk. 2 theoretisch erörtert: Gegenüber seinem Schüler und. Freund Alkibiades, der im Begriff ist zu beten, skizziert Sokrates dort die Folgen eines unbedachten Gebets unter der Annahme, dass die Gottheit Gebetswünsche vorbehaltlos erfüllt (148a-b). Aus dieser Schrift scheint Maximos den Begriff des reuigen Widerrufs (148b; vgl. 142d) aufzunehmen, wenngleich er das Substantiv $\pi \alpha \lambda \omega \omega \delta i ́ \alpha$ verwendet und nicht, wie $\operatorname{der} A \mid k .2$, das Verb $\pi \alpha \lambda$ w des Begriffs im Phaidros 243b (aufgenommen bei Max. or. 21,6). Stesichoros hat ein (verlorenes) Gedicht mit dem Titel «Widerruf», Palinodie, verfasst.

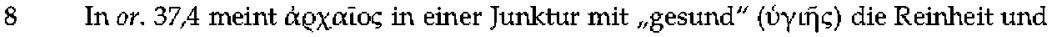
Echtheit der "wahren Musik".

9 Aber auch: "leicht zu tragen", vgl. Lukian, Podagra 324.

I0 Vgl. die ähnlichen Komposita bei Plat. Leg. IV 704c-705b (zitiert bei Euseb und Stobaios) sowie or. 1,7. Die Übersetzungen formulieren vielfach aus, was hier durch Attribute über die ${ }_{s}$ Armut ${ }^{\prime \prime}$ gesagt wird, die auf diese Weise als Persontifikation erscheint (vgl. or. 4,4, wo Penia in Aufnahme von Platon, Symp. 203b-c ebenfalls als Mutter des Eros personifiziert erscheint). Auch in der Folge tauchen immer wieder sehr plastisch Figuren auf, die zum Standardrepertoire von Komödie und. Satire gehören, am Ende des Kapitels die Tyche, die wahllos Geschenke verteilt (man mag an die Personifikationen der populären Tabula Cebetis denken, die auf ihre Art ethische Philosophie betreibt). Als Personifikation einer alten Frau erscheint die Armut in 
der Komödie Der Reichttum (Plutos) des Aristophanes, den Maximos verschiedentlich zitiert (vgl. E. BowIE, "The Ups and Downs of Aristophanic Travel", in: E. HALL / A. WRIGLEY [ $\mathrm{Hg}$.], Aristophanes in Performance $421 B D-A D$ 2007, London 2007 [32-51] 50 Anm. 14, führt fünf Aristophaneszitate bei Maximos auf, allerdings sämtlich aus den Wolken). Zeitgenössisch tritt die Penia in Lukians Timon 31-33 auf (mit deutlichem Bezug auf Aristophanes und unter Bearbeitung des Themas "Unendliches Gold als Gebetserhörung"; \$ 34; 41-42). Sehr schön ist, wie die Armut bei Maximos

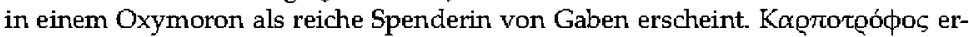
scheint als Epitheton der Demeter.

11 Andere Versionen berichten, wie Midas sich schließlich von dem Zauberfluch befreien konnte: nach Ovid etwa ließ dieser Fluch sich erst durch ein Bad in einem Fluß bei Sardis lösen, das zugleich als Reinigungsbad von der Schuld des Miclas interpretiert wird. Maximos freilich lässt die Lösung aus didaktischen Gründen bewusst weg: die Leserin oder der Hörer soll selbst zu einem Umdenken geführt werden.

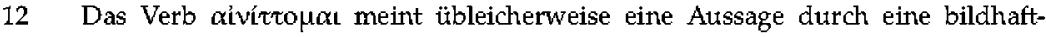
verrätselte Darstellungsform, die vielfach dem Mythos oder der (religiösen) Tradition entnommen ist (or. 10,1, vgl. Plut. An seni 797F; HiRsch-Luirold 2002, 130f.), eine Rede, die "das eine sagt, etwas anderes aber andeutet" (or. 18,5; für allegorische Redeweise, Etymologien, Fabel tusw, bei Homer or. 22,7;34,3;41,2 bzw. Hesiod or. 38,2; den Dichtern und Künstlem 8,6; 10,9; 41,$2 ;$ bzw. in der Dichtung insgesamt

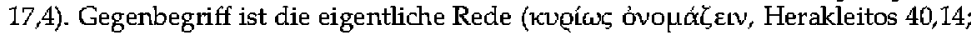

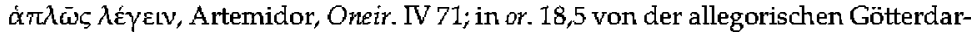
stellung bei Homer). An der vorliegenden Stelle handelt es sich nicht um eine Rätselrede, sondern um ein illustratives Einzelbeispiel aus der Tradition, das in seiner allgemeinen Bedeutung zu begreifen ist. Besonders nahe ist 32,1 (vgl. 36, I): Aesop versinnbildliche mit seinen Fabeln Aspekte der Wahrheit. Semantisch freilich behält

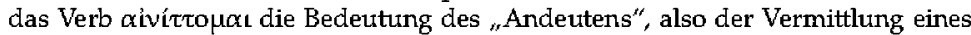
Inhalts durch eine subtile Andeutung oder einen Subtext (úróvoux), den der Leser

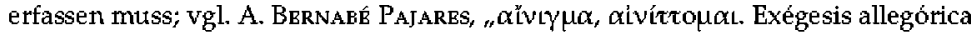
en Platón y Plutarco", in: A. PÉrez Jiméngz u.a. ( $\mathrm{Hg}$,), Plutarco, Platón y Aristóteles. Actas del V congresso internacional de la I.P.S. (Madrid 1999) 189-200; zum Begriff an unserer Stelle vgl. Soury 1942, 17.

13 Midas wird also als Beispiel verwendet: Die Menschen bitten aus Unkenntnis des wahrhaft Guten oder doch wertigstens dessen, was ihnen zuträglich ist (vgl. tunten § 4; Diog. Laert. VI 42; VIII 9). Der Fokus des Maximos liegt auf einem unvernünftigen Gebet. Alkibiades 2 dagegen führt Ödipus als klassisches Beispiel an. Dabei handelt es sich eher um ein unbedachtes Gebet, das die Konsequenzen des an sich gut Gemeinten nicht übersieht. Unvernunft wird man dem Ödipus normalerweise nicht vorwerfen.

14 Vgl. Ps.-Plat. Alk. 2 141a: Falsche Gebete aus Unwissenheit bezüglich dessen, was gut ist.

15 Gegenüber den Handschriften (,... wonach sie verlangt, nicht worum sie gebeten hatten...") sind die beiden Verben umzustellen (vgl. TrApP 1994). In dieser knappen Formulierung steckt eine tiefe Lebensweisheit: was man im Leben ersehnt und erstrebt (Geld, Ruhm, Karriere), erweist sich, wenn man es erlangt, bisweilen als Fluch, weil es gar nicht war, wonach man sich eigentlich gesehnt hatte (nämlich Glück). Der Gedanke wird in der Bildtafel des Kebes ausformuliert: dort wird der Mensch auf dem Weg zur Glückseligkeit (Eudaimonia) von Tyche und anderen Fraten aufgehalten, die zwar attraktiv aussehen, den Menschen aber an der Verwirklichung seiner Lebensziele hindern.

16 In dieser theologischen Grundüberzeugung stimmen Platoniker und Stoiker überein, vgl. or . 5,3; 13,8; 42,2-3; Plat. Rep. II 379-380c; Tim. 30a; Euthyphr. 14b-e; Sen. ep. 95,49-50; Philostr. V. Ap. Nach Plat. Rep. II 379d kann der gute Gott nicht Urheber 
von Üblem sein. Das Thema wird auch in verschiedenen Schriften zur TheodizeeFrage im 1. Th. aufgegriffen (Seneca, Prov.; Philo, Prov.; Plut. De sera num. vind.).

Die rhetorisch aufs Außerste verktıappte Formttliertung lässt sich nicht ohne Auflösung ins Deutsche bringen.

An der berühmten Erzählung von dem Lyderkönig Kroisos (vgl. Hdt. I 46-91) kommt auch Maximos nicht vorbei.

Hdt. I 53,3; vgl. or. 13,5 (im Zusammenhang der menschlichen Mitwirkung an der Erfüllung des Schicksals).

Es ist also sein eigenes Reich, das er vernichtet.

21 Nach dem unverzichtbaren Zitat aus Herodot entrimmt Maximos die folgenden Beispiele sämtlich Homer. Während Maximos üblicherweise Homer als den theologischen Grundlagentext der Griechen und die wichtigste Autorität neben Platon behandelt, wird er am Beginn des nächsten Kapitels interessanterweise kritisch beleuchtet. Maximos hat die Kritik an dieser Stelle vermutlich als notwendig tund legitim empfunden, weil sie die Kritik Platons im 3. Buch der Politeia aufnimmt. Oder will Maximos mit diesen Überlegungen lediglich vorführen, welche Fehlinterpretationen Homers sich aus einem falschen Verständnis des Gebets ergeben können? In jedem Fall nutzt er das (Miss-)verständris Homers rhetorisch als Folie für das von ihm als richtig erachtete Verständnis des Gebets, das er im Folgenden entwickeln will.

Il. VII 179f.

Offensichtlich bringt $\delta \eta \lambda \alpha \delta \emptyset$ hier eine ironische Note.

Ir. VII 182f.

IR. II 112f.

Seinem eigenen Priester!

Maximos verweist auf II. I 35-42, gewissermaßen den locus classicus zum Gebet und wohl das älteste Gebet der griechischen Literatur überhaupt. In der Stadt Chryse vor den Toren Trojas war Chryses in frevelhafter Weise von Agamemnon, dem König der Griechen, zurückgewiesen worden bei dem Versuch, seine Tochter Chryseis atszulösen, die Agamemnon als Ktiegsbeute genommen hatte (der Fortgang dieser Episode motiviert den Zorn des Achilles und seinen fatalen Rückzug aus der Schlacht)! Bei Lukian, Sacr. 3 erscheint diese Szene als Beispiel eines problematischen Gebets, wie auch in Maximos' or. 22,7, wo es der Bitte um Heilung einer (durch die Leidenschaften) erkrankten Seele gegenitber gestellt wirc.

Offenbar geht es Maximos allein um die unhaltbaren theologischen Implikationen einer bestimmten Sicht der Gebetserfüllung durch das Göttliche. Das könntie ein Grund sein, warum er die Kritik Epikurs nicht aufnimmt, dass nämlich die Menschen schon zugrunde gegangen wären, wenn die Götter auf ihre Bitten hören würden, weil sie mit Sicherheit schon viel Schlechtes gegeneinander erbeten hätten (fr. 66). Auch das Problem, dass Lukian brilliant parodistisch in Szene gesetzt hat (Icarom. 25), hat er nicht aufgenommen, nämlich, dass Gott bei entgegengesetzten Bitten nicht wüsste, welcher Bitte er nachkommen soll.

Vgl. Luk. Sacr. 1 und 14; Alk. $2149 \mathrm{~d}-150 \mathrm{a}$. Bereits Platon kritisiert in Euthyphr. 14e,

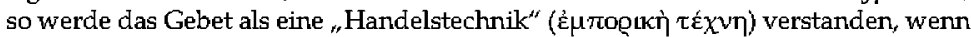
nämlich Opfern als Geschenk an die Götter und Gebet entsprechend als Bitte um

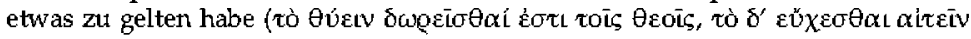

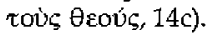

30 Il. IX 497. Sie drehen also ihr Fähnchen nach dem Wind und unterliegen damit ätBeren Einflüssen. Die Stelle wird bereits bei Platon kritisiert (Rep. II 364b-365a; Leg. $X 905 \mathrm{~d})$.

31 Gott ist unfähig zum Wandel, sagt Platon, Rep. II 381c, da er als das absolut Gute sich ja zum Schlechteren wandeln müsste. Die ganze Passage 380c-382e steht im Hintergrund von Maximos' Darstellung. Was allerdings bei Platon auf das Wesen 
Gottes bezogen ist, das detutet Maximos im Zusammenhang der vorliegenden Frage auf dessen Ratschlïsse und Handlungen. Zwei weitere Aspekte der Gotteslehre werden im vorliegenden Zusammenhang von Platon hervorgehoben, von denen der erste bei Maximos wiederbegegnet 1. Gott ist gut und nur Urheber von Gutem (380c); 2. Gott lügt nicht (dies wird hier im Zusammenhang der Frage nach dem Gebet nicht aufgegriffen). Zum Vergleich menschlicher Tugend und des göttlichen Wesens vgl. or. 13,3.

32 Dass die Götter dem Würdigen das Erbetene ohnehin verleihen, auth ohne dass der Betreffende darum bitten muss, ist ein Argument, das auch bei Juvenal erscheint. Juvenal allerdings verwendet statt des griechischen $\alpha \hat{\alpha} \xi \ldots \zeta$ das lateinische aptus verwendet (Iuv. 10,349: nam pro iucundis aptissima quaegue dabunt di, "denn nicht das Gewünschte, sondern das für jeden Angemessene verleihen die Götter" $)$. Juvenal begründet dies mit der Liebe der Götter zu den Menschen (350: carior est illis homo quam sibi, „sie lieben den Metrschen mehr als sich selbst"), während Maximos den Diskurs um das Wesen der Götter ausführlicher behandelt und mit den folgenden Erläuterungen zu den vier Faktoren (Vorsehung, Schicksal, Glück und. Sachverstand), die entwe der von den Göttern verliehen oder in der Verantwortung des Menschen stehen, philosophisch untermauert. [SB]

33 Ähnlich Alk. 2 149d-150a; Philostr. V. Ap. I 11; IV 40. Deshalb empfiehlt Philostrat an beiden Stellen übereinstimmend ein entsprechendes Gebet: "Gebt mir, o Götter, das, was mir zukommt!" (

34 Zur vollkommen gegensätzlichen Gebetstheorie des Lukasevangelium, s. unten, den Beitrag von Rainer Hirsch-Luipold, S. 109-110.

35 Die Verbindung von Selbstbewusstsein und Bescheidenheit, die dem Würdigen hier zugeschrieben wird, erinnert doch sehr an die Haltung des Stoikers, der sich durchaus im Bereich der an sich indifferenten Dinge (Adiaphora) solche wünschen darf, die er bevorzugt (Gesundheit, Wohlstand, Sicherheit usw.), aber immer nur mit Vorbehalt ( $\mu \varepsilon \theta^{\prime}$ v́ $\pi \varepsilon \xi \alpha$ ழé $\left.\sigma \varepsilon \omega \zeta\right)$ ), so dass er es mit bescheidener Gelassenheit akzeptiert, wenn das Schicksal ihm das Erwünschte einmal nicht ztgedacht hat (vgl. für diese Lehre SVF 3,564 [=Stob. II 115,5 Wachsmuth], Seneca, Ben. IV 34, Epict. Ench. 2; Mark Aurel 4,1;5,20;6,50;11,37).

36 Maximos wiederholt im Folgenden ein Arsenal an Beispielen relativ schematisch an unterschiedlichen Stellen; vgl. etwa or. 1,5: Kaufmann, Soldat, Seefahrer, Rätuber (und Ehebrecher, der in or. 5 nicht vorkommt); or. 3,1.7; 4,9. Der Lastträger ist eine Figur in der antiken Komödie (vgl. Aristophanes, Frösche 498). Das Beispiel verlagert unter der Hand das Thema vom Individuellen zum Kollektiven, von der individuellen Würdigkeit zum gesellschaftlich-militärischen Status und zu den Erfordernissen der Schlacht. Diese Bilder lenken die Aufmerksamkeit auf die Vorstellung einer Führungsfigur, die aufgrund der Einsicht in Mittel und Ziele das reibungslose Funktionieren eines komplexen Ganzen unter ihrer Kontrolle sicherstellt. Auf diese Weise führen solche Bilder das Thema der göttlichen Vorsehung und des Wirkens des Schicksals ein, zu dem Maximos nun wechseln will.

37 Vgl. Clem. Strom. VII 7,41,5; 12,73,1-6. Zwei Beispiele, die ganz ähnlich in einer Art Schluss a minore ad maius von einem schon unter menschlichen Verhältnissen absurden Beispiel auf die völlige Urmöglichkeit bei Gott schließen, finden wir in Lk 11,5-13.

38 Die zentrale Kategorie der Würdigkeit hat durchaus auch soziale Aspekte, die am Vergleich des Hopliten mit seinem Lastknecht deutlich wird; ats der Sicht Gottes freilich haben diese sozialen Aspekte auch ethische Implikationen, insofern Gott cafür zu sorgen hat, dass jeder an seinem richtigen Ort intnerhalb des Gemeinwesens steht und seine Rolle erfüllt. Zum Thema vgl. ausführlich Rainer Hirsch-Luipold in diesem Band, sowie Anm. 81 zur Übers., Franco Ferrari, S. auf Seite 85, Alfons Fürst, S. 123, 135 und 138 Anm. 76. 
Gegenüber der vielleicht näherliegenden Übersetzung "Kunıtfertigkeit" (VAN DER HoRst 1996, 334: „,skill") erlaubt es die gewählte Übersetzung, auch Beispiele wie die des Stetermanns (tund damit des Weltenlenkers) einzubeziehen.

Der Satz ist sorgfältig rhetorisch geformt und bildet gewissermaßen die Überschrift und Struktur der folgenden Kapitel. Die Glieder sind ganz parallel formuliert und jedes Substantiv ist in einer variatio mit einem passenden Verb versehen, das in den Gliedern a) und b) nachgestellt ist, bei c) und d) dagegen voransteht (so dass sich eine chiastische Struktur ergibt). Nachdem die ersten drei Glieder göttliche Größen sind, zu denen man beten könnte, kommt der menschliche Sachverstand als viertes Glied überraschend. Eine Vorlage wird Platon gewesen sein: Platon nenut in

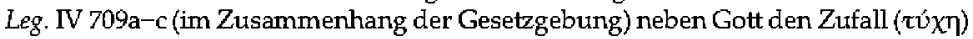
und den glïcklichen Augenblick (אaڤós) als Größen, die auf das menschliche Leben Einfluss nehmen, sowie schließlich den menschlichen Sachverstand ( $\tau \dot{\varepsilon} \chi \chi \vee \eta$; vgl. Leg. X 888e sowie 902e-903a und dazu u. Franco Ferrari, S. 866.). Auch die Vergleiche mit Seefahrt, Heilkunst und Heeresleitung finden sich hier. Dadurch allerdings, dass Maximos die Liste auf Adressaten des Gebets überträgt, passt die Kategorie menschlichen Sachverstands nicht mehr unproblematisch. Die platonische Vorlage wird in or. 13,7 noch einmal etwas präziser aufgenommen, wo menschlicher Sachverstand ( $\left.\tau \varepsilon_{\chi} \backslash \eta \eta\right)$ neben Gott, Glück und glücklichem Zeitpunkt als Faktor erscheint, der auf das Leben einwirkt. Dort ist deutlicher erkernbar, dass Maximos gegenüber der stoischen Sicht des allherrschenden Schicksals Raum für autonomes menschliches Handeln schaffen will.

41 Maximos setzt Vorsehung und. Gott faktisch in eins (ähnlich Senenca, Prov. I,I) in $\$ 4$ wird das Verb "vorsehen" ( $\pi$ povoeiv) mehrfach mit Gott verbunden. Die Handlungsinstanz hinter der Vorsehung ist also Gott. Maximos wird diese Ersetzung aber mit Bedacht vornehmen: zwar hat Gottes Vorsehung alles bereits eingerichtet, weshalb sich hier ein Gebet erübrigt. An Gott selbst kann man sich aber doch sinnvoll im recht verstandenen Gebet wenden, wie Maximos in \$8 zeigt. Es ist auffällig, dass Substantiv wie Verb innerhalb der Dialexeis nur in or. 5 erscheinen, obwohl verschiedene andere der Reclen (wie z.B. or. 13,3; 41,4) sich mit einer verwandten Thematik beschäftigen.

42 Zum diesem Begriff Arist. Met. 1032aI2-32: "Alles, was ist, entsteht entweder durch natürliche Ursachen oder durch Kunstverstand, manches aber auch aufs

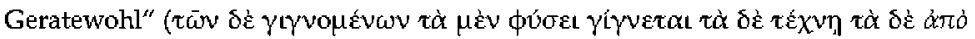

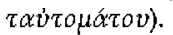

43 Ähnliche, aber nicht identische Listen von Dingen, die auf das menschliche Schicksal Einfluss nehmen, finden sich auch anderswo in platonischen und stoischen Texten der Kaiserzeit (Apul. De Platone et eius dogmate XII 205-206; Ps.-Plut. Fat. 570b), dazu in doxographischer Literatur (Ps.-Plut. Placita 885C-D; Sextus, Pyrrh. Hyp. I 237; Diog. Laert. III 96). Mit seiner Liste gibt Maximos implizit der Überzeugung Platons Recht, dass neben dem allumgreifenden Schicksal noch weitere Faktoren Einfluss auf den Gang der Dinge nehmen, und wendet sich so gegen die Stoiker, die darauf beharren, dass Vorsehung und. Schicksal miteinander zu identifizieren sind, und dass es bloßen Zufall gar nicht gibt (z.B. Seneca, Nat. guaest. II 45). Diese Überzeugung wird weiter ausgeführt bei Ps.-Plut. Fat., Alcin. Didasc. 26 und Apul. De Plat. I 12 (vgl. auch Plut. Quaest. conv. 740C; zum Ganzen vgl. Dillon 1996, 166-168. 208-211. 294-298. 320-326).

44 Die folgenden Gedanken beziehen sich nicht nur auf das Gebet, sondern sind allgemeine Überlegungen zum Konzept einer guten Vorsehung, die atch an eiter Theodizee interessiert sind (vgl. ähnliche Gedanken in Senecas De providentia, Plutarchs De sera numinis vindicta usw.). Eneut zielt die Darlegung aber auf den Gedanken, dass Gott als der Fachmann den Überblick darüber hat, was dem Menschen im Klejnen und der Welt im Ganzen zuträglich ist. 
45 Für die Vorstellung, dass die göttliche Vorsehung sich um die großen Rahmenbedingungen kümmert, vgl. Cic. Nat. deor. II 66.167; Epict. I 12,2; Justin, Dial. I 47. Vgl. weiter Ps.-Plut. Fat. 569d-570a; Alkin. Didasc. 26; Philo, Prov. II 44.54.

46 In Leg. $X 900 \mathrm{c}-\mathrm{d}$ argumentiert Platon dafür, dass die Gottheit auch um die kleinen Dinge besorgt ist (vgl. u. Franco Ferrari, S. 86f.).

47 Die Glieder antworten hier gemeinsam gleichsam als Schicksalsgemeinschaft.

48 Der Vergleich des Gemeinwesens mit einem Organismus ist stoisch (Sen. Prov. 3,2; Epict. II 5,24; Mark Aurel 5,8); im Neuen Testament wird er insbesondere in 1 Kor 12 aufgegriffen. Auch die medinizische Metaphorik eines Eingreifens der Gottheit zugunsten der salus publica gehört in diesen Zusammenhang.

49 Dieselbe Liste erscheint in or. 41,4, die Beispiele sind aber bereits aus der klassischen Literatur bestens bekatunt (vgl. TRapr 1997 a ad loc.).

50 Der Mensch versteht Gottes Rationalitäten bei seinem manchmal schmerzlichen Eingreifen in die Welt ticht immer (vgl. Plat. Leg. X 903c-d). Vorausgesetzt ist hier das Bild Gottes als eines Arztes, dessen heilendes Eingreifen bisweilen schmerzlich, immer aber wohlwollend und im Situte der Heilung des Ganzen ist, wie wir es bei Plutarch in Über die späten Strafen der Gottheit (De sera numinis vindicta) ausformuliert finden; vgl. dazu HiRsCh-LuIPOLD 2002, 225-281. Der Gedanke, dass dem Menschen eine letzte Einsicht in die größeren Zusammenhänge und in die Rationalität des Handelns Gottes nicht zu gewinnen ist, impliziert eine skeptische Zurückhaltung des Urteils, die bei Plutarch auch im Dienste der Theoclizee steht.

51 Der Text folgt Laur. Conv. sopp. 4 und Koniaris 1995 gegenüber dem akzentlosen dvves in den Haupthandschriften.

52 Vgl. Ps.-Plat. Alk. 2 142e-143a mit dem dort als Mustergebet vorgeschlagenen Gebet eines Dichters: „Zeus, Herrscher, das Gute gib uns, ob wir es uns erflehen oder nicht, das Schlimme aber mögest du uns verweigern, auch wenn wir drum bitten"

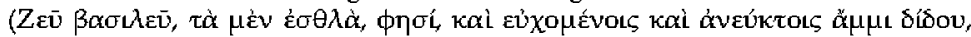

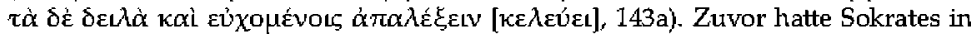
138b-143a ausführlich mit dem Gedanken gespielt, Gott könnte auch etwas Negatives erfüllen, um das man gebeten hat, und die Implikationen dessen für das Gebet diskutiert. Nach $148 \mathrm{~b}$ beten die Athener „immer, sowohl öffentlich als jeder für sich, ein ähtrliches Gebet, indem sie die Götter antrufen, ihnen das Schöne zu dem Guten zu verleihen. Mehr wird niemals jemand einen von ihnen beten gehört haben" ${ }^{\prime \prime}$ Zum Alkibiades 2 siehe die Einführung, S. 7-8 sowie die Beiträge von Franco Ferrari, S. 81, Alfons Fürst, S. 122-123 und Rainer Hirsch-Luipold, S. 96 Antn. 16 in diesem Band.

53 Maximos zieht den stoischen Begriff "Schicksal dem Begriff des „Zwangs" (Avó $\gamma$ kワ) vor, den Platon in Rep. X 617b-e verwendet. Zwang ist dort die Mutter der drei Schicksalsgöttinnen (Moiren) Lachesis, Klotho und Atropos. Ähnlich. personifiziert tritt hier das Schicksal auf (im Griechischen Femininum) wie die Vergleiche zeigen.

54 Nach Platon ist die Tyrannis eine Gewaltherrschaft, die sich an kein Gesetz und nicht einmal an die Verpflichtungen gegenüber Vater, Mutter und. Vaterland gebunden fühlt (Platon, Rep. VIII 565a-IX 580c). Freilich findet sich in der anschließenden Liste mit Peisistratos auch ein Name, der durchaus nicht nur für Gewaltherrschaft, sondern auch für eine soziale Umverteilung nach unten steht.

55 Seneca hat es sprichwörtlich so formuliert ductunt volentem fata, nolentem trahunt, (ep. 107,11: „Es führt einen das Schicksal, wenn man zustimmt, wenn man sich weigert, schleppt es einen fort", Übers. Rosenbach; vgl. or. 13,8). Das Bild vom Zügeln des Pferdes findet sich verschiedentlich bei Plutarch (De sera 3, 549C-D; vgl. im Blick auf das Miteinander von Matn und Frau Praec. coni. 139B). Besonders interessant ist De genio Socratis, wo es metaphorisch in 22, 592A-B erscheint (vgl. 588F; explizit übertragen auf den Umgang des Göttlichen mit den Menschen in 593A-C) und damit einen Aspekt der historischen Rahmenerzählung atfgreift: das Fehlen eines Zaumzeugs hatte das Ausreiten eines Boten verhindert (587F), was sich im Nach- 
hinein als göttliches Eingreifen entpuppt. In pädagogischem Zusammethang wird die Metapher bei Max. or. 1,8 verwendet.

56 Es handelt sich urm vier sprichwörtliche Tyrannen der griechischen Geschichte. Die Liste beginnt mit dem Jüngsten: Dionysios von Syrakus, der u.a. Platon an seinen Hof holte, Peisistratos im Athen in der Mitte des 6. Th.s v. Chr., Periander und Thrasybulos im Wechsel vom 7. zum 6. Jh. v. Chr. Bei den genannten Namen handelt es sich durchaus nicht nur um Willkürherrscher; sowohl Peisistratos als auch Periander gelten als Herrscher, die mit starker Hand und beinahe absoluter Macht wesentlich politische Neuerungen einführten.

57 Die älteren Maximos-Handschriften bieten hier den Namen „Homer". Dies würde allerdings eine ausgesprochen harte Ellipse voraussetzen (,wie Homer [scil. durch die Reaktion seiner Helden] im Krieg aufzeigt”). Wie der Florentiner Gelehrte Zanobi Acciaiuoli erkannt hat, ist "Homer" sehr wahrscheinlich die Hitzufügung eines Lesers, als Randglosse sollte sie den Autor des folgenden Zitats identifizieren, ist dann aber fälschlicherweise in den Text eingedrungen. Zanobi Acciaituoli löschte die Hinzufügung in dem ihm vorliegenden Text (Laur. conv. sopp. 4) und er findet sich von da an nicht mehr in späteren Kopien dieser Handschrift. Il. VI 46.

59 Sohn des Zeus und der Laodameia (Il. VI 196-199).

60 Diese wie die folgenden Verse hat bereits Platon in Rep. III $388 \mathrm{c}-\mathrm{d}$ zitiert. Es ist eine der im Blick auf die homerische Gotteslehre besonders fruchtbare Szene und. wurde entsprechend häufig in der religiös-philosophischen Literatur diskutiert (Stellen bei TRAPP 1997a, Anm. 26): steht Zeus über dem Schicksal? Da er von Hera an die kosmischen Spielregeln erinnert werden muss, ist die Antwort, die die Ilias nahelegt: er könnte sich wohl über das Schicksal hinwegsetzen (und tut dies bei Sarpedon auch zweimal), aber er würde dadurch letztlich die gesetzte Ordnung der Welt in Frage stellen, deren Garant er selbst ist. Dass die Stelle hier aufgenommen ist, ist mehr als eine Reverenz an Platon. Es unterstreicht, dass es Maximos immer um die Gotteslehre zu tun ist. Dass hier Zeus selbst in der Rolle des Betenden erscheint, ist wiederum mehr als eine gewollte Komik der Darstellung, sondem nimmt das von Homer angedeutete Dilemma auf: in Fragen des Schicksals ist selbst das Göttliche gebunden, wenngleich es sich atffrutund des Postulats der Allmacht theoretisch darüber hinwegsetzen könnte. Die Überlegungen über das Gottesverhältnis erhalten damit einen skeptischen, oder, stärker stoisch gewendet, einen fatalistischen Zug: wir können die Rationalitäten des göttlichen Handelns und Verfügens nicht immer verstehen, oder: es gibt ewige Setzungen, denen sich selbst der höchste Gott unterwirft.

61 Maximos deutet die Namen der drei Moiren etymologisierend durch die fol-

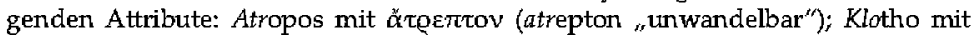

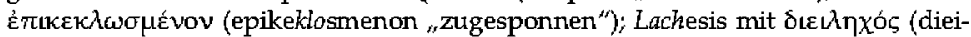
lechos "das Los zuteilend"). Für die philosophische Deutung von Namen und Begriffen in diesem Sinne, die nicht in modernem Sinne sprachgeschichtlich missverstanden werden darf, sondern vielfach etwas Spielerisches hat, ließen sich in der Kaiserzeit unzählige Beispiele angeben; die Wortspiele mögen auf den Stoiker Chrysipp (Stob. I 5,15. [79 Wachsmuth]), und über ihn schon auf Platon, Rep. X $620 \mathrm{~d}-\mathrm{e}$ zurückgehen, wo die drei Moiren bereits mit Etymologisierungen verbunden werden (vgl. VAN DBR HORsT 1996, 333 mit weiteren Stellen).

62 Als von Trieben beherrscht und gesteuert hatte Platon gerade den Tyrannen gekennzeichnet.

63 Hier hat der Autor offenbar wieder eine Personifikation vor Augen.

64 Meerenge bei Euböa. Vgl. Platon, Phaidon 90c und mehrmals bei Maximos (or. 10,5; $28,3 ; 41,3)$. 
65 Mit dem letzten Stichwort der Kutnst des Steuermanns hat er bereits zu seinem letzten Stichwort übergeleitet: der $\tau \dot{x} \chi \vee \eta$.

66 Dieses Bild der unsteten, unverlässlichen und blinden Tyche finden wir in Tkonographie und Literatur verschiedentlich; vgl. insbesondere ihre Kennzeichnung in der Tabula Cebetis 7,1-3, wo auch auf die ikonographische Darstellung der Tyche auf einer Kugel angespielt wird. Sehr viel positiver zeichnet Maximos sie in or. 40,5. $\mathrm{Zu}$ Tyche als Ursache des Schlechten siehe den Beitrag von Franco Ferrari, S. 82-85 in diesem Band.

67 Vgl. die ähnlichen Beispiele bei Cic. Tuss. II 12 (vgl. H.-G. Nbssblrath, Lukians Parasitendialog. Untersuchungen und Kommentar [Berlin 1985] 141 Anm. 87 und Index, s.v. $\tau \dot{x} \chi \vee \eta)$.

68 Mit Sachverstand oder Kunstfertigkeit umschreibt Maximos das garze Spektrum zielgerichteten, fachmänntischen Handelns von Menschen, von der Produktion kütnstlerischer Gegenstätıde über die Steuerung komplexer Vorgänge bis hin zur persönlichen Lebensführung. Kunst, Handwerk und Wissenschaft stehen so, wie seine Beispiele zeigen, neben einer ethischen Lebensführung, die damit ihrerseits als eine Art lehrbare Kunstfertigkeit erscheint. Damit führt er atf ein letztlich auf Sokrates und Platon zurückgehendes Verständnis von Philosophie hin, das als s, Le-

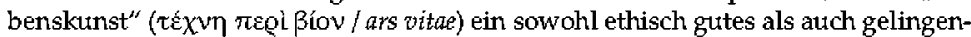
des und glückliches Leben ermöglicht (vgl. Plutarch, Quaest. conv. I 1, 613B; SVF II 117). Seneca bringt dies mit der Problematisierung des Gebets in Zusammenhang: "Du tust etwas Vortreffliches und für Dich Heilsames, wenn Du, wie Du schreibst, beharrlich auf dem Weg zu einer guten Sinnesart (bona mens) bist, die (im Gebet) zu erbitten töricht wäre, da Du sie ja von Dir erlangen kannst" (Sen. ep. 41,1; vgl. u. Franco Ferrari, 5. 89f.).

69 Die ganz parallel formulierte Reihe gerät am Ende etwas aus den Fugen, obwohl Maximos freilich die Tugend auch als eine $\tau \dot{x} x \nu \eta$ beschreiben kann. Das Argumentationsziel indes ist klar: vieles im Leben ist in die Verfügung des Menschen gestellt, insbesondere die Fertigkeit zutm Ausführen bestimmter Tätigkeiten, aber zuletzt auch itber die Tugend der Weg ztum Glitck. Wiederum fühlt man sich sehr an die Tabula Cebetis erinnert.

70 Oben hatte Maximos Gott und Pronoia in eins gesetzt, insofern es die gute Vorsehung Gottes ist, die alles zum Guten wendet. So müssen wir es auch hier verstehen: Um was könnte der Merısch Gott sintuvollerweise bitten, das der nicht sowieso schon entsprechend eigerichtet hätte?

71 Den Gedanken muss der Leser oder die Leserin im Anschluss atı die oben geätıerten Gedanken zu Ende führen: „„... und nur Gutes gewähren die Götter".

72 Menander, fr. $363 \mathrm{~K}$-A.

73 Der Text ist hier unheilbar verderbt, was durch die cruces angezeigt ist; eine überzeugende Konjektur konnte bisjetzt nicht vorgeschlagen werden. Der Sinn lässt sich folgendermaßen paraphrasieren: „Wenn es Geld ist, worauf du aus bist, ..., belästige auch nicht den Sachverstand (mit deinen Gebeten). Du hörst doch, was Menander sagt: ... Sachverstand ist etwas, für das allein die Menschen zuständig sind, und das durch den allermenschlichsten Antrieb funktioniert, nämlich Gier. Also schlage alle deine Skrupel in den Wind und werde reich, indem du dein Geschäft mit allen Kunstkniffen verfolgst, wie verabscheutungswürdig sie auch sein mögen".

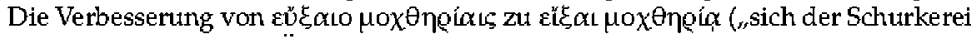
hingeben") würde den Übergang zu den folgenden spöttischen Imperativen glatter

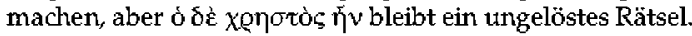

74 Eine ähnliche Liste findet sich bei Aristophanes, Plut. 30f.

75 Die Reihe von Exempla ist nicht ganz klar. Jedenfalls handelt es sich um drei Figuren von mehr als zweifelhaftem Ruf, die trotz (oder gerade wegen) ihrer moralischen Verworfenheit erfolgreich waren. Während Hipporikos, der Sohn des Kal- 
lias und ein sprichwörtlich reicher, degenerierter Athener, den Reichtum bereits mitbringt und durch nichts verdient hat, weshalb die Logik offenbar ist, dass man selbst als Hipponikos noch mehr anhäutfen kann, scheint bei Kleon als einem homo novus die Betonung darauf zu liegen, dass man auch ohne Voraussetzung Karriere machen kann, wenn man nur ruchlos genug ist. Kleon errang einen glänzenden Sieg bei Sphakteria (Thukydides IV 27-41), galt aber als Volksverführer und Opportunist (vgl. das Portrait in den Komödien des Aristophanes, vor allem den Rittern, und bei Thukydides). Meletos betrieb erfolgreich die Verurteilung des Sokrates aus der Sicht des Maximos, für den Sokrates höchstes Vorbild einer ethischen und religiösen Philosophie und Lebensführung ist, äußerstes Beispiel eines durch und durch schlechten und doch im Ergebnis erfolgreichen Handelns. Die Frage, warum das Göttliche dies zulässt, eben jene Frage, die der Ausgangspunkt von Plutarchs De sera numinis vindicta ist, wird hier nicht gestellt. Das Argument zielt ganz auf den Adressaten und seine Ethik bzw. sein Gottesverhältris.

Hier befindet sich eine gedankliche Zäsur. Maximos wechselt in einen anderen $\mathrm{Mo}$ dus, und ruft nach den vorausgehenden ironischen Bemerkungen über das Bittgebet die Emsthaftigkeit des Gebets im Sinne eines Gesprächs mit der Gottheit ins Bewusstsein.

Maximos greift insbesondere den Kontext des Gerichtssaales atf, der in seinen Exempla bereits präsent war, um den Ernst des Gebets deutlich zu machen. Es ist diese Ethik und Theologie des Gebets, die die Haltung der Aseneth am Anfang des hellenistisch-jüdischen Romans Joseph und Aseneth bestimmt. Bevor die Bekehrte schließlich ihren Mund zum Gebet öffnet, denkt sie lange clarüber nach, ob sie als Verworfene es riskieren kann, sich im Gebet an den Gott Israels zut wenden. Siehe dazu den Beitrag von Rainer Hirsch-Luipold, S. 110-113 in diesem Band.

Maximos evoziert eine Gerichtsszene. Fin solches Verhalten konnte man von Menschen erwarten, die sich vor Gericht zu verantworten hatten und versuchten, einen Freispruch zu erreichen, selbst wenn die Fakten gegen sie zu sprechen schienen (vgl. z.B. Aristophanes, Vesp. 967-984). Sokrates hatte sich bei seinem Prozess geweigert, eben dies zu turn, wie Maximos in or. 3,3 betichtet.

79 Il. I39; vgl. aben \$2 Anm. 27.

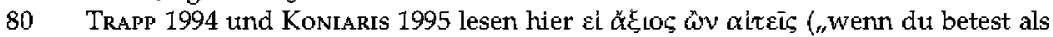
einer, der dessen würdig ist, worum er bittet"). Die doppelte Bedingutng ("wenn du würdig bist" und ,werth deine Bitten auf etwas Positives gerichtet sind") wirkt etwas merkwürdig. Wir übernehmen deshalb Reiskes Konjektur. Auf diese Weise bestimmt sich Würdigkeit als Folge der vorausgehenden Frage daher, ob das Gebet auf etwas Gubes hinzielt. Wer um etwas Gutes bittet, ist würdig, es auch zu erhalten. Der Abschnitt wiederholt, was oben bereits über die Vorsehung gesagt wurde.

82 Im Diatribenstil, den er schon am Ende des letzten Kapitels begonnen hatte, fingiert der Autor einen Einwand seines Gesprächspartners, auf den er dann reagieren kann. Das Stilmittel war dem Leser so vertraut, dass der Sprecherwechsel nicht explizit ausgedrückt werden musste.

Vom Gebet des Sokrates erzählt Platon im ersten Satz der Politeia (Rep. I 327a). In typischer Weise werden abschließend die großen Philosophen als Beispiele praktischen philosophischen Vollzugs angeführt; Sokrates, Platon und Pythagoras sind die Philosophen, die bei Maximos (neben dem Kyniker Diogenes) am häufigsten angeführt werden; vgl. die Einfüthrung oben, S. 16.

84 Gemeint ist die Thrakische Bendis, deren Heiligtum im Piräus stand. Mit Glatkon war Sokrates dorthin gegangen am jährlichen Fest der Göttin, den Bendideia (vgl. Plat. Rep. I 354a), die mit einem Umzug der Thraker gefeiert wurden. markanten Stellen Gebete in seine Schriften ein, die auch dettlich machen, was der 
rechte Inhalt des Gebets von Philosophen ist: neben den genannten Stellen vgl. Tim. 27c; Leg. VII 801a-b sowie Dillon 2016; Clay 1979.

86 Vgl. Plat. Leg. IV 716d. In Platons Folge definiert atth Clem. Strom. VII 7,42,1 das Ge-

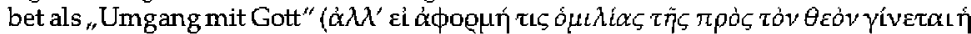

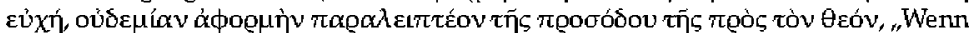
aber das Gebet eine Möglichkeit bietet, mit Gott in Verkehr zu kommen, so darf man keine Möglichkeit eines Zugangs zu Gott unbenützt lassen“" [Übers. Stählin]). SZARMACH 1985, 55, sieht hier eine Anspielung auf das pagane Konzept, man sollte aber besser sagen: Klemens befindet sich im selben gedanklichen Strom des religiösen Platonismus der frühen Kaiserzeit. Selbstverständlich lassen sich aber auch eine Reihe von Stellen angeben, an denen Klemens das Gebetin christlicher Tradition als Bittgebet versteht (vgl. Trapp 1997a, 49 Anm. 39).

87 Vgl. Plat. Symp. 203a.

88 Sowohl Juvenal als atch Maximos sehen das einzig wirklich erstrebenswerte Gut, um das man beten sollte, in einem tugendhaften Lebenswandel, der durch philosophische Bildung erreicht wird. Juvenal ist dabei stark von den stoischen Tugenden Apatheia und Ataraxia beeinflusst (357-360: fortem posce animum mortis terrore carentem, / qui spatium vitae extremum inter munera ponat / naturae, qui ferre queat quosctinque dolores, / nesciat irasci, cupiat nihil, ,bete um ein tapferes Herz, das den Tod richt fürchtet, das von den Geschenken der Natur ein langes Leben als das geringste achtet, das alle Schmerzen zu tragen vermag, niemals jähzornig wird, keinen Versuchungen erliegt"; siehe dazu den Beitrag von Alfons Fürst in diesem Band, S. 117 Anm. 2). Wie Maximos weist auch Juvenal seine Leser (bzw. Hörer) darauf hin, dass sie selbst tätig werden können, um solches zu erlangen (10,363: monstro quod ipse tibi possis dare, "sieh, das alles kannst du selbst dir verleihen"). [SB]

89 Diese Formulierung spielt auf die Haltung und die Argumentationen des Sokrates angesichts des Todes in seinen letzten Tagen im Gefängnis an, wie Platon sie im Phaidon vorführt. Das ändert sich in der frühen Kaiserzeit. Nun sind die klassischen Antworten auf die Frage nach einer Fortexistenz über den Tod hinaus problematisch geworden ist, wie der ps.-platonische Axiochos oder "Über den Tod" eindrucksvoll in Szene setzt. Entsprechend setzt Paulus in 1 Thess 4,13 angesichts des Todes von Gliedem der Gemeinde in Thessalonich trotz der Überzeugtung des in Christus neu geschenkten Lebens die Christen ab von denen, die "keine Hoffnung haben"

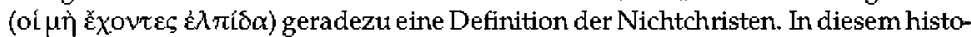
rischen Kontext scheint in der Formulierung des Maximos doch Grundsätzlicheres mitzuschwingen.

90 Der letzte, antiklimaktische Satz des Kapitels kann als Abschluss des gesamten vorausgehenden Abschnitts gesehen werden: zentral ist, an der richtigen Stelle nach der Erfüllung der jeweiligen Wünsche zu suchen.

91 Dieser Schluss ist formal besonders bemerkenswert: Er beschreibt das philosophische Gebet nicht nur, sondern bietet ein Beispiel eines solchen Gebets, gewissermaßen ein philosophisches Mustergebet. Das Gebet wird so zu einem zentralen Baustein eines philosophischen Lebens insgesamt. Dabei greift Maximos auf eine Metaphorik zurück, die auch an anderer Stelle in seinem Werk die Bedeutung der Philosophie für die Lebensführung unterstreicht (z.B. die Philosophie als Licht auf dem Weg in or. 1,3). Ein ähnlich markanter Ausruf findet sich am Schluss von verschiedenen der ,philosophischen Predigten' des Maximos (vgl. oben Einführung, S. 16).

92 Vgl. Hom Od. IV 341.

93 Паџ $\varepsilon_{i \alpha} \alpha$, also (religiöse) Bildung und Ausbildung, wird vielfach in die Metapher des Ackerbaus gefasst (vgl. etwa Plutarchs De audiendis poetis; Mk 4; I Kor 3).

94 Der Vergleich der Philosophie mit einem Lichtfunken in der Finsternis ist ein Lieblingsbild des Maximos: vgl. orr. 1,3 (philosophische Bildung als Licht auf dem 
Weg des Lebens); 29,5 (die Streben nach dem Guten im Menschlichen als Stche nach Gold in der Dunkelheit); 11,1 (philosophische Interpretation der Schriften Platons als schwaches Lichtsignal verglichen mit dem hellen Sonnetlicht der Dialoge selbst).

95 Vgl. or. 1,3.

96 Vgl. hierzu Röm 7-8. 


\section{Essays}





\title{
Philosophie als wahres Gebet. Platonische Elemente in der fünften Oratio des Maximos von Tyros*
}

\author{
Franco Ferrari
}

\section{Maximos und die Philosophie}

Wer sich auf die Lektüre der Orationes ( $\Lambda \alpha \lambda \dot{\varepsilon} \xi \varepsilon 1 \zeta)$ des Maximos von Tyros einlässt, wird selbst bei denjenigen, die einen ausgesprochen philosophischen Inhalt präsentieren, unweigerlich feststellen, dass ihr Autor nicht als professioneller Philosoph betrachtet werden kann, in dem Sinne wie dies für zeitgenössische Figuren wie Alkinoos gilt, den rätselhaften Autor des Didascalicus, ${ }^{1}$ für Albinos, Kalbenos Tauros oder Numenios. Auch mit Plutarch ist er nicht vergleichbar, wenngleich der sicherlich ein Philosoph sui generis gewesen ist, den man seinerseits nicht einfach mit den zuvor genannten Denkern gleichsetzen kann. Plutarch zeigt aber in einigen seiner Werke (z.B. De animae procreatione, Platonicae quaestiones, De virtute morali, den Delphischen Schriften), dass er über alle Qualitäten und Mittel eines professionellen Philosophen verfügt.

Die philosophische und kulturelle Haltung des Maximos wird manchmal in die Nähe derjenigen des Apuleius gerückt; mit ihm verbindet Maximos sowohl ein ausgesprochenes Interesse an den populären Aspekten der Philosophie, als auch der durchgängige Rekurs auf rhetorisch-literarische Mittel und damit die Absicht, die Philosophie auch außerhalb professioneller Kreise und allgemein der Schulphilosophie attraktiv zu machen. Philosophie will er so zu einem fundamentalen Teil der Grundausstattung des pepaideumenos machen. ${ }^{2}$ Indes dürfen solche Parallelen nicht dazu füh-

\footnotetext{
* Aus dem Italienischen übersetzt von Simone Seibert unter Mithilfe von Andrea Villani und Rainer Hirsch-Luipold.

${ }^{1}$ Whittaker 1987, 83-102; J. WhitTaker, Alcinoos. Enseignement des doctrines de Plato. Introduction, texte établi et commenté par J. Whittaker et traduit par P. Louis. Collection des universités de France (Paris 1990), hat auf Basis paläographischer, stilistischer und inhaltlicher Überlegungen gezeigt, dass Alkinoos, der Autor des Didascalicus, nicht mit dem Platoniker Albinos, dem wir die Autorschaft des Prologos verdanken, gleichgesetzt werden darf, wie die Forschung dies irrtümlicherweise etwa ein Jahrhundert lang getan hatte.

${ }^{2}$ Vgl. z.B. Donini 1982, 133f.; M. B. Trapp, "Apuleius of Madauros and Maximus of 'Tyre", in: R. W. Sharples / R. Sorabji (Hg.), Greek E' Roman Philosophy 100 BC-200 AD, Bd. II (London 2007) [467-482] 468. Zur Rolle der Philosophie bei der Bildung des pepaideumenos
} 
ren, Maximos auf die Ebene des berühmten lateinischen Schriftstellers zu heben, dessen Ansehen, insbesondere auf literarischer Ebene, das des Autors der Dissertationes wesentlich übersteigt.

Wenn man aber den Begriff, Philosophie' ausreichend weit und flexibel zu fassen gewillt ist, entsprechend der Definition Philostrats in der Einleitung der Vitae Sophistarum, ${ }^{3}$ dann lässt sich problemlos atuch Maximos in die Kategorie der Philosophen einreihen. Seine Philosophie ist in der Tat

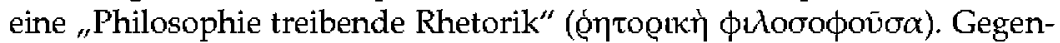
über den von Philostrat erwähnten Persönlichkeiten sind die philosophischen Qualitäten des Maximos sogar ohne Weiteres höher einzuschätzen. In seinen Reden finden sich durchaus tiefgehende Reflexionen und Auslegungen, die, wenn sie auch nicht originell sind, Zeugnis ablegen von einer erheblichen Kenntnis und der Fähigkeit, Themen zu behandeln, die alles andere als simpel und banal sind.

Maximos kann demnach nicht als Schulphilosoph oder ,akademischer' Philosoph im eigentlichen Sinne betrachtet werden, wohl aber als ein interessanter Rhetor (oder Lehrer), der an philosophischen Fragestellungen und Problemen interessiert ist. ${ }^{4}$ Dass er durchaus ein philosophisches Verständnis besitzt, ist daraus $\mathrm{zt}$ ersehen, dass Maximos in seinen Reden Argumentationsgänge aufnimmt, um die sich die Debatte unter den philosophischen Schulen der ersten Jahrhunderte der Kaiserzeit drehte. ${ }^{5}$ So finden sich in den Dissertationes Reflexionen über die Natur des Göttlichen und über das Verhältnis von Gott und Welt, über die Vorsehtung und den freien Willen, über den Ursprung und die Ursache des Schlechten, über die Vorstellung der "Wiedererinnerung" ( $\dot{\alpha} v \alpha \dot{\alpha} \nu \nu \eta \iota \varsigma)$, über die Frage nach der rechten Lebensweise und nach dem Zusammenhang zwischen Tugend und Wissen, über Dämonologie allgemein und speziell über ein Thema, das unter den Platonikern dieser Zeit sehr en vogue war, nämlich die Natur

im Umfeld der Zweiten Sophistik vgl. C. MoreschinI, „Aspetti della cultura filosofica negli ambienti della Seconda Sofistica“" ANRW II 36.7 (1994) 5001-5033.

${ }^{3}$ II $480 f$. Kayser: „Die alte Sophistik hat man als philosophierende Rhetorik zu betrachten, denn sie spricht über dieselben Themen wie die Philosophen [...] sie sprach nämlich über die Tapferkeit, über die Gerechtigkeit, über die Heroen und Götter und über die Art, wie die Welt ihre Gestalt bekommen habe ${ }^{\prime \prime}$ (Übers. Brodersen).

${ }^{4}$ In seiner Einleitung schreibt Trapr 1997a, xxiii: ${ }_{,}$Maximus is not a school philosopher offering a systematic course of instruction in philosophical doctrine."

${ }^{5}$ Ich denke beispielsweise an Passagen aus or. 11, die dem platonischen Gottesbegriff gewidmet sind, insbesondere an 11,8 (= H. DörRIB / M. BALTEs, Der Platonismus in der Antike, Bd. 4, Die philosophische Lehre des Platonismus. Einige grundlegende Axiome / Platonische Physik [im antiken Verständnis] I, Bausteine 101-124 [Stuttgart / Bad Cannstatt 1996] Baust. 106.2, 315-317), wo sich eine ausgearbeitete Einteilung des Seienden findet, eine Propädeutik zur Stellung und Definition Gottes, verstanden als „die vollkommenste Vernunft,

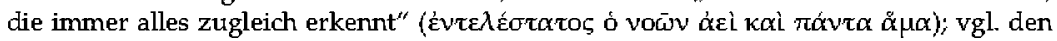
Stellenkommentar von M. Baltes zu Baust. 106.2, 315-317. 
des Daimonions des Sokrates. ${ }^{6}$ Man kann also ohne Weiteres sagen, dass in den Werken des Maximos Reflexionen mit theologischem, psychologischem, epistemologischem und vor allem ethischen Charakter vorhanden sind, wobei die Ethik ihn besonders beschäftigt hat ${ }^{7}$

Wenn man sich mit den Schriften des Maximos beschäftigt, muss man sich immer vor Augen halten, dass sie keine philosophischen Traktate im eigentlichen Sinne sind, sondern Lehrvorträge. Ihr Ziel ist nicht ein Beitrag zur philosophischen Schuldebatte, sondern eine Einführung in die Grundprobleme der Philosophie. Aus der Lehrsituation erklärt sich auch ihre Struktur. ${ }^{8}$ Daher darf man von Maximos nicht die Präzision und Gründlichkeit vieler Platoniker seiner Zeit erwarten: die komplizierten metaphysischen Unterscheidungen zwischen dem ersten und einem zweiten Gott, die sich bei Eudoros, Numenios und Alkinoos finden lassen, die tiefgehenden philosophischen und philologischen Untersuchungen zur zusammengesetzten Struktur und numerischen Einteilung der Weltseele, die von Plutarch (und Eudoros) entwickelt wurden, ebenso die Diskussionen um den Zusammenhang zwischen dem Demiurgen, dem Guten, der Ideenwelt sind seinem Zugang fremd. ${ }^{9}$ Aber, wie gesagt, ihm fehlt es nicht an einem grundlegenden Verständnis philosophischer Problemstellungen und seine Schriften repräsentieren ein interessantes Zeugnis für den Verbreitungsgrad philosophischer Themen außerhalb der Grenzen professioneller Kreise. ${ }^{10}$

\section{Der Platonismus und andere philosophische Richtungen}

Bekanntermaßen wird Maximos üblicherweise zu den ,platonischen' Philosophen gezählt. Die Berechtigung dieser Zuordnung zeigt sich eindrucksvoll bei einer Interpretation der fünften oratio. Es muss aber hinzugefügt werden, dass sein primäres Interesse nicht darin besteht, die plato-

\footnotetext{
${ }^{6}$ Vgl. VAN DER Horst 1996, 323; TRAPP 1997, 66-69 und. P. L. DonsnI, "Sokrates und sein Dämon im Platonismus des 1. und 2. Jahthutuderts n. Chr." De Deo Socratis / Über den Gott des Sokrates. SAPERE 7 (Darmstad. 2004) 142-161. Über die dämonologische Abhandlung des Maximos siehe Trм0 TIN 2012, 204-208.

${ }^{7}$ TRAPP 1997a, xix spricht von einer ${ }_{s}$ overwhelming concentration on ethics".

${ }^{8}$ Trapr 1997a, xxiii.

${ }^{9}$ Als einleitende Übersicht zu den Grundzügen der mittelplatonischen. Theologie siehe F. Frrrari, "Metafisica e teologia nel medioplatonismo", Rivista di Storia della Filosofia 70 (2015) 321-337.

${ }^{10}$ Dillon 1996, 400 sieht in den Dissertationes "useful evidence of what was common currency by way of Platonic philosophy in educated circles in the latter half of the second century".
} 
nischen Lehren mit den Meinungen anderer kaiserzeitlicher Schulen ${ }^{11} \mathrm{zu}$ kontrastieren, und auch nicht darin, eine korrekte Interpretation einzelner Passagen der Dialoge zu liefern. Die allgemeine Haltung der Dissertationes zielt vielmehr darauf, die Philosophie als fundamentale Komponente der kulturellen Bildung und als entscheidendes Element für das moralische Leben des Einzelnen herauszustellen. Deshalb verzichtet Maximos auch nicht darauf, Begriffe und gedankliche Konzepte aufzunehmen, die anderen philosophischen Richtungen, insbesondere dem Stoizismus entstammen. Das heißt jedoch nicht, dass er als Stoiker zu betrachten wäre, wie manchmal behauptet wurde, ${ }^{12}$ oder dass man ihm den Willen zuschreiben könnte, eine bewusste Verschmelzung des Platonismus mit den anderen philosophischen Strömungen zu betreiben. ${ }^{13}$

Tatsächlich zeigen viele der orationes, die fünfte inbegriffen, eine gewisse Affinität zur Diatribe (stoisch oder kynisch-stoisch), und dieser Aspekt könnte dazu verleiten, ihrem Autor die Zustimmung zu philosophischen Positionen zuzuschreiben, die dem Platonismus fremd sind. Man darf aber nie vergessen, dass seine Haltung insgesamt ,harmonisierend' und generell davon geprägt ist, innerhalb eines ,platonischen' Rahmens Elemente aufzunehmen (terminologisch und bisweilen auch im Blick auf die Lehrinhalte), die aus anderen Schulen stammen, vor allem aus dem Stoizismus, ohne dass daraus ein konsistentes und kohärentes philosophisches System entsteht. ${ }^{14}$

Maximos präsentiert sich also als ein Platoniker außerhalb der Schulund Lehrkontroversen. Aber was bedettete es, ein ,Platoniker' ztu sein im Diskurs des zweiten Jahrhunderts n. Chr.? Tatsächlich zeigt der Platonismus dieser Periode nicht länger das einheitliche Erscheintungsbild der hellenistischen Zeit, als die Bezeichnung ,Platoniker' die Zugehörigkeit zur Akademie und die Zustimmung zum Skeptizismus implizierte. Mit der Schließung der von Platon gegründeten Schule 88-87 v. Chr. ging der institutionelle Rahmen verloren und auch atuf philosophischer Ebene waren die zwei folgenden Jahrhunderte geprägt von einem langen, wenn auch nicht einheitlichen Prozess, der darauf abzielte, das Weltbild Platons , dogmatisch" auszuarbeiten, d.h. durch konkrete „Lehrmeinungen" (סór $\mu \alpha \tau \alpha)$ auf den Gebieten der Metaphysik, Theologie, Kosmologie, Epistemologie, Psychologie und Ethik festzuschreiben, und vor allem als einheitlich und

\footnotetext{
${ }^{11}$ Siehe die Einleitung von Trapr 1997b, 1949, der schreibt: "the Dialexeis are remarkable for the complete absence of the language of sectarian confrontation and exclusion."

${ }^{12}$ In einigen Punkten überzeichnet Soury 1942 die Abhängigkeit des Maximos vom stoischen Gedankengut.

${ }^{13}$ Richtige Beobachtungen finden sich bei Trapp 1997b, 1948 sowie oben Einführung, $S$. $20-25$.

${ }^{14}$ Die Zustimmung von Maximos zu einer allgemeinen, philosophischen koine würde einzig den Ausschluss des Materialismus und Hedonismus der Epikureer voraussetzen: vgl. Trapr 1997a, xxiii-xxiv.
} 
kohärent, d.h. ,systematisch' zu erweisen. ${ }^{15}$ Der gemeinsame Nenner der in dieser Periode wirkenden Platoniker wird gerade durch die dogmatische Haltung repräsentiert, d.h. durch den entschieden anti-skeptischen Versuch, das platonische Weltbild in ein komplexes, einheitliches und kohärentes Lehrgebäude auszuformen. Gleichwohl verfolgten die Platoniker bei der Systematisierung je eigene, bisweilen konträre Meinungen. Sie griffen häufig auf diejenigen,Verbündeten' zurück, die ihrer jeweiligen Intention am nächsten kamen: So entsteht neben einem aristotelisierenden Platonismus, wie er von Alkinoos vertreten wurde, ein stoizierender Platonismus, repräsentiert durch Antiochos von Askalon und vielleicht durch Attikos (einen erbitterten Feind des Aristoteles), sowie ein pythagoreisiender Platonismus, dessen bedeutendste Vertreter Eudoros und vor allem Numenios waren. ${ }^{16}$ Daher gab es nicht nur einen einzigen Platonismus, wenngleich man gemeinsam darauf zielte, den hellenistischen Skeptizismus zu überwinden und Platon als einen, dogmatischen' Denker zu verstehen.

Bekanntermaßen wird diese komplexe Phase in der Geschichte des antiken Platonismus von den Gelehrten mit dem Begriff "Mittelplatonismus' bezeichnet. Maximos gehört zu dieser Phase des Platonismus, wenn auch aufgrund der oben erwähnten Besonderheiten eher im Randbereich. Wie die eben erwähnten Autoren sieht er sich selbst als Platoniker und ist geneigt, Platon bestimmte Lehrmeinungen zuzuschreiben, d.h. die skeptischaporetische Haltung der hellenistischen Akademie zurückzuweisen. Auch ein ausgeprägtes Gefühl für die literarische Tradition (insbesondere Homer) und die Tendenz, das Religiöse in das philosophische System des Platonismus zu integrieren, stellt Maximos in die Nähe von Attoren wie Plutarch und Numenios. Insofern der Platonismus des zweiten Jahrhunderts, wenigstens in manchen Strömungen, Religion als Bestandteil eines einheitlichen philosophisch-kulturellen Zusammenhangs betrachtete, erklärt sich auch das Bedürfnis, ein Thema wie das Beten aufzugreifen. ${ }^{17}$

Angesichts der Natur des Platonismus zur Zeit des Maximos, des sogenannten Mittelplatonismus, überrascht es nicht, dass sich in den Dissertationes stoische und manchmal auch aristotelische Elemente finden, denn

\footnotetext{
${ }^{15}$ Zum Prozess der Systematisierung des Platonismus zwischen dem ersten vorchristlichen und dem Anfang des dritten nachchristlichen Jahrhunderts vgl. F. FERRARI, s, Quando, come e perché nacque il platonismo", Athenaetum 100 (2012) [71-92] 77-92.

${ }^{16} \mathrm{Zu}$ verschiedenen Ausprägungen des kaiserzeitlichen Platonismus vgl. DoNini 1982, 100-159; WhitTakBr 1987, 110-121; zum Einfluss des Aristotelismus bei der Ausformung des systematischen Platonismus siehe G. E. Karamanolis, Plato and Aristotle in Agreement? Platonists on Aristotle from Antiochus to Porphyry (Cambridge 2006). Allgemein zum nachhellenistischen Platorismus bleibt die Darstellung von DiLlon 1996 grundlegend.

${ }^{17}$ Vgl. dazu ausführlich die Einführung, S. 36-38 sowie Hirsch-LuipoLd 2009.
} 
weite Teile des Mittelplatonismus waren durchlässig für Einflüsse anderer philosophischer Schulen. ${ }^{18}$

Die fundamentale Übereinstimmung des Maximos mit dem dogmatischen Platonismus seiner Epoche findet in der fünften oratio ihren offensichtlichsten Ausdruck darin, dass er ein unveränderliches, gütiges und fürsorgliches Göttliches vorauaussetzt. Diese theologische Theorie könnte Maximos, wie wir sehen werden, direkt aus den platonischen Dialogen gewonnen haben. Es ist jedoch auch ein gewisser Einfluss von indirekten Quellen nicht auszuschließen, also von Lehr- und Schulbüchern vom Beginn der Kaiserzeit.

Bevor ich mich auf den, platonischen' Charakter der Philosophie in der fünften dissertatio konzentriere, möchte ich die Aufmerksamkeit auf die Bedeutung des Gebetsmotivs lenken. Indem er eine seiner Reden der Frage widmet, ob es sinnvoll sei, zu beten, geht Maximos ein Problem an, das in einer Zeit religiöser Umwälzungen besonders sensibel war. Bei den christlichen Autoren wurde das Gebetsthema von Klemens von Alexandria und Origenes behandelt, aber die fortschreitende Verflechtung von Religion und Philosophie, die vom ersten und zweiten Jahrhundert an den Platonismus prägte, hat bewirkt, dass die Reflexion über die Art und Weise, die Bedeutung und die Nützlichkeit des Betens zu einem zentralen Motiv wurde, auch unter denjenigen pagenen Autoren, die sich auf die Autorität Platons berufen haben. ${ }^{19}$ Es sei schließlich angemerkt, dass dieses Thema der klassischen Tradition der griechischen Philosophie durchaus nicht fremd war, wie das zehnte Buch der Gesetze, der pseudoplatonische Dialog Alkibiades 2, einige Abschnitte des Euthyphron und das verlorene Werk von

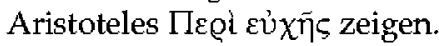

\section{Die Unkenntnis des Menschen im Blick auf die Natur des Guten und dessen göttlichen Ursprung}

Die Position des Maximos kann mit folgenden Eckpunkten zusammengefasst werden: Es ist nutzlos, zu den Göttern zu beten, um ein bestimmtes Ereignis eintreten zu lassen. Handelt es sich nämlich um etwas Gutes, wird es auch ohne Gebet eintreten, denn die Gottheit handelt in fürsorglicher Weise und ist Ursache nur des Guten. Handelt es sich andererseits

\footnotetext{
${ }^{18}$ Man darf nicht vergessen, dass sowohl der Aristotelismus als auch der Stoizismus sich aus der Philosophie Platons herausentwickelt haben und dass die Vorstellung ihrer Herkunft vom Platonismus bei den platonischen Autoren der Kaiserzeit ziemlich verbreitet war, angefangen bei Antiochos. Zur Bedeutung dieses Motivs vgl. Boys-STonss 2001, 99 122.

${ }^{19}$ Zur Präsenz und zur Rolle der Religion im Denken von Platon und im Platonismus vgl. die profunde Diskussion bei Helmig 2013; zum Verbreitungsgrad des Gebetsthemas im Neuplatonismus vgl. Dillon 2016.
} 
um etwas Schlechtes, so wäre es absurd, zu den Göttern zu beten, damit sie etwas Schlechtes verursachen - sie würden damit auf eine Art handeln, die mit ihrer eigenen Natur nicht vereinbar ist.

Diese philosophische These wird von Maximos auf verschiedene Arten und unter verschiedenen Blickwinkeln diskutiert. Aber alle wesentlichen philosophischen Aspekte der Rede lassen sich auf Positionen zurückführen, die direkt oder indirekt in den platonischen Schriften enthalten sind.

In $\$ 1$ weist Maximos darauf hin, dass einige Menschen das Eintreffen von Dingen erbeten, die sich in Wirklichkeit als schädlich für sie selbst herausstellen; sind sie aber eingetroffen, dann beschuldigen sie den Gott,

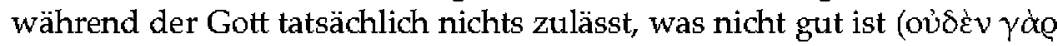

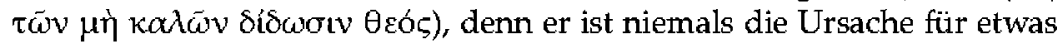
Schlechtes, sondern nur für das Gute.

Die These, nach der die Menschen geneigt sind, von der Gottheit Dinge zu erbeten, die sich als negativ herausstellen, wird explizit in der Einleitung der pseudoplatonischen Schrift Alkibiades 2 formuliert, in der Sokrates seinen Gesprächspartner einlädt, "im Gebet nicht zu bitten, ohne sich bewusst zu machen, dass große Übel für große Güter gehalten werden"

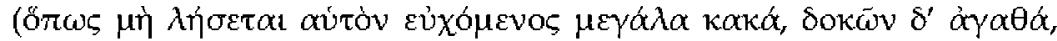
138b). Dasselbe Prinzip wird im siebten Buch der Gesetze formuliert, in dem der Athener als drittes Gesetz, an das sich die Dichter halten müssen, festlegt, darauf achtzugeben, dass sie nicht versehentlich etwas Schlechtes von den Göttern erbitten als wäre es etwas Gutes, denn „ein solches Gebet

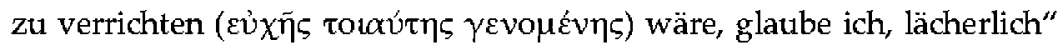
(801a-b).

Aus platonischer Sicht basiert dieser Einwand gegen das Gebet auf der Vorstellung, dass der moralisch Handelnde oft das Gute nicht kennt und deshalb ständig in der Gefahr schwebt, etwas Schlechtes mit etwas Gutem zu verwechseln, im Glauben, etwas scheinbar Gutes (tatsächlich aber Schlechtes) sei etwas wirklich Gutes. So versteht sich die berühmte Anrufung des Sokrates, die der korrekten Art, ein Gebet an einen Gott zu richten, entspricht: „O Zeus, der du König bist, ob wir nun beten oder nicht, gib, was gut ist, halte aber fern, was von Übel ist, selbst wenn wir dich im Gebet darum bitten" (Alk. 2, 143a). Dieser Art des "Betens" ( $\varepsilon$ vै $\varepsilon \varepsilon \sigma \theta a \imath$ ) hätte Maximos wohl sicher zugestimmt. Die Vorstellung, dass das verfehlte Verhalten von Menschen oft damit zusammenhängt, dass sie sich hinsichtlich der Natur des Guten im Unklaren sind und die Konsequenzen ihrer Entscheidungen nicht einzuschätzen vermögen, durchzieht viele platonische Dialoge und kann als einer der Angelpunkte der sokratischen Ethik betrachtet werden. ${ }^{20}$ Ähnliche Überlegungen liegen den Ausführun-

\footnotetext{
${ }^{20}$ Siehe z.B. J. Hardy, Jenseits der Täuschungen - Selbsterkenntnis und Selbstbestinnung mit Sokrates. Neure Studien zur Philosophie 25 (Göttingen 2011). Zum Alkibiades 2 siehe außer-
} 
gen des Maximos zugrunde, auch wenn sie nicht explizit formuliert werden.

Die Abhängigkeit des Maximos von Platon wird besonders deutlich, wenn man sich klarmacht, dass seine Reflexionen über die Nutzlosigkeit des Betens sich direkt oder indirekt auf die bekannten túnot $\pi \varepsilon \rho i$ $\theta \varepsilon \circ \lambda \circ \gamma$ íac zurückführen lassen, die im Schlussteil des zweiten Buches von Platons Staat von Sokrates innerhalb einer Diskussion formuliert werden, die darauf abzielt, die traditionelle Vorstellung von den Göttern, wie sie in den homerischen Dichtungen und in Hesiod enthalten ist, zu deuten durch eine philosophisch korrekte ,Theologie', die sich auf philosophische Prinzipien und Annahmen gründet. Sokrates zufolge sollten Erzählungen über die Götter zwei fundamentale Punkte beachten: a) Gott ist gut und Ursache nur des Guten b) Gott ist einfach und unveränderbar, in dem Sinne, dass seine Natur keinerlei Modifikation erfährt (Rep. II 379a-383a). ${ }^{21}$

Wenn Maximos als Schlussfolgerung aus or. 5,1, bekräftigt, dass Gott nichts zulässt, was nicht schön ist, und damit zugleich sagt, dass die Gottheit Ursache nur des Guten ist (womit die ,platonische' Austauschbarkeit

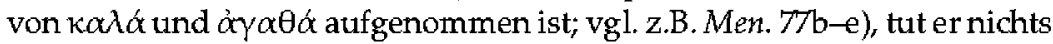

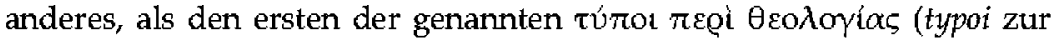
Theologie) aufzunehmen. Der erste dieser typoi schreibt das Prinzip der göttlichen Güte fest, oder besser das Prinzip, demzufolge Gott gut und Ursache des Guten ist, aber nicht verantwortlich für das Schlechte sein kann ( $\tau \tilde{\omega} \nu \delta \dot{\varepsilon} \kappa \alpha \kappa \bar{\omega} v \dot{\alpha} v \alpha i \tau(o \zeta)$, für das man eine andere Ursache als die Gottheit suchen muss $(379 \mathrm{a}-\mathrm{c}){ }^{22}$ Das Thema der göttlichen Güte und der Schuldlosigkeit Gottes am Schlechten kehrt in or. 41 wieder (,Wenn Gott das Gute bewirkt, woher kommt dann das Schlechte", Tov $\theta \varepsilon \circ \bar{v} \tau \dot{\alpha} \alpha \dot{\alpha} \gamma \alpha \theta \dot{\alpha}$

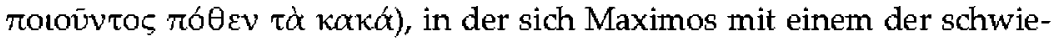
rigsten Themen der antiken Diskussion der Theodizee atuseinandersetzt. ${ }^{23}$

dem die Einführung, S. 7-8, Anm. zur Übers. 52 sowie die Beiträge von Alfons Fürst, S. 122-123 und Rainer Hirsch-Luipold, S. 96 Anm. 16.

${ }^{21} \mathrm{Zu}$ den theologischen Prämissen, nach denen sich Erzählungen über die Götter richten sollten vgl. F. FERRARI, "Theologia", in: M. VeGETTI (Hg.), Platone. Repubblica, Bd. 2, libri II-III. Elenchos 28 (Napoli 1998) 403-425 und außerdem M. Bordt, Platons Theologie. Symposion 126 (München 2006) 95f; НвLмic 2013, 238f.

${ }^{22}$ Zum platonischen Prinzip der Güte Gottes und zu seiner Nichtverantwortlichkeit für das Schlechte vgl. die ausführliche Diskussion bei Lanzi 2000, 107-118. Auch Sen. ep. 95,49f. schließst aus der Güte der Götter, dass sie Kausalursache des Guten sein müssen.

${ }^{23}$ Hier scheint Maximos, nachdem er festgestellt hat, dass sich das Schlechte nur auf der Erde und nicht im Himmel finden lässt, seine Ursache von zwei Quellen herrühren zu las-

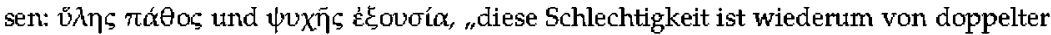
Natur: Einerseits Leidenschaft durch unsere Stofflichkeit, andererseits freier Wille der Seele" (or. 41,4; vgl. Soury 1942, 68-76; VAN DER Horst 1996, 326). Grundlegend zum Thema des Ursprungs des Schlechten im späteren Platonismus allgemein C. ScHёFBR, Unde malum. Die Frage nach dem Woher des Bösen bei Plotin, Atgustinus und Dionysius (Würzburg 2002). Zur Theodizee siehe die Einführung, S. 35 sowie die Anm. 16, 44 und 50 zur Übersetzung. 
Es ist interessant zu beobachten, dass Maximos sich einen Schritt über Platon hinauswagt, der sich damit begnügte, zur Suche nach einer anderen Ursache für das Schlechte einzuladen (,die schlechten Dinge müssen aber auf andere Ursachen zurückgeführt werden"), denn Maximos sieht

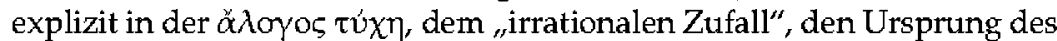
Schlechten $(5,1)$. Diese Lösung wirft durchaus einige Probleme auf, auch weil Maximos sich von seinem Lösungsvorschlag in or. 41 zu distanzieren scheint. Zieht man indes die Analyse von or. 8,7 hinzu, so kann man die zweite These, nach der $\tau \dot{v} \chi \eta$ die Ursache des Schlechten ist, durchaus mit derjenigen in or. 41 in Übereinstimmung bringen, dass nämlich eine der

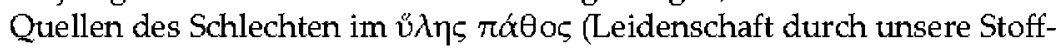
lichkeit) zu sehen ist. In or. 8,7 bekräftigt Maximos nämlich, dass die Tugend, die „schön und höchst gewandt und tatkräftig" ist, in der irdischen Welt vermischt ist "mit einer argen und dunklen und von viel Undeutlichkeit erfüllten Materie, die die Menschen Zufall ( $\tau \dot{v} \chi \eta)$ nennen“. Demnach

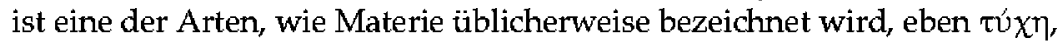
nach or. 5,1 der Terminus für jene Größe, auf die alles Schlechte zurückgeführt werden muss. Also ist der "Zufall", von dem Maximos hier spricht, offenbar nichts anderes als die Materie, die von ihm als eine der Quellen des Schlechten betrachtet wird.

Für die Möglichkeit, Maximos die Identifikation oder wenigstens eine enge Verbindung zwischen $\tau \dot{v} \chi \eta$ und $\cup \lambda \eta z u z u s c h r e i b e n$, lässt sich ein Beleg bei Numenios anführen, der sich im Timaios-Kommentar des Chalcidius findet. Innerhalb der Darstellung des ontologischen und kosmologischen Dualismus des Numenios, der Pythagoras die Auffassung zugeschrieben habe, dass die gesamte Realität auf zwei fundamentale Prinzipien zurückgeführt werden kann, nämlich auf die Gott-Monade (Deus-singularitas), die Ursache des Guten, und auf die Materie-Dyade (silva-duitas), die Ursache des Schlechten, stellt Chalcidius fest, dass dem Pythagoras des Numenios zufolge "die Vorsehtung das Werk und die Aktivität Gottes ist, während der blinde Zufall und das Schicksal von der Materie herrühren" (sed providentia quidem est dei opus et officium, caeca vero fortuitaque temeritas ex prosapia silvae); auf diese Weise ergibt sich offensichtlich, dass nach Numenios die Gesamtheit der Dinge durch den Kampf von Vorsehung und Zufall, d.h. Gott und Materie, hervorgebracht wird. ${ }^{24}$ Der sich auf Numenios beziehende Abschnitt ist deshalb interessant, weil er zeigt, wie weit die Absicht, den "Zufall" ( $\tau u ́ \chi \eta)$ und die Materie nebeneinanderzustellen und zum Ursprung des Schlechten zu machen, im Platonismus des zweiten

\footnotetext{
${ }^{24}$ Numen. fr. 52,95-100 dbs Placbs. Zum Dualismus des Numenios und zu seiner Auffassung der Materie als "unbestimmte Dyade" vgl. F. Jourdan , "Materie und Seele in Numenios' Lehre von Übel und Bösen", in: Dies. / R. Hirsch-Luipolo (Hg), Die Wurzel allen Übels. Vorstellungen über die Herkunft des Bösen und Schlechten in der Philosophie und Retigion des 1.4. Jahrhunderts. STAC 91 (Tübingen 2014) [133-210] 161f.; Druse 1983, 69-73.
} 
Jahrhunderts verbreitet war, und dass Maximos von dieser Absicht beeinflusst gewesen sein könnte.

Es ist hinzuzufügen, dass auch einige ,heterogene' Richtungen des Stoizismus den Zufall als eine Ursache des Schlechten betrachten haben. Ein interessantes Zeugnis in dieser Richtung liefert wiederum Chalcidius. Nachdem er die orthodox-stoische Gleichsetzung von Vorsehung und Schicksal diskutiert hat, spielt er auf die Position des Kleanthes an, der bekräftigt habe, dass alles, was von der Vorsehung abhängt, sich ",auf schicksalhafte Weise" (fataliter) zuträgt, während das, was durch das Schicksal geschieht, nicht von der Vorsehung herbeigeführt wird (nec tamen quae fataliter ex providentia). ${ }^{25}$ Für Kleanthes ist demnach das Schicksal eine Ursache, die von der Vorsehung unabhängig und teilweise im Gegensatz zu ihr wirkt. Zwar spricht Maximos an dieser Stelle von $\tau u ́ x \eta$ und nicht von "Schicksal" oder "Verhängnis" ( $\varepsilon i \mu \alpha \varrho \mu \varepsilon ́ v \eta)$, aber beide Autoren sehen zweifellos im Gegensatz zum traditionellen Stoizismus einen Unterschied zwischen Vorsehung und Zufall (bzw. $\tau u ́ x \eta)$, wobei letzterer für Ereignisse verantwortlich ist, die nicht direkt von der pronoia abhängen.

Die Überlegungen des Maximos zum Ursprung des Übels führen jedenfalls zu einer wichtigen Feststellung: Er zieht weder in diesem Abschnitt noch in or. 41 die bei den mittelplatonischen Autoren (besonders bei Plutarch und Attikos) weithin bezeugte These in Erwägung, der Ursprung und die Ursache des Schlechten müsse in der irrationalen, vorkosmischen Seele gesucht werden, von der im zehnten Buch der Gesetze gesprochen wird, wenn auch in einer alles anderen als klaren Weise. ${ }^{26}$

\section{Die Unveränderlichkeit des Gottes und seine Unzugänglichkeit für das Beten}

Die Nutzlosigkeit des Betens hängt nach Maximos zudem mit der Natur des Göttlichen zusammen, das sich selbst und seine Meinung nicht

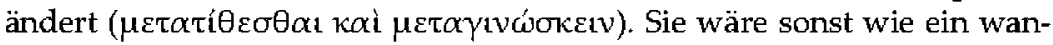
kelmütiger Mensch: „Denn wenn sich ein biegsamer und wankelmütiger Mensch vom Schlechteren zum Besseren umentscheidet, dann war er zuerst schlecht beraten; wenn aber von einer sehr guten Lösung zu einer schlechteren, dann war seine Meinungsänderung schlecht. Das Göttliche hingegen steht jenseits alles Schlechten" (or. 5,3).

Eine ähnliche Position wird von Sokrates mit seinem zweiten theologischen typos im Staat formuliert: was perfekt ist, kann in keiner Weise seinen

\footnotetext{
${ }^{25}$ Chalc. In Tim. 183,6f. WAszINK $=$ SVF II 933. Zu diesem problematischen Zeugnis von Chalcidius vgl. LANZr 2000, $159 \mathrm{f}$.

${ }^{26} \mathrm{Zur}$ Vorstellung der bösartigen vorkosmischen Seele siehe die exzellente Rekonstruktion von Deuse 1983, 12-27. 42-45. 51-61.
} 
Zustand ändern, weder zum Besseren, noch zum Schlechteren (380e-381c). Für Platon, und entsprechend auch für Maximos, geht das vollkommene Sein mit einer Unveränderlichkeit einher: da das Göttliche perfekt ist, erfährt es keine Veränderung und ändert demzufolge seine Meinung nicht. Selbstverständlich kann es dann auch nicht durch Gebete ,überredet' werden, irgendetwas zu tun, das nicht seiner Natur gemäß ist, die darin besteht, Gutes hervorzubringen.

Der Kern von Maximos' Position ist in einer knappen, aber sehr klaren

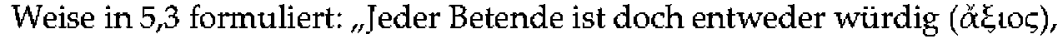
das zu erhalten, worum er gebeten hat, oder aber unwürdig. Wenn er also würdig ist, wird er das Erbetene erlangen, auch wenn er kein Gebet spricht. Wenn er aber nicht würdig ist, wird er es nicht erlangen, selbst wenn er ein Gebet spricht. ${ }^{\prime 27}$

Für Maximos ist folglich der göttliche Wille gänzlich unzugänglich für den Einfluss der Menschen, und die einzigen Kriterien, die dem Handeln Gottes zugrundeliegen, sind das Gute und die Würdigkeit des Beters, beziehungsweise, entsprechend dem Hinweis im Alkibiades 2 (150a-b), "Ge-

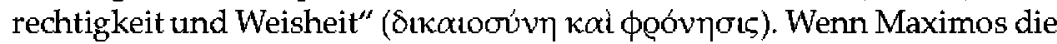
Wichtigkeit der Würdigkeit bei der göttlichen Handlung erwähnt, nimmt er damit das platonische Motiv der Gerechtigkeit auf.

Von einem philosophischen Standpunkt aus ist die Beobachtung erwähnenswert, dass Maximos, indem er die Unbeeinflussbarkeit des Göttlichen auf dessen Unveränderlichkeit zurückführt, die Nutzlosigkeit des Betens auf einer ontologischen Ebene begründet, denn er lässt sie von der metaphysischen Natur des Gottes abhängen. Damit wird jede anthropomorphe Charakterisierung des Göttlichen aufgegeben, wie sie ihm von der homerischen und archaischen Epik zugeschrieben wurden. ${ }^{28}$

Es lässt sich leicht zeigen, dass die These der Unbeeinflussbarkeit der Götter direkt vom dritten theologischen Prinzip hergeleitet ist, das in der Vorrede zum zehnten, dem Thema des Frevels gewidmeten Buch der Gesetze erscheint. Dort gibt bekanntermaßen der Athener den Gesetzesbestimmungen für Gottlosigkeit einen argumentativen logos in drei Punkten bei, bezogen auf a) die Existenz der Götter, b) die Fürsorge, mit der sie für die kosmischen und menschlichen Geschehnisse im Großen wie im Kleinen sorgen, und c) ihre Unbeeinflussbarkeit durch Gebete (X 885b). In der Vorrede bekräftigt der Protagonist des Dialogs: „Denn dass es Götter gibt und dass sie sich um die Menschen kümmern, das haben wir, so möchte ich meinen, gar nicht übel nachgewiesen. Dass sich Götter aber von denen umstimmen lassen, die Unrecht tun, indem sie von ihnen Geschenke annehmen, das dürfen wir niemandem zugeben und müssen es nach Kräf-

\footnotetext{
${ }^{27}$ Zur Wichtigkeit dieser Passage und der Bedeutung von ỏ $\zeta$ ía vgl. VAN DER Horst 1996, 329 und den Essay von Rainer Hirsch-Luipold im vorliegenden Band, S. 99-101.

${ }^{28}$ Zu diesem Aspekt siehe Dörrir 1977, 62.
} 
ten auf jede Weise widerlegen" (Leg. X 905d, Übers. nach Schöpsdau, wie im Folgenden). Am Ende der Darlegung lädt er seinen Gesprächspartner dazu ein, anzuerkennen, dass der Beweis auf überzeugende Art gelungen ist: "Sollen wir nun sagen, dass die von uns aufgestellten drei Sätze - dass die Götter existieren, dass sie fürsorglich sind und dass sie sich wider das Gerechte schlechterdings nicht umstimmen lassen - zur Genüge bewiesen sind?" $(907 \mathrm{~b}){ }^{29}$

Die Existenz der Götter wird von Maximos nicht diskutiert, sondern als selbstverständlich vorausgesetzt; mit ihrer fürsorglichen Natur setzt er sich in $\$ 4$ auf analytische Weise auseinander, während die Unbeeinflussbarkeit durch Gebete in dem Abschnitt über die Nutzlosigkeit des Betens vorausgesetzt wird. Die Vorstellung, dass die Götter durch Gebete beeinflussbar seien und die absolute Norm der Gerechtigkeit aufheben könnten, wäre für Maximos ebenso undenkbar wie für jeden anderen antiken Platoniker. Eine solche Vorstellung würde eine unerträgliche Form der Geschäftemacherei zwischen Menschen und Göttern implizieren, die Gefahr läuft, die Praxis der "Frömmigkeit" (óotó ๆఢ) in eine Art "Handelstechnik" ( $\left.\dot{\mu} \mu \pi \circ \mathrm{guk}_{\eta} \tau \dot{\varepsilon} \chi v \eta\right)$ zu verwandeln, wie Platon im Euthyphron dargelegt hat (14e).

\section{Die Vorsehung: Das Ganze und die Teile}

Am Anfang von $\S 4$ liefert Maximos eine Liste der Faktoren, von denen das Eintreten der Ereignisse abhängt, die gewöhnlich Gegenstand der Gebete seitens der Menschen sind. Behandelt wird die "Vorsehung" ( $\pi$ eóvou $\alpha$ ),

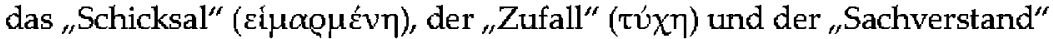
( $\tau \dot{\chi} \chi \vee \eta)$. Maximos beabsichtigt zu beweisen, dass das Beten sich in jedem dieser Fälle als völlig nutzlos erweist.

Der erste Kausalfaktor, der in Betracht gezogen wird, ist die Vorsehung, die, wie Maximos ausführt, ein "Werk Gottes" ( $\theta \varepsilon o v$ Ěp̧ov) darstellt. Die Argumentation, mit der die fürsorgliche Natur des göttlichen Handelns bekräftigt wird, spiegelt weitgehend die Struktur der platonischen Ausführungen im zehnten Buch der Gesetze wider. Von Platon übernimmt Maximos die These, derzufolge die göttliche Vorsehung, obwohl sie sich vornehmlich am Wohlergehen des Ganzen orientiert, die einzelnen Teile nicht vernachlässigt. Wenngleich auch einer Reihe von stoischen Texten ähnliche Überlegungen zu entnehmen sind, ${ }^{30}$ kann kein Zweifel an der - unmittel-

\footnotetext{
${ }^{29} \mathrm{Zu}$ den drei ,theologischen' Thesen, die im zehnten Buch der Gesetze ausgeführt werden vgl. M. Bordt, "Die theologische Fundierung der Gesetze", in: C. Horn (Hg.), Platon. Gesetzte - Nomoi. Klassiker auslegen 55 (Berlin 2013) 209-226.

${ }^{30}$ Vgl. z.B. Sen. Prov. 3,2; Marc. Aur. IX 39. Siehe dazu Sourr 1942, 26.
} 
baren oder indirekten - platonischen Herkunft des Inhalts dieses Kapitels bestehen.

Wie der Athener in den Gesezen, zieht auch Maximos die zwei sich nicht gegenseitig ausschließenden Möglichkeiten in Betracht, dass nämlich die göttliche Vorsehung sich auf das Ganze richtet und dass sie dennoch die Teile nicht vernachlässigt. Bei Platon steht das Wohlergehen des Ganzen im Zentrum; jeder Teil erleidet und tut demgegenüber, was ihm zukommt: "Wir wollen den jungen Mann durch Argumente davon überzetugen, dass von dem, der für das Ganze sorgt, alle Dinge auf die Erhaltung und Vollkommenheit des Ganzen hin angeordnet worden sind, von denen auch jeder Teil nach Möglichkeit erleidet und tut, was ihm zukommt" (Leg. X $903 \mathrm{~b})$. Um seinen Gesprächspartner von der Priorität des Ganzen zu überzeugen, bedient sich der Athener einiger Beispiele, die auch Maximos (wie viele andere Autoren) nutzen wird, nämlich das des Arztes und das des Handwerkers $(903 c-d)$. Aber die Orientierung am Heil und der "Bewahrung des Ganzen" ( $\sigma \omega \tau \varepsilon \varrho i ́ \alpha$ tov̄ ơ $\lambda \circ v$ ) bedeutet nicht die Vernachlässigung der einzelnen Teile, wie Platon dettlich macht, indem er ein weiteres Mal auf die Analogie mit dem Handwerker zu sprechen kommt: "wir wollen also niemals die Gottheit für unfähiger halten als die sterblichen Handwerker, welche die ihnen obliegenden Arbeiten, je tüchtiger sie sind, desto genauer und vollkommener ausführen, und zwar mit einer einzigen Kunst sowohl die kleinen wie die großen; die Gottheit dagegen, die doch am weisesten ist und sowohl den Willen wie die Kraft zur Fürsorge besitzt, die sollte sich um das, wofür leicht zu sorgen wäre, da es klein ist, überhaupt nicht kümmern wie ein fauler und feiger Mensch, welcher wegen der Anstrengungen sich lieber der Bequemlichkeit hingibt, sondern nur um das Große?" (902e-903a).

Maximos scheint also tatsächlich das platonische Schema in den groBen Linien nachzuzeichnen. Als erstes bekräftigt er, dass der Gott für das Ganze sorgt, ohne aber die einzelnen Teile zu vernachlässigen ( $\phi \varrho o v \tau i \zeta \varepsilon t$

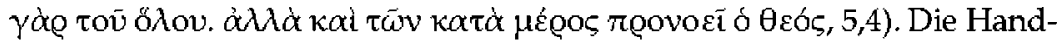
lung der göttlichen Vorsehung ist daher vornehmlich auf die Bewahrung des Ganzen ausgerichtet, aber vernachlässigt nicht die einzelnen Teile, die nach platonischer Lehre (Leg. X 903b-d) ihre Rolle im Rahmen des Ganzen ausfüllen. Für die Priorität des Ganzen unter Rüicksicht auf die Teile argumentiert Maximos mit einigen von Platon entlehnten Beispielen: der Befehlshaber, der König, der Arzt, sie handeln immer in Hinblick auf die Bewahrung und das Wohl des Ganzen. ${ }^{31}$ Getreu der platonischen Lehre unterstreicht Maximos mit Nachdruck: „Gleichwohl dehnt Gott seine Vorsehung durchaus auch auf die einzelnen Dinge aus" $(5,4)$. Folglich dehnt

\footnotetext{
${ }^{31}$ Die Meinung, dass die Unterscheidung zwischen allgemeiner und partikulärer Fürsorge auf das zehnte Buch der Gesetze hinweist, vertritt auch VAN DER HoRsT 1996, 331 f.
} 
sich die göttliche Vorsehung auf alle Aspekte der Wirklichkeit aus, auf kosmischer ebenso wie auf menschlicher Ebene. In einem solchen Rahmen erweist sich das Beten als gänzlich nutzlos, da die Existenz eines vorsorgenden Planes ohnehin die Orientierung am Guten des Weltenlaufs garantiert.

\section{Die anderen Kausalfaktoren: Schicksal, Zufall, Sachverstand}

Wie wir gesehen haben, erwähnt Maximos außer der Vorsehung drei weitere Faktoren, die den Lauf der Dinge bestimmen, aber nicht sinnvoll durch Gebete beeinflusst werden können: das Schicksal, den Zufall und den Sachverstand.

Diese Liste erweist sich als ziemlich problematisch, auch weil es in den platonischen Dialogen keine Parallelen dazu gibt. Es ist sehr wahrscheinlich, dass Maximos sie, vielleicht unter Hinzunahme einiger persönlicher Modifikationen, aus ähnlichen Sammlungen entnommen hat, wie sie unter den philosophischen Texten dieser Periode zirkuliert haben müssen. Wir wissen, dass es in der frühen Kaiserzeit eine Debatte über den Zusammenhang von Vorsehung, Schicksal oder freier Wahl gegeben hat, die in Reaktion auf stoische Vorstellungen entstanden ist. An dieser Debatte waren alle philosophischen Schulen, einschließlich der Platonischen, beteiligt, wie aus Ciceros De fato zu ersehen ist. ${ }^{32}$

Eine ähnliche Liste, wenn auch nicht identisch mit derjenigen des Maximos, findet sich in einem doxographischen Text, der auf die Placita von Aetios zurückgeführt werden kann. Innerhalb des Abschnitts, der der $\tau u ́ x \eta$ gewidmet ist, bekräftigt der Doxograph: "Anaxagoras und die Stoiker sagen, dass sie [scil. die $\tau u ́ x \eta]$ eine für den Verstand des Menschen undurchdringliche Sache sei. Tatsächlich geschehen einige Dinge nach der Notwendigkeit, andere nach dem Schicksal, andere nach dem freiem Willen, andere wieder aus sich selbst heraus ${ }^{\prime \prime} .^{33} \mathrm{Im}$ Vergleich zur Liste des Maximos ist bei Aetios der Sachverstand durch den "Willen" ( (wobei es jeweils um einen Faktor geht, der in die individuelle Sphäre hin-

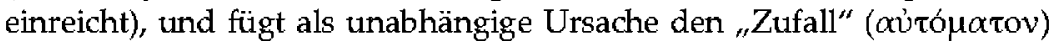
hinzu, der bei Maximos dem Schicksal zugeordnet wird.

\footnotetext{
${ }^{32}$ Eine exzellente Rekonstruktion der Debatte um das Verhältnis von Determinismus und freiem Willen findet sich in Pıвтsсн 2013b, 197-209; vgl. auch Dörrie 1977. Zum Thema vgl. den Beitrag von Alfons Fürst, S. 128-140 in diesem Band sowie die Einführung, S. 3435.

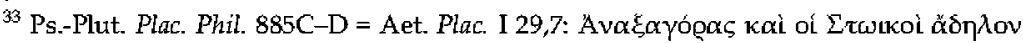

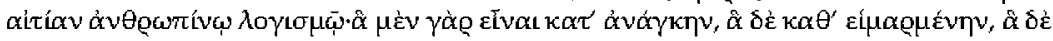

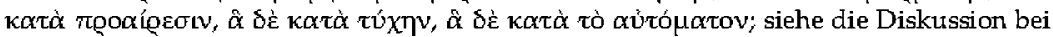
Sourr 1942, 23 .
} 
Als ebenso interessant erweist sich ein parallel gestalteter Text, den die Überlieferung fälschlicherweise Plutarch zugeschrieben hat, der aber wahrscheinlich im zweiten Jahrhundert n. Chr. von einem Autor mit platonischer (oder platonisch-aristotelischer) Neigung verfasst wurde und der eine besonders kritische Haltung gegenüber dem rigiden Determinismus der Stoiker einnimmt: Die Liste der die Geschehnisse in der Welt verur-

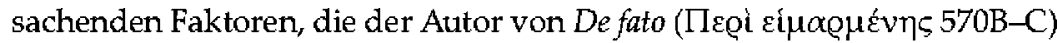
vorlegt, ist derjenigen des Maximos ziemlich ähnlich. Pseudo-Plutarch verfolgt die Absicht, sorgfältig den Zusammenhang zwischen Schicksal, Vor-

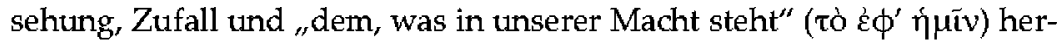
auszuarbeiten; auch in diesem Fall wird den drei traditionellen Faktoren ein Element beigefügt, das zum anthropologischen Bereich gehört, und das sicherlich die Debatte über den Zusammenhang zwischen Determinismus und freiem Willen widerspiegelt, die sich als Reaktion auf stoische Texte entwickelt hat. Hier ist nicht der Ort, tum im Detail die in diesem Traktat enthaltene Diskussion zu untersuchen, es ist aber wichtig zu betonen, wie der Autor versucht hat, in einer nicht immer logisch einwandfreien Weise eine komplette Überschneidung $z$ wischen Vorsehung und Schicksal zu vermeiden (z.B. 573A-B) und generell die Grenzen der individuellen Freiheit zu wahren. ${ }^{34}$

Wahrscheinlich hat Maximos seine Liste aus Quellen entnommen aus doxographischen oder philosophisch-polemischen Texten und Lehrbüchern -, die im zweiten Jahrhundert $\mathrm{n}$. Chr. kursierten und die er mit einigen eigenen Anmerkungen versehen hat, die er vielleicht atus einem bereits konsolidierten literarischen Repertoire gewonnen hat. Es scheint atuf jeden Fall schwierig, atus seinen Reflexionen über die Ursachenkette der Ereignisse eine auf philosophischer Ebene kohärente und gänzlich konsistente Lehre zu gewinnen.

Eigens gewürdigt zu werden verdient hingegen der Hinweis auf die

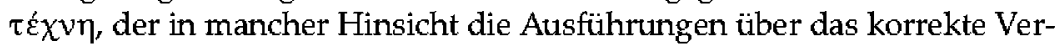
ständnis des Betens vorztubereiten scheint, die den letzten Paragraphen bestimmen. Maximos bemerkt, dass viele Ereignisse durch unser gezieltes Eingreifen beeinflusst werden und folglich ", in unserer Macht" ( $\left.\dot{\varepsilon} \phi^{\prime} \eta \dot{\eta} \bar{i} v\right)$ liegen, wie der Autor von De fato gesagt hätte. Zu den Dingen, die von uns selbst beeinflusst werden können, zählt Maximos interessanterweise neben den Produkten des Sachverstandes auch die Tugenden (wie etwa den

\footnotetext{
${ }^{34}$ Der Begriff des "Schicksals" ( Didasc. 179,1-33 (und sicherlich auch bei Maximos) unterscheidet sich freilich von dem der Staiker. Diese mittelplatonischen Autoren fassen das Schicksal nicht wie eine vorherbestimmte und unbeeinflussbare Reihe natürlicher Ursachen auf, sondern als „generelle Bestimmungen im Sinne allgemein gültiger Regelungen, was im Falle dieser oder jener Verhaltensweise zu geschehen hat", wie PгвTsch 2013b, 205 richtig feststellt. Mit anderen

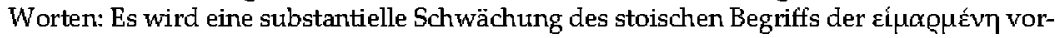
genommen.
} 
Mut), und sogar die "Glückseligkeit" ( äußeren Faktoren abhängt, sondern einzig von der Tugend: „Welcher gute Mensch [würde] um Glückseligkeit [beten], wenn er doch die Tugend besitzt?" $(5,6)$. Eine solche Behauptung scheint in der Tat die sokratischplatonische Vorstellung vorauszusetzen, die später freilich von den Stoikern übernommen wurde, dass das Erreichen des Glücks oder der Glückseligkeit gänzlich vom Besitz der Tugend abhängt, welche folglich die not-

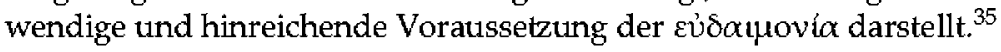

\section{Philosophie als authentisches Beten und Annäherung an Gott}

Die zuletzt genannte These nimmt die Formulierung der positiven Seite des Betens vorweg. Nachdem atufgezeigt worden ist, wie unvernünftig das traditionelle, d.h. nicht-philosophische Verständnis des Betens ist, skizziert Maximos die Merkmale, die das richtig verstandene Gebet als Gespräch mit der Gottheit haben muss. Das Gebet kann nicht auf der Bitte um

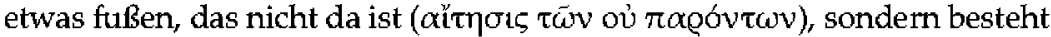

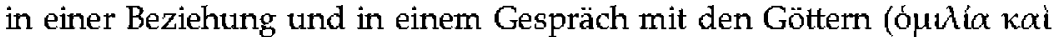

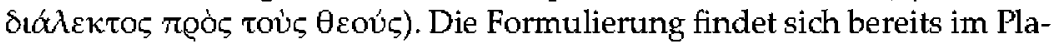
tons Symposion (203a), das die durch den Eros vermittelte Beziehung zwischen Menschen und den Göttern zum Thema macht. Insofern Eros die Philosophie personifiziert, legt sich der Schluss nahe, dass für Platon die Ausübung der Philosophie die korrekte Art darstellt, wie die Menschen sich an die Götter wenden müssen. Das "Gebet" ( $\left.\varepsilon \dot{u} \chi \gamma_{\dagger}\right)$ des tugendhaften Menschen besteht folglich in der Ausübung der Philosophie, und in diesem Sinne repräsentiert das Leben des Sokrates die Verwirklichung eines in diesem Sinne tugendhaften und schließlich authentisch ,heiligen' Lebens.

Indem Maximos die traditionelle Auffassung des Gebets als "Bitten”

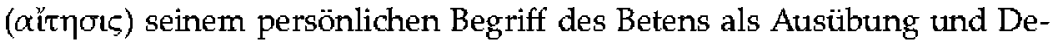
monstration der Tugend gegentuberstellt, nimmt er eines der zentralen Motive der platonischen Philosophie wieder auf. Am Schluss der Rede stellt er genau diesen Ansatz explizit heraus: Wenn man dem Leben die Philosophie nimmt, beraubt man es der einzigen Komponente, die das Beten

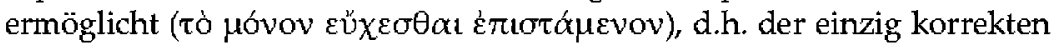
Art zu beten $(5,8)$.

\footnotetext{
${ }^{35}$ Zum sokratisch-platonischen Motiv der Tugend als Garantie der Erlangung der zúbotuovíx siehe M. ErLbr, "Platon", in: H. Flashar (Hg), Die Philosophie der Antike, Bd. 2/2 (Basel 2007) 432f. Auch für Seneca gilt: stultum est optare cun possis a te inpetrare (ep. 41,1, "das zu erbeten töricht ist, was du von dir selbsterlangen kannst", Übers. nach Rosenbach).
} 
Maximos stellt dem Namen des Sokrates diejenigen des Pythagoras und Platon an die Seite als Beispiele korrekter religiöser, d.h. philosophischer, Praxis. Die drei Philosophen repräsentieren in den Augen des Maxi-

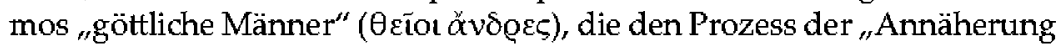

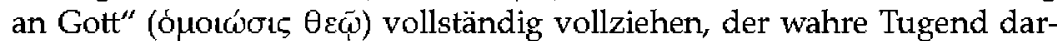
stellt. ${ }^{36}$ Die Genealogie Pythagoras - Sokrates - Platon ist alles andere als zufällig. In der Tat spielte bei einigen im ersten und zweiten Jahrhundert n. Chr. wirkenden platonischen Autoren wie Plutarch (besonders in De genio Socratis) und Numenios eine solche Genealogie eine wichtige Rolle bei der Herausbildung des Platonismus als dogmatische und propositive, also anti-skeptische Philosophie. Indem Sokrates und später Platon als Erben des Pythagoras betrachtet wurden, konnten sie dem skeptischen und aporetischen Bild entzogen werden, in dem die beiden für mehr als zwei Jahrhunderte erstarrt waren. ${ }^{37}$ Es ist durchatus möglich, dass Maximos an ein solches historiographisches Schema dachte, als er Pythagoras neben Sokrates und Platon stellte.

Insofern das Beten als Gespräch mit der göttlichen Sphäre zu begreifen ist, lässt sich das wahre Gebet für Maximos also mit Philosophie gleichsetzen, verstanden als ständige Praxis der Tugend. Hinter einem solchen Konzept dürfte wie gesagt, auch wenn dies nicht explizit wird, die bekannte Lehre von der ó $\mu$ otwoı $\zeta \varepsilon \dot{\omega}$ stehen, die unter den im zweiten Jahrhundert n. Chr. wirkenden Platonikern weithin verbreitet war. Im Übrigen findet sich eine Anspielung auf diese Lehre am Anfang von $\$ 3$, wo Maximos entsprechend der göttlichen Unbeugsamkeit und Unbeeinflussbarkeit bekräftigt, dass solche Eigenschaften auch zum tugendhaften Menschen gehören.

Dass Maximos die, platonische' Lehre der Angleichung an Gott kennt und ihr beipflichtet, lässt sich anhand zahlreicher Stellen in den Dissertationes und speziell durch den Anfang von or. 6 belegen. Dort wird erklärt, was den Menschen vom Tier unterscheide, sei die "Erkenntnis" ( $\varepsilon \pi \sigma \tau \eta \mu \eta)$, was ihn aber von Gott unterscheide, sei die Tatsache, dass letzterer "Weisheit" ( $\sigma o \phi i \alpha$ ) besitze, die sich von menschlicher Erkenntnis unterscheide, nicht in qualitativer, sondern in quantitativer Hinsicht, $d$.h. weil sie ein unendliches Leben voratussetze, während das Leben der Menschen begrenzt sei. Folglich ist der Mensch nicht von Gott verschieden, so lange er seine

\footnotetext{
${ }^{36}$ Zum Konzept der, Angleichung an Gott' und zum Motiv der ,heiligen Männer' vgl. I. Männlein-Robert, "Tugend, Flucht und Exstase: zur ónoẃós $\theta \varepsilon \bar{\varphi}$ in Kaiserzeit und Spätantike", in: РівTsCH 2013a, 99-111.

${ }^{37}$ Grundlegend zur ,pythagoreischen Genealogie des Sokrates und Platons und ihrer anti-skeptischen Wirkung P. L. DonINI, "Socrate ,pitagorico" e medioplatonico", Elenchos 24 (2003) 333-359. Zur Präsenz des Motivs des ópow

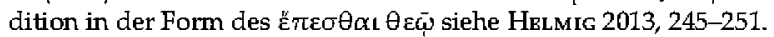


Erkenntnis einsetzt, mag auch sein Wissen auf die Länge seines Lebens begrenzt sein. ${ }^{38}$

Die durch Sokrates (ebenso wie durch Pythagoras) beispielhaft vorgeführte Praxis des Philosophierens, d.h. das tugendhafte Leben, stellt die einzige Form des Betens dar, die nach Maximos diesen Namen verdient, und bildet die Art und Weise, mit der der Mensch sich dem göttlichen Sein annähern kann.

\footnotetext{
${ }^{38}$ Hinweise auf die Vorstellung der Annäherung an Gott mittels der Erkenntris finden sich auch in or. 35,1-2 und 38,1.
} 


\title{
Würdigkeit versus Hartnäckigkeit. Gebetstheorie und -praxis bei Maximos von Tyros im Vergleich mit Lukas, Joseph und Aseneth und Plutarch
}

\author{
Rainer Hirsch-Luipold
}

Ziel der folgenden Überlegungen ist es, die philosophische Auseinandersetzung des Maximos mit dem Gebet in den Zusammenhang der zeitgenössischen jüdischen und christlichen Diskussionen zu stellen. ${ }^{1}$ Maximos wird also als pagan-religiöse ${ }^{2}$ Stimme zum Thema in den Blick genommen. Dass sich ein philosophischer Lehrer überhaupt mit dem Gebet beschäftigt, mag zunächst überraschend erscheinen. Solches Erstatunen beruht indes auf einer nicht unproblematischen Prämisse, dass sich nämlich Philosophie mit religiösen Fragen nur im Sinne einer "philosophischen Theologie" beschäftige in einem "attempt to rationalize the irrational" ${ }^{3}$ Demgegenüber soll die religiöse Thematik im vorliegenden Beitrag als originärer Bestandteil philosophischer Überlegungen im Rahmen der religiösen Philosophie der Kaiserzeit wahrgenommen werden. ${ }^{4}$ Die Gotteslehre (insbesondere die Frage nach den archaî und der Vorsehtung) hatte in der Stoa ihren selbstverständlichen Ort im Rahmen der Physik gefunden, war aber freilich seit jeher bei den Philosophen aller Schulen verhandelt wor-

\footnotetext{
${ }^{1}$ Vgl. Dillon / Timotin 2016; Trmotin 2016; H. Klein u.a. (Hg.), Das Gebet im Neuen Testament. Vierte europäische orthodox-westliche Exegetenkonferenz in Sâmbăta de Sus 4.-8. August 2007 (Tübingen 2009); D. E. Auns, "Prayer in the Greco-Roman World”, in: R. N. Longrnbcker ( $\mathrm{Hg}$.), Into God's Presence. Prayer in the New Testament (Grand Rapids, MI / Cambridge, UK 2001) 23-42 [formale Kategorisierungen untersch. Formen von Gebet]; darin auch I. H. Marshall, "Jesus - Example and Teacher of Prayer in the Synoptic Gospels", 113-131; FrLdmbirr 2016.

${ }^{2}$ Die Junktur ersetzt das Attribut "heidnisch", das mit gutem Grund problematisch geworden ist, weil es schon begrifflich aus christlich-jüdischer Perspektive eine normative Grenze zieht zwischen der als angemessen empfundenen Religiosität der Juden und Christen auf der einen und der polytheistischen Religion der Griechen auf der anderen Seite. Während das lateinische (und im Englischen übernommene) pagan im Deutschen immerhin einen deskriptiveren Klang hat, stellt sich dabei das weitere Problem, dass zumeist das Pagan-Griechische als philosophisch oder rhetorisch verstanden tund verschiedentlich it Gegensatz zu einer religiösen Betrachtungsweise gestellt wird (wie dies in der Behandlung des Maximos in der Literatur dettlich zu Tage tritt).

${ }^{3}$ J. Mansfbld, "Theology", in: K. Algra u.a. ( $\mathrm{Hg}$.), The Cambridge History of Hellenistic Philosophy (Cambridge 1999) [452-478] 452.

${ }^{4}$ Vgl. oben, Einführung, S. 36-38 sowie jetzt O'Brian 2016; Timotin 2016.
} 
den. In der frühen Kaiserzeit machen insbesondere platonische Autoren alle Aspekte des Religiösen bis hin zur gelebten Religion zum Gegenstand theologischer und ethischer Reflexion, was den betreffenden Autoren bisweilen den Ruf des "Halbphilosophischen" einbrachte. Hierfür stellt das Werk des Maximos ein wichtiges Zeugnis dar. ${ }^{5}$ Denn es sind beileibe nicht nur die theologischen Implikationen für das Gotteskonzept, die den philosophischen Lehrer interessieren. Die religiösen und theologischen Themen, die Maximos diskutiert, reichen von im engeren Sinne theologischen Fragen ("Wer ist Gott gemäß der Philosophie Platons?"; oder "Wenn Gott gut ist, woher kommt dann das Böse?"), bis hin zu Problemen der religiösen Praxis (wie etwa der Verehrung von Bildern oder eben des Gebets). ${ }^{6}$ Dieses Interesse steht innerhalb der Philosophie der Kaiserzeit keineswegs isoliert da, sondern kann geradezu als ein charakteristischer Zug betrachtet werden. ${ }^{7}$

Als nettestamentlicher Gegenpol ztu diesen pagan-philosophischen Überlegungen zum Gebet bietet sich das lukanische Gebetsverständnis an. ${ }^{8}$ Innerhalb des Neuen Testaments spricht Lukas am ausführlichsten vom Gebet und ist deshalb mit einigem Recht als der Evangelist des Gebets bezeichnet worden. ${ }^{9}$ In Lk 11 finden wir eine Darlegung zum Gebet einschließlich eines Mustergebetes. Schon die Bitte der Jünger, mit der sie am Beginn von $L k 11$ an Jesus herantreten, ist einzigartig im Rahmen der

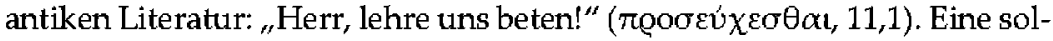
che Bitte um Unterweisung im Gebet finden wir andernorts nicht, und der Verweis der Jünger auf Johannes den Täufer, der ebenfalls seine Jünger beten gelehrt habe, bleibt religionsgeschichtlich dunkel $(11,1)$, da uns ein Gebet des Täufers oder eine entsprechende Unterweisung nicht überliefert ist. ${ }^{10}$ Jesus formuliert als Antwort auf die Bitte der Jünger zunächst das Vaterunser, von dem er explizit sagt, es solle bei jedem Gebet gesprochen werden ("wann immer ihr betet..."). ${ }^{11}$ Damit ist - einzigartig in der Religionsgeschichte - ein für alle verbindliches Mustergebet geschaffen, das über alle Jahrhunderte und über alle Aufspaltungen der christlichen Kirchen hinweg seinen zentralen und verbindenden Status nicht verloren

\footnotetext{
${ }^{5}$ Vgl. oben Einführung, S. 29-31. Dort haben wir auch bereits diskutiert, dass die Frage nach dem Bittgebet auch im philosophischen Diskurs eine lange, bereits mit Platon beginnende Geschichte hat (S. 6-8).

${ }^{6}$ Vgl. ausführlich oben, Einführung, S. 28-29. Zur bildlichen Darstellung Betender vgl. den Beitrag von Barbara E. Borg in diesem Band.

${ }^{7}$ Vgl. Hirsch-LuIPOLd 2009, 124-135. Zum Verhältris von Religion und Philosophie in der Kaiserzeit siehe auch die Beiträge von Franco Ferrari, S. 79 und Alfons Fürst, S. 117-118 in diesem Band.

${ }^{8}$ Vgl. FörstBR 2007, 273-297.

${ }^{9}$ A.-G. Hamman, La prière, Bd. I, Le Nouveau Testament (Tournai 1959).

${ }^{10}$ Freilich stammt die Bitte und die folgende Unterweisung wohl aus der Redenquelle Q, der man eine besondere Beziehung zur Täufertradition nachsagt.

${ }^{11}$ So wird es in der lukanischen Gemeinde wohl längst Usus gewesen sein.
} 
hat. ${ }^{12}$ In der paganen Gräzität findet sich hierzu kein Gegenstück, wenngleich auch dort zur Zeit des Neuen Testaments sich die Tendenz zeigt, Mustergebete zu formulieren. ${ }^{13}$ Eine ähnlich zentrale Stellung gewinnen im Bereich des Judentums das "Sche ma Jisrael" und später das "Achtzehnbittengebet". An das Vaterunser schließt sich eine kurze Lehrrede Jesu über das Beten mit einer Reihe von Gleichnissen an $(11,5.13)$. In Lk 18,1-14 wird die Thematik mit zwei Gleichnissen fortgeführt.

Schon all dies legt nahe, Lukas als neutestamentlichen Gesprächspartner des Maximos in den Blick $z u$ fassen. Es lassen sich zudem thematische Berührungen in der Frage nach den Gebetsinhalten sichtbar machen, wobei Lukas gegenüber Maximos eine markante Gegenposition einnimmt. Beide, Lukas wie Maximos, setzen sich kritisch mit der Theorie und Praxis des Gebets zunächst einmal in ihren je eigenen Traditionen auseinander. ${ }^{14}$ Beide setzen dabei die Frage der Gebetspraxis zur Gottesfrage in Beziehung. Bei Lukas wird das Gebet selbstverständlich als Bitte um etwas interpretiert, und zwar gerade als existentielle Bitte im Anschluss an die Brotbitte des Vaterunsers (die Gleichnisse Lk 11,5-13 kreisen insgesamt um die Brotbitte in $11,3 !) .{ }^{15}$ Genatı ein solches Gebetsverständnis wird von Maximos scharf kritisiert. Wie Maximos wirft Lukas die Frage atuf, inwieweit gerade das Bittgebet eine Belästigung des Göttlichen darstellt, tund beide setzen sich, wie wir sehen werden, zentral mit der Frage der Würdigkeit des Beters als Voraussetzung für die Erfüllung des Gebets auseinander. Aber wie anders nimmt sich die Antwort des lukanischen Jesus aus!

Im Kontext unserer religionsgeschichtlichen Untersuchung wollen wir abschließend einen Blick werfen auf die Rolle des Gebets in dem hellenistischjüdischen Roman Joseph und Aseneth und bei Plutarch, dem wichtigsten paganen Vertreter des religiösen Platonismus der frühen Kaiserzeit, dessen Vorstellungen vom Gebet sich charakteristisch von jenen des Maximos unterscheiden.

\footnotetext{
${ }^{12}$ Vgl. FeLDM EIER 2016, 28. Breit diskutiert wurden freilich seit jeher in der exegetischen Literatur die Unterschiede zwischen Matthäus und Lukas in ihren Fassungen des Herrengebets.

${ }^{13} \mathrm{Vgl}$. die Belege bei U. Schndrlb (Hg.), Neuer Wettstein. Texte zum Neuen Testament aus Griechentum und Hellenismus, Bd. I/2, Texte zum Johannesevangelium (Berlin / New York 2001); freilich finden sich entsprechende Tendenzen auch schon in Ps.-Plat. Alk. 2 143a (s. oben, Einführung S. 8).

${ }^{14}$ Gegen pagane Formen des Gebets wendet sich dagegen explizit Mt 6,7: „Und wenn ihr betet, sollt ihr nicht viel plappern wie die Heiden; denn sie meinen, sie werden erhört, wenn sie viele Worte machen. "Sein Argument in 6,8 (,Darum sollt ihr ihnen nicht gleichen. Denn euer Vater weiß, wessen ihr bedürft, bevor ihr ihn bittet") nimmt unmittelbar einen Gedanken des Maximos auf: Es braucht nicht viele Worte, weil Gott schon weiß, wessen wir bedürfen. Der Gedanke dient hier dazu, das Vaterunser als das einzige Standard-Gebet zu legitimieren.

15 11,5-8: ein Freund bittet des Nachts um Brote; 11,11f.: Bitte an den Vater um einen Fisch und ein Ei.
} 


\section{Das Gebet bei Maximos}

\subsection{Platonisches und Stoisches}

In seiner Beurteilung des Gebets wie auch sonst bewegt sich Maximos zwischen den philosophischen Traditionen. Während er für das Thema selbst auf platonische Quellen, insbesondere im Euthyphron, der Politeia und den Gesetzen, aber freilich auch im (ps.-platonischen) Alkibiades 2 zurïckgreifen kann, ${ }^{16}$ verdankt sich das Vertrauen auf die göttliche Wohlordnung des Alls, das eine Einflussnahme mittels des Bittgebets wenig sinnvoll erscheinen lässt, stoischem Denken. Wenn der Mensch in den Zusammenklang des Alls eingebunden ist, bedarf es aus dieser Sicht lediglich des Einschwingens in diese Harmonie, nicht aber einer Wendung nach atußen im Gebet (in diesem Sinne einer Wendung nach Innen erscheint das philosophische Gebet in $\$ 8$ als ein Gespräch mit den Göttern). Gebet in diesem Sinne dient der "Souveränität und Seelenstärkung des Betenden". ${ }^{17}$ Was Maximos in kurzen Strichen ausführt an Kritik an gängiger Gebetspraxis, die sich weder über den Inhalt noch über die Adressaten eines vernünftigen Gebets im Klaren ist, spiegelt einen breiteren zeitgenössischen Diskurs zum Gebet. ${ }^{18}$ Wenn Maximos neben die Akteure, an die man sich im Gebet wenden könnte, weil sie Einfluss auf unser Leben nehmen (Vorsehung, Schicksal und Zufall), auch die menschliche Kunstfertigkeit ( $\tau \dot{\varepsilon} \chi \nu \eta)$ stellt, so nimmt er jenen Punkt auf, den Epiktet meinte, als er einmal sagte (Diss. I 6,30), man solle nicht mit Gott wegen eines Schnupfens hadern, wenn man doch die Möglichkeit habe, sich die Nase zu putzen: Manche Dinge, so muss man das offenbar verstehen, kann der Mensch einfach selbst in die Hand nehmen und muss deshalb nicht die Gottheit bemühen. ${ }^{19}$ An Senecas 41. Brief erinnert der Gedanke eines göttlichen Richters $(\$ 7)$, an den man sich im Gebet wendet. ${ }^{20}$ Bei Maximos allerdings ist die Gottheit nicht im Sinne des Gewissens ein innerer Wächter über die menschlichen

\footnotetext{
${ }^{16}$ Den Alkibiades 2, der manchen Forschern bis heute als echt erscheint, wird Maximos selbstverständlich als platonischen Text begriffen haben. Zum Alkibiades 2 siehe die Einführung, S. 7-8, Anm. zur Übers. 52 sowie die Beiträge von Franco Ferrari, S. 81 und Alfons Fürst, S. 122-123.

${ }^{17}$ M. ERLER, "Selbstfindung im Gebet. Integration eines Elementes epikureischer Theologie in den Platonismus der Spätantike" ${ }^{\prime \prime}$ in: T. A. SLgzÁK (Hg.), Platonisches Philosophieren. Zehn Vorträge zu Ehren von H.-j. Krämer. Spudasmata 82 (Hildesheim u.a. 2001) [155-171] 165.

${ }^{18}$ Einige der einschlägigen Texte bespricht FrLDMBIBR 2016, 30-47.

${ }^{19}$ Interessant ist, dass Epiktet praktischer an das Thema herangeht als Maximos, der das Gebet wesentlich als Problem der Gotteslehre behandelt. Epiktet dagegen geht es wirklich um religiöse "Lebenshilfe".

${ }^{20}$ Senca, ep. 41,2: Sacer intra nos spiritus sedet, malorum bonorumque nostrorum obseruator et custos (",ein heiliger Geist wohnt in uns, unserer schlechten und guten [Taten] Beobachter und Wächter", Übers. Rosenbach).
} 
Taten. Vielmehr implizieren die Aussagen des Maximos, dass der Mensch im Gebet Kontakt zur Gottheit herstellt und sich damit ihrem harten Gericht aussetzt (ein Gedanke, der wohl letztlich als Auseinandersetzung mit den entsprechenden Aussagen des Alkibiades 2 zu verstehen ist).

\subsection{Gotteslehre als wesentliches Thema des Nachdenkens über das Gebet}

Anders als der wohl sekundäre Titel erwarten lässt, aber für einen Philosophen durchaus einsichtig, geht es Maximos in seiner unter der Über-

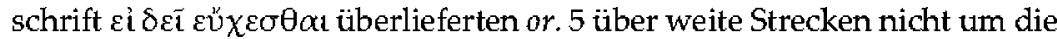
Praxis des Gebets, sondern um die durch die jeweilige Praxis implizierte Gottesvorstellung. Die historischen oder mythischen Exempla am Anfang der Schrift, die von den verfehlten Gebeten des Midas und des Kroisos erzählen, erscheinen eher als latunig-rhetorische Hinführung. In den ersten sieben Kapiteln der Rede diskutiert Maximos dabei ausschließlich - und kritisch - das Bittgebet im Sinne der Bitte um etwas. Andere Gebetsformen wie Dank, hymnische Verehrung und kultische Anrufung, aber auch die für die frühchristlichen Gebete zentrale Fürbitte, bleiben außer Betracht. ${ }^{21}$

\subsection{Das philosophische Gebet als die aus dem Gottesgedanken sich ergebende Frömmigkeitspraxis}

Wenngleich im Zentrum der Überlegungen das Gottesverständnis steht, so hat dieses freilich entscheidende Folgen für die (Frömmigkeits-)Praxis. ${ }^{22}$ Im abschließenden 8. Kapitel zieht der Autor Folgerungen bezüglich einer angemessenen, philosophischen Gebetspraxis, und damit zusammenhängend kommt der Gedanke der Beziehung zum Göttlichen als einer Funktion des Gebets in den Blick. Formal setzt dieses Abschlusskapitel ein Ausrufezeichen, indem Maximos hier tatsächlich ein Gebet des philosophischen Lehrers an Zetus, Athena und Apollon spricht.

\subsection{Das Bittgebet als verfehltes Gebet}

Aufgrund des Postulats der Allwissenheit sowie der Unveränderlichkeit, Unbeeinflussbarkeit ${ }^{23}$ und Gerechtigkeit Gottes erscheint Maximos jeder

\footnotetext{
21 Ähnlich schon im Ps.-Plat. Alkibiades 2. Anders dagegen Plat. Eutyphr. 14b-e.

${ }^{22}$ Ganz ähnlich endet Plutarchs Schrift De tranguillitate animi (477C-F), indem sie die Konsequenzen der theoretischen Erörterungen über die Seelenruhe für eine gelebte religiöse Praxis zieht, die das Leben insgesamt als Götterfest begreift und auf diese Weise unmittelbar die Lebenseinstellung verwandelt.

${ }^{23} \mathrm{Vgl}$. die auch von Seneca zur Legitimation des Gebets herangezogene aristotelische Lehre vom Schicksal, das bestimmte Dinge in der Schwebe lässt: "Alle durch menschliche
} 
Versuch der Einflussnahme durch ein Bittgebet unsinnig und verfehlt. Wenn Gott, wie es bei Homer scheint, dem einen die Bitten erfüllt, dem anderen aber die Erfüllung verweigert, wie ließe sich das mit göttlicher Gerechtigkeit, Souveränität und Unwandelbarkeit vereinbaren? Homer, der ansonsten gewissermaßen als Bibel des Maximos fungiert, zeigt das Problem. Bei Chryses etwa, dem Priester des Apollon, hört der Gott erst, als ihm der Priester aufzählt, welche Opfer er ihm stets dargebracht hat. "Was soll das bedeuten, o Bester der Dichter?", fragt Maximos (or. 5,3). Kann der ewige Gott denn seinen Entschluss ändern? Ist er am Ende sogar beeinflussbar durch Geschenke und dergleichen? Nein, Gott ist nicht wandelbar und deshalb durch Bitten nicht zu beeinflussen. Maximos führt hier an den theologischen Implikationen des Bittgebets im Blick auf die Vorsehung ein Argument durch, das sich in ähnlicher Weise bei Alkinoos findet (Didasc. 10,7): Wäre Gott wandelbar, dann müsste er seine Meinung entweder vom Guten zum Schlechteren wenden oder umgekehrt. Das aber würde implizieren, dass das Göttliche bzw. seine Ratschlüsse und Handlungen entweder vorher oder nachher nicht absolut gut wären, was der Definition des Göttlichen als des absolut Guten widerspricht.

In den systematisch durchgeführten Kap. 4-6 diskutiert Maximos neben der göttlichen Vorsehung ${ }^{24}$ drei weitere Größen, die Einfluss auf das menschliche Leben haben könnten, nämlich Schicksal, Glück und menschlichen Sachverstand. ${ }^{25}$ Bei allen drei erweist sich ein Gebet ohnehin als sinnlos: Das Schicksal ist unerbittlich, das Glück verteilt wahl- und vernunftlos und ist deshalb rationalen Zugängen grundsätzlich verschlossen und menschlicher Sachverstand steht in der Verfügungsgewalt des Menschen - weshalb sollte man also ein Gebet sprechen?

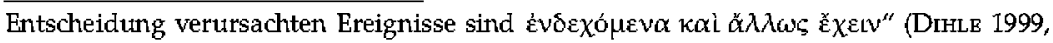
26 mit Hinweis auf Eth. Eud. 1134b31; Hist. an. 371b25; Rhet. 1402b2If.). Originär stoisch dagegen sei die Argumentation Mark Aurels, dem zufolge man die Götter um die Dinge bitten soll, die in der eigenen Macht stehen, also um die richtigen Urteile (IX 11.40).

${ }^{24}$ Gott und Vorsehung fließen im Rahmen der Darstellung des Maximos weitgehend ineinander.

${ }^{25}$ Man kann hier einen Einfluss peripatetischer Überlegungen zur Verursachung sehen, die entweder der Weltordnung oder dem Zufall oder der freien Entscheidung von Menschen zuggeordnet werden (vgl. DiнLe 1999, 27). 


\subsection{Zwei Voraussetzungen für den Empfang des Gewünschten von der Gottheit: Würdigkeit und Zuträglichkeit}

Unter der Voraussetzung der Gerechtigkeit des allwissenden Gottes hängt die Erfüllung der Wünsche des Beters durch Gott bzw. die Vorsehung nach Maximos allein von zwei Faktoren ab:

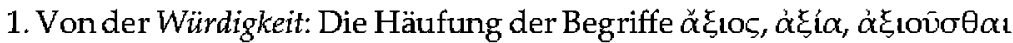
in or. 5 ( 3 und 7) ${ }^{26}$ ist ausgesprochen auffällig. Ist der Beter würdig, das Erbetene zu erhalten, so argumentiert Maximos, dann wird er es in jedem Fall von der Gottheit erhalten, auch dann, wenn er nicht darum bittet. Dieser erste Punkt verbindet anthropologische und ethische, aber natürlich auch soziale Aspekte miteinander: Der Mensch ist durch seine Taten selbst dafür verantwortlich und auch in der Lage, die Voraussetzung für die Erfüllung seiner Wünsche zu schaffen. Im Blick hat der philosophische Lehrer dabei freilich den gebildeten, "edlen" Menschen, wie in $\$ 8$ unterstrichen wird.

2. Von der Zuträglichkeit für den Beter: ${ }^{27}$ Das Zuträgliche nämlich kann dem Gebetswunsch gerade entgegenstehen (wie etwa der Wunsch des Patienten sich nicht notwendig mit dem deckt, was aus Sicht des Arztes angezeigt ist). Das Problem des Bittgebets sieht Maximos wesentlich darin, dass sich der Mensch im Unterschied zur Gottheit oft nicht im Klaren ist, was ihm wirklich zuträglich ist. (Das war der entscheidende Einwand im pseudo-platonischen Alkibiades 2 gegen das Bittgebet gewesen.) Die Gottheit dagegen ist wie ein Arzt - sie weiß genau, was für den Menschen gut ist, und wird es ihm entsprechend zuweisen. Dieser zweite Punkt charakterisiert das Wesen der göttlichen Vorsehung und kontrastiert sie mit der mangelnden Einsicht des Menschen in das wahrhaft Gute. ${ }^{28}$

Eine Reihe von Beispielen (Regierung, Kriegsführung, Arztkunst) verdeutlicht den ungleich besseren Überblick des Göttlichen, der es angeraten sein lässt, dem Urteil des Göttlichen im Blick auf das, was uns zuträglich ist, zu vertrauen.

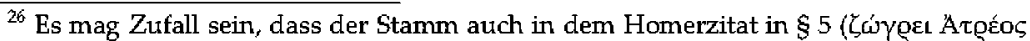

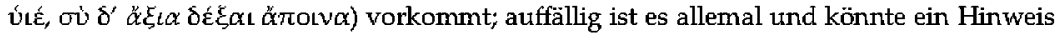
darauf sein, dass für Maximos bei der Auswahl von Zitaten das Stichwortprinzip eine Rolle spielte.

${ }^{27}$ Vgl. schon Plat. Euthyphr. 14d-e. Völlig zu Rechthebt VAN DER Horst 1996 die Bedeutung der Würdigkeit heraus, und doch kann ich ihm nicht völlig zustimmen, wenn er sagt: "For Maximus the criterion of worthiness is the only one that counts in the question of whether or not someone will receive from the gods what he neeeds or thinks he needs ${ }^{\prime \prime}$ (329; Hervorhebung RHL). Es sind m.E. zwei deutlich unterschiedene Kriterien, die Maximos aufführt.

${ }^{28}$ Bereits aus der platonischen Tradition hätte man vom zweiten Punkt her den ersten problematisieren können. Denn das mangelnde Wissen um das Gute und Zuträgliche ist freilich auch der Grund dafür, dass Menschen schlecht handeln: „Niemand handelt freiwillig schlecht" (vgl. Plat. Prot. 351b-357e).
} 


\section{Umstrittene Würdigkeit}

Es ist der erste Punkt, die Rolle der Würdigkeit des Beters, bei der sich in einer vergleichenden Betrachtung zu Voraussetzungen, Inhalten und Wirkung des Gebets mit den Aussagen im Lukasevangelium sowie im hellenistisch-jüidischen Roman Joseph und Aseneth und in der religiösen Philosophie Plutarchs besonders signifikante Unterschiede zeigen. Diese Unterschiede lassen sich auf die je unterschiedlichen theologischen und anthropologischen Grundkonzeptionen zurückführen.

Für christliche wie jüdische Ohren ist der Punkt der Würdigkeit besonders problematisch. Es sei lediglich ins Gedächtnis gerufen, wie Luther in seiner Auslegung des Artikels von der Schöpfung im Kleinen Katechismus den fundamentalen Gedanken der Rechtfertigung allein aus Gnade auf den Punkt bringt: „Ich glaube, dass mich Gott geschaffen hat, ...mich... reichlich und täglich versorgt... und vor allem Übel behütet und bewahrt - und das alles aus lauter väterlicher, göttlicher Güte und Barmherzigkeit, ohn all mein Verdienst und Würdigkeit" ${ }^{29}$

Mit dem Aspekt der Würdigkeit des Beters, den Maximos ausführlich zum Thema macht (\$ 3), nimmt der philosophische Lehrer lediglich die Tatsache auf, dass der Aufbau jedes Bittgebets in der Antike der Logik der Würdigkeit folgt. Wie ein Bittsteller seinen Klientelherren an dessen Verpflichtung erinnern würde, die sich auch aus der eigenen Vorleistung ergibt, um so zugleich an dessen Milde zu appellieren und die eigene Würdigkeit herauszustellen, so gehört es zum Aufbau des Gebets, nach der Anrufung der Gottheit (invocatio) die sogenannte pars epica folgen zu lassen, die begründet, warum der Bitter auf ein positives Echo der Gottheit hoffen darf, bevor in den preces schließlich die konkreten Bitten vorgetragen werden. ${ }^{30}$ Maximos mokiert sich über die theologischen Implikationen dessen, dass ein Beter der Gottheit die eigenen Verdienste vorhält, um sie dadurch dazu zu bewegen, in seinem Interesse zu handeln, und dass dies in Homers Epen tatsächlich funktioniert.

Apollon kam dem Chryses, als diesem Unrecht widerfuhr, zunächst nicht zu Hilfe, aber als der ihn ganz offen an den Fettduft der Schenkel erinnerte, da schickte er seine Pfeile gegen das griechische Heer und attackierte sie neun Tage lang nebst ihren Lasttieren und Hunden (or. 5,2).

Maximos setzt sich von einem solchen Verständnis des Gebetes ab, das ihm aus theologischen Erwägungen heraus gänzlich abwegig erscheint. Wenn

${ }^{29}$ BSLK 510,33-511,8.

${ }^{30}$ Die Unterteilung stammt ursprünglich von C. Ausfeld, sie dürfte aber letztlich auf die Dreiteilung des Hymnos kletikos in der Rhetorik zurückzuführen sein (vgl. W. BURKERT, "Griechische Hymnoi" , in:Ders. / F. Stolz [Hg.], Hymnen in der Alten Welt im Kulturzergleich [Freiburg/Schweiz u.a. 1994] [9-17] 10, mit Verweis auf Menandros in L. Spengel, Rhetores Graeci [Leipzig 1856] III 33). 
jemand des Erbetenen würdig ist, so der Einwand, dann wird ihm die Gottheit das Notwendige unabhängig von einem Gebet zuteil werden lassen. Wenn er seine Bedürfnisse nicht im Gebet vortragen will, macht ihn das des Erbetenen nicht weniger würdig. Und umgekehrt: keiner wird durch

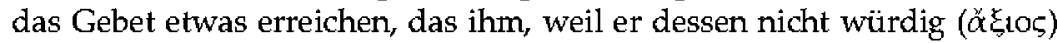
ist, nicht zusteht.

Das Verhältnis von Gebet und Würdigkeit ist sogar umgekehrt zu beurteilen: Wenn jemand etwas verdient hat und dennoch davon Abstand nimmt, auf sein Recht zu drängen, macht ihn das nur umso würdiger. Er

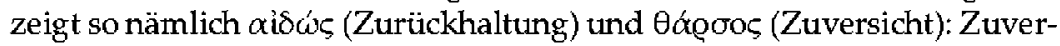
sicht, dass ihm die Gottheit schon zuteilen wird, was ihm zusteht; Zurückhaltung gegenüber dem Höhergestellten selbst dann, wenn er es einmal nicht bekommen sollte. Und umgekehrt erweist sich der Unwürdige, der bittet, durch sein Bitten als noch unwürdiger. Ihn kennzeichnen $\alpha \mu \alpha \theta i \alpha$

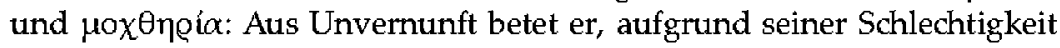
wird er nicht erhört.

Würdigkeit wird hier über die ethische Haltung und Lebensführung bestimmt. Sie ersetzt gewissermaßen das Gebet im Sinne der Bitte um etwas. Diese Betonung zeigt deutlich die stoischen Einflüsse in der Gebetstheorie und im Gottesbegriff des Maximos. Das Gebet besteht, richtig verstanden, im Einstimmen in eine durch die Gottheit repräsentierte Weltvernunft. Es liegt in der Natur der schulmäßigen Dissertationes des philosophischen Lehrers, dass diese Gedanken einen Konsens in seiner Zeit repräsentieren, oder doch jedenfalls einen Konsens der Gesellschaftsschicht, unter der wir seine Schüler vermuten können.

\section{Würdigkeit als Voraussetzung des Empfangens? Der Einspruch des Lukas}

\subsection{Nicht Qualität oder Leistung des Menschen, sondern gnädige Zuwendung Gottes}

Carlo O'Brian unterstreicht die große Ablehnung unter den gebildeten Zeitgenossen, mit der sich das frühe Christentum gerade beim Bittgebet konfrontiert sah: „This aversion towards petitionary prayer was widespread in antiquity and caused some embarrassment for the Christians in relation to the request for daily bread in the Lord's Prayer. ${ }^{\prime 31}$ Vor diesem Hintergrund gewinnen die Aussagen des Lukas zum Gebet noch einmal an Schärfe. Thm geht es offenbar darum, mit seinen Beispielen die Wichtigkeit des in Frage stehenden Bittgebets gerade zu unterstreichen. Dabei

\footnotetext{
${ }^{31}$ ỚRIAN 2016, 62. Zurr späteren Diskussion bei Origenes vgl. Fürst im vorliegenden Band.
} 
ist im Vergleich mit Maximos insbesondere sein Einspruch gegen die Vorstellung deutlich, die Voraussetzung der Gebetserfüllung sei die Würdigkeit des Betenden. Er formuliert diesen Einspruch über seine charakteristischen Gleichnisse, die hier wie anderswo als Provokationen gegenüber einem common sense intendiert sind. Die Beter des Lukas wie überhatupt die Protagonisten seines Evangeliums zeichnen sich gerade nicht durch ihre Würdigkeit aus, weder im Blick auf ihren Lebenswandel noch im Blick auf ihre soziale Stellung - im Gegenteil: ${ }^{32}$ Eine Witwe (Lk 18,2-8), ein Zöllner (Lk 18,10-13), eine stadtbekannte Sünderin (Lk 7,36-50) stehen den Königen, Philosophen und Weisen gegenüber, von denen Maximos erzählt. Es sind die ethisch und sozial Marginalisierten, an denen bei Lukas die Probleme des Gebets beispielhaft diskutiert werden. Wo aber einmal eine Person mit einer höheren sozialen Stellung auftritt, bei der Heilungsbitte des Hauptmanns von Kapernaum in Lk 7,6f. nämlich, dort kommt das Element der Würdigkeit in explizit negativer Weise ins Spiel: „Ich bin nicht würdig (ik $\alpha v o ́$ )... Deshalb habe ich mich nicht für wert gehalten...

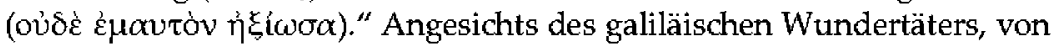
dem er sich Rettung verspricht, hat der Hauptmann nichts, um auf seine eigene Würdigkeit zu verweisen - und gerade diese Einsicht wird zur Gebetserfüllung entscheidend sein. In weiser Voraussicht hatten die Jünger ihrerseits bereits zuvor gegenüber Jesus auf die Würdigkeit des Haupt-

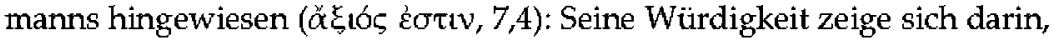
dass er das Volk Israel lieb habe (es handelt sich also offenbar um einen Gottesfürchtigen) und mit seinem Vermögen die Synagoge erbatt habe. Jesus seinerseits lobt den besonderen Glauben des Hauptmanns, den er so

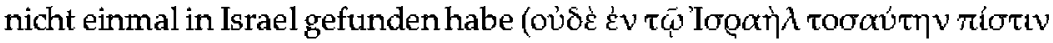
$\varepsilon \tilde{\tau} \varrho o v, 7,9)$, und vollzieht die Heilung. Wiederum ergibt sich die Würdigkeit nicht aus der sozialen Stellung oder den Taten, nicht einmal aus der Mitgliedschaft im Volk Gottes, sondern aus dem Vertrauen auf die Zusage!

Das Gleichnis in Lk 18,9-14 vom Pharisäer und dem Zölner nimmt das Thema der Würdigkeit auf - diesmal mit einer warnenden Note gegenüber allen, die meinen, sich gegenüber Gott auf ihre Würdigkeit beziehen zu können (hier freilich in einem Dankgebet). Mit einem Vertreter der Pharisäer lässt Lukas diejenige Gruppe auftreten, die aufgrund ihrer vollkom-

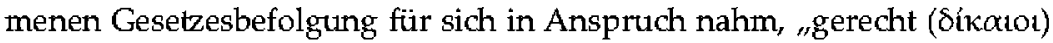
zu sein" $(18,9)$, deshalb am ehesten eine besondere Würdigkeit für sich reklamieren konnte und dies nach dem Zeugnis des Neuen Testaments auch getan hat:

Der Pharisäer stellte sich allein hin tund betete mit folgenden Worten: "Ich danke dir, Gott, dass ich nicht bin wie die ancleren Letute, Räuber, Übeltäter, Ehebrecher oder auch

\footnotetext{
${ }^{32}$ VBRSNBL 1981 untersucht programmatisch die Quellen zum alltäglichen Gebet. Leider gehter in seiner Analyse nicht auf die pars epica ein, die für uns von besonderer Bedeutung ist.
} 
wie dieser Zöllner. Ich faste zweimal in der Woche und gebe den Zehnten von allem, was ich einnehme" $(18,11 \mathrm{f})$.

Der Pharisäer verweist im Gebet auf seine in Fasten und der Gabe des Zehnten sich manifestierende besondere religiöse Haltung, die ihn von den Zöllnern und Sündern abhebt. Damit spricht er von einer Position aus, die der von Maximos vorausgesetzten Logik des Gebets sehr ähnlich ist: Er zählt zunächst einmal auf, in welch vorbildlicher Haltung er sein Leben führt. Wenngleich Maximos deshalb der Logik der Würdigkeit durchaus folgen und der Position des Pharisäers Einiges abgewinnen könnte, würde er freilich argumentieren, dass man gegenüber Gott nicht die eigenen Verdienste aufzählen müsste und sollte.

Lukas indes greift das Gottes- tund Selbstverständnis an. Er führt den Pharisäer deshalb als Negativbeispiel vor, weil er sich selbst erhöht, indem er auf seine eigene Gerechtigkeit verweist $(18,14)$. Demgegentiber wird demjenigen, der sich selbst erniedrigt, Erhöhung zugesprochen ( $\delta \delta \dot{\varepsilon}$

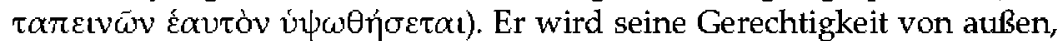

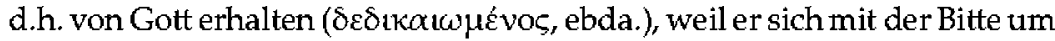
Erbarmen an Gott gewandt hat. Der Zöllner ist als Gegenfolie zum Pharisäer konstruiert. Seine ganze Haltung spricht dafür, wie unwürdig er sich selbst empfindet: Er stellt sich abseits, traut sich nicht, seine Augen zum Himmel zu erheben, und schlägt sich unablässig auf die Brust $(18,13)$.

Der theologische Einspruch des Evangeliums trifft die Überlegungen des Maximos zum Bittgebet (und mit ihnen die dahinterstehende- im Kern stoische - Anthropologie) ins Mark: Welcher Mensch wäre denn vor Gott dessen würdig, um das er bitten könnte? Zuwendung wie Urteil ergeht, so die entgegengesetzte Position dieses Evangeliums, gerade nicht nach Würdigkeit und Gerechtigkeit des Menschen. Vielmehr kann dem Menschen eine Würde, die ihn gerecht macht, immer nur aufgrund seiner vertrauenden Hinwendung an Gott von diesem zugesprochen werden.

Gegenüber der Behauptung des Maximos, dass die Erfülltung der Gebetswünsche von der individuellen Würdigkeit des Beters abhängt und es folglich das Gebet überhatupt nicht braucht, weil Gott die Bedürfnisse des Beters bereits kennt und sie, wenn der Beter es verdient hat, auch erfïllen wird, betont Jesus mehrfach, dass Gott denen gibt, die ihn um etwas bitten, eben weil sie darum bitten: „Bittet, und es wird euch gegeben werden ... Jeder, der bittet, wird empfangen ..." (11,9f.). Der Satz fasst die Pointe der unmittelbar vorausgegangen Parabel von einem Freund zusammen, bei dem man mitten in der Nacht klopft, um ihn um drei Brote zu bitten, weil überraschend Besuch gekommen ist. Während theoretisch zwei mögliche Ausgänge der Geschichte impliziert sind, stellt doch der eine, dass nämlich ein Freund in der geschilderten Situation nicht helfen könnte, ei- 
ne unmögliche Möglichkeit dar. ${ }^{33}$ Selbst wenn der Freund sich bereits im Bett befindet, wird er schließlich der Bitte nachkommen, denn: "Ich sage euch: Wenn er auch nicht aufstehen und es ihm geben mag, weil er ihm als Freund verpflichtet ist, dann wird er doch wegen seines unverschämten Drängens $^{34}$ aufstehen und ihm geben, wessen er bedarf" $(11,8)$. War also bereits über die Wahl der Protagonisten deutlich, dass nicht die Würdigkeit, sondern das hartnäckige Vorbringen des Wunsches die Erfüllung des Gebetswunsches herbeiführt, so erhärtet sich dies, wenn Jesus über Beispielerzählungen deutlich macht, in welcher Haltung das Gebet zu vollziehen ist.

Es schließen sich weitere Beispiele an, die derselben argumentativen Struktur folgen: Würde ein Vater seinem Sohn, wenn der ihn um einen Fisch bittet, anstatt dessen eine Schlange vorsetzen? Oder einen Skorpion anstelle eines Eies? (Lk 11,11f.). Wohl katum. Jesus zieht - ganz ähnlich wie Maximos - einen theologischen Schluss a minore ad maits: "Wenn nun ihr, die ihr böse seid, euren Kindern gute Gaben geben könnt, wie viel mehr wird der Vater im Himmel den heiligen Geist geben denen, die ihn bitten!" $(11,13)$.

Dass Lukas nicht nur allgemein die Bitte um etwas, sondern im Anschluss an die Brotbitte speziell die existentielle Bitte um Speise zum Thema macht, passt zum Duktus des Evangeliums, in dem das Essen eine ganz herausragende Rolle in einer existentiellen, aber auch einer sozialen Dimension spielt. Hier ist beides miteinander verknüpft. Gerade durch die Bitte um etwas stellt der Mensch eine Beziehtung her, der sich Gott, so die argumentative Zielrichtung, selbst dann nicht entziehen könnte, wenn er ein ungerechter Richter oder ein wenig williger Freund und Vater wäre. Mit seinen Zusagen hat er sich selbst an sein Volk gebunden. ${ }^{35}$

Zwei Aussagen über Gott ergeben sich bereits hier, die mit dem Schluss a minore ad maius zusammenhängen:

1. Gott geht mit uns um wie ein Vater. Dass diese Übertragung vom Leser / Hörer geleistet werden soll, zeigt die Vateranrede im einleitenden Vaterunsergebet $(11,2)$. Freilich: Wenn ein menschlicher Vater auch anders

\footnotetext{
${ }^{33} \mathrm{Vgl}$. WoLtBr 2008, 410f. Ein irdischer Freund oder Vater, so ist impliziert, wird niemals so handeln, aber selbst wenn er so handeln könnte, so ist das doch bei Gott gänzlich ausgeschlossen.

${ }^{34}$ Luther übersetzt: ,wegen seines unverschämten Geilens." WoLTER 2008 weist zu Recht die in der Forschung vielfach diskutierte ethische Beurteilung des Verhaltens ab. Es geht lediglich um die Erfolgsaussicht eines Verhaltens, das gesellschaftlich als unschicklich zu gelten hätte.

${ }^{35}$ Diese Bindung gilt selbst dann, wenn der Mensch sie einseitig aufkütndigt Auch dem Verlorenen Sohn, der sein Sohnsein bereits verwirkt hat, indem er das Erbe genommen und sich vom Vater abgewendet hat, hilft der Vater nicht nur in der Stunde der Not; er tut viel mehr als das. Weil der Sohn sich bittstellend zum Vater umgewandt hat, versorgt der ihn nicht nur mit der lebensnotwendigen Speise, sondern schlachtet ein Mastkalb und richtet ein Fest aus - und setzt damit den Verlorenen erneut zum Sohn ein.
} 
handeln könnte, so gilt das auf keinen Fall von dem himmlischen Vater. Das Argument entspricht strukturell genau dem Vergleich Gottes mit einem irdischen Fachmann bei Maximos (\$3). Inhaltlich freilich erweist sich der Gott des Maximos als ein Fachmann für eine Gerechtigkeit, die jedem das ihm oder ihr Zustehende zuteilt, während der lukanische Jesus seinen Gott als einen fürsorgenden Vater zeichnet, der das Gebet von jedem erhört, der sich vertrauend und beständig im Gebet an ihn wendet.

2. Warum werden die Gesprächspartner Jesu hier pauschal als "böse" bezeichnet ("wenn selbst ihr, die ihr böse seid, gute Gaben geben könnt...", 11,13 par Mt 7,11)? Die Logik von gut und böse entspricht hier, so denke ich, derjenigen von würdig und unwürdig: Im Horizont des Gebetes als eines Gesprächs mit dem guten Gott erscheint schlechterdings kein Mensch als gut. Mit anderen Worten: Die Bezeichnung „böse“ ist hier gewählt wegen ihrer semantischen Gegenseite, die auf Gott zu übertragen ist. Dies zeigt sich später im Anschluss an die zweite Gebetsparänese in der Antwort auf die Frage des Oberen in Lk 18,19: "Niemand ist gut außer dem einen Gott".

Die genannten illustrativen Gleichnisse in Lk 11 sind Teil einer längeren Darlegung über das Gebet, die einsetzt mit der außergewöhnlichen Bitte der Jünger in 11,1: „Herr, lehre uns beten" ${ }^{36}$

Jesus antwortet auf diese Bitte zunächst mit dem Vaterunsergebet, ${ }^{37}$ bevor er durch die folgenden Überlegungen erläutert, wieso es sinnvoll ist, dieses Gebet täglich zu sprechen (die folgende kurze Lehrrede über das Gebet kreist, wie wir gesagt hatten, ausschließlich um die Brotbitte!). In der Tat ist es dies, was das Vaterunsergebet von allen paganen Gebeten unterscheidet: zwar werden auch in der paganen Literatur Mustergebete formuliert, aber hier ist ein Gebet entstanden, das von allen Anhängern der Religion als zentrales Gebet übereinstimmend gebetet wird.

\subsection{Das fortwährende Gebet}

In dem bereits angesprochenen zweiten Set von Gleichnissen zum Gebet in Lk 18 illustriert der lukanische Jesus die Notwendigkeit, fortwährend

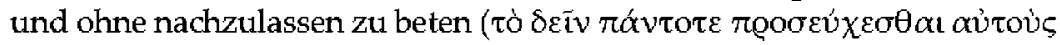

\footnotetext{
${ }^{36}$ Auch Jesus selbst wird im Lukasevangelium verschiedentlich als Betender dargestellt, besonders eindrücklich in der Szene im Garten Getsemane (Lk 22,39-46). Wir konzentrieren uns bei der Untersuchung indes auf solche Stellen, an denen das Thema des Gebets in der Lehre Jesu verhandelt und in Gleichnissen thematisiert wird. Zum Getsemanegebet im Matthäusevangelium vgl. den Beitrag von Vincenzo Vitiello, S. 184-185 in diesem Band.

${ }^{37}$ Lukas bietet eine kürzere Version des Vaterunser gegenüber Matthäus (interessant: hier hat er das oŕfعeov, das bei ihm so stark eschatologisch aufgeladen ist, nicht aufge-

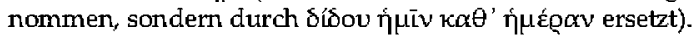




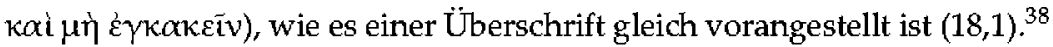
Auch diese Aufforderung zum immerwährenden Gebet liest sich geradezu als Antithese zur Ablehnung des Bittgebets in Maximos' 5. Rede: Anstelle einer ethisch-sozialen Würdigkeit wird im Folgenden das immerwährende Bittgebet geradezu zur Voratussetzung des Empfangs von Gaben gemacht, wie wir das auch in Lk 11 bereits gesehen hatten. Zunächst das Gleichnis von der bittenden Witwe (Lk 18,2-8): Eine Witwe, die sich in einer sozial und rechtlich prekären Situation befindet, weil sie des Schutzes durch ihren Mann verlustig gegangen ist und zugleich üblicherweise das Erbe nicht antreten kann, trifft auf einen Richter, der sich keinerlei ethischen Maßstäben unterordnen will, seien sie nun irdischen oder göttlichen Ursprungs. Zweimal wird betont, dass der Richter weder Gott fürchtet noch sich um die Nöte von Menschen schert $(18,2.4)$. Zuerst appelliert die Witwe an seine Verantwortung als Richter - ohne Erfolg. Als die Frau dennoch eine längere Zeit unablässig fortfährt, den Richter zu bitten, setzt sich dieser schließlich doch für sie ein. Nicht etwa - das arbeitet die Geschichte sorgfältig heraus -, weil er seine religiöse und ethische Pflicht eingesehen hätte, sondern lediglich, weil sie ihm aufgrund ihres beständigen Drängens lästig wird und er befürchtet, dass sie ihn zuletzt noch ins Gesicht schlagen könnte $(18,5)$.

Das Gleichnis von der bittenden Witwe verbindet also beide genannten Themen. Es wird jede Form individueller Würdigkeit abgelehnt. ${ }^{39}$ Gott wird ihr Gebet wie ein gerechter Richter einfach deshalb erhören, so die Pointe des Gleichnisses, weil er den Entrechteten Recht schafft. ${ }^{40}$ Das Gleichnis hat aber noch eine zweite Pointe: Entscheidend für die Gebetserfüllung ist das fortgesetzte Bitten. Wenn selbst ein ungerechter Richter sich zuletzt erweichen lässt, so erklärt der Evangelist, um wie viel mehr wird Gott seine Auserwählten erhören, wenn sie Tag und Nacht ztu ihm beten - und er wird sie sicherlich nicht $\mathrm{zt}$ lange warten lassen $(18,7 \mathrm{f}$.). Das Gleichnis folgt dabei der bereits gelätufigen argumentativen Struktur a minore ad maits. Als theologische Aussage würde diese Folgerung freilich der Kritik des Maximos tunterliegen: Würde der gerechte Gott denn den Entrechteten nicht helfen, wenn sie ihn nicht auf ihre Notlage hinweisen? Angesichts dieser berechtigten Anfrage gilt es noch einmal auf die Einleitung des Gleichnisses zurüickzublicken. Es will primär die Betenden in den Blick nehmen, und die theologischen Aussagen sollen lediglich unter-

\footnotetext{
${ }^{38}$ Die beiden Parabeln in Lk 18 (Der gottlose Richter und die bittende Witwe einerseits und der Pharisäer und der Zöllner andererseits) stehen in deutlicher Nähe zur Lehre über das Gebet in Lk 11. WoLTER 2008, 586, sieht einen motivischen Zusammethang im Aspekt der Bosheit, die in Lk 11,13 auf der Bildebene von den Menschen, in Lk 18,6 von dem ungerechten Richter ausgesagt wird.

${ }^{39}$ Wie schon in Lk 7,7 .

${ }^{40} \mathrm{Vgl}$. Lk 1,51-53.
} 
stützend wirken: Das christliche Gebet schöpft seine Kraft, so die Aussage, aus dem beständigen Dialog mit Gott im Gebet. Deshalb ist es so wichtig, ein Gebet zu schaffen, das immer neu gebetet werden kann.

Fazit: Nicht die Würdigkeit der Frau ist Thema, sondern allenfalls ihre entrechtete Stellung, die dazu verpflichtet, sich für sie einzusetzen und ihr Recht zu schaffen. ${ }^{41}$ Gleichwohl: Die Erfüllung ihrer Wünsche ist kein Automatismus, wie dies durch Maximos auch aufgrund eines Prinzips der Weltgerechtigkeit impliziert sein könnte, sondern es ist die hartnäckige Bitte und das andauernde Gespräch mit Gott, das schließlich das Ergebnis zeitigen wird. ${ }^{42}$

\subsection{Drängen als geforderte Gebetshaltung}

Lukas geht indes über die Forderung des immerwährenden Gebets noch hinaus in einer Weise, die wiederum den bei Maximos für das Gebet vorausgesetzten sozialen Umgangsformen vollkommen zuwiderläuft: Gegenüber Gott wird sogar die unziemliche, unverschämte Bitte geradezu gefordert. Das entscheidende Stichwort in Lk 11,8 formuliert geradezu die Antithese zur Gebetstheorie des Maximos: nötig sei fortwährendes Bitten und Schamlosigkeit ( $\alpha$ vai $\delta \varepsilon ı, 11,8$ ) - der unmittelbare Gegenbegriff zur $\alpha i \delta \omega \zeta$, die nach Maximos denjenigen auszeichnet, der gerade nicht bittet. ${ }^{43}$

Auch dieser Unterschied ist wieder im divergierenden Gottesbild begründet. Was wäre das für eine Gerechtigkeit eines Gottes, der lediglich festschriebe, was der Mensch getan, vielleicht sogar, was Gott selbst verhängt hat? Diesem Gott ginge jene Eigenschaft $\mathrm{ab}$, die Lukas ins Zentrum seiner Theologie rückt: die Barmherzigkeit (Lk 6,36: „Seid barmherzig, wie auch euer Vater barmherzig ist" ${ }^{\prime 4} .{ }^{44}$ Immer wieder hat sich der Gott Israels als ein Gott erwiesen, der gegenüber seinen Geschöpfen die Barmherzig-

\footnotetext{
${ }^{41}$ In provozierender Weise stellt sich das Lukasevangelium auf die Seite der Armen und Entrechteten, ohne dass von ihnen eine entsprechende ethische oder religiöse Haltung gefordert würde (man vergleiche nur den armen Lazarus in Lk 16,19-31, der nur als Ausgleich am Ende in Abrahams Schoß aufgenommen wird). Man mag das durchaus als ein Indiz dafür sehen, dass sich das Evangelium schwerpunktmäßig nicht an die Armen richtet, sondern den Wohlhabenderen die Armen anzuempfehlen beabsichtigt.

${ }^{42}$ Das Gleichnis zeigt die Chancen und Grenzen bildhafter Sprache. Durchaus spielt die Geschichte mit der Identifikation des Richters mit Gott. Dass aber Gott einfach mit dem Richter zu identifizieren wäre, wie FörsTER 2007, 278f. schreibt, übersieht doch das feine Spiel mit den Grenzen der Übertragung. Ein besonderes Moment der Verfremdung, das an einen Kalauer grenzt, bildet dabei die Bezeichnung des Richters als "gottlos" (bzw. ohne Achtung gegeniüber Gott) in Lk 18,2 ( überhaupt nicht der allegorisierenden Identifikation des Richters mit Gott, die ganz im Stile des Maximos den göttlichen Fachmann in einem argumentum a minore ad maitus mit menschlichen Spezialisten vergleicht, wie wir schon gesehen haben.

${ }^{43} \mathrm{Vgl}$. das Verhalten der bittenden Witwe in Lk 18,2-8.

${ }^{44}$ Als barmherziger Gott offenbart sich Gott am Sinai (Ex 34,6; vgl. Dtn 4,31; Ps 86,15; 103,$8 ; 145,8$; Joel 2,13 u.ö.).
} 
keit über das Recht stellt. Wie anders sollte Gott dem sündigen Menschen begegnen? Hier zeigt sich das ungleich personalere Gottesbild des Lukasevangeliums. Es beruht auf der Geschichte eines Gottes, der von Anfang an eine Beziehung zu seinem Volk aufbauen wollte und jedem Einzelnen das Leben geschenkt hat und ihn deshalb fürsorgend begleitet.

In diesem Zusammenhang kommt neben der Vorstellung des gerechten Richters, der den Entrechteten Recht verschafft, in den lukanischen Darlegungen zum Gebet eine wesentliche Rolle der Vatermetapher zu, die von pagan-religiösen Griechen ebenso verwendet wird wie von Christen, von Stoikern ebenso wie von Platonikern - und doch in je ganz unterschiedlicher Weise gebraucht wird. ${ }^{45}$ Während sie insbesondere in stoischer Tradition (man denke an den berühmten Zeus-Hymnos des Kleanthes) einen ontologischen Zusammenhang voraussetzt, geht es in der biblischen Tradition vor allem um einen Beziehungszusammenhang, der von Gott initiiert ist und vom Menschen immer wieder aktualisiert werden muss.

\subsection{Gebet als Beziehungspflege}

Durchaus einig sind sich Juden und Christen mit dem pagan-philosophischen Beter, dass das Gebet atus der Gottesbeziehung heratuswächst, sie manifestiert und ernetuert. Bei Maximos und auch in der stoischen Literatur basiert diese Beziehung aber auf der natürlichen Verbindung des Menschen als eines animal rationale mit dem Göttlichen. Die Verwandtschaft mit Gott gründet im menschlichen Logos. Bei Juden tund Christen verdankt sich die Beziehung der Erwählung durch Gott, auf die der Mensch zu antworten hat ${ }^{46}$ Durch die Vateranrede treten Christen damit in ein Beziehungsgeschehen mit einem göttlichen Du ein, während der philosophische Beter (insbesondere stoischer Herkunft) durch den Gebrauch seiner Vernunft lediglich die Möglichkeit zur Einheit mit Gott realisiert, die in seinem vernüinftigen Wesen angelegt ist. ${ }^{47}$ Dies ist auch der Grund, warum sich das Gebet des Stoikers nicht eigentlich nach außen, sondern nach innen richtet. ${ }^{48}$

\footnotetext{
${ }^{45}$ R. FELDM BIER, „Der oberste Gott als Vater. Die frühjüdische und frühchristliche Rede vom göttlichen Vater im Kontext stoischer und platonischer Kosmos-Theologie", itr: ders., Der Höchste (Tübingen 2014) 178-193; ders. / H. SpIBCKBRmanN, Der Gott der Lebendigen. Eine biblische Gotteslehre (Tübingen 2017; ${ }^{1}$ 2011) 51-92.

${ }^{46}$ Dies ähnelt in erstaunlicher Weise Aussagen, die sich bei Plutarch am Ende der Schrift über das rätselhafte E-Zeichen in Delphi finden. Dort interpretiert er das E-Zeichen als Anrede " $\varepsilon[-d u$ bist"; mit dieser Anrede soll der in den Tempel Eintretende die Gottheit begrüßen. Damit nimmt der Eintretende den Impuls auf, den der Gott ihm mit der Gabe des E-Zeichens gegeben hat. Indem er die Gottheit als einzig wahres Sein anerkennt, erkennt er zugleich sein eigenes Nichts-Sein - tnd gewinnt damit den Imptls zur Angleichtung an Gott und damit zur Überwindung der eigenen Endlichkeit; vgl, unten, S. 113-114.

$47 \mathrm{Vgl}$. die Ausfïhrungen zur Vateran rede bei FbLDMBIBR 2016, 64.

${ }^{48} \mathrm{Vgl}$. die Aussagen Senecas aus dem 41 . Brief $(\$ 1)$ : Non sunt ad caelum elevandae manus nec exorandus aeditutus ut nos ad aurem simulacri, quasi magis exaudiri possimus, admittat: prope
} 
Indem der christliche Beter sich in seinem fortwährenden Gebet auf die Zusagen Gottes beruft, drückt er sein unbedingtes Festhalten an diesen Zusagen aus. Nicht Gott wird so primär an seine Zusagen erinnert, sondern der Beter selbst aktualisiert im Gebet die Zusage Gottes. Der Kerngedanke des Gleichnisses also ist der des unbedingten Festhaltens an der Zusage atuf der Seite der Betenden.

\subsection{Zum Vergleich von Maximos und Lukas}

Eine große Übereinstimmung hat sich im rhetorischen Zugriff und der dahinterstehenden theologischen Intention gezeigt. Maximos setzt wie der lukanische Jesus in seinem rhetorischen Duktus Bilder ein, um das Gesagte anschaulich zu machen. Dabei werden nicht nur Wesen und Wirkweise des Gebets illustriert, sondern implizit auch Aussagen über das Wesen Gottes getroffen. Beide Autoren stellen Gott in einem Vergleich als eine überlegene Instanz (Feldherr, Arzt, Richter) dar bzw. als eine Instanz, die man um Hilfe angeht. Zugleich unterstreicht der Vergleich jeweils gegenüber menschlichen Instanzen die Unfehlbarkeit des Göttlichen bzw. Gottes. Das Argument a minore ad maius ist also mit einem Kontrast verbunden. Wenn auch gegenüber dem göttlichen Fachmann gilt, was im menschlichen Umgang selbstverständlich ist, dass man sich dem Fachmann vertrauensvoll anheimstellt, dann gilt hier ein kategorialer Unterschied: Während der Fachmann mit Befehlsgewalt in unterschiedlicher Weise fehlbar ist (Fehlurteil; Bestechung; Täuschung), und selbst ein Richter "gottlos" sein und ein Vater oder Freund sich gegen seine Pflichten vergehen und entsprechend agieren kann, so gilt das nicht von Gott ( $\tau$ ò $\delta \dot{\varepsilon} \theta \varepsilon i \bar{o}$ oủ totoṽ or. 5,3). Beide Autoren setzten in ihrer Argumentation das gute Wesen Gottes axiomatisch voraus. ${ }^{49}$ Unterschiedlich sind freilich die Folgerungen im Blick auf das Bittgebet, die damit zusammenhängen, dass für Maximos das Bild des Fachmanns, sei es eines Arztes oder Feldherrn, bestimmend ist, für Lukas dagegen das Bild einer Respektsperson, an die man sich vertratuensvoll um Hilfe wendet. Für Maximos ist entscheidend, dass der göttliche Fachmann aus Sorge um das Ganze gerade nicht auf die Befindlichkeiten des Einzelnen Rücksicht nehmen darf, wo dies die Gesundheit des Gesamtorganismus negativ beeinflusst. Diese Vorstellung der sympatheia mutet ausgesprochen stoisch an. Aus diesem Grund macht, wie Maximos am Ende von $\$ 4$ resümiert, in Fragen der Vorsehung (und das heißt auch:

est a te deus, tecum est, intus est (,weder muss man die Hände zum Himmel erheben noch den Tempelaufseher eindringlich bitten, uns an das Ohr der Götterplastik heranzulassen, als würden wir dadurch eher erhört: nahe ist dir Gott, er ist mit dir, er ist in dir").

${ }^{49}$ Bei Maximosist dies ein platonischer Zug in der'Theologie, dem er eine eigene Dialexis gewidmet hat (or. 41). 
im Blick auf das Handeln des guten und gerechten Gottes) das Beten im Sinne der Einflussnahme eines Einzelnen keinen Sinn.

Gegenüber dieser Vorstellung einer göttlichen Weltordnung, der sich der Einzelne um des Ganzen willen zu fügen hat, impliziert die Gebetsvorstellung des Lukas ein sehr viel unmittelbareres Verhältnis zu Gott. Dabei geht Lukas keineswegs von der selbstverständlichen, gewissermaßen automatischen Erfüllung von Bitten durch Gott aus, wie Niclas Förster dies im Vergleich mit paganen Gebetsvorstellungen ausführt: „Diesem Gleichnis liegt demnach die Auffassung zu Grunde, dass man Gott nicht als allmächtige Schicksalsmacht sehen solle, denn Gott wird den Menschen wie ein liebender Vater seinen Kindern ihre Wünsche erfüllen. ${ }^{\mu 50}$ Vielmehr ist es entsprechend der Gleichniseinleitung in Lk 18,1 der in der fortwährenden Bitte sich ausdrückende Glaube, der die Erhörung der Bitte nach sich ziehen wird. ${ }^{51}$ Dem entspricht eine Anthropologie, die Würdigkeit allein über das Gottesverhältnis definiert bzw. als Restultat des Festhaltens an der von Gott initiierten Beziehung.

\section{Das Gebet im hellenistisch-jüdischen Bekehrungsroman Joseph und Aseneth}

Um Würdigkeit in einem fundamentalen Sinne geht es in den Gebeten der Aseneth und deren vorbereitenden Überlegungen im hellenistischjüdischen Roman Joseph und Aseneth. ${ }^{52}$ Als die ägyptische Priestertochter aufgrund ihrer Begegnung mit Joseph den Gott Israels als den wahren Gott erkannt hat und damit zugleich ihre eigene, aufgrund ihres Götzendienstes nichtige und todverfallene Existenz, will sie sich im Gebet diesem Gott zuwenden. Deutliche Parallelen zu Lukas fallen ins Auge. Mit einer Gebetshaltung, wie wir sie eben bei dem Zöllner und zuvor beim Hauptmann von Kapernaum kennengelernt hatten, unterstreicht Aseneth, dass sie nichts hat, womit sie würdig vor Gott treten könnte. Symbolisch äuBert sie zudem durch ihre Trauerhaltung, dass sie nichtig ist, sie scheidet gewissermaßen aus der Welt der Lebenden aus: Sie verschließt ihre Tür, stimmt eine Totenklage an (10,3f.), vertauscht ihr königliches, golddurchwirktes Gewand gegen ein schwarzes Trauergewand $(10,10),{ }^{53}$ legt

\footnotetext{
${ }^{50}$ FöRsTBR 2007, 291.

${ }^{51}$ Am Beispiel des Hauptmanns von Kapernaum wird deutlich, wie sehr sich in der Bitte gerade der Glaube an die Erfüllung ausdrückt.

${ }^{52} \mathrm{Vgl}$. S. von Sтвмм, Der betende Sünder vor Gott. Studien zu Vergebungsvorstellungen in urchristlichen und frühjüdischen Texten (Leiden u.a. 1999) 54-103; R. BLocH, Jüdische Drehbühnen. Biblische Variationen im antiken Judentum. Tria Corda 7 (Tübingen 2013) 1-28; J. ReINMUTH (Hg.), Joseph und Aseneth. SAPERE XI (Tübingen 2009).

${ }^{53}$ Das Gewand hatte sie beim Tod ihres Bruders getragen, so wird erzählt $(10,8)$ und damit unterstrichen, dass sie auch nun um eine Tote trauert.
} 
all ihren Schmuck mitsamt Gürtel und Diadem ab und wirft alles - auch ihre "zahllosen goldenen und silbernen Götzenbilder" mitsamt den für sie vorgesehenen Opfergaben - aus dem Fenster (10,11-13). Schließlich streut sie Asche auf ihr Haupt $(10,14)$, schlägt sich mit beiden Händen gegen die Brust, und fastet "in diesen sieben Tagen ihrer Erniedrigung" ( $\pi \tilde{\eta} \zeta$

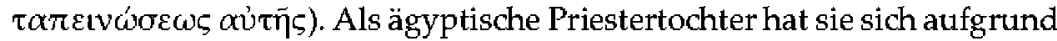
ihrer Begegnung mit dem wahren Gott von ihren Göttern ebenso wie ihrer Familie losgesagt und in Trauergewand, Asche und Fasten im Grunde auch dem Leben entsagt. Sie hat sich all dessen entkleidet, was ihr bisher Sicherheit, Status und Würde verliehen hat.

Aseneth reflektiert in einer Weise, die durchaus an die or. 5 des Maximos erinnern kann, dass sie sich durch die Hinwendung zu Gott dem ultimativen Richter unterordnet. Maximos ermahnt den Beter $(5,7)$ :

\footnotetext{
Wenn du dich allerdings daranmachst, dich im Gebet an die Götter zu wenden, danu hast du dich an ein sorgfältiges und unbestechliches Gericht gewandt. Kein Gott wird es zulassen, dass du um etwas bittest, für das sich ein Gebet nicht schickt, oder wird dir geben, was dir nicht zusteht. Als harter Prüfer untersucht er die Gebete jedes Einzelnen genau und spricht jedem das Seine nach dem Maß des für ihn Zuträglichen zu. Du wirst nicht mit ihm verhandeln können, indem du deine Bedürfnisse gleichsam in den Zeugenstand aufrufst, die erbarmungswürdig betteln, die "hab Erbarmen" rufen, die den Kopf mit viel Staub überschütten...
}

Bei Aseneth freilich ist das Gericht ungleich existentieller verstanden. Indem sie im Gebet mit dem wahren Gott in Kontakt tritt und sich ihm mit ihrer ganzen Existenz anheimstellt, läuft sie nach eigener Aussage Gefahr, dass dieser sie in ihrer Unreinheit aufgrund seiner Heiligkeit vernichten könnte. Dabei geht Aseneth offenbar davon aus, dass der Kontakt erst dann hergestellt wird, wenn sie tatsächlich ihren Mund öffnet. Am siebten Tag nämlich erhebt sie ihren Kopf aus der Asche und beginnt erstmals zu sprechen, allerdings zunächst „in ihrem Herzen, ohne den Mund zu

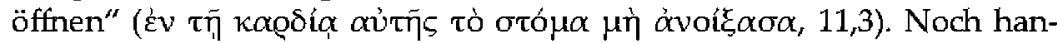
delt es sich um ein Selbstgespräch, in dem sie ihre Situation reflektiert: Sie ist wie eine Waise, verlassen, schutzlos und - weil sie sich von den Eltern und deren Göttern losgesagt hat - gehasst (11,3-5). An wen aber soll sie sich wenden, wenn doch auch der Gott Josephs all jene hasst, die tote und stumme Gottesbilder verehren?

Aseneth zögert, tatsächlich ihren Mund zum Gebet an diesen Gott zu öffnen. Zwei Überlegungen streiten in ihrer Brust: Weil ihr Mund durch den Verzehr von Götzenopferfleisch verunreinigt ist, müsste der Zorn des einen Gottes und seine Strafe sie treffen, wenn sie sich an ihn richtet $(11,9)$. Durch ihr Gebet würde sie sich auch dem Urteil dieses Gottes unterstellen, den sie als den einzig wahren erkannt hat. ${ }^{54}$ Andererseits hat sie viele Leute sagen hören,

\footnotetext{
${ }^{54}$ Vgl. Max. or. 5,7.
} 
dass der Gott der Hebräer cler wahre und lebendige Gott ist, barmherzig, mitleidig, großherzig, voller Erbarmen, milde, der die Sünden eines erniedrigten Menschen nicht zurechnet und die Schuld eines betrübten Menschen in cler Stunde seiner Trübsal (11,10).

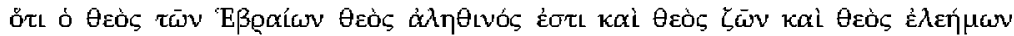

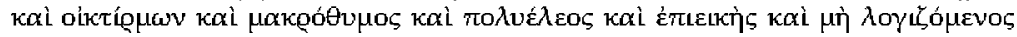

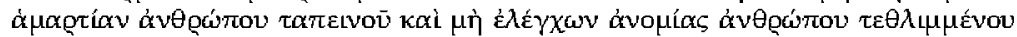

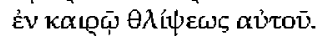

Es ist ein kleiner Hymnus auf die Langmut Gottes mit vielen biblischen Anklängen. Aseneth repetiert ihn in ihrem Herzen, ohne ihn tatsächlich auszusprechen. Noch ist die Furcht, sich diesem Gott auszusetzen, gröBer als die Hoffnung auf seine Milde und den Schutz für Zerschlagene $(11,15)$. Ein weiteres inneres Gespräch mit erneuter Abwägung der Argumente schließt sich an $(11,16-18)$ : Wie soll sie seinen ",heiligen, furchtbaren Namen nennen", ohne den Zorn Gottes heraufzubeschwören für die Entweihung seines Namens durch ihren Mund? $(11,17)$. Zunächst versichert sich Aseneth innerlich dessen, dass der Gott Josephs, sollte er sie züchtigen, sie schlagen und seinen Zorn über ihr ausgießen, sie als gnädiger Gott wieder heil machen und sich mit ihr versöhnen wird. ${ }^{55}$

Und so wagt sie es schließlich beim dritten Anlauf, ihren Mund zu öffnen $(11,19)$ und Gott im Gebet anzusprechen. Sie spricht ihn als den Schöpfergott an, beschönigt dabei ihre Fehler nicht, beruft sich lediglich auf ihre Unwissenheit $(12,5)$, vor allem nimmt sie die Vatermetapher auf, die uns bereits in der Gebetsparänese des Lukas als Leitmetapher begegnet war, und formuliert sie aus $(12,8)$ : Sie wendet sich an den Vater, der seine Hände nach ihr wie nach einem verängstigten kleinen Kind ausstreckt, um es auf den Arm zu nehmen. Es ist ein überaus zärtliches und vertrauensvolles Bild, das sie so zeichnet, das Bild eines Gottes, der in aller seiner Strenge über die ernstliche Erschütterung des Kindes zu lächeln vermag, vor allem aber eines Gottes, der - wie der Vater des Verlorenen Sohnes in Lk 15 - auf das Gebet hin die zerstörte Beziehung wiederherstellt und so neues Leben möglich macht.

Neben den relationalen Aspekten des Gebets, die damit im Gebetsverständnis der Aseneth sichtbar werden, stehen auch ontologische, insofern das Gebet - wie das auch Maximos in $\$ 7$ der or. 5 voraussetzt - eine tatsächliche Verbindung zu Gott herstellt, die die Beterin dem Urteil des Gottes unterstellt, an den sie sich wendet.

\footnotetext{
${ }^{55}$ Freilich ist ihr hoffnungsvolles Gebet bereits vorbereitet durch das Segensgebet Josephs $(8,9)$, in dem Aseneth bereits in Aussicht gestellt wird, dass sie zu Gottes Volk gezählt werden wird und das Leben Gottes zugeeignet bekommt. Es wird betont, dass es der Schöpfungstag ist, an dem Joseph diese Segensworte spricht, und dass er in sieben Tagen zurückkehren wird $(9,5)$, wohl auch - so darf man mithören - um zu sehen, ob das Schöpfungswerk dann vollendet ist.
} 


\section{Das Gebet bei Plutarch}

Wie kein anderer pagan-religiöser Autor der Kaiserzeit macht Plutarch Themen der religiösen Tradition zum Gegenstand philosophischer Überlegungen ${ }^{56}$ So werden auch Gebete in unterschiedlichen Schriften an programmatischen Stellen zum Thema. Die Diskussion eines Gebets bildet etwa den Auftakt in Plutarchs Eheratschlägen, ${ }^{57}$ die er zweien seiner Schüler als Hochzeitsgeschenk gewidmet hat. Auf eine allgemeinere philosophische Ebene wird das Gebet am Beginn von Plutarchs Schrift De Iside et Osiride gehoben. Alles Gute müsse man vernünftigerweise von den Göttern erbitten, so sagt er da, vor allem aber das Wissen über sie. ${ }^{58}$ Nicht eine Bitte um Güter also ist hier Gegenstand des Gebets, sondern die Bitte um Erkenntnis der Götter und der durch sie repräsentierten Wahrheit, die zugleich Teilhabe ( $\mu \varepsilon \tau \sigma v \sigma i \alpha)$ impliziert. Während eine solche Teilhabe in der körperlichen Existenz nur partiell wie in einem Traumbild gelingen kann, führt der Gott den Menschen durch sie am Ende des Lebens aus seiner sterblichen Existenz heraus zu sich selbst hin, wie Plutarch am Ende der Schrift ausführt. ${ }^{59}$ Dies wird in einer der Spätschriften Plutarchs, Über das $E$ in Delphi, in einer Weise existentiell ausformuliert, die der Grundhaltung des Gebets bei Aseneth durchaus nicht unähnlich ist ${ }^{60}$ Gotteserkenntnis (und vor allem die mit der Gotteserkenntnis implizierte Erkenntnis der eigenen Nichtigkeit) erscheint hier als Weg zur Überwindung der Todverfallenheit. Die in Delphi aufgeschriebene Maxime "Erkenne dich selbst" und das rätselhafte Epsilon-Zeichen vor dem Tempel des Apollon in Delphi sind einander zugeordnet und interpretieren sich gegenseitig. Das Epsilon (EI) repräsentiert eine Gottesanrede, die zugleich mit dem Gipfel der Gotteserkenntnis Erkenntnis der eigenen Nichtigkeit birgt und damit wie bei Aseneth den Impuls, Todüberwindung und Heil allein von diesem Gott zu erhoffen. Durch das Zeichen nämlich fordere der Gott den Eintretenden

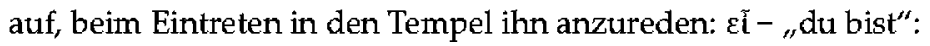

Ich glatube also, dass der Buchstabe weder eine Zahl noch ein Rangverhälttris noch ein Verbindungswort noch sonst einen ausgelassenen Redeteil bezeichnet, sondern er ist als selbständiger Satz eine Anrede an den Gott und eine Begrüßßung, die zugleich mit

\footnotetext{
${ }^{56}$ RoHDICH 1879 hielt deshalb Plutarch für den unmittelbaren Vorgänger cer Theologie des Maximas.

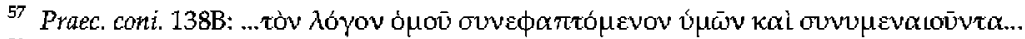

${ }^{58} \mathrm{De}$ Is. 1, 351C-D. Die Rede vom Gebet klingt hier insgesamt doch recht abstrakt, und man mag sich fragen, von welchen Göttern Plutarch eigentlich redet.

${ }^{59} \mathrm{Vgl}$. De Is. 78, 382E-383A. Das ist Plutarchs Erklärung dafür, dass der ägyptische Totengott Osiris, den er als den göttlichen $\lambda$ óyos interpretiert, zugleich als der höchste, lebenspendende Gott zu betrachten ist.

${ }^{60}$ Freilich kann man trefflich darüber streiten, ob man das hier Gesagte überhatupt unter "Gebet" einordnen möchte. Wenn man aber das Gebet als eine Zwiesprache mit Gott definiert, die hier sogar im heiligen Bezirk verortet ist, dann lässt sich diese Zuordnung zweifelsohne rechtfertigen.
} 
dem gebrauchten Wort dem, der es atsspricht, die Macht des Gottes zum Bewußtsein bringt. Denn der Gott ruft jedem von uns, die wir hier herkommen, gleichsam als GruB das "Erkentue dich selbst." entgegen, das doch gewiß nicht weniger ist als das tibliche Grußwort "Sei froh!", und wir wiederum sprechen, dem Gott antwortend, "Du bist!", wornit wir ihm das wahre, nicht irrende, ihm allein zukommende Prädikat, das des Seins, als Anrede widmen. ${ }^{61}$

Wenn R. Feldmeier schreibt, in den biblischen Schriften gelte "als essentielle Voraussetzung für die Kommunikation mit Gott die Unterscheidung von diesem", ${ }^{62}$ dann lässt sich derselbe Gedanke in der Logik dieser Gottesanrede in der Ammonios-Rede bei Plutarch wiedererkennen. Indem der Mensch mit der Anrede „Du bist" Gott als den einzig Seienden anspricht, erkennt er zugleich an, dass er als körperliches Wesen keinerlei Anteil am wahren Sein hat; ${ }^{63}$ daraus entsteht der Impuls, sich angesichts der eigenen Todverfallenheit zu Gott als dem Sein und Leben in Beziehung zu setzen. Mit dieser Interpretation der Gebetsanrede steht der platonische Priester aus Delphi, der ca. zwei Generationen vor Maximos gelebt hat, in manchem der biblischen Tradition näher als den Gedanken seiner paganen Zeitgenossen.

Eine eigene Schrift über das Gebet gibt es von Plutarch, der die religiöse Tradition insgesamt als Grundlegung der philosophischen Wahrheits-

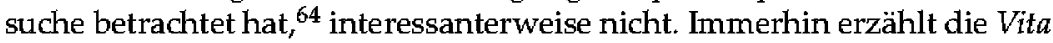
des Numa, die eine Aitiologie einer Reihe religiöser Gesetze und Gebräuche enthält, in einem eigenen Gebetskapitel (14) von der Gesetzgebung Numas bezüglich des Gebets als eines selbstverständlichen Teiles der Frömmigkeit. Thematisiert wird nicht der Inhalt der Gebete, sondern die Haltung, in der sie gesprochen werden. Auch in den Quaest. Rom. 10, 266C-D und anderswo diskutiert Plutarch ganz selbstverständlich Gebetshaltungen und Gebetsinhalte. Als eigenes theologisches Problem scheint sich ihm das Gebet indes, im Unterschied zu Maximos, nicht gestellt zu haben.

\section{Schlussgedanken}

Vergleicht man die Darlegung des Maximos zum Gebet mit anderen religiös inspirierten Überlegungen zum Thema, so zeigen sich signifikante Unterschiede nicht nur zur jüdischen und christlichen Gebetspraxis und dem entsprechenden Gottesbild, sondern auch zu den platonischen Posi-

${ }^{61}$ De E 17, 392A (Übers. Ziegler); vgl. 393B. Dies ist die abschließende Detutung des Zeichens durch Plutarchs philosophischen Lehrer Ammonios. Wenn sie attch die übrigen innerhalb des Dialogs vorgetragenen Deutungen nicht einfach obsolet macht, dürfen wir sie durchaus als theologisches Statement des Verfassers verstehen.

${ }^{62}$ FBLDMBIBR 2016, 71.

${ }^{63}$ Diese Überzeugung wird am Ende der Schrift mit stark dualistischen Tönen gewissermaßen im Sinne einer dialektischen Theologie ausformuliert (393F-394C).

${ }^{64}$ Hirsch-Lutrold 2013. 
tionen Plutarchs. Ihnen gegenüber erweist sich Maximos - wiewohl seine Theorie des Gebets deutliche Anklänge an platonische Aussagen zeigt in ihren theologischen Voraussetzungen als deutlich stoisch beeinflusst. Die geforderte Gebetshaltung erinnert an Epiktet oder auch Seneca (,gib mir, was mir zusteht"), entsprechend einer Gottesvorstellung, derzufolge das als Vorsehung gedachte Göttliche das Gute bereits vorherbestimmt. Das Gebet erscheint dementsprechend mehr als Kontemplation denn als Gespräch (oder allenfalls als Selbstgespräch) und führt den Weg aus der Selbstgenügsamkeit heraus zum Glück.

Wie bei Maximos zielt die Gebetsparänese des Lukas neben der Frömmigkeitspraxis auf den Gottesbegriff. Sie will der Vorstellung eines Gottes, der in das Prokrustesbett seiner eigenen Unveränderlichkeit gezwängt ist, die Vorstellung eines liebenden Vaters gegenüberstellen, der sich den Bedürftigen zuwendet. Gegenüber dem in seiner Umwelt so präsenten stoischen Gottesverständnis, das ein Bittgebet obsolet macht, sucht Lukas Gott über seine Gleichnisse als einen echten Gesprächspartner zu etablieren, der den Argumenten und Nöten des Menschen gegenüber aufgeschlossen ist, auch wenn seine Reaktion dem Menschen nicht immer erkennbar und verständlich sein mag. Während die a-minore-ad-maius-Argumentation des Lukas derjenigen des Maximos nicht unähnlich ist, batıt seine Korrektur der Gebetspraxis auf einer skeptischen Kritik menschlicher Erkenntnisfähigkeit im Blick auf das Göttliche auf, die eher derjenigen Plutarchs in seiner Schrift Über die späten Strafen der Gothheit ähnelt: der Einsicht nämlich, dass man - im Gegensatz zu dem positivistischen Gottesbild mancher philosophischer Denker, die aus einer philosophischen Gottesidee Folgerungen für die religiöse Praxis ableiten zu können meinen - keinerlei sichere Aussagen über das Wesen Gottes treffen kann. Aus der Unmöglichkeit, stringent-logische Aussagen über das Göttliche zu treffen, folgt im einen Fall, bei Plutarch, in der Diskussion der Frage, wieso manche Übeltäter ungestraft ein gutes Leben zu führen scheinen, die Forderung, alle Geschehnisse in der Welt unter der Voraussetzung der göttlichen Gerechtigkeit zu interpretieren, anstatt umgekehrt das Göttliche aufgrund der vermeintlichen eigenen Kenntnis zu tadeln. Im anderen Fall, bei Lukas, wird das Gebetshandeln legitimiert durch die - aus der Analogie gewonnene - Überzeugung, dass doch das Göttliche in jedem Fall nicht weniger Verantwortungsgefühl gegenüber einem Bittsteller zeigen wird als ein Mensch in der entsprechenden Situation. Definitorisch wird bei Lukas wie bei Plutarch eine göttliche Eigenschaft vorausgesetzt, nämlich die göttliche Güte; alles Andere ergibt sich unter dieser Voraussetzung in einem Schluss $a$ minore ad maius.

Bei Plutarch wie bei Lukas und auch im hellenistisch-jüdischen Roman Joseph und Aseneth ist die Gottesbeziehung durch eine beiderseitige Kommunikation gekennzeichnet, die auf der Vorstellung eines stärker personal 
gedachten Gottes beruht. Andererseits ist die ontologische Komponente, die das göttliche Sein der sterblichen Existenz des Menschen gegenüberstellt und deshalb das Heil in der Angleichung des Menschen an Gott erblickt, der ethischen Komponente vorgeordnet. Allen aber, Lukas wie Maximos und Plutarch, geht es bei der Diskussion des Gebets nicht nur um Lebenskunst oder praxis pietatis, sondern sie diskutieren anhand von Problemen gelebter Religiosität den dahinterstehenden Gottesbegriff. 


\title{
Beten als Akt der Freiheit. Zu den philosophischen Aspekten der Gebetsschrift des Origenes
}

\author{
Alfons Fürst
}

In menoriam Thomas Pröpper. der in seiner Anthropologie und Theologie der Freiheit die Freundschaft mit Gott zur Bestimmung des Menschen erhoben hat

\section{Philosophie des Betens}

Ist beten sinnvoll? Über diese Frage ist in der Antike intensiv diskutiert worden. Überraschen mag an dieser Debatte, dass diese Frage, die so überaus christlich anmutet, keineswegs erst von den christlichen Theologen gestellt wurde, sondern schon bei den paganen Philosophen Thema war. Von Platon an wurde darüber nachgedacht, ob Beten möglich und sinnvoll sei und welche Haltung des Beters erforderlich, welcher Inhalt des Gebets philosophisch akzeptabel sei. ${ }^{1}$ In der Römischen Kaiserzeit und in der Spätantike gewann diese Diskussion noch an Intensität, jedenfalls sind aus diesen Jahrhunderten etliche Zeugnisse dafür erhalten. ${ }^{2}$ Dies dürfte mit einer generellen Entwicklung in der Geisteswelt dieser Epoche zusam-

\footnotetext{
${ }^{1}$ Vorzüglich dazu ist der Aufsatz von DiHLb 1999, eine gute Übersicht bietet voN SEvbRus 1972, 1145-1152.

${ }^{2}$ Neben der Dissertatio des Maximos von Tyros über das Beten ist als ganz dieser Thematik gewidmeter Traktat der psettdo-platonische Zweite Alkibiades erhalten (138a-151c in der Stephanus-Ausgabe), der wohl in die hellenistische Zeit gehört (Übersetzung: O. ApblT, PhB 172b [Leipzig 1922]). Zu dieser Thematik gehört auch - darauf hat Simone Seibert die Teilnehmer des Kolloquiums in Göttingen zu diesem SAPERE-Band aufmerksam gemacht - die bislang in der Forschung in diesem Zusammenhang noch nicht beachtete zehnte Satire Juvenals, in der die Schwierigkeiten rechten und falschen Wünschens und Betens satirisch erörtert werden (Übersetzung: W. PLANKL, Juvenal Satiren [München 1958]). Nur ein Fragment gibt es von Aristoteles' Jugendschrift Пegl củx $\bar{\eta} \varsigma$, in dem lediglich seine Auffassung zitiert wird, "dass Gott entweder Geist (voūc) oder etwas jenseits des Geistes ist" ( $f$. 49 Rose $=$ S. 57 Ross), desgleichen eines mit rein linguistischem Inhalt von Favorinus' Пzè̀

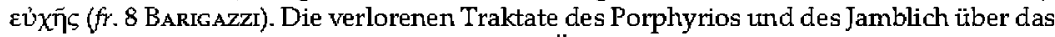
Gebet sind zusammengefasst und um eigene Überlegungen ergänzt bei Proklos, In Tim. Plat. II (I 207,21-214,12 DirHL).
} 
menhängen: Philosophie und Religion, die in der "philosophischen Religion" der Antike seit jeher untrennbar verbunden waren, ${ }^{3}$ rückten noch enger zusammen. Einerseits wurden religiöse Traditionen zunehmend als Ressource für die philosophische Suche nach Wahrheit aufgewertet, andererseits verstanden sich die Philosophen als religiöse Menschen und legten ein entsprechendes Verhalten bis hinein in die persönliche Lebensführung an den Tag. Dazu gehörte auch das Beten.

In diesem Kontext steht die Gebetsschrift des Origenes. ${ }^{4}$ Mit seinem Traktat Über das Gebet (Пعei $\varepsilon \dot{\chi} \times \bar{\eta} \varsigma$ ) schrieb Origenes zwischen 233 und 235 nicht nur umfangreiche Erläuterungen zum christlichen Beten, sondern erbrachte nicht zuletzt einen fundamentalen philosophischen Beitrag zur Frage nach Sinn und Unsinn des Betens. Im engeren Sinne steht seine Schrift natürlich in einem spezifisch christlichen Kontext, vor allem weil ihr zweiter Hauptteil (Orat. 18-30) eine Auslegung des Vaterunsers enthält. Das ist charakteristisch für antike christliche Schriften über das Gebet. Sind schon die einzelnen Gedanken seiner Vaterunser-Exegese philosophisch gefärbt, so gilt dies noch mehr für den ersten Hauptteil (Orat. 1-17). In diesem geht Origenes auf Einwände gegen das Beten ein und denkt ausführlich über die Möglichkeit des Betens überhaupt sowie über Voraussetzungen und Bedingungen für ein sinnvolles Gebet nach. Besonders damit lässt sein Traktat sich philosophiegeschichtlich verorten. In diesem Kontext verteidigt Origenes nämlich das Beten als Akt der Freiheit. Mit seinen philosophisch-theologischen Reflexionen liefert er aus der Perspektive der von ihm begründeten Freiheitsmetaphysik einen grundlegenden Beitrag zur antiken philosophischen Debatte über das Beten.

Die philosophischen Aspekte der Ausführungen des Origenes über Möglichkeit und Sinn des Betens werden in der - nicht sehr umfangreichen ${ }^{5}$ - Forschung zu seiner Gebetsschrift zwar manchmal berücksichtigt,

\footnotetext{
${ }^{3}$ Unter diesen Begriff stellt HALFWAssBN 2015 seine vorzüglichen Ausführungen dazu. Siehe auch Th. Konusch / M. ErLer (Hg.), Metaphysik und Religion. Zur Signatur des spätantiken Denkens. BzA 160 (München / Leipzig 2002); HrRsch-LutPold / GörgBManNs / von Albrecht 2009.

${ }^{4}$ Die kritische Edition von P. KobTschau, Origenes Werke. Zweiter Band: Buch V-VIII Gegen Celsus. Die Schrift von Gebet, GCS 3 (Leipzig 1899) 297-403 ist abgedruckt und mit deutscher Übersetzung versehen in voN STRITZKY 2014, 95-285; aus der letzten Ausgabe wird im Folgenden zitiert (zum Teil leicht modifiziert).

${ }^{5}$ Die erste Monographie dazu, die Pariser Thèse von GeNET 1903, bietet im Hattptteil (9-52) kaum mehr als einen paraphrasierenden Durchgang durch diese Schrift, ergänzt um Hinweise auf analoge Stellen in anderen Werken des Origenes (bes. aus Contra Celsum). Unpubliziert und mir nicht zugänglich ist die Turiner Dissertation von N. ANTon Iono, $l l$ „De oratione di Origene (1955/1956), die GessвL 1975, 9 als "unzulänglich“ beurteilt. Die ers-

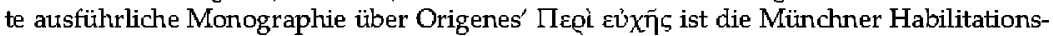
schrift von Grssbu 1975, in der verschiedene Aspekte eingehend erörtert werden. Auf die Vaterunser-Auslegung in der vorkonstantinischen christlichen Literatur ist der profunde Beitrag in der Münsteraner Dissertation von von STrITzky 1989, 70-180 fokussiert. Die neu-
} 
und zu deren Interpretation werden teilweise auch die antiken philosophischen Debatten über das Beten herangezogen. ${ }^{6}$ Der Traktat des Origenes wird seinerseits aber nicht als Teil dieser Debatte interpretiert und in den Kontext dieses nicht nur christlichen, sondern gemeinantiken Diskurses gestellt. ${ }^{7}$ Und selbst wo dieser intensiver herangezogen wird, um zumindest manche Ausführungen des Origenes zu profilieren, leidet die Darstellung meist an einer falschen Frontstellung zwischen der christlichen "Glaubenssubstanz" und der Philosophie und an einer simplifizierenden Unterscheidung zwischen der philosophischen Terminologie, die Origenes übernehme, und dem Inhalt, den er ablehne, weil der christliche Heilsweg angeblich "in diametralem Gegensatz zur späthellenistischen Philosophie steht ${ }^{\prime \prime} .8$ Die Zusammenhänge sind einerseits komplexer, insofern das Denken des Origenes formal und sachlich ebenso biblisch wie philosophisch grundiert ist und er sowohl aus biblischen Ressourcen philosophische Fragen traktiert als auch die Bibel im philosophischen Horizont seiner Zeit deutet; pagane, jüdische und christliche Autoren der frühen Kaiserzeit teilen die methodische Ansicht, dass sich religiöse Traditionen und platonische Philosophie gegenseitig interpretieren lassen. Daher sind die Zusammenhänge andererseits einfacher, insofern philosophische und

erliche Dissertation in Marburg von CHANG 2010 ist hingegen eine weitgehend oberflächliche Reproduktion der voratsgegangenen Arbeiten ohne neue Erkenntrisse. Schwung gewann die Erforschung dieses Textes dadurch, dass ihr auf der zweiten "Origeniana“Tagung 1977 in Bari eine eigene Sektion gewidmet wurde, was sich in einigen kleineren Aufsätzen im Tagungsband niedergeschlagen hat: Crouzbl / Quacquarrler 1980, 79-129. Die italienische Forschergruppe über "Origene e la Tradizione Alessandrina" hat sich dieses Themas dann auf einem Treffen 1996 in Chieti angenommen und einen Sammelband mit mehreren Beiträgen publiziert: Cocchins 1997. Die Ergebnisse der vielen Aufsätze, die

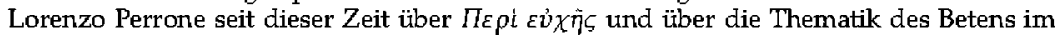
gesamten Schrifttum des Origenes verfasst hat, sind schließlich in eine umfangreiche $\mathrm{Mo}-$ nographie eingeflossen: Perrone 2011a. In einem Forschungsüberblick zeichnet L. PrRro$\mathrm{NE}_{s}$, Origenes' Rede vom Gebet zwischen Frömmigkeit und Theologie. Zur Rezeption von

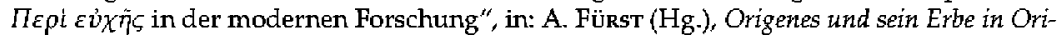
ent und Okzident. Adamantiana 1 (Münster 2011) 101-127 die verschiedenen Perspektiven nach, aus denen diese Schrift des Origenes im 20. Jahrhundert interpretiert worden ist (auf Italienisch zu finden in PBrRone 2011a, 27-50).

${ }^{6}$ So bei von Stritzky 1989, 71-104; Chang 2010, 37-58; PERrone 2011a, 79-90.

${ }^{7}$ Gessel 1975 und PBrRone 2011a erörtern die Schrift lediglich im Rahmen des binnenchristlichen Diskurses. Das gilt auch für VöLKER 1931, 197-215, auch wenn er das Gebet bei Origenes zu Recht im Kontext seiner Spiritualität interpretiert, es dabei aber zu stark vom "philosophischen Element" (ebda. 199) absetzt. Die folgenden Ausführungen werden erweisen, dass die Ansicht von von Sevbrus 1972, 1236, dass "sich in De oratione eine unmittelbare Auseinandersetzung oder ein Einfluss antiker Gebetstheorien nicht nachwei$\operatorname{sen}^{\prime \prime}$ lasse, falsch ist.

${ }^{8}$ So von STR ITZKY 1989, 4; diese falschen Gegensätze auch ebda. 94f. 103f. 106f. 111. 126. 135. 138. 153 156. 160. 163.177. 179; besonders krasse falsche Oppositionen ebda. $130 \mathrm{f} .132$. 134f. (nur 143 ist diese Kontrastierung richtig, wo die Heiligkeit Gottes in der Geschichte tatsächlich im Gegensatz zur Philosophie steht). Im selben Sinne Grssel 1975, 250. 
biblisch-christliche Grundeinsichten über das Sein des Menschen im Ganzen der Welt in einigen wesentlichen Punkten übereinkommen. Das christliche Denken des Origenes ist nur als Teil des antiken philosophischen Diskurses zu begreifen, nicht als Gegensatz zu ihm. An seinen Überlegungen zum Sinn des Betens lässt sich dieses Amalgam paradigmatisch verdeutlichen.

Die angesprochenen Lücken und Mängel in der Forschung zu Пe९i $\varepsilon \dot{v} \chi \bar{\eta} \varsigma$ hängen nicht zuletzt damit zusammen, dass Wert und Bedeutung der Theologie des Origenes für das philosophische Denken in der Origenesforschung der letzten Jahrzehnte kaum eine Rolle gespielt haben und nur vereinzelt überhaupt wahrgenommen worden sind. Origenes wurde nicht als Philosoph betrachtet und seine Theologie nicht als Teil und Frucht der antiken Philosophie. Erst seit einiger Zeit rückt diese Bedeutung des alexandrinischen Intellektuellen Origenes stärker in den Fokus. ${ }^{9}$ Natürlich soll damit nicht in Abrede gestellt werden, dass die Theologie des Origenes im gleichen Maße Teil und Frucht der biblischen Überlieferung und der sich bildenden christlichen Tradition ist. Seine Leistung für die christliche Theologie kommt aber nicht in den Blick, wenn man diese nicht als Teil des philosophischen Diskurses seiner Zeit begreift. Aus einer solchen Perspektive fällt netues Licht auf seine bemerkenswerte Gebetsschrift, mit der er nicht nur in der christlichen Gebetsliteratur den Rahmen des Üblichen überschreitet, sondern auch einen ausgesprochen originellen Beitrag zur antiken philosophisch-theologischen Debatte über das Gebet erbringt.

\section{Ist Beten möglich?}

Origenes eröffnet seinen Gebetstraktat mit der alten Frage, ob Beten ẗberhatupt möglich sei (Orat. 1f.). In der Antike wurde diese Frage in der Form gestellt, "wie der Beter den Gott, zu dem er betet, auch kennen und seinen richtigen Namen wissen könne", und "mit dem gleichfalls alten Motiv zu beantworten" versucht, "dass die Götter selbst die Menschen das rechte und erfolgreiche Beten gelehrt haben" ${ }^{10}$ Weil die Menschen das nicht von sich aus können, forderte der Platoniker Numenios, ein älterer Zeitgenosse des Origenes, "dass dem eigentlichen Gebet die Anrufung Gottes mit der Bitte um Offenbarung vorausgehen solle" (vgl. fr. 11 des Places). ${ }^{11}$

\footnotetext{
${ }^{9}$ Die bahubrechenden Aufsätze hierzu waren H. Holz, „Über den Begriff des Willens und der Freiheit bei Origenes", Neue Zeitschrift für systematische Theologie 12 (1970) 63-84, und Th. KoBusch, „Die philosophische Bedeutung des Kirchenvaters Origenes. Zur christlichen Kritik an der Einseitigkeit der griechischen Wesensphilosophie", Theologische Quartalschrift 165 (1985) 94-105. Eine Zusammenschau aller hierfür wesentlichen Aspekte im Denken des Origenes bietet FürsT 2014, 507-565.

${ }^{10}$ Dhrle 1999, 36.

${ }^{11}$ Ebda. Zu Numenios vgl. den Beitrag von Franco Ferrari, S. 83 in diesem Band.
} 
Origenes sieht den Grund für dieses Unvermögen des Menschen ontologisch in der Größe und Erhabenheit der Weisheit Gottes, die "tunsere vergängliche Natur unendlich übertrifft", weshalb es nur "durch die überbordende Gnade Gottes möglich" wird, "durch Jesus Christus" "unter Mitwirkung des Geistes" "das Himmlische zu ergründen (vgl. Weish 9,16)" (Orat. 1). ${ }^{12}$ Durch Gnade und im Geist Gottes wird das Unmögliche, nämlich die Gotteserkennntis, für den Menschen möglich. Zu den Dingen, zu denen der Mensch aufgrund dieser "Schwäche" und Begrenztheit seiner natürlichen Konstitution ${ }^{13}$ nicht in der Lage ist, zählt für Origenes „auch eine genatue und Gott angemessene Abhandlung über das Gebet" (Orat. 2,1). Im Rahmen des Proömiums zu seiner Gebetsschrift kleidet Origenes diesen Gedanken vordergründig in den gemeinantiken Topos, als Autor, "der sich keineswegs herausnimmt, das Gebet zu begreifen", die eigene Unzulänglichkeit gegenüber dem zu behandelnden Gegenstand zu betet1ern und daher darum zu beten, „vor der Erörterung des Gebetes den Geist zu erlangen, damit uns eine vollständige und geistgemäße Darstellung geschenkt wird und wir die in den Evangelien aufgeschriebenen Gebete verstehen lernen" (Orat. 2,6; vgl. auch den Schluss, in dem Origenes die Unzulänglichkeit seiner Abhandlung ernetut hervorhebt: Orat. 34). Ähnliche Äußerungen begegnen vielfach in seinen Werken, so wenn er im Vorwort zum Johanneskommentar Gott anruft und bittet, ihm durch Christus im Heiligen Geist zu helfen, den verborgenen Sinn in den Worten des Evangeliums aufzudecken (In loh. comm. I 15,89) ${ }^{14}$ Weit über diesen durchaus ernst gemeinten Topos hinausgreifend, fängt Origenes seine Überlegun-

\footnotetext{
${ }^{12}$ É. Junod, "L'impossible et le possible. Étude de la déclaration préliminaire du De oratione $e^{\prime \prime}$, in: Crouzbl / QuACQuarelli 1980, 81-93 arbeitet diesen Gedarken als Grundzug der Theologie des Origenes heraus, beschränkt sich in seiner Analyse von Orat. 1-2,1 allerdings weitgehend auf literarische Aspekte. VoN STRITZKY 1989, 105-111 hingegen erläutert zutreffend den philosophischen Hintergrund der Einleitung in die Gebetsschrift: Es geht um die Möglichkeit der Gotteserkennttris angesichts der gerade im Platonismus betonten Transzendenz Gottes und damit um ein erkenntnistheoretisches und hermeneutisches Problem. Doch abgesehen von der falschen Front, die sie dabei zwischen Philosophie und Christentum aufmacht (ebda. 106f. 111), verknüpft sie diese Thematiknicht mit der spezifischen Frage, auf die hin Origenes sie hier anspricht, nämlich die nach der grundsätzlichen Möglichkeit des Betens angesichts der Schwierigkeit der Gotteserkenntnis.

${ }^{13}$ Auf die Schwäche als Kennzeichen des Menschen kommt Origenes in der Gebetsschrift öfter zu sprechen: Orat. 2,4; 11,2; 15,2; 29,18.19; vgl. Perrone 2011a, 62-66. - Andernorts, nämlich In Rom. comm. X 15,2, führt Origenes die Bedrohung des Gebets auf die Dämonen zurück, unter deren Einfluss der Mensch ständig zu leiden hat, wie er in Princ. III 2f. ausführlich erläutert. Siehe dazu Prrrone 2011b, 158f. $163 f$.

${ }_{14}$ Ähnliche Gebete begegnen in den Vorreden zu anderen Büchem: In Ioh. comm. VI 2,10; XX1,1; XXVIII 1,6; XXXII 1,2; vgl. auch Cels. IV 1; V 1; VII 1; VIII 1. Siehe dazu L. Perrone, ,I discorso protrettico di Origene sulla preghiera. Introduzione al $\Pi \varepsilon \rho i \varepsilon \dot{v} \chi \dot{\eta} \zeta^{\prime \prime}$, in: CocchINI 1997 [7-32] 7-11; Ders. 2001, 2-6. 17f. Für solche Gebete in den Predigten siehe D. ShBBRIN, "The role of prayer in Origen's homilies", in: Ch. Kannengresser / W. L. Petersen (Hg.), Origen of Alexandria. His world and his legacy (Notre Dame 1988) 200-214.
} 
gen in der Gebetsschrift aber mit dem Eingeständnis an, mit Paulus, der "sah, wie weit er trotz aller Kenntnisse von der Einsicht, was man in rechter Weise beten muss, entfernt war" (Orat. 2,3), zu bekennen, "nicht $\mathrm{zu}$ wissen, wie man beten soll'; denn was wir , in rechter Weise beten sollen', sagt er, ,wissen wir nicht' (Röm 8,26)" (Orat. 2,1; vgl. 2,3). Sowohl die rechten "Worte des Gebets" als auch "die rechte Weise", d.h. der "Zustand des Betenden", sind dem Menschen, so Origenes, von sich aus nicht bekannt (Orat. 2,2). Darin besteht "das Problem des Gebets" (Orat. 18,1; 31,1; 34; vgl. 2,6). ${ }^{15}$

Obgleich Origenes diese Ausführungen rein biblisch fundiert und formuliert (vgl. die vielen in Orat. 2,2 zitierten Bibelstellen), steht er damit doch in einer langen antiken Tradition. Aus der Erfahrung, dass Gebete auch wirkungslos bleiben können - "die Götter", heißt es später im Zweiten Alkibiades, "gewähren von dem, worum wir sie bitten, einiges, anderes

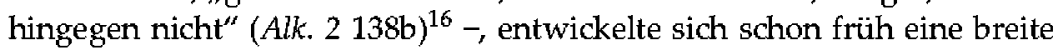
Reflexion über die rechte Einstellung des Beters, über kultische und sittliche Voratussetzungen, die für den potentiellen Erfolg eines Gebets gegeben sein müssen, sowie über die richtigen Inhalte eines Gebets. Man darf von den Göttern nichts Unsittliches erbitten, wie aus einer Geschichte bei Herodot hervorgeht (Hdt. VI 86). ${ }^{17}$ "Die philosophische Reflexion auf das Gebet setzt mit der Kritik an der konventionellen Gebetspraxis ein, weil diese sich auf irrige Anschatungen vom Wesen und Wirken der Gottheit stützt. ${ }^{\text {18 }}$ So polemisierte Heraklit gegen die Menschen, die zu den Götterbildern beten, "ohne von Göttern und Heroen zu wissen, wer sie sind“ (DK 22 B 5) eine Kritik, die der Platoniker Kelsos im 2. Jh. n. Chr. referierte (vgl. Origenes, Cels. VII 62). ${ }^{19}$ Platon äußerte sich ebenfalls kritisch zur traditionellen Frömmigkeit als "Handelsgeschäft", in dem Beten "das rechte Bitten" darum sei, wessen der Mensch von den Göttern bedürfe, und Opfern „das rechte Geben" dessen, wessen die Götter bedürften (Euthyphr. 14d-e), da "man Verhaltensweisen des zwischenmenschlichen Verkehrs nicht auf das

${ }^{15}$ É. Junon, "La construction du Peri Euchès d'Origène et le "problème da la prière" , itr: G. Heinl / R. Somos (Hg.), Origeniana Nona. Origen and the Religious Practice of His Time. BEThL 228 (Leuven u.a. 2009) 429-446, bes. 442-446, lässt dieses „Problem” unnötig kom-

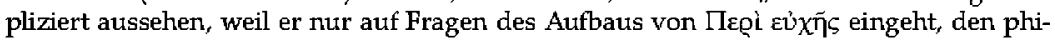
losophischen Kontext dieses Proömiums aber nicht einbezieht. Altch L. Perrone, „La preghiera come ,problema'. Osservazioni sulla forma del $\Pi \varepsilon \rho \dot{\imath} \varepsilon \dot{v} \chi \bar{\eta} \zeta$ di Origene", inv Paideia Cristiana. Studi in onore di Mario Naldini, Rom 1994, 323-334, diskutiert dieses "Problem" rein literarisch im Zusammenhang mit Fragen des Aufbaus der Schrift, ebenso Prrrone 2011a, 51-62. 69-77.

${ }^{16}$ Zum Alkibiades 2 siehe die Einführung, S. 7-8, Anm. 52 zur Übers. sowie die Beiträge von Franco Ferrari, S. 81 und Rainer Hirsch-Luipold, S. 96 Anm. 16 in diesem Band.

${ }^{17}$ Vgl. von SEvBrus 1972, 1138f.

18 Ebda. 1145.

${ }^{19}$ Der wörtlich zitierte Teil dieses Heraklit-Fragments ist nur durch dieses Kelsos-Zitat bei Origenes überliefert. 
Verhältnis zur Gottheit übertragen dürfe". ${ }^{20}$ Im pseudo-platonischen Zweiten Alkibiades wird das Beten um falsche Güter aufgrund irriger Annahmen scharf kritisiert (Alk. 2 141a-143b), wenn Menschen „in ihren Handlungen und Gebeten nicht das wirklich Heilsame erstrebten, sondern was ihnen als heilsam erschien" (Alk. 2 142e). Der anonyme Verfasser legt daher Alkibiades die Einsicht in den Mund: "In der Tat muss man sehr behutsam sein, wenn man nicht ahnungslos sich selbst Unheil erflehen will in dem Glatuben, es sei etwas Gutes" (Alk. 2 148b), was Sokrates bestätigt: "Es bedarf großer Behutsamkeit und Überlegung, was man von den Göttern erbitten muss und was nicht" (Alk. $2149 \mathrm{c}$ ); "es ist nicht ungefährlich, sich dem Gotte mit Gebet zu nahen" (Alk. 2 150c). Maximos von Tyros eröffnete seinen Gebetslogos mit exempla aus der klassischen Literatur Griechenlands (Midas, Kroisos, Priamos, Chryses) für törichte Gebete um unsinnige oder unheilvolle Dinge (or. 5,1f.) und folgerte daratus die Unsinnigkeit des Bittgebets: „Ist das Göttliche etwa verfressen und bestechlich, ist es also nicht besser als die meisten Menschen?" (or. 5,3). Im Zweiten Alkibiades heißt es ähnlich, "es ist nicht die Art der Götter, sich durch Geschenke umstimmen zu lassen wie ein elender Wucherer" (Alk. $2149 \mathrm{e}$ ). Entschieden in diesem Sinne hatte sich bereits Platon geäußert (Rep. II 364d; Leg. $X$ 905d-907b). Die entscheidende Größe ist vielmehr , unsere Frömmigkeit und Gerechtigkeit" (Alk. 2 149e), für Maximos die Würdigkeit des Menschen: Wer würdig ist, erhält von den Göttern, was er verdient, auch wenn er nicht darum betet; dem Unwürdigen aber hilft sein Beten nichts (or. 5,3). Maximos erklärt nicht näher, was er unter dieser Würdigkeit versteht. Im Kontext der skizzierten antiken Debatte dürfte, würdig' sein, wer mit der rechten inneren Einstellung um das Rechte betet - und gerade ein solcher Mensch braucht laut Maximos nicht zu beten.

Origenes zog nicht die Konsequenz, atfgrund solcher Schwierigkeiten in der Gebetspraxis das Beten für unmöglich und unsinnig zu erklären, sondern suchte nach Auswegen aus der Aporie, etwas dem Menschen eigentlich Unmögliches wie das rechte Beten doch zu praktizieren. Zum einen verschafft der "Geist" ( $\pi \nu \varepsilon \bar{v} \mu \alpha$ ) Abhilfe, der im Menschen betet und "rmit wortlosen Seufzern für uns bei Gott eintritt" (Röm 8,26), indem er unsere Seufzer wegen seiner großen Menschenliebe und seines Mitleids atuf sich nimmt" (Orat. 2,3; vgl. 14,5). Hier geht es nicht um törichte Bitten um banale Dinge, sondern um den "Seufzer" des Menschen, den non-verbalen Ausdruck "des in ihm vorhandenen Mangels" (Orat. 2,3). In diesem Gestus wendet sich der Mensch an Gott. Zu diesem Urakt des Betens fragt Origenes nach der Möglichkeit, wie solches "Seufzen“ zu Gott gelangen kann, wo dieser doch "unsere vergängliche Natur unendlich übertrifft" (Orat. 1), und verweist dazu auf die "wortlosen Seufzer" aus dem Römerbrief des

\footnotetext{
${ }^{20}$ Dihle 1999, 25.
} 
Paulus, "die unsagbare Worte enthalten, die ein Mensch nicht aussprechen darf' (2 Kor 12,4)" (Orat. 2,3). Auch die neuplatonische Philosophie kannte solche "unsagbaren Worte" (vgl. Porphyrios, ep. ad Aneb. bei Eusebios, Praep. ev. V 10,8, dazu Jamblich, Myst. VII 4f.), "die dem Menschen in die Seele gelegt wurden. Ihr Aussprechen vereint den Beter, der sich im Bewusstsein seiner Niedrigkeit nach dieser Vereinigung sehnt, mit der angebeteten Gottheit" (vgl. Jamblich, Myst. I 15; V 240; Proklos, In Tim. Plat. II [I 211,1-4 Diehl]). ${ }^{21}$ Origenes dachte allerdings nicht wie die genannten Neuplatoniker an ein magisch-theurgisches Aussprechen solcher Worte. Er konzipierte mit dem "Geist" ( $\pi v \varepsilon v \tilde{\mu} \alpha$ ) - eine biblische Größe ohne Parallele in der Philosophie - eine Vermittlungsinstanz zwischen dem kreatürlichen irdischen Menschen, dessen non-verbales Beten sich in einem gesprochenen oder gedachten Laut verdichtet, und dem transzendenten Gott, für den das im Laut des Menschen, im Seufzer, Enthaltene in für Menschen "unsagbare Worte" transferiert wird, so dass durch diese Vermittlungsaktion des "Geistes" die Kluft zwischen dem Schöpfer und dem Geschöpf überwunden wird. ${ }^{22}$ Umgekehrt ist es der "Geist", der dem Verstand des Menschen die rechte Weise des Betens eingibt, "denn unser Verstand kann nicht beten, wenn nicht vor ihm der Geist gleichsam in Hörweite von ihm gebetet hat" (Orat. 2,4; vgl. Cels. VII 44). ${ }^{23}$ Ohne diese Gedanken in der Einleitung ztu seiner Gebetsschrift näher auszuführen, offeriert Origenes mit dem "Geist", der „bei Gott für uns eintritt" (Orat. 2,3), eine Überlegung, wie etwas dem Menschen Unmögliches wie das Beten zu Gott doch möglich werden könnte. ${ }^{24}$

Zum anderen sucht Origenes Hilfe für dieses Problem in der Bibel, wo es seinerseits schon thematisiert wird und wo er, wie vor ihm Klemens von Alexandria (Strom. VI 29,3), Beispiele für richtiges Beten findet (Orat. 2,2). Neben ,solchen Gebeten, die wirklich geistiger Art sind, da sie der

\footnotetext{
${ }^{21}$ Ebda. 36. Vgl. Bendin bler 1997, 47.

${ }^{22}$ Zur Kluft zwischen Menschlichem und Göttlichen vgl, den Beitrag von V. Vitiello in diesem Band.

${ }^{23}$ Auch die Engel, insbesondere die Schutzengel der einzelnen Metıschen, können als Vermittler betrachtet werden, die einerseits mit den Menschen zusammen beten und deren Gebete zu Gott emportragen (Orat. 11,1.3.5; 31,5; vgl. Cels. V 4; VIII 34.36.64), andererseits als "Gehilfen des väterlichen Willens Gottes" (Orat. 11,4) "zum Vermittler der Wohltatwerden für den, der sie braucht" (Orat. 11,5). Siehe dazu Grssbl 1975, 200-204; Perrone 2011b, 162-167. E. Osborn, "The intermediate world in Origen's, On prayer" ${ }^{\prime \prime}$, in: Crouzel / QuacQUARBLLI 1980, 95-103 betont, dass es hierbei um Gotteserkenntnis geht, arbeitet dies aber nicht stringent aus dem Text des Origenes heraus. Zum Gebet als christlichen, gleichwohl aber philosophisch konfigurierten Weg zur Gotteserkenntnis in Cels. VII 44 siehe Perrone 2001, 13-19.

${ }^{24}$ Die Ausführungen von GBssbL 1975, 115-127 zur „Interzession des Geistes“ gehen auf die grundsätzliche Frage nach der ontologischen Möglichkeit des Betens überhaupt nicht ein, sondern beschränken sich auf die ethische Seite des Problems, weshalb er, 118-122,

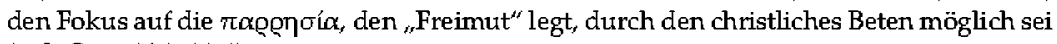
(vgl. Orat. 14,2;22,1).
} 
Geist in den Herzen der Heiligen betet, und die zudem von unaussprechlichen und wunderbaren Lehren erfüllt sind" (Orat. 2,5), etwa dem Gebet der Hanna (vgl. 1 Sam 1f.) und einigen Psalmen (er nennt Ps 17, 90 und 102) - siehe auch die Beispiele für wirksames Beten in der Bibel in Orat. 12f., vor allem die Gebete Jesu (Orat. 13,1; vgl. dazu In Ioh. comm. XXVIII $4,25)^{25}$, dachte Origenes natürlich in erster Linie an das Vaterunser (Orat. 2,4), das im Lukasevangelium als Reaktion auf die Bitte steht: "Herr, lehre uns beten!" (Lk 11,1).

Die antiken christlichen Traktate über das Beten, so gattungsmäßig unterschiedlich sie auch sein mögen, sind jeweils auf das Vaterunser fokussiert. ${ }^{26}$ Das gilt neben Origenes' Gebetsschrift für Tertullians zwischen 200 und 206 entstandene katechetische Unterweisung De oratione (zum Vaterunser: Orat. 2-9) ${ }^{27}$ ebenso wie für die exegetische Abhandlung Cyprians De dominica oratione von $251 / 52$ (besonders Dom. orat. $7-30)^{28}$ und die fünf Homilien Gregors von Nyssa De oratione dominica. ${ }^{29}$ Abgesehen von vielen Bemerkungen zum Vaterunser in der altchristlichen Literatur kann Augustinus' Brief an Proba De orando Deo (ep. 130) von 411/12 als Analogie zum Traktat des Origenes gelten: Wie dieser geht Augustinus von Röm 8,26 aus, wonach der Mensch die rechte Art des Betens von sich aus nicht kennen kann (ep. 130,1), und behandelt die rechte Disposition für das Gebet (ep. $130,2-8$ ) sowie den rechten Inhalt (ep. 130,9-30), wobei das Vaterunser allerdings nur kurz durchgegangen wird (ep. 130,21)..$^{30}$ Die Kristallisierung der christlichen Überlegungen zum Gebet am Vaterunser ist wohl nicht nur binnenchristlich und innerkirchlich damit zu erklären, dass dieses Gebet auf Jesus selbst zurückgeführt wird, eine prägnante Kurzfassung seiner Verkündigung bietet - ein breviarium totius evangelii, wie Tertullian bündig schrieb (Orat. 1,6) - und nicht zuletzt in der Liturgie verwendet wurde. Im weiteren religions- und philosophiegeschichtlichen Umfeld der späteren Antike kann man im Vaterunser und in den Kontexten, in denen es im Matthäus- tund im Lukasevangelium unterschiedlich ausführlich, aber

\footnotetext{
${ }^{25}$ Vgl. dazu Gessel 1975, 216f:; Perrone 2011a, 140-150.

${ }^{26}$ Umfangreiche Textsammlung einschließlich der liturgischen Ordnungets J. X. VIviss, Expositio in orationem dominicam iuxta traditionem patristican et theologicam (Rom 1903); ferner Walther 1914; A. Hamman, Le Pater expligué par les Pères (Paris ${ }^{2}$ 1962). Siehe dazu von Sevgrus 1972, 1234-1248; Chang 2010, 59-132.

${ }^{27}$ Text: G. F. DirRCKs, CCSL I (Turnhout 1954) 255-274; Übersetzung: D. SCHLEYER, FC 76 (Turnhout 2006) 218-279. Vgl. von STRITZKY 1989, 50-69.

${ }^{28}$ Text: C. MoresCHINI, CCSL 3A (Turnhout 1976) 87-113; Übersetzung: J. Bär, BKV $V^{2}$ I 34 (Kempten/München 1918) 161-197.

29 Text: J. F. CALLAHAN, GNO 7/2 (Leiden u.a. 1992) 1-74; Übersetzung: K. WEIss, BKV ${ }^{2}$ I 56 (München 1927) 89-150. Für einen Vergleich zwischen den Vaterunser-Auslegungen des Origenes und Gregors siehe G. LozzA, ,Origene e Gregorio Nisseno esegeti del ,Padre nostro" ", in: Pizzolato / Rizzi 2001, 211-221.

${ }^{30}$ Text: A. Goldbacher, CSEL 44 (Wien / Leipzig 1904) 40-77. Vgl. J. Drvjak / Redaktion, "Epistulae", Augustinus-Lexikon 2 (1996-2002) [893-1057] 973.
} 
im Kern übereinstimmend referiert wird (Mt 6,5-15; Lk 11,1-4), auch die christliche Antwort auf die antike Frage sehen, wie und was man in rechter Weise beten soll. Anders als Origenes gehen die genannten kirchlichen Autoren allerdings nicht auf die antiken philosophischen Traditionen ein, in denen die mit dem Beten zusammenhängenden Fragen erörtert wurden. ${ }^{31}$

Auch die Erklärungen des Origenes zu den Vaterunser-Bitten (Orat. $18-30)^{32}$ sind philosophisch grundiert und von meist platonischen Grundannahmen durchzogen, beispielsweise dass Gott unter Abkehr von der Außenwelt und den Sinneswahrnehmungen im Inneren der Seele zu finden ist, weshalb man laut Mt 6,6 „in der Kammer" und „im Verborgenen" beten soll (Orat. 20,2), oder dass das Gute und das Wahre Eines ist, das Schlechte und die Lüge aber Vieles, weshalb man nach $\mathrm{Mt}$ 6,7 beim Beten nicht "plappern" und nicht „viele Worte machen" soll (Orat. 21,2). Hierher gehören die platonische Dichotomie zwischen Wahrheit und Bild (Orat. $20,2 ; 22,4)$, die Unkörperlichkeit Gottes, um die Gebetsanrede an den Vater „im Himmel" angemessen zu verstehen (Orat. 23; vgl. auch 26 zum Willen Gottes "im Himmel"), ${ }^{33}$ die ethische Unveränderlichkeit Gottes, wie sie im Gottesnamen "der Seiende" in Ex 3,14 zum Ausdruck kommt (Orat. 24,2; vgl. Cels. I 21), die Theorie der Erkenntnis, speziell der Gotteserkenntnis als Anamnesis (Orat. 24,3), ebenso der kontradiktorische Gegensatz zwischen Gut und Böse (Orat. 22,4;25,1.3;26,6;29,13), der einer der ethischen Grundsätze des Origenes ist. ${ }^{34}$ Auch die Überzeugung des Origenes, dass die Seele immer über die Freiheit der Entscheidung verfügt, taucht verschiedentlich in seinen exegetischen Überlegungen auf (Orat. 25,1;26,5; 29,13.15.19; $30,1)$. Der auffälligste philosophische Passus ist die Erklärung des Adjektivs غ̇ंuoúoı́s (Mt 6,11; Lk 11,3). Diese fällt bei Origenes originell ats, weil er die wohl richtige Ableitung von غ̇ $\pi$ ı́val, "bevorstehen", also das Brot "für den nächsten Tag", ausdrücklich als weniger überzetugend ablehnt (Orat. 27,13). Origenes verbindet dieses Wort stattdessen mit oúoi $\alpha$, "Substanz" (Orat. 27,7), und versteht es als "substantielles" Brot im geistigen Sinn (Orat. 27,7-12). Im Zuge dieser Erklärung rekurriert er auf die

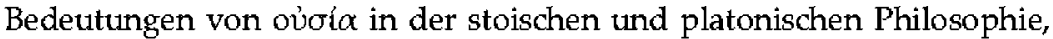
die er katalogartig atus einem vermutlich stoischen Lexikon (des Herophi-

\footnotetext{
${ }^{31}$ Siehe auch die Skizze zu den Unterschieden zwischen den frühen christlichen Gebetsschriften in Bezug auf den Traktat des Origenes bei Perrone 2011a, 15-17.

${ }^{32} \mathrm{Zu}$ diesen siehe WaLtHBR 1914, 4-22; von STrITZKY 1989, 125-180 = von STritzKY 2014, 40-89; Chang 2010, 191-236; Perrone 2011a, 195-239 (in dieses Kapitel ist der Aufsatz eingegangen: L. Perrone, "La "Preghiera del Signore' vita del cristiano. I Padre nostro nell' interpretazione di Origene", Rudiae 13/14 [2001/02] 271-292).

${ }^{33}$ Die Körperlosigkeit Gottes verteidigt Origenes oft und energisch: Princ. I praef. 8; I 1; In Gen. hom. I 13; Cels. III 75; VI 70f.; VIII 49.

${ }^{34} \mathrm{Vgl}$. In Ioh. comm. XX 13,107: "Entweder sündigt man, oder man sündigt nicht, wobei es keinen Zwischenraum zwischen dem Sündigen und dem Nicht-Sündigen gibt."Siehe dazu Fürst 2014, 548f.
} 
los) referiert, ohne sie als solche weiter zu diskutieren (Orat. 27,8). ${ }^{35}$ Die Auslegung des Origenes läuft freilich nicht einfach auf eine Spiritualisierung der Brotbitte hinatus, ${ }^{36}$ obwohl der Akzent darauf gewiss sehr stark ist. Offenbar schwebt ihm eine Art Synthese aus einem materiellen (stoischen) und einem geistigen (platonischen) Verständnis der Substanz des Brotes vor. Diese Erklärung ist im Zusammenhang mit seiner Theorie der geistigen Sinnlichkeit zu interpretieren, in der materielle Sinneseindrücke und -wirkungen eine Analogie auf geistiger Ebene haben. ${ }^{37}$ Diese Hinweise mögen an dieser Stelle genügen, um die philosophische Prägung der Exegese des Origenes auch bei seiner Vaterunser-Auslegung zu demonstrieren, die nur im Zusammenhang mit den philosophischen Traditionen und Konzepten seiner Zeit zu begreifen ist.

Entsprechend verhält es sich mit der rechten Disposition des Beters. Diese gilt, wie aus den oben vorgeführten paganen Zetgnissen hervorgeht, in der Antike von alters her als Voraussetzung für richtiges Beten. Vor allem in der platonischen Tradition wurde der Gedanke geprägt, ,dass derjenige, der sich dem Gott naht, seiner würdig sein muss, d.h. dass der

\footnotetext{
${ }^{35}$ Der Passus ist aufgenommen in SVF II 318. Weiteres hierzu bei Ch. MarksCHIES, „Was bedeutet oủoíx? Zwei Antworten bei Origenes und Ambrosius und deren Bedeutung für ihre Bibelerklärung und Theologie", in: W. GBbrlings / H. König ( $\mathrm{Hg}$.), Origenes - vir ecclesiasticus. Symposion zu Ehren von H. J. Vogt. Her. 9 (Bonn 1995) 59-82, erneut in: Ch. MarkschiBs, Origenes und sein Erbe. Gesammelte Studien. TU 160 (Berlin/ New York 2007) [173-193] 175-187.

${ }^{36}$ So die Deutung von von Stritzky 1989, 154; Perrone 2011a, 221. Zur Geschichte der bei einigen Theologen eher wörtlichen, bei anderen eher spirituellen Auslegung der Brotbitte in der Alten Kirche siehe WaLtHBR 1914, 22-99 und W. DürING, „Die Deutung der Brotbitte des Vaterunsers bei den lateinischen Vätern bis Hieronymus", Liturgisches Jahrbuch 18 (1968) $72-86$.

${ }^{37}$ Vgl. Orat. 27,9: "Wie nämlich das materielle Brot, das der Körper erhält, in die Substanz dessen eingeht, der sich davon ernährt, so teilt auch, das lebendige' und, vom Himmel' herabgekommene ,Brot' (Joh 6,51), das Geist und Seele erhalten, von der ihm eigenen Kraft demjenigen mit, der die von diesem Brot ausgehende Nahrung in sich aufrimmt. Und dies wird das tägliche, substantielle ${ }^{x}$ Brot sein, um das wir bitten. [...] Tägliches, substantielles Brot ist somit das, das der vernünftigen Natur am meisten entspricht und der Strbstanz selbst verwandt ist. Es vermittelt der Seele gleichzeitig Gesundheit, eine gute Kondition und Stärke, und dem, der davon isst, verleiht es Anteil an der eigenen Unsterblichkeit, denn das Wort Gottes ist unsterblich." Zur Theorie der geistigen Sinnlichkeit siehe K. RAHNBR, "Le début d'une doctrine des cinq sens spirituels chez Origène", Revue d'ascétique et de mystique 13 (1932) 113-145; J. Dillon, "Aisthesis Noete. A Doctrine of Spiritual Senses in Origen and in Plotinus", in: A. CAquot u.a. (Hg.), Hellenica et Judaica. Festschrift für V. Nikiprowetsky (Leuven / Paris 1986) 443-455, erneut in: Ders., The Golden Chain. Studies in the Development of Platonism and Christianity. Variortum. CS 333 (Aldershot u.a. 1990) Nr. XIX;

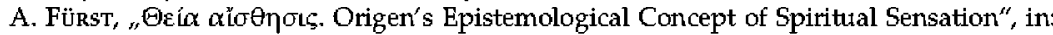
Ch. Hengstermann (Hg.), God in the Iconic Imagination. Spiritual Sensation in Douglas Hedley's Christian Platonism (London, im Druck). Gessel 1975, 180-186 erkennt zwar die Verbindung von platonischer und stoischer oủoía-Konzeption (1836), bezieht die Auffassung des Origenes aber einseitig auf die Vergöttlichung des Menschen, um die in der Brotbitte gebetet werde (vgl. ebda. 182. 185).
} 
Mensch in seinem Innern ethisch wie intellektuell dem Gott ähnlich werden muss"; die Missachtung dieser Forderung wird zu Heuchelei und Schamlosigkeit, wie Epiktet moniert (Diss. II 20,27). ${ }^{38}$ Origenes schildert ausführlich die Vorteile der rechten inneren Einstellung als Argument für das Beten und erklärt sie mit Beispielen aus der Bibel (Orat. 8-10; vgl. 19-21;31,2.5f.).$^{39}$ Hauptsächlich geht es dabei um die moralische Disposition des Beters, denn unmoralische Gedanken, Regungen und Verhaltensweisen führen von Gott weg und stehen damit dem Gebet im Weg. Wer aber in ethisch rechter Weise betet, "ist eher geeignet, mit dem Geist des Herrn" und mit Gott "verbunden zu werden", und wird "Anteil haben an dem Gebet des Wortes Gottes, das auch inmitten derer steht, die es nicht kennen (vgl. Joh 1,26), und das niemandem seine Hilfe versagt und zusammen mit demjenigen zum Vater betet, dessen Mittler er ist" $\left(\right.$ Orat. 10,2). ${ }^{40}$ Ohne die rechte moralische Disposition des Beters kann es demnach keine Verbindung zu dem,Medium' geben, das dem Menschen gleichsam die Kontaktaufnahme mit Gott vermittelt und damit Beten erst möglich macht: dem "Geist" als dem Prinzip der Heiligung nicht im kultischen, sondern im ethischen Sinn und dem "Wort" Gottes als dem Prinzip und der Summe aller Tugenden (vgl. Orat. 11,2). ${ }^{41}$ Auch diese Ausführungen des Origenes sind Teil eines weiteren, philosophischen Diskurses über die rechte Weise des Betens als Bedingung der Möglichkeit des Gebets überhaupt.

\section{Ist Beten sinnvoll?}

Abgesehen von der grundsätzlichen Frage, ob Beten angesichts der "Grö$\mathrm{Be}^{\prime \prime}$ und der "überragenden Art" Gottes dem Menschen in seiner Schwäche und Begrenztheit überhaupt möglich ist, sah sich Origenes mit einem

\footnotetext{
${ }^{38} \mathrm{Vgl}$. von Stritzkr 1989, 78f. (das Zitat 78).

${ }^{39}$ Dazu Gessel 1975, 136-143. 204-206; Perrone 2011a, 151-170. 181-188.

${ }^{40}$ Origenes versteht Joh 1,26 so, dass das "Wort Gottes" inmitten jedes eirzelnen Menschen steht, der Logos als Grund und Sinn des Seins sich also im Itnersten jedes Metischen befindet, ab dieser sich dessen bewusst ist oder tricht. Vgl. In Ioh. conm. XXXII 30,378, ferner VI 38,188-193; Cels. V 12. In einem durch und durch platonischen Passus erlättert Origenes in Orat. 20,2 die Aufforderung in Mt 6,6, „in der Kammer" und ,im Verborgenen " zu beten, damit, dass Gott (Vater und Sohn) "in unserem Verborgenen präsent ist". Dem entspricht sein Begriff vom ,Reich Gottes in Orat. 22,5: „Das Reich Gottes ist nämlich auf alle gegründet, die ,das Bild des Himmlischen (1 Kor 15,49) tragen", d.h. das Bild des Sohnes Gottes, nach dem sie geschaffen worden sind (Gen 1,26) - "und deshalb zu Himmlischen geworden sind". Ausführlich dazu: Orat. 25 zu Mt 6,10 (Lk 11,2): „Dein Reich komme”, bes. Orat. 25,1: „Das Reich Gottes ist als der selige Zustand des leitenden Prinzips der Seele (des stoischen Hegemonikon: vgl. Orat. 9,1;12,1;13,3) und als Ordnung der weisen Gedanken zu denken."

${ }^{41}$ Siehe dazu Ch. Hengstramann, "Leben des Einen. Der Tugendbegriff des Origenes", in: F. W. Horn / U. Volp / R. ZImm grmann (Hg.), Ethische Normen des frithen Christentums. Gut - Leben - Leib - Tugend. WUNT 313 (Tübingen 2013) 433-453.
} 
zweiten Einwand gegen das Beten konfrontiert: Selbst wenn eine Kontaktaufnahme mit dem Göttlichen durch die von ihm dazu skizzierten Wege der Vermittlung möglich sein sollte - ist Beten denn sinnvoll, wenn alles von Gott vorherbestimmt ist? Diese Frage war der eigentliche Anlass seiner Gebetsschrift. Die Adressaten, sein Mäzen Ambrosios und eine ansonsten unbekannte Christin namens Tatiana (Orat. 2,$1 ; \mathrm{vgl} .34),{ }^{42}$ hatten Origenes aufgefordert, zu diesem Problem Stellung zu nehmen. Origenes zitiert die entsprechende Passage wörtlich aus ihrem Brief: „Erstens: Wenn Gott die zukünftigen Ereignisse vorher kennt und sie notwendigerweise geschehen, ist das Gebet zwecklos. Zweitens: Wenn alles nach dem Willen Gottes geschieht und seine Entscheidungen unaufhebbar sind und nichts von dem, was er will, geändert werden kann, ist das Gebet zwecklos" (Orat. $5,6)$.

Bedingt durch diese Anfrage, steht die Stellungnahme des Origenes zu diesem Problemkreis auch, wenngleich nicht zuvörderst, im Rahmen seiner beständigen Auseinandersetzung mit der Gnosis und ihrem Determinismus, wie das für viele seiner theologischen Argumente der Fall ist. Offenbar sind Einwände gegen das Beten wie die aus dem Brief der Tatiana und des Ambrosios - eines früheren Gnostikers, wohl Valentinianers, den Origenes für die nicht-gnostische kirchliche Gemeinde in Alexandria gewonnen hatte ${ }^{43}$ - von Gnostikern vorgebracht worden. Origenes sagt das zwar nicht direkt, doch lässt sich aus seiner Polemik gegen den "Einfluss des Widersachers (vgl. 2 Thess 2,9), der die gottlosesten Auffassungen mit dem Namen Christi und der Lehre des Gottessohnes verknüpfen will", wohl schließen, dass er gnostische Christen im Auge hat. Aus gnostischen Texten des 2. Jahrhunderts, dem Philippusevangelium (Ev. Phil. 7) und dem Thomasevangelium (Ev. Thom. 14), lässt sich belegen, dass in diesen Kreisen das Gebet zumindest für vollkommene Gnostiker abgelehnt wurde. Die näheren Hintergründe für diese Einstellung bleiben allerdings unklar. ${ }^{44}$ Welche Gnostiker oder Texte Origenes genau meint, ist nicht zu sagen, weil sich seine Beschreibung auf mehrere gnostische Gruppen, wie sie in der häresiologischen Literatur beschrieben werden, beziehen lässt: "Diese Meinung vertreten diejenigen, die das sinnlich Wahrnehmbare gänzlich verwerfen, weder Taufe noch Eucharistie praktizieren und auch den Sinn der Schriften so verdrehen, als ob diese nicht einmal das Beten selbst wollten, sondern etwas anderes, der eigentlichen Bedeutung Entgegenge-

42 Dazu Perrone 2011a, 18; von Stritzky 2014, 6-8.

${ }^{43}$ So laut Eusebios, Hist. eccl. VI 18,1. Vgl. A. Fürss, Christentum als Intellektuellen-Religion. Die Anfänge des Christentums in Alexandria. SBS 213 (Stuttgart 2007) 68f.

${ }^{44}$ Siehe E. Segrlbbrg, „Prayer among the Gnostics? The evidence of some Nag Hammadi Documents", in: M. Krause (Hg.), Gnosis and Gnosticism. NHS 8 (Leiden 1977) 55-69, bes. 56-60 und das Fazit 68. 
setztes lehrten" (Orat. 5,1) ${ }^{45}$ Klemens von Alexandria liefert hierzu eine präzisere Nachricht: Die gnostischen Anhänger des Prodikos haben nach seiner Auskunft die "gottlose Weisheit" vertreten, "dass das Beten nicht nötig sei" (Strom. VII 41,1f.). Sehr viel weiter hilft diese Auskunft freilich auch nicht. Allerdings ist diese Frontstellung nicht so wichtig: Sie zeigt, dass die Ausführungen des Origenes auch apologetisch motiviert waren, ${ }^{46}$ doch reichten seine Interessen bei diesem Thema weit über die antignostische Apologetik hinaus.

Angestoßen von der zitierten Anfrage, geht Origenes die Frage, ob Beten sinnvoll sei, grundsätzlich an. In seiner Antwort nimmt er dieses Problem in der ganzen antiken Philosophie in den Blick. ${ }^{47}$ Dabei beschäftigt er sich nicht mit den "reinen Atheisten", die entweder Gott oder die Vorsehung leugnen (Orat. 5,1.2), worunter Epikureer und in bestimmter Hinsicht Peripatetiker gemeint sind (vgl. Cels. I 13; II 13) ${ }^{48}$ Ihn interessieren "unter denen, die eine Vorsehung annehmen und Gott an die Spitze des Universums stellen" (Orat. 5,1), also Platoniker, Stoiker und in anderer Hinsicht erneut Peripatetiker, diejenigen, die die Gebete ablehnen (Orat. 5,2). Ungeachtet der möglichen Zuordnungen dieser Einstellung zu bestimmten philosophischen Schulrichtungen, die sich im Einzelnen sehr differenziert darstellt, spitzt Origenes die Kritik am Beten auf das zugrundeliegende Sachproblem zu: In einem deterministischen Weltbild gleich welcher Couleur ist Beten überflüssig (Orat. 5,2f.). Das gilt nicht nur, wenn man stoisch einen streng determinierten Katusalzusammenhang allen Geschehens annimmt. Dieses Problem stellt sich vielmehr auch, wenn man aristotelisch die Vorsehung auf den supralunaren Bereich beschränkt, weil dadurch zwar dem Menschen ein Entscheidungs- und Handlungsspielraum eingeräumt wird, Gebete aber dennoch sinnlos bleiben, weil die gött-

\footnotetext{
${ }^{45}$ Mögliche Identifizierungen dieser Gruppen sind aufgeführt bei Grsser 1975, 151 mit Anm. 12. Siehe dazu Prrronb 2011a, 92-96.

${ }^{46}$ Gessbl 1975, 149-171 stellt die Überlegungen des Origenes in einen apologetischen Kontext, bekommt das Neue an seiner Argumentation (nämlich den Freiheitsbegriff) damit aber nicht in den Blick (vgl. 171).

${ }^{47}$ LöHr 1999, 88-90 fasst den Passus in Orat. 5,1-5 zu eng, wenn er nur an "christliche Gebetsgegner" denkt. Origenes nimmt klar philosophische Positionen in den Blick, "th retroterra filosofico", das Perronb 2011a, 79 richtig als "Sitz im Leben" des Traktats identifiziert. Von STRITzKY 1989, 111-121 erkentut zwar die freiheitstheologischen Gedanken des Origenes als Kern seiner Position, "das Bittgebet ... als einen Akt des freien Willens des Menschen" zu betrachten (119), und nimmt auch kritisch gegen Gessel (vgl. ebda. 112 Anm. 159) wahr, dass Origenes von da aus eine "Auseinandersetzung mit antiker Gebetstheorie" führt (112), fokussiert diese aber doch zu sehr auf christliche Häretiker und setzt seine christliche Position zu einfach von den philosophischen Überlegungen dazu ab (vgl. 115. 118. 119).

${ }^{48}$ Vgl. Perrone 2011a, 94. Gesser 1975, 150 Anm. 6 denkt nur an Epikureer und ebda. 152f. nur an Stoiker, hat die Platoniker aber überhaupt nicht im Blick. Ganz oberflächlich und unzulänglich sind die Zuordnungen, die CHANG 2010, 183-187 vornimmt (dasselbe gilt für die Ausführungen über Gebet und Vorsehung 187-190).
} 
liche Vorsehung auf die Menschenwelt gerade nicht einwirkt. Und es stellt sich auch und sogar verschärft, wenn man platonisch eine Vorsehung für jedes Einzelwesen annimmt, weil "der Vater und Schöpfer des Alls", wie Origenes mit dem locus classicus des Mittelplatonismus sagt (vgl. Platon, Tim. 28c), diesen mit Weish 11,25 kombinierend, "die Angelegenheiten jedes Einzelnen auch ohne dessen Gebet zum Heil führt wie ein Vater, der sich von vornherein seiner unmündigen Kinder annimmt und nicht erst auf ihre Bitte wartet, weil sie entweder überhaupt nicht in der Lage sind zu bitten oder aus Unkenntnis häufig das Gegenteil von dem, was ihnen Nutzen und Vorteil bringt, erlangen wollen ${ }^{\prime \prime}($ Orat. 5,2). Origenes rekurriert hier deutlich auf die oben vorgeführten Einwände, die gegen das Beten gerade im Platonismus vorgebracht worden sind. Ein kurzer Blick in die diesbezüglichen Debatten der antiken Philosophie dürfte hilfreich sein, um die Ausführungen des Origenes in diesem Kontext zu profilieren.

Schon in den homerischen Dichtungen ist die Vorstellung anzutreffen, dass Gebet und Opfer gegenüber einem Determinationsztusammenhang, der als Wille Gottes aufzufassen ist, wirkungslos sind. Die Differenz zwischen dem im Gebet Erbetenen, meist zeitliche Güter wie Gesundheit, ein gutes Leben oder Befreiung aus einer Notlage, und dem von den Göttern als erstrebenswert Erachteten und damit schicksalhaft Bestimmten war dem griechischen Denken von seinen Anfängen an bewusst. "Götter! Doch warum zu Göttern flehn? Sie hören ja schon lange nicht mehr meinen Ruf", schrieb Euripides in aufklärerischer Manier (Tro. 1280f.). ${ }^{50}$ Aus derSensibilität für die vielfache Determiniertheit des Daseins entwickelten sich in der philosophischen Reflexion Vorbehalte gegen das Beten. Der Begründer der kyrenäischen Schule, der Sokratesschüler Aristippos, dürfte der erste gewesen sein, ${ }^{51}$ der das Argument gegen das Beten formulierte, dessen Kern auch Origenes wiedergibt. Aristippos bediente sich dafür der Metaphorik, dass der Arzt dem Patienten die Medizin, die dieser bratucht, unabhängig davon, ob dieser ihn darum bittet oder nicht, verabreicht, weshalb beten lächerlich sei (Grom. Vat. $32=$ Aristippos, fr. 132 Giannantoni). Über Karneades, das Hatupt der skeptischen Mittleren Akademie, verbreitete sich dieses Argument weithin in philosophischen Kreisen, klassisch formuliert bei Nemesios (Nat. hom. 35,289). ${ }^{52}$

Zum Problem wurde die Möglichkeit des Betens vor allem in der stoischen Philosophie mit ihrer Betontung des Schicksals als der alles bestim-

\footnotetext{
${ }^{49}$ Vgl. von SEverus $1972,1138 f$.

${ }^{50}$ Zitiert aus ebda. 1143.

${ }^{51}$ Nachgewiesen von J. Périn, ,Prière et providence au $2^{\mathrm{e}}$ siècle (Justin, Dial. I 4$)^{\prime \prime}$, in: C. LAGA (Hg.), Images of Man in Ancient and Medieval Thought. Festschrift fü G. Verbeke (Leuven 1976) [111-125] 124f., erneut in: J. PÉPIn, De la philosophie ancienne d̀ la théologie patristique (London 1986) Nr. X.

${ }^{52}$ Vgl. ebda. 119 mit den Hinweisen auf Stellen und Literatur in Anm. 36.
} 
menden Macht. ${ }^{53}$ Das Schicksal im Sinne eines lïckenlosen Kausalnexus (Heimarmene) und einer ebenso unabänderlichen wie segensreichen Weltordnung lässt sich durch kein Gebet beeinflussen oder verändern (Seneca, Nat. quaest. II 35,1). „Individuelle Bitten an die Gottheit sind unter dieser Voraussetzung überflüssig. ${ }^{\mu 54}$ Stoische Frömmigkeit kann nur darauf ausgerichtet sein, im eigenen Denken und Handeln in die tunabänderliche Weltordnung als vernünftig und gut einzustimmen (Epiktet, Ench. 31; M. Aur. V 8). In diesem Sinne wird Beten auch stoisch möglich tund praktiziert, großartig bezeugt im Zeus-Hymnus des Kleanthes (SVF I 537, der Anfang zitiert von Seneca, ep. 107,11 und Epiktet, Ench. 53). Gebete als Dank und Lobpreis für die Wohltaten der Götter (Verleihung des Verstandes, Erhaltung der menschlichen Existenz) sind nicht nur möglich, sondern, so Epiktet, vom Weisen, der diese Wohltaten und die Güte Gottes kraft seiner gottgleichen Vernunft erkennt und dankbar anerkennt, sogar gefordert (Diss. I 16,15-21; III 26,30). Noch einen Schritt weiter gehend, ist Mark Aurel davon überzetugt, dass das Gebet sogar bei dem sinnvoll ist, "was in unserer Macht steht", und das zeige sich, wenn der Mensch ", anfängt, darum zu

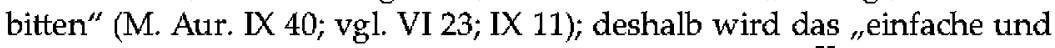
freimütige" Beten von ihm geschätzt (V 7$)$ und praktiziert. ${ }^{55} \mathrm{Im}$ Rahmen ihres deterministischen Weltbildes, in dem das Bittgebet sinnlos ist, rätumen die Stoiker die Möglichkeit eines Gebets ein, in dem ihre Einwilligung in das göttliche Schicksal als Wunsch, Dank und Lobpreis zum Ausdruck gebracht wird. Dass eine solche Einstellung nicht frei von Inkonsistenzen zu halten ist, zeigen gegenläufige Aussagen Senecas: Er stellt den Nutzen des Gebets in Frage, da der Weise das Prinzip seines Glïcks in sich selbst hat; es ist daher Aufgabe des Menschen, selbst für sein Glück zu sorgen und es nicht von den Göttern zu erbitten (ep. 31,5; 41,1). Während er es demgemäls ablehnt, um die bona mens zu beten (ep. 41,1$)$, gesteht er andernorts gerade dies $\mathrm{zu}(e p .10,4)$. Im Rahmen der Vorsehung haben, so seine Annahme, die Götter "vieles im Ungewissen gelassen", und eben dies sei durch Gebete zu beeinflussen (Nat. quaest. II 37,1-3). ${ }^{56}$ Gebete seien vom Schicksal "als Bedingung der göttlichen Hilfe vorgesehen", insofern das "Gebet nicht den Zweck hat, die Götter zu zwingen, sondern sie an die menschlichen Anliegen zu erinnern" (vgl. Benef. V 25,4) ${ }^{57}$ Hierher gehört wohl auch die stoisch gefärbte Position Juvenals: Während er einerseits - ganz in der Manier des Maximos von Tyros - tunvernünftige und schädliche Wünsche nach Reichtum, Macht, langem Leben und Schönheit kritisiert und demge-

\footnotetext{
${ }^{53} \mathrm{Vgl}$. Dинцв 1999, 23f. $25 \mathrm{f}$.

${ }^{54}$ Ebda. 24.

55 Vgl. von Sevbrus 1972, 1149f; von STRITZKy 1989, 80; Dihle 1999, 26.

${ }^{56}$ Vgl. GBssbl 1975, 152f. mit einer unnötigen Herabsetzung der stoischen Position als Entleerung und Entwurzelung der Gebetspraxis; Drrue 1999, 26.

${ }^{57}$ VoN STRITZKY 1989, 76.
} 
genüber empfiehlt, ,den Göttern selbst die Entscheidung darüber zu überlassen, was uns am meisten entspricht und was sie für uns am nützlichsten halten", weil die Götter den Menschen "das jeweils Beste" verleihen (Sat. 10,347-349), fordert er andererseits, gewissermaßen als Zugeständnis an das fromme Bedürfnis, zum Beten auf, allerdings um "ein mutiges Herz" (Sat. 10,357), das den Versuchungen der Angst vor dem Tod, des Zorns, der Begierde und der Gelüste nicht unterliegt (Sat. 10,354-362). Im Widerspruch dazu erklärt er abschließend das Beten dann doch implizit für überflüssig, denn all dies stehe in der Macht des Menschen selbst: „Sieh, dies alles kannst du dir selber verleihn, wahrhaftig nur durch die Tugend öffnet der Pfad sich zu ruhigem Leben" (Sat. 10,363f.). Diese stoische Einstellung, insbesondere die Haltung Senecas, erinnert an das Konzept der gestuften Vorsehung, aus dem Platoniker und Peripatetiker die Möglichkeit individuellen Betens ableiteten: Da die Vorsehung zwar die Welt insgesamt ordnet und lenkt, jedoch nicht das Leben eines Menschen im Einzelnen, gibt es einen Spielraum für individuelles Handeln, und in diesem ist auch individuelles Beten sinnvoll. ${ }^{58}$ Porphyrios (nach dem Referat bei Proklos) hat die platonische Position hierzu so beschrieben: "Alle diejenigen aber, die sagen, dass es die Götter gibt und dass sie die Dinge vorherwissen und dass vieles von dem, was geschieht, auch anders hätte sein können, diese lassen vernünftigerweise auch die Gebete $z \mathrm{tu}$ und erkennen, dass sie unser Leben bessern können" (In Tim. Plat. II [I 208,3-6 Diehl]) ${ }^{59}$ Im Rahmen des Glaubens an eine Vorsehung Gottes kann Beten nur sinnvoll sein, wenn es einen Freiraum für menschliches Handeln gibt.

Sehr viel radikaler und kritischer argumentiert Maximos von Tyros gegen das Beten. ${ }^{60}$ In seiner oratio über das Gebet sind aus einer platonisch und stoisch geprägten Perspektive ${ }^{61}$ die Gründe zusammengefasst, die das Bittgebet sinnlos erscheinen lassen (or. 5,4-6): "die Vorsehung", denn diese ",ist die Sache Gottes", "das Schicksal", denn dieses ist die Sache "der Notwendigkeit", "der Zufall", denn dieser "ist Geschehen ohne Grund", und "Sachverstand", denn dieser ",ist Sache des Menschen" (or. 5,4) ${ }^{62}$ Die

${ }^{58}$ Vgl. Dihle 1999, 27f.

59 Übersetzung: LöHr 1999, 92.

${ }^{60}$ Siehe dazu O'Brian 2016, ferner die "Tesi di laurea" von D. Gurisattr, Ricerche sull'Or. 5 di Massimo di Tiro (Università di Bologna, 2015/16), die der Verfasser mir freundlicherweise hat zukommen lassen.

${ }^{61}$ Siehe dazu den Beitrag von Franco Ferrari in diesem Band.

62 Ähnliche Reihen begegnen bei anderen Autoren: von STRITZKY 1989, 85 Anm. 97; TRAPP

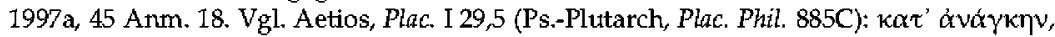

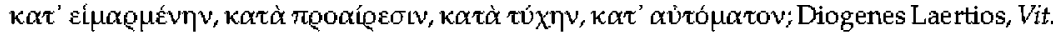
philos. III 96 (in der Vita Platons) und Stobaios, Ecl. I 7,10 (I 93 WACHSMUTH / HensB) bieten

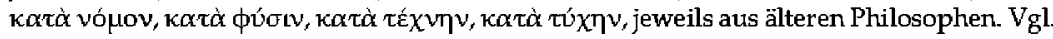
ferner Sextus Empiricus, Pyrrh. hypoth. I 237. Der Ausgangstext hierfür ist Platon, Leg. IV

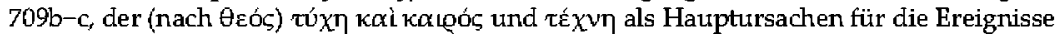
bezeichnet, zitiert von Maximos, or. 13,7. Plutarch, Quaest. conv. IX 5, 740C, scheint darauf 
ersten drei Größen sind vom Menschen nicht zu beeinflussen, weshalb zu beten sinnlos ist; die letzte ist eine Fähigkeit des Menschen, mit deren Hilfe er sich verschafft, was er haben will, weshalb es sinnlos ist, die Götter darum zu bitten (vgl or. 5,7). Auch Plotin betont, dass Gebete um Sieg im Kampf, eine gute Ernte oder Gesundheit sinnlos sind, wenn der Betende sich nicht aus eigenen Kräften bemüht, diese Ziele zu erreichen, weil Gebete den Weltlauf nicht ändern können (Enn. III 2,8,37-40; III 2,9,10-12). ${ }^{63}$ In einer Weise, die stark an das Referat solcher Positionen in der Gebetsschrift des Origenes (Orat. 5,1f.) erinnert und vielleicht sogar davon beeinflusst ist, ${ }^{64}$ referiert Porphyrios (gemäß der Zusammenfassung bei Proklos) die antike Gebetskritik folgendermaßen: "Der Philosoph Porphyrios unterschied, welche von den Alten das Gebet zuließen und welche nicht: So führte er uns zu anderen und wieder anderen Lehrmeinungen, indem er - kurz gesagt - erklärte, dass weder diejenigen, die an der ersten Art von Gottlosigkeit leiden, sich vom Beten einen Nutzen verschaffen - sie bestreiten sogar die Existenz von Göttern -, noch diejenigen, die an der zweiten Art von Gottlosigkeit leiden - alle, die zwar die Existenz von Göttern zugestehen, aber rundweg bestreiten, dass diesen ein Vorherwissen zukommt -, noch diejenigen, die zugeben, dass es Götter gibt und dass sie die Dinge vorherwissen, aber meinen, dass alles mit Notwendigkeit von ihnen verursacht geschieht. Wenn es nichts gibt, was auch anders hätte geschehen können, wird der Nutzen des Gebets aufgehoben" (In Tim. Plat. II [I 207,23-208,3 Diehl]). ${ }^{65}$ Gerade die frommen Philosophen der Kaiserzeit und der Spätantike hatten aufgrund eines starken Begriffs von Vorsehung Vorbehalte gegenüber dem Beten. Eben mit dieser Position von Leuten, "die zwar Gott an die Spitze des Universums stellen tund eine Vorsehung annehmen, die Gebete aber ablehnen" (Orat. 5,2), setzte Origenes sich in seiner Gebetsschrift auseinander, denn zu denen, die an Gott und seine Vorsehung glatuben, gehörten auch die Christen. Auch diese mussten sich zu den genannten Einwänden verhalten, weil damit ihre eigene Weltsicht und Gebetspraxis in Frage gestellt war.

Aus christlicher Perspektive tauchte dieses Problem zudem aus einer Richtung auf, die es noch verschärfte. Zunächst einmal waren für Origenes von den vier Mächten, die Maximos von Tyros gegen das Gebet ins Feld führte, nur Vorsehung und Schicksal relevant. Die von Menschen gemachte Technik erwähnt er nicht, wohl weil er menschliches Tun als Ursache für

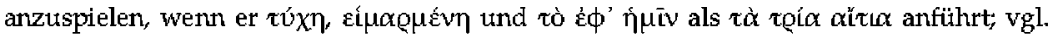
Trapp 1997a, 122 Anm. 30.

63 Vgl. von SEvBrus 1972, 1152; von STRITZKY 1989, 94.

64 So die Vermutung von von STRITzky 1989, 100; vgl. LöHr 1999, $94 \mathrm{f}$.

65 Übersetzung: LöHr 1999, 92 (leicht modifiziert). Vgl. auch die Texte aus Porphyrios, ep. ad Aneb. 1-3, und ad Marcell. 12, bei Perrone 2011a, 88f. Anm. 252 und 253. Dazu ausführlich Bendineler 1997, 36-41.
} 
Erzeugnisse und Ereignisse als Teil seiner Freiheitslehre betrachtet (s.u.). Der Zufall ist für ihn keine ernst zu nehmende Erklärung des Weltgeschehens - "ginge es zufällig und regellos $\mathrm{zu}^{\prime \prime}$, könnten die Menschen nicht für ihre Taten verantwortlich gemacht werden (Princ. II 9,5) -, zumal die Positionen der ihn vertretenden Philosophen, der Epikureer und der Skeptiker, für Origenes generell indiskutabel waren (Orat. 5, 1 ; vgl. Cels. III 75) ${ }^{66}$ Bleiben Vorsehung und Schicksal, also der Determinismus als Vorherwissen und Vorherbestimmung durch Gott, denn "Gott hat die Zukunft nicht nur im Voraus erkannt, sondern auch im Voraus so geordnet, dass nichts gegen seine Anordnungen geschieht" (Orat. 5,3). Die oben zitierte Zusammenfassung, die Origenes von dieser Position gibt (Orat. 5,2), erinnert an die Position des Maximos, der unter Verweis auf die Würdigkeit des Menschen argumentierte, Gott teile jedem Menschen ohnehin zu, wessen er würdig sei, ganz unabhängig davon, ob dieser darum bitte oder nicht (or. 5,3). Origenes' Referat entspricht diesem Gedanken so sehr, dass man daraus vielleicht sogar den Schluss ziehen kann, dass er den Text des Maximos kannte ${ }^{67}$ Allerdings findet sich exakt derselbe Gedanke auch bei Klemens (Strom. VII 41,5-7), ${ }^{68}$ so dass Origenes ihn vielleicht auch von seinem alexandrinischen Vorgänger übernommen hat.

Die christliche Problemverschärfung ergab sich daraus, dass es in der Bibel Stellen gibt, die von göttlicher Prädestination und damit von Determinismus sprechen. Im Traktat über die Willens- und Entscheidungsfreiheit des Menschen in De principiis hat Origenes diese Stellen zusammengestellt und ausführlich erörtert (Princ. III 1,6-24). In De oratione bietet er eine kurze Auflistung solcher Stellen (Orat. 5,4f.), mit denen biblisch-christlich zugunsten der Prädestination und damit gegen den Sinn des Betens argumentiert werden kann. ${ }^{69}$ Das Paradebeispiel sind Jakob und Esau (vgl. Röm 9,11-13): Wenn der Sünder wie Esauı "vom Mutterschoß an abtrünnig" (Ps 58,4), der Gerechte wie Jakob hingegen "vom Mutterleib an auserwählt" (Gal 1,15) ist, "dann bitten wir vergeblich um die Vergebung der Sünden oder darum, die Kraft des Geistes ztu empfangen” bzw. „wird uns auch ohne Gebet das Beste begegnen" (Orat. 5,4). Ausgehend von Bibelstellen, an denen von Auserwählung und Vorherbestimmung von Menschen zu guten oder bösen Geschicken die Rede ist (v.a. Eph 1,4f., ferner Röm

\footnotetext{
${ }^{66}$ Weiteres bei FürsT 2014, 508 .

${ }^{67}$ Diese "curieuse ressemblance" und ", analogie des idées" ist schon E. DE FAyz, Origène. Sa vie, son ceuvre, sa pensée. 3 Bde. (Paris 1923, 1927, 1928) Bd. 2, L'ambiance philosophique, 158 aufgefallen. $\mathrm{Vgl}$. autch von Stritzky 1989, 113 und schon J. Daniślou, "Origène et Maxime de Tyr", Recherches de Science religieuse 34 (1947) 359-361.

${ }^{68} \mathrm{Vgl}$. von Severus 1972, 1212.

${ }^{69}$ Diesen Kanon biblischer Beispiele für prädestinatorische bzw. deterministische Aussagen verwendet Origenes häufig in seinen Schriften, meist gegen valentinianische und markionitische Positionen: PERrong 2011a, 103-107 mit den Parallelen zu den einzelnen Bibelstellen.
} 
8,29f.; Phil 3,21; 1 Kön 13,1-3; 2 Kön 22,11-13.18f.; Ps 109,7f.; Apg 1,16.20), formuliert Origenes dasselbe Dilemma: „Entweder gehört jemand zu den ,vor der Grundlegung der Welt' (Eph 1,4) Auserwählten, dann ist es unmöglich, dass er die Erwählung verliert, und hat deshalb das Gebet nicht nötig, oder jemand ist nicht auserwählt und nicht vorherbestimmt, dann betet er umsonst und wird selbst bei unzähligen Gebeten keine Erhörung finden" (Orat. 5,5). Die desaströsen Folgen für die christliche spirituelle Praxis müssen nicht eigens hervorgehoben werden. Ernetut nahe bei der Ansicht des Maximos über den Unsinn des Betens fasst Origenes die Ansicht der Gegner des Gebets so zusammen: „Da Gott unveränderlich ist und die ganze Schöpfung vorher erfasst hat und bei seinen vorher getroffenen Anordnungen bleibt, ist es von vornherein unsinnig zu beten, in der Meinung, man könne durch sein Gebet den Entschluss Gottes ändern, oder zu glauben, Gott warte das Gebet erst ab, um das Anliegen des Beters zu erfüllen, als ob er nicht schon vorher seinen Entschluss gefasst hätte und erst auf das Gebet hin das Vernünftige anordne, als ob er es vorher nicht in Betracht gezogen hätte" (Orat. 5,5) ${ }^{70}$

In seiner grundsätzlich ansetzenden Antwort auf diese Einwände gegen das Beten legt Origenes die Grundsätze seines Freiheitsdenkens dar. Neben dem Freiheitstraktat in De principiis (Princ. III 1,1-5) ist dieser Passus in De oratione (Orat. 6f.) die zweite Stelle in seinen erhaltenen Werken, an denen er seine Freiheitslehre vorstellt. ${ }^{71} \mathrm{Er}$ geht jeweils von einer Bewegungslehre atus, in deren Rahmen er unterschiedliche Ursachen für Bewegung aufführt (Orat. 6,1; Princ. III 1,2). Die Bewegung, die den Vernunftwesen zukommt, ist die Bewegung "durch sich selbst" (Orat. 6,1: $\left.\delta i^{\prime} \alpha v i \bar{\omega} v\right)$. Wird diese "freie Selbstbestimmung" ( $\left.\dot{\varepsilon} \phi^{\prime} \eta \dot{\eta} \mu v^{\prime}\right)$ geleugnet, dann wäre der Mensch weder ein Vernunftwesen noch ein Lebewesen, das

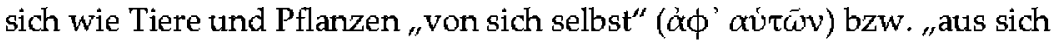
selbst" ( $\dot{\xi} \xi \alpha \dot{\tau} \tau \bar{\omega} v)$ bewegt, sondern wie materielle Dinge, die "von außen" ( $\check{\xi} \xi \omega \theta \varepsilon v$ ) bewegt werden (Orat. 6,2). Den Nachweis für die "freie Selbstbestimmung" führt er zum einen mit einem sprachlogischen Argument, aus dem sich die Unhintergehbarkeit des "Selbst" ergibt: Im Blick auf Denken, Reden und Tun des Menschen wäre es unsinnig, wenn jemand, der

\footnotetext{
${ }^{70}$ Aufgrund dieser Sachlage kann man nicht, wie Bendinglut 1997, 51, eine große Differenz zwischen der paganen und der christlichen Einstellung zum Gebet mit dem Verweis auf "il motivo dell'inutilità della preghiera", das sich "nella negazione della efficacia della preghiera" auswirkte, behaupten. Die Problemlage und die Suche nach Lösungen stellt sich vielmehr auf beiden Seiten sehr ähnlich dar.

${ }^{71}$ Ein detaillierter Vergleich beider Passagen bei Prrrone 2011a, 111-114. Origenes gibt aber nicht einfach stoische bzw. platonische Quellen wieder (so 109-111), und die Unterschiede zwischen beiden Texten sind nicht auf unterschiedliche polemische Frontstellungen zurückzuführen (so 113). Vielmehr entwirft Origenes ausgehend von den herangezogenen philosophischen Traditionen ein eigenes, differenzierteres und dynamischeres Bild der vielfältig bewegten Wirklichkeit.
} 
etwas will oder isst oder spazieren geht oder einer Aussage zustimmt oder sie verwirft, behaupten würde, "er wolle nicht selbst, er esse nicht selbst, er gehe nicht selbst spazieren, er stimme nicht selbst zu oder nehme irgendwelche Lehrsätze an noch missbillige er selbst andere als unwahr" (Orat. 6,2). Zum anderen und eng damit verknüpft erweist er die "freie Selbstbestimmung" aus der Praxis menschlichen Tuns mittels einer Analyse der Alltagssprache: "Wer tadelt nicht seinen Diener, wenn er den Eindruck gewinnt, dass dieser einen Fehler begangen hat? Und wer macht seinem Sohn keinen Vorwurf, wenn er den Eltern nicht die gebührende Achtung entgegenbringt, oder bezeichnet die Tat einer Ehebrecherin nicht als schamlos und verurteilt sie?" (Orat. 6,2). Ermahnung, Lob und Tadel, von den Menschen spontan geäußert, werden sinnlos ohne die Annahme, dass die angezielten Handlungen nicht in der Verfügungsgewalt der ermahnten, gelobten und getadelten Menschen stehen: "Denn die Wahrheit nötigt und zwingt uns, auch wenn jemand unzählige Male Gegengründe erfindet, zu ermahnen, zu loben und zu tadeln, damit die freie Selbstbestimmung gewahrt bleibt und diese für uns zum Lobredner oder Tadler wird" (Orat. 6,2). Aus der Erfahrung praktischen Handelns und mittels einer Analyse der Sprache gelangt Origenes zum Postulat der freien Selbstbestimmung als Apriori menschlichen Tuns. Dieser Passus in der Gebetsschrift des Origenes ist von weitreichender Bedeutung für eine Begründung der Freiheit auf der Ebene der praktischen Vernunft. ${ }^{72}$

Der Gedanke als solcher ist vorbereitet bei Alexander von Aphrodisias, der ihn philosophisch in der zwischen 198 und 209 entstandenen Schrift $D e$ fato sogar ausfïhrlicher und eingehender entfaltet hat als Origenes. Ausgehend von den stoischen Diskussionen über Determinismus und Freiheit $^{73}$ plädiert Alexander im Rahmen einer peripatetischen Bewegungslehre ebenfalls für die freie Selbstbestimmung vernunftbegabter Wesen. ${ }^{74}$ Wie Origenes argumentiert er daztu, seine vorausgehenden Einwände gegen den Determinismus zusammenfassend, mit der Alltagserfahrung: Wer bestreitet, dass der Mensch kraft dessen, was ,an ihm” liegt, die Möglichkeit alternativen Handelns hat, "dem ist es nicht möglich, einen zu tadeln, einen zu loben, einem zu raten, einen zu ermuntern, zu den Göttern zu beten, ihnen für irgendetwas zu danken oder etwas anderes zu tun, was billigerweise von denjenigen zu geschehen hat, die glauben, die Macht zu besizen, jegliches, was sie tun, auch nicht zu tun" (Fat. 20,190f., Übers. Zierl; vgl. Fat. 16, 187). Es ist davon auszugehen, dass Origenes diesen Traktat Alexanders kannte. Erneut schreibt er sich mit seinen diesbezüglichen

\footnotetext{
${ }^{72}$ Weiteres dazu bei Fürss 2014, 535-537.

${ }^{73}$ Meisterhaft dazu: S. BobzIEn, Determinism and Freedom in Stoic Philosophy (Oxford 1998).

${ }^{74}$ Siehe dazu M. Frede, A Free Will. Origins of the Notion in Ancient Thought. Sather Classical Lectures 68 (Berkeley u.a. 2011) 95-101.
} 
Ausführungen in De oratione in die zeitgenössische philosophische Debatte ein. Während Alexander das Beten als Thema, für das die Freiheit relevant ist, allerdings nur kurz anspricht (Fat. 20,190; vgl. 39, 212), ${ }^{75}$ stellt Origenes diesen Konnex explizit her. Der Alexandriner betont das aus seiner freien Selbstbestimmung fließende Änderungspotential des Menschen, dessen Sein und Agieren nicht deterministisch festgelegt sind; eben deshalb ist Beten sinnvoll (Orat. 6,4f.).

Darin vorausgegangen ist ihm Klemens von Alexandria. Dieser war zwar zunächst nicht weiter auf die gnostische Infragestellung des Betens eingegangen (Strom. VII 41,3), kam kurz darauf aber doch auf die Freiheit als Widerpart gegen den Determinismus zu sprechen. Er entwarf freilich keine philosophisch tiefgehend fundierte Freiheitstheorie wie Origenes, sondern betonte lediglich, dass der Gnostiker (im orthodoxen Sinn) ebenso freiwillig und in bewusster Wahl nach dem Heil strebt, wie Gott nicht unfreiwillig gut ist und den, der gerettet wird, nicht unfreiwillig rettet, sondern ihm aus freiem Willen Anteil an den Heilsgütern gewährt (Strom. VII 42,4). Es war sinnvoll, dass Gott dem Menschen Gebote gab, weil dieser ", aus sich selbst heraus" zur Zustimmung wie zur Ablehnung fähig ist (Strom. VII 42,5), weshalb Gott in bewusster Wahl denen Gutes tut, die sich ihm "aus sich selbst heraus" zuwenden (Strom. VII 42,6). Origenes kannte diesen Text des Klemens, ${ }^{76}$ ging mit seiner umfassenden Neukonzeption von Gott, Mensch, Natur und Geschichte als dynamisches Kontinuum sich selbsttätig bewegender Freiheiten aber weit über Klemens und in dieser Universalität auch über Alexander hinaus.

Von seinem Freiheitsgedanken aus argumentierte Origenes sodann gegen dessen deterministische Infragestellung durch die Vorsehung. Hier liegt eine crux des antiken Vorsehungsdenkens, die zunächst einmal nur so zu lösen ist, dass, wie Origenes andernorts schreibt, "die Tatsache, dass Gott etwas Zukünftiges kennt, nicht die Ursache dafür ist, dass es geschieht, sondern weil etwas in Zukunft geschehen wird, weiß Gott es, bevor es geschieht" (In Rom. comm. VII 6,5). "Nicht, weil es erkannt ist, geschieht es, sondern weil es geschehen wird, ist es erkannt" (Philoc. 23,8). Dieser Erkenntnis entsprechend hat Gott vorsorglich die Vorsehung angeordnet, indem er die zu jeder Freiheitsentscheidung passende Reaktion vorweg bereits arrangierte: „In allen seinen vorher getroffenen Anordnungen hat Gott entsprechend seiner Vorsehung einer jeden Tat unseres freien Willens für jede seiner Regungen als Verdienst ${ }^{77}$ das festgesetzt, was er ihr durch seine Vorsehung zuteil werden lässt, aber auch, was ihr durch

\footnotetext{
75 Vgl. von STRITZKr 1989, 82-84.

${ }^{76}$ Siehe den detaillierten Vergleich bei Le Bouldubc 2003, 398-400 (= 2006, 138-141).

7 Zu diesem ,Verdienst"-Gedanken, in dem die göttliche Vorsehung ,in Entsprechung" ( $\kappa \alpha \tau^{\prime} \alpha \zeta \zeta ́(\alpha v)$ zur menschlichen Freiheit agiert, was dem Kriterium der "Würdigkeit" bei Maximos entspricht, vgl. Princ. III 1,24; dazu: A. Fürst, OWD 7 (Berlin u.a. 2014) 57-59.
} 
den Zusammenhang der Dinge, die in der Zukunft liegen, begegnen wird. Nicht aber ist das Vorherwissen Gottes die Ursache für alle künftigen und durch den freien Willen entsprechend unserem Antrieb bewirkten Dinge $^{\prime \prime}($ Orat $.6,3) .{ }^{78} \mathrm{Ob}$ damit das Problem gelöst ist, darf bezweifelt werden. Zeitlich kommt nämlich der menschlichen Freiheitstat die Priorität zu, logisch aber dem Vorsehungshandeln Gottes, obwohl dieses vom zeitlich späteren menschlichen Handeln abhängt. Origenes hat diese Aporie bereits selbst gesehen (Philoc. 23,8) und dadurch zu lösen versucht, dass er die Erkenntnis nicht vom Objekt des Erkannten, sondern vom Subjekt des Erkennenden abhängig machte. Wenn für diesen, wie im Falle Gottes, die Zeit keine Rolle spielt, entfällt das logische Problem der zeitlichen Abfolge und ist die Aporie in dieser Hinsicht gelöst. Das entspricht der späteren, wirkmächtigen Vereinbarung von notwendiger Vorsehung und kontingenter Freiheit bei Boethitus: Aufgrund der Einheit und Ewigkeit seines Wesens erfasst Gott auch vielfältige kontingente (freie) Akte in ewiger Gegenwart (zeitlos) als bestimmt und notwendig (Cons. philos. V 3,1-6,48). ${ }^{79}$ Das Bemerkenswerte am Vorsehungskonzept des Origenes ist, dass er dieser theoretischen Schwierigkeit zum Trotz ats den genannten praktischen Argumenten heraus am Postulat der Freiheit festgehalten hat. ${ }^{80}$

Origenes ist nicht nur innerhalb der Theologiegeschichte, sondern auch innerhalb der Philosophiegeschichte - mit und vor Plotin - der Begründer einer Metaphysik der Freiheit. ${ }^{81}$ Die überragende Bedeutung, die dieser geistesgeschichtlichen Innovation zukommt, ist auch für die antiken Debatten über Sinn und Unsinn des Betens in Anschlag zu bringen. Origenes liefert der Frage, inwiefern innerhalb einer von der Vorsehung bis ins Einzelne wohlgeordneten und gelenkten Schöpfung und Geschichte Beten sinnvoll sein kann, ein neues Argument: Es geht nicht nur um die dankende und lobende Einstimmung in ein als 'Wille Gottes' interpretiertes Schicksal, wie es stoisch und auch platonisch möglich ist. Es geht auch nicht nur um die "Flucht des Einen zum Einen" (Plotin, Enn. VI 9,11,51; vgl. V 1,6,12), um die Einung von Gott und Mensch in der Gottwerdung wie im Platonismus. Alle diese Aspekte spielen auch im Konzept des Origenes eine Rolle. Vor allem aber geht es ihm beim Beten um eine geistige

\footnotetext{
${ }^{78}$ Es ist eine Missdeutung der Position des Origenes, wenn Grssel 1975, 164, ihn so versteht, dass das Vorauswissen Gottes und sein Vorsehungshandeln den Metıschen zwar nicht prädestinieren, sondern "prädisponieren” (vgl. 171). Nichts davon steht im Text des Origenes.

${ }^{79}$ Siehe dazu P. Hurbr, Die Vereinbarkeit von göttlicher Vorsehung und menschlicher Freiheit in der Consolatio Philosophiae des Boethius (Diss. Zürich 1976) 37-58.

${ }^{80}$ Näheres dazu bei E. SchocквnноF;, Zum Fest der Freiheit. Theologie des christlichen Handelns bei Origentes. TTS 33 (Mainz 1990) 135-137; H. S. Benjamins, Eingeordnete Freiheit. Freiheit und Vorsehung bei Origenes. SVigChr 28 (Leiden u.a. 1994) 71-121.

${ }^{81}$ Nunmehr umfassend dargestellt von Ch. HengstermanN, Origenes und der Ursprung der Freiheitsmetaphysik. Adamantiana 8 (Münster 2016).
} 
Begegnung zweier Freiheiten, der "ungezeugten Freiheit" Gottes, wie er bedeutungsschwer formulierte (In Lev. hom. XVI 6), und der geschaffenen Freiheit des Menschen, die in dieser Begegnung ihre Erfüllung finden. ${ }^{82}$

\section{Das Gebet als Gespräch mit Gott und die Praxis des Betens}

An diesem Punkt kommt es zu einer Konvergenz zwischen antiker und christlicher Gebetsphilosophie, die man zunächst vielleicht nicht vermuten würde. Bei allen philosophischen Vorbehalten gegen das Beten im Rahmen eines weitgehend deterministischen Weltbildes und besonders gegen das Bittgebet mit seinen verfehlten Annahmen und Inhalten wurde das Beten philosophisch doch auch verteidigt. Manchen Philosophen galt es als Ausdruck der Freiheit, die dem Menschen als nicht gänzlich determiniertem Wesen, peripatetisch gesprochen: im sublunaren Bereich, wo die Vorsehung nicht alles im Einzelnen regelt, doch bleibt. Vor allem aber galt das Gebet im Sinne der Kommunikation mit den Göttern als Ausdruck der inneren Verwandtschaft zwischen Mensch und Gott, an den sich anzugleichen in der Römischen Kaiserzeit zum obersten Ziel allen Philosophierens avancierte.

In diesem Sinne finden sich in den Schriften Platons, auf den auch das Programm der Angleichung an Gott zurückgeht (Tht. 176b; Rep. X 613b), viele sozusagen affirmative Referenzen auf das Beten. ${ }^{83}$ Als Ankertext für alle späteren Reflexionen zu dieser Thematik kann der Passus in den Nomoi betrachtet werden, in dem zur Frage nach den Grundlagen für die Gesetze des darin entworfenen Idealstaats Gott als "das Mass aller Dinge” aufgeführt wird, an dem sich orientiert, „wer einem solchen Wesen lieb und teuer werden will", und das ist der, "der ihm ähnlich" ist. Aus dieser Gottähnlichkeit des besonnenen Menschen, der eben dadurch "dem Gotte lieb" ist, ergibt sich für die Beziehung zwischen Mensch und Gott "der schönste und wahrste von allen Sätzen: dass für einen guten Menschen das Opfern und der ständige Verkehr mit den Göttern durch Gebete, Weihgeschenke und alle Formen der Gottesverehrung das schönste und beste und wirksamste Mittel zu einem glücklichen Leben und ihm daher auch ganz besonders angemessen ist" (Leg. IV 716c-d; Übers. Schöpsdau). Das Gebet gilt hier zusammen mit allen anderen Formen traditioneller Gottesverehrung als Ausdruck der besonderen Beziehung zwischen Gott und einem besonnenen und guten Menschen, der in dieser ethischen Hinsicht Gott ähnlich

\footnotetext{
${ }^{82}$ Ähnlich LöHr 1999, 95 als Fazit: „Für Origenes [...] ist das Gebet das Zentrum des Dialoges zwischen der freien Menschenseele und dem Gott, der dem Menschen nur im Raum der Freiheit begegnet."

${ }^{83}$ Beispiele bei von Sevbrus 1972, 1147f., etwa Phaedr. 279b-c, ein Gebet des Sokrates.
} 
ist, und eben dadurch als Weg zum Glück, als Beitrag zur Eudämonie. Das ist die für Platon nicht untypische Verbindung von konventioneller Frömmigkeit mit dem philosophischen Ideal der Gottähnlichkeit des Menschen, in der er das Gebet als Ausdruck dieses Verhältnisses auf eine neue Stufe hebt. Voraussetzung für die Lehre vom Gebet als einer Kommunikation mit Gott ist die Annahme, dass Gott dem eigenen Inneren verwandt ist. ${ }^{84}$

Damit hat Platon einmal mehr seinen Epigonen die Richtung gewiesen. Im Platonismus der Spätantike wird das Gebet als Gespräch mit Gott oder den Göttern und als Mittel der Vereinigung der Seele mit dem Göttlichen aufgefasst. ${ }^{85}$ In diesem Sinne wird es auch von Maximos von Tyros akzeptiert, der auf die Beter Sokrates, Pythagoras, Platon "und jeden anderen" verweist, "der sich je im vertrauten Gespräch mit den Göttern befand": Das "Gebet des Philosophen" ist nicht "eine Bitte um Dinge, die gegenwärtig nicht vorhanden sind" - das ist seine Ablehnung des Bittgebets -, sondern er hält es "für den Umgang und das Gespräch mit den Göttern über Dinge, die bereits vorhanden sind, und für einen Aufweis der Tugend" (or. $5,8) .{ }^{86}$ Für Plotin ist die wahre Form des Gebets nicht eine Anrufung Gottes , mit dem Schall von Worten", sondern das Sich-Ausstrecken der Seele nach dem Göttlichen, das mit dem Einen identisch ist (Enn. V 1,6,9-12). Der Mensch muss dafür selbst "Einer' werden, also alles ,Viele', das mit dem Materiellen und ethisch, Unreinen' einhergeht, ablegen (Enn. I 6,7,8-10; V 8,9,1-13). Beten ist damit die Hinwendung des Einen zum Einen (Enn. V 1,6,12; vgl. I 6,7,9; VI 9,11,51) und die Einswerdung von Gott und Mensch in der intellektuellen Schatu des Einen, die atfgrund der Transzendenz des Einen nur in einem überrationalen Modus erfolgen kann (Enn. IV 8,1,1; V $8,9,13-18){ }^{87}$ In diesem Sinne wird das Beten im Neuplatonismus dann aufgefasst, etwa bei Proklos, der im Kommentar zum Timaios in einem Exkurs zunächst die Gebetslehre des Porphyrios referiert, für den "das Gebet eine

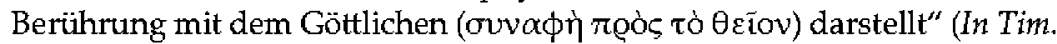
Plat. II [I 208,7f. Diehl]), und dann im selben Sinne (ebda. 210,30-211,19) seine Meinung im Anschluss an Jamblichs Position (ebda. 209,1-9) darlegt (ebda. 209,9-214,12) ${ }^{88}$ Für Jamblich gelangt die Seele ztu ihrer Vollkommenheit im beständigen Gespräch mit Gott (Myst. I 47f.); das theurgische Gebet hat die Kraft, die Seele zu Gott ztu erheben und mit ihm ztu vereinen (Myst. V 238-240). ${ }^{89}$ Auch Proklos gilt das philosophische Gebet , als Medi-

\footnotetext{
${ }^{84}$ Vgl. Dihle 1999, 29.

85 Ausführlich dazu Dhle 1999, 28-38. Vgl. auch von Stritzky 1989, I00f. Weitere Hinweise bei DilLon 2016.

${ }^{86}$ Vgl. vON SBVbrus 1972, 1151; vON STRITZKY 1989, $88 \mathrm{f}$.

${ }^{87}$ Vgl. von STRITzKr 1989, 91f. 94; Drfle 1999, 34. 37f.; HaLFWAssen 2015, 27. Es trifft daher nicht zu, wie BendinkLli 1997, 35 von „l'esclusione della preghiera dalla riflessione plotiniana" zu sprechen.

${ }^{88}$ Siehe dazu Bendinglir 1997, 47-49.

${ }^{89}$ Siehe ebda. 43-47.
} 
um und Modus des Ähnlichwerdens des Menschen mit seinem Ursprung, der Selbstklärung, der Berührung, Verbindung und Einung mit dem Göttlichen ${ }^{\prime 90}$ Im Gebet wendet sich die Seele ihrem Ursprung zu und kehrt zu ihm zurück (In Tim. Plat. II [I 208,14 Diehl]). Diese Rückkehr beschreibt Proklos als Aufstieg in fünf Schritten: von der Erkenntnis über die Aneignung, die Kontaktaufnahme und die Annäherung bis hin zur Vereinigung mit Gott (ebda. 211,10-30), und verbindet diesen Prozess der Vervollkommnung der Seele durch Angleichung an Gott mit einer zunehmend intensivierten Ausübung der Tugenden Glaube, Wahrheit, Liebe und Hoffnung (ebda. 212,20-25). „Gebet ist daher die sich als Anrede vollziehende, in der Erkenntnis des Wahren anfangende, von der Liebe nach der Einheit und Schönheit des göttlichen Seins bewegte und von der Hoffnung auf das Einleuchten des göttlichen Lichtes getragene Erhebung des Denkens, die sich glaubend in die Einung mit dem Ursprung aufhebt. "91 Diese "mystische Einung mit dem Göttlichen durch das Gebet" bedeutet die "Selbstaufgabe" des Betenden: ${ }^{92}$ "Die Eintung gründet das Eine der Seele in das Eine selbst der Götter und schafft eine Wirklichkeit unserer selbst und der Götter, durch die wir nicht mehr unser sind, sondern den Göttern (gehören), indem wir in dem göttlichen Lichte bleiben und von ihm im Kreise umfasst sind" (ebda. 211,24-28).

Eine eigens profilierte Stellung nimmt Porphyrios ein. ${ }^{93}$ Anders als sein Lehrer Plotin verbindet er in seiner theurgischen Philosophie das magische Gebet, das für Plotin eine rein innerweltliche Funktion hat (Enn. IV 4,40-44), ${ }^{94}$ mit dem mystischen Gebet dadurch, dass es für den Aufstieg der Seele zum Einen eine Rolle spielt: Das Gebet in Form der Anrufung eines ,Dämons' ist das Mittel für die vielen im philosophischen Sinn ungebildeten Menschen, diesen Aufstieg immerhin ein wenig anzugehen (Regress. an. fr. $2\left[29^{*}, 3-6\right.$ Bidez]). Damit gesteht Porphyrios auch dem Bittgebet eine Rolle $\mathrm{zu}$, was in der platonischen Tradition neu ist. Man kann darüber spektulieren, ob hier womöglich ein christlicher Einfluss vorliegt, ${ }^{95}$ was angesichts der Kommunikationskultur unter diesen kaiserzeitlichen Intellektuellen durchaus denkbar ist. Der Aufstieg zum Göttlichen ist aber auch in

\footnotetext{
${ }^{90}$ Siehe dazu Berbrwaltes 1979, 313-329. 391-394; Ders., Denken des Einen. Studien zur neuplatorischen Philosophie und ihrer Wirkungsgeschichte (Frankfurt a.M. 1985) 309-318 (das Zitat 311). Vgl. auch DirLe 1999, 33-36.

${ }^{91}$ BeIERwaltbs 1979, 327. Siehe dazu die Beiträge von L. Brisson, sPrayer in Neoplatonism and the Chaldaean Oracles. Porphyry, Iamblichus, Proclus", und D. A. LAYNB, "Cosmic Etiology and Demiurgic Mimesis in Proclus' Account of Prayer", in: Dillon/Timotin 2016, 108-133 bzw. 134-163.

${ }^{92}$ BeIERWALTBS 1979, 319.

${ }^{93}$ Vgl. von StritzKy 1989, 100-103; Dihle 1999, 33. Siehe atch A. Timotin, "Porphyry on Prayer. Platonic Tradition and Religious Trends in the Third Century", in: Dillon / Timotin 2016, 88-107.

94 Vgl. von Stritzky 1989, 95f.; Dafle 1999, 37.

95 Vgl. von STRITZKr 1989, 104
} 
den Augen des Porphyrios nur durch Philosophie möglich, und zwar platonisch traditionell als Angleichung des Menschen an das Göttliche durch die Abwendung vom Irdischen und Materiellen (Abstin. I 30) und durch die Reinigung von Affekten (Marcell. 31). Darin hat das Gebet als geistiges Opfer, mit dem der Mensch Gott dankt, seinen Platz und fällt wie bei Plotin mit der Schau zusammen (Abstin. II 34). ${ }^{96}$

Die christlichen Platoniker unterscheiden sich in diesem Punkt in nichts von ihren paganen Kollegen. Für Klemens von Alexandria, der in einem Kapitel der Stromateis eine der ersten christlichen Abhandlungen über das Gebet geschrieben hat (Strom. VII 35-49), ist das Gebet ein Gespräch mit

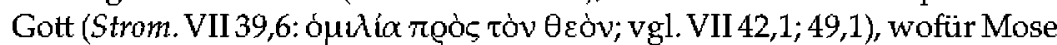
als Beispiel steht (Strom. VI 104,1). Es dient als Mittel zur Verbindung des gottähnlichen Gnostikers mit Gott (Strom. VII 40,3) und als Weg zur Schat Gottes (Strom. VII 49,4) ${ }^{97}$ Da der vollkommene Gnostiker der Freund Gottes ist (Strom. VII 42,3), ist "das Gebet in diesem Fall geistige Kommunion unter Freunden, von der es nicht genug geben kann" ${ }^{98}$ "Die ständige Gegenwart Gottes macht schließlich das ganze Leben des Gnostikers zum Festtag, dessen Ausdruck und Gestalt das den ganzen Tag durchwirkende Gebet ist" (vgl. Strom. VII 35,6.49,3). ${ }^{99}$ Origenes versteht das Gebet, wenn die Seele sich über das Irdische und Materielle zur Betrachtung Gottes erhebt (vgl. Cels. VII 44), als "würdigen und gebührenden Umgang" mit Gott (Orat. 9,2; vgl. In Ioh. comm. XXXII 27,338), womit er einen fundamentalen Beitrag zur christlichen Spiritualität erbringt. ${ }^{100}$ In der Spätantike haben diese Gedanken auf die monastische Spiritualität eingewirkt, in der das Gebet als Gespräch mit Gott und als Aufstieg zu ihm verstanden wird. Sie begegnen in der griechischen Tradition, etwa bei Evagrios Pontikos, ebenso wie in der lateinischen, hier vermittelt durch Johannes Cassianus, für den das Gebet als Gespräch mit Gott gleichbedeutend mit der contemplatio

\footnotetext{
${ }^{96}$ Vgl. ebda. $96 \mathrm{f} .98$.

97 Vgl. von Sevbrus 1972, 1207-1213; Grssel 1975, 246; von STrrTzKy 1989, 40f.; Le BoulLUEC 2003, 400-403 (= 2006, 141-144).

${ }^{98}$ LöHr 1999, 92 (vgl. $91 \mathrm{f}$ ).

99 Von Severus 1972, 1209. Vgl. von Stritzky 1989, 122f. L. Perrone, glemens vot Alexandrien und Origenes zum Gebet. Versuch eines Paradigmenvergleichs anhand ihrer Schriftstellen", in: M. HAvrda / V. HušEk / J. PlÁtová (Hg.), The Seventh Book of the Stromateis. SVigChr 117 (Leiden / Boston 2012) 141-164, zeigt, dass im Rahmen der oratio continua das ó $\mu \lambda \hat{\imath} \alpha$-Motiv bei Klemens stärker ausgeprägt ist als bei Origenes (151-160).

${ }^{100}$ So die Deutung von A. MoNACI CASTAGNO, ss Un invito alla vita perfetta. II $\Pi \varepsilon \rho l \varepsilon \dot{v} \chi \tilde{\zeta} \zeta$ di Origene", in: CocchInI 1997, [117-138] 126-138. Zur Interpretation von Orat. 9,2 im engeren Kontext siehe L. Prrrone, ghiera come ascesa, colloquio e conoscenza di Dio", in: Pizzolato / Ruzzr 2001, [123-139] 126-134, sowie PBrrons 2011a, 189-193, der zeigt, dass die contemplatio Dei der deificatio der Seele (vgl. dazu Orat. 27,13) entspricht (191). Zum Gebet als Aufstieg zu Gott in Contra Celsum (bes. Cels. VII 44) siehe Prrrong 2001, 18f.
} 
Dei ist (Conl. IX 18,1). ${ }^{101}$ Noch für Dionysios Areopagites ist das Gebet wesentlich Vereinigung mit Gott (Div. nom. 3,1). ${ }^{102}$ Am Anfang dieser christlichen Tradition steht, neben Klemens, Origenes. Seine Weisung, nicht für das Kleine und Irdische, sondern für das Himmlische und Große zu bitten (Orat. 14,1; 17,1f.), ${ }^{103}$ impliziert eben dieselbe Vorstellung vom Gebet als Gespräch und Vereinigung mit Gott, ${ }^{104}$ denn das Himmlische und Große ist eben dies: die innerste Vereinigung mit der Weisheit Gottes, eine gleichsam "mystische Gottverbundenheit" ${ }^{\text {"105 }}$ durch das "Wort" und den "Geist" Gottes, der, wie oben dargestellt, das Beten eigentlich erst ermöglicht. Das Kleine und Irdische kommt, wenn der Mensch sich betend sozusagen im "Geist" und in der "Wahrheit" aufhält (Orat. 14,1), als "Schatten" in dem Maße dazu, das Gott für den jeweiligen Beter für angemessen hält (Orat. $16,2 ; 17,1)$, weshalb man darum - im Sinne eines Bittgebets - eigentlich nicht zu beten braucht: "Ihr, die ihr geistig sein wollt, bittet in euren Gebeten um <das Himmlische und Große>, damit ihr beides erlangt, nämlich als Himmlisches das Himmelreich erbt und als Großes die größten Güter genießst. Das Irdische und Kleine aber, das ihr wegen der körperlichen Bedürfnisse braucht, möge euch der Vater dem jeweiligen Bedarf

${ }^{101}$ Belege für Evagrios (für diesen siehe auch PERrone 2011a, 130 Atun. 22) und weitere Hinweise zu Basileios von Caesarea, Johannes Chrysostomos bis hin zu Johatnes Klimakos und Maximos Confessor bei von Severus 1972, 1209. 1237-1240. Für Klemens, Origenes und Evagrios siehe auch A. Méhat, "Sur deux définitions de la prière”, in: G. DorrvaL / A. Le Boullubc (Hg.), Origeniana Sexta. Origène et la Bible. BEThL 118 (Leuven 1995) 115-120.

$102 \mathrm{Vgl}$. von SeVBrus 1972, 1247.

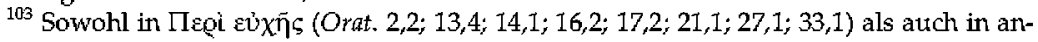
deren Schriften (In Matth. comm. XVI 28f; Cels. VII 44; VIII 46; vgl. In Ioh. comm. XXVIII 4,24f.; zu den Fragmenten aus der Psalmenkommentierung, Sel. in Ps. 4,4; 19,6; 27,1, vgl. VöLKRR 1931, 205 Atm. 1) greift Origenes immer wieder auf dieses Agraphon zurück; siehe dazu A. Rescr, Agrapha. Aussercanonische Evangelienfragmente in möglichster Vollständigkeit zusammengestellt und quellenkritisch untersucht. TU $5 / 4$ (Leipzig 1889) 114f. (Nr. 41) bzW. J. $\mathrm{H}$. Ror's, Die Sprüche Jesu, die in den kanonischen Evangelien nicht ïberliefert sind. Eine kritische Bearbeitung des von D. Alfred Resch gesammelten Materials. TU 14/2 (Leipzig 1896) 140 (Nr. 143). Erneut ist sein Vorgänger hier Klemens, Strom. I 158,2; IV 34,6; vgl. RBsch, ebda. 230-233; Perrone 2011a, 60; femer Grssel 1975, 172-180. Grnkt 1903, $53-82$ missversteht diesen Gedanken des Origenes als Spiritualisierung, die auf einer zu starken Transzendenz Gottes beruhe. Siehe auch F. Cocchins, „La Bibbia nel $\Pi \varepsilon \rho i \varepsilon \dot{\boldsymbol{v}} \chi \hat{\eta} \zeta$. Problematiche storico-esegetiche", in: Cocchinr 1997, [97-115] hier 100-103; H. Buchinger, "Gebet und Identität bei Origenes. Das Vaterunser im Horizont der Auseinandersetzung um Liturgie und Exegese", in: A. Gerhards / A. Dogker / P. Egenbauer (Hg.), Identitüt durch Gebet. Zur gemeinschaftsbildenden Funktion institutionalisierten Betens in Judentum und Christentum (Paderborn u.a. 2003), [307-334] 310f.

${ }^{104}$ Dieselbe Vorstellung steht hinter der Ansicht des Origenes, dass die Gestirne in ihrer vollkommenen Freiheit in ständigem Gebet begriffen sind (Cels. V 11; VIII 66f.).

${ }^{105}$ So W. Gesset, ${ }_{\text {is }}$ Kennt der origeneische Gebetslogos eine Theologie der Mystik des Gebetes?", in: Crouzgl / Quacouarklli 1980, [119-127] 127. Gegen VölKER 1931, 209f. weist Gessel nach, dass Origenes zwar keine entpersönlichte ,mystische Ekstase' meint, aber mit Orat. 9,2 und 10,2 doch ,einen Beitrag zu einer Theologie der Mystik geliefert hat" (127); siehe auch GBssBL 1975, 138f. 206-213. 248. 252. 
entsprechend noch zusätzlich geben“ (Orat. 14,1), "denn der Gott der Heiligen weiß" - laut Mt 6,8 - "als Vater, der er ist, was seine Söhne brauchen, weil das seiner väterlichen Erkenntnis entspricht" (Orat. 21,2).

Eine zweite Konvergenz betrifft das Verhältnis von Gebetstheorie und Gebetspraxis. Die christlichen wie die paganen Platoniker verbinden die Vorstellung des Gebets als eines Gesprächs mit Gott mit der konventionellen Gebetspraxis ihrer jeweiligen kulturellen tund religiösen Traditionen. ${ }^{106}$ Die antiken Platoniker pflegten ihrerseits ein religiöses Leben und beteten, wie das etwa von Proklos bezeugt ist, regelmäßig und sogar mehrmals am Tag. Zudem empfahlen fast alle Philosophen ihren Anhängern, sich am religiösen Leben der Gemeinschaft, in der sie lebten, zu beteiligen. Das galt zwar nicht für die Skeptiker, da sie die Existenz Gottes für ungewiss hielten (Sextus Empiricus, Adv. math. VII 401; IX 61), wohl aber für die Epikureer (fr. 169. 387 Usener) und, trotz ihrer radikalen Kritik am traditionellen Götterkult, auch für die Stoiker (SVF III 608 atıs Diog. Laert. VII 119). Epiktet hielt an den Ausdrucksformen der überkommenen Religion fest (Ench. 31), als entscheidend galt ihm freilich die rechte innere Einstellung, ohne die der Götterkult leeres Tun bleibt (Diss. III 21, 12-16). ${ }^{107}$ Seneca hatte hier ebenso wie beim Gebet eine zwiespältige Einstellung: Einerseits stellte er die ätußeren Formen der tradierten Frömmigkeit so radikal in Frage (ep. 90,28; 95,47f.; fr. 123 Haase aus Laktanz, Div. inst. VI 25,3), dass christliche Apologeten wie Augustinus sich dieses Arsenals heidnischer Kultkritik gerne bedienten (Civ. VI $10 \mathrm{mit}$ den Auszügen aus Senecas Kritik am Staatskult in De superstitione), andererseits lehnte er den Götterkult nicht vollständig ab (Benef. I 6,3): „All das wird der Weise beobachten, weil es durch die Gesetze geboten ist, nicht als ob es den Göttern gefiele" ( $f r .38$ Haase bei Augustinus, Civ. VI 10; Übers. Thimme). ${ }^{108}$

Die Christen kritisierten diese philosophische Einstellung tund insbesondere die traditionelle Gebetspraxis der Platoniker polemisch als inkonsequent (etwa Origenes, Cels. VI 17). Tatsächlich aber liegt hier strukturell eine Gemeinsamkeit zwischen heidnischen und christlichen Platonikern vor (die das Abgrenzungsbedürfnis und die Polemik provozierte). Die Christen rekurrierten in ihrer Praxis auf eine andere religiöse Tradition, die sich in ihren Gemeinschaften allmählich herausbildete, in erster Linie auf das Vaterunser (und in höchstem Maße auch auf die Psalmen). ${ }^{109}$ Sie taten damit im Gebetsleben das, was sie generell vorantrieben: die Schaffung einer christlichen Kultur und Spiritualität auf der Basis der Bi-

\footnotetext{
${ }^{106}$ Vgl. DiHLE 1999, 24f. 38-40.

${ }^{107}$ Vgl. von STRITZKY 1989, 78.

${ }^{108}$ VoN STRITZKY 1989, 77 bescheinigt Seneca eine „zwiespältige Stellung zum römischen Kult".

${ }^{109}$ Vgl. von Severus 1972, 1248-1250 (für das Stundengebet der Mönche). 1254 (für alle Christen).
} 
bel in Konkurrenz zur antiken Kultur und deren Basisüberlieferungen. ${ }^{110}$ In diesem neuen Rahmen plädierten die christlichen Theologen noch entschiedener als ihre platonischen Kollegen für eine regelmäßige Praxis des Betens, sehr energisch beispielsweise Gregor von Nyssa in seiner ersten Homilie über das Vaterunser, deren Thema ist, "Dass man überhatupt beten muss" (Orat. dom. hom. 1 GNO 7/2, 5). ${ }^{111}$ Daher dachten die Christen nicht nur intensiv über den Text des Vaterunsers nach, sondern auch über die innere und äußere Haltung des Beters, über Gebetsgesten, über Zeiten und Orte und sonstige Umstände für ein Gebet. Klemens von Alexandria ist hier wieder einmal vorangegangen (etwa Strom. VII 40,1-4). Daneben steht Tertullian, der den größeren zweiten Teil seiner Gebetsschrift ebenso praktischen Fragen widmete (Orat. 11-27) wie Cyprian den Schluss seiner Vaterunser-Auslegung (Dom. orat. 31-36). ${ }^{112}$ Origenes geht in seiner Gebetsschrift in einem Nachtrag auf Haltung und Ort beim Gebet, auf die Gebetsrichtung und in einer unfertig wirkenden Skizze auf die Hauptteile des Gebets ein (Orat. 31-33) ${ }^{113}$ und verbindet diese praktischen Aspekte mit den einleitenden philosophischen Reflexionen über den Sinn des Betens (Orat. 1-17). Indem er in letzteren das Beten als Akt der Freiheit verteidigt und als Ausdruck des Zusammenwirkens von göttlicher Vorsehungspädagogik und menschlichen Freiheitsentscheidungen atffasst, bietet er eine freiheitstheoretische Variante der Idee des Betens als Gespräch und vertratten Umgang mit Gott, der in der "Freiheit der Liebe" (In Gen. hom. VII 4) als Ziel des Lebens „ztum Freund wird für die, deren Herr er vorher war" $^{\prime \prime}$ (Orat. 1; vgl. 10,2; 27,14). ${ }^{114}$

\footnotetext{
${ }^{110}$ Beschrieben von F. M. Young, Biblical Exegesis and the Formation of Christian Culture (Cambridge 1997). Siehe atuch A. Fürst, "Origenes - der Schöpfer christlicher Wissenschaft und Kultur. Exegese utnd Philosophie im frühen Alexandria", in: Ders., Von Origenes und Hieronymus zu Augustinus. Studien zur antiken Theologiegeschichte. AKG 115 (Berlin/Boston 2011) $81-114$.

111 Siehe dazu A. Penati Brrnardint, sLa preghiera nel De Oratione Dominica di Gregorio di Nissa", in: CocchINi 1997, [173-181] 173-177.

112 Siehe dazu ausführlich von SBverus 1972, 1213-1217. 1219-1234.

${ }^{113}$ Siehe dazu Gessel 1975, 128-136; PERrone 2011a, 170-181; ferner St. HeID, "Gebetshaltung und Ostung in frühchristlicher Zeit" , Rivista di archeologia cristiana 82 (2006) [347-404] 350-366; L. Perrone, , Goldene Schalen voll von Räucherwerk (Apc. 5,8). Das Bild vom Gebet bei Origenes", JAC 50 (2007) 51-71.

${ }^{114}$ Im Hoheliedkommentar zitiert Origenes die einschlägige Passage aus Joh 15,15: „Ich werde euch nicht mehr Diener nennen, sondern Freunde" (In Cant. comm. II 1,30).
} 


\title{
Ikonographie des Betens
}

\author{
Barbara E. Borg
}

Die Forschung hat sich schwer getan, eine allgemeingültige Definition des Betens zu finden, und es ist leicht verständlich warum. Zu sehr hängen Inhalt und Form des Gebets von der Natur der Gottheit und dem postulierten Verhältnis zwischen Mensch und Gott ab. ${ }^{1}$ Doch wird man sich wohl auf die grundsätzliche Erklärung verständigen können, dass das Gebet eine Anrede an oder ein Gespräch mit der Gottheit sei. Der Text des Maximos von Tyros sowie die übrigen Beiträge diese Bandes zeugen von den komplexen und oft kontroversen Diskussionen um Form und Inhalt des Betens unter Philosophen und Theologen während der römischen Kaiserzeit, die nicht selten überaus aktuell erscheinen und eine große Nähe zwischen den antiken und unseren zeitgenössischen Diskursen suggerieren. Doch dürfen sie nicht darüber hinweg täuschen, dass die antike Praxis, wie sie sich aus literarischen, vor allem aber auch aus epigraphischen und bildlichen Quellen erhellt, in der Mehrheit erheblich einfacher, und durch etablierte Konventionen und formale Regeln strukturiert war. Für die griechische wie die römische Kultur ist oft bemerkt worden, dass sich das Repertoire an Gebeten in einem relativ engen Rahmen bewegt und weitgehend auf Bitten und Dank beschrärkt war. Bitten scheinen zudem weit in der Überzahl zu sein. Während der mehr oder weniger ausführliche Preis der Gottheit oft Teil solcher Gebete ist, ist die reine Kontemplation oder Anbetung dagegen überaus selten. ${ }^{2}$ Maximos' Traktat wendete sich somit gegen die gängige Praxis seiner Zeit.

Anderes ist dagegen von bildlichen Darstellungen des Betens zu erwarten, denen dieser Beitrag gewidmet ist. Bilder haben in aller Regel eine affirmative Funktion. Zudem finden sich Darstellungen von Betenden, von einigen mythologischen Bildern vor allem auf attischen und unteritalischen Vasen abgesehen, ausschließBlich auf Denkmälern, die letztlich zumindest auch der Selbstdarstellung ihrer Auftraggeber dienten. Von Ihnen kann daher angenommen werden, dass sie die tatsächliche, gesellschaftlich akzeptierte Praxis des Betens in idealtypischer Form darstellen.

\footnotetext{
${ }^{1}$ S. den Überblick in JAKOv / VoutiRas 2005, 106-108.

${ }^{2}$ VERSNBL 1981, der betont, dass "prayer [is] born out of need" und dass Dankesgebete sehr selten sind. Zum vornehmlichen Bittcharakter römischer Gebete s. auch V. FYNTIKoGLOU „Gegenstand des Gebetes", in: Fyntrkoglou / VoutrRas 2005, 156f. mit Bibliographie.
} 
Wie gebetet wurde, und wie bildliche Darstellungen des Betens identifiziert werden können, lässt sich am besten an Darstellungen eines ausgedehnteren Kultgeschehens sowie Beschreibungen von Gebetsgesten in schriftlichen Quellen - literarischen wie epigraphischen - ablesen. Der übliche Kontext des Betens war das Opfer. Das Verhältnis von Griechen und Römern zu ihren Göttern war essenziell als ein reziprokes gedacht, in dem den Göttern Ehre erwiesen und Gaben dargebracht wurden, welche diese dann mit Wohltaten an die Stifter erwiderten. Insofern war jedes Opfer nicht nur von - laut gesprochenen - Gebeten begleitet, sondern können Opfer auch selbst als - nonverbale - Gebete oder Gebetsteile angesehen werden. ${ }^{3}$ Die Äquivalenz von Opfern und Beten lässt sich in der römischen Bildkunst vielleicht am besten auf Sarkophagen sehen, wo die Grabherrin wahlweise bei einem Weihrauchopfer oder in betender Haltung mit erhobenen Armen dargestellt wird. Wir kommen auf diese Darstellungen zurück. Im Zusammenhang des vorliegenden Bandes möchte ich mich jedoch auf Bilder konzentrieren, die durch Gesten und Gebärden die Anrede an die Gottheit zum Ausdruck bringen, und Opferbilder nur am Rande behandeln. ${ }^{4}$ Nach einem Überblick über die Ursprünge der römischen Gebetsikonographie in der griechischen Kunst, wende ich mich römischen Darstellungen zu, um am Ende auf die Übernahme des Gebetsgestus in die christliche Kunst des 3 . und frühen 4 . Jh.s einzugehen.

\section{Ursprung des römischen Gebetsmotivs}

Die verbreitetste Gebetsgeste zeigt die Betenden mit mehr oder weniger stark erhobenen und vom Körper abgespreizten Armen und mit nach außen in Richtung auf die (imaginäre) Gottheit gekehrten Handflächen. ${ }^{5}$ Streng genommen handelt es sich um Gesten, die eine Konversation oder eine Reaktion auf ein (imaginiertes) Gegenüber anzeigen, und nicht notwendigerweise exklusiv auf die Kommunikation mit einer Gottheit beschränkt sind. In Einzelfällen hat diese Ambiguität daher zu Unsicherhei-

\footnotetext{
${ }^{3}$ S. Jakov / Voutiras 2005, 119-125, und Fyntikoglou / Voutiras 2005, 151-168, für einen Überblick über Quellen und Ergebnisse; zum griechischen Gebet s. auch W. BuRKERT, Griechische Religion der archaischen und klassischen Epoche. Die Religionen der Menschheit 15 (Stuttgart 2011) 118-121.

${ }^{4}$ Die Literatur zum antiken Opfer ist gewaltig. Ein guter Überblick findet sich in V. Lambrinoudakis / J. C. BaLty (Hg.), Thesaurus cultus et rituum antiguorum (ThesCRA), Bd. 1, Processions, sacrifices, libations, fumigations, dedications (Los Angeles 2004) 59-268.

${ }^{5}$ Zu den verschiedenen Gesten des Betens s. Jakov / VoutiRas 2005, 119-123. Zum beschriebenen Gestus im Speziellen s. ConnelLy 2007, 173-176; literarische Quellen: JAKov / VoutiRas 2005 132-135; epigraphische Quellen: ebda. 135f; bildliche Quellen: ebda. 137141. Es scheint allerdings, dass die beschriebene Geste nicht immer als Gebet aufgefasst wurde. Von minoischer und mykenischer Zeit bis ins mittlere 7. Jh. v. Chr. charakterisierte sie (auch) Gottheiten, und wird daher als Epiphaniegestus interpretiert: ebda. 120f.
} 


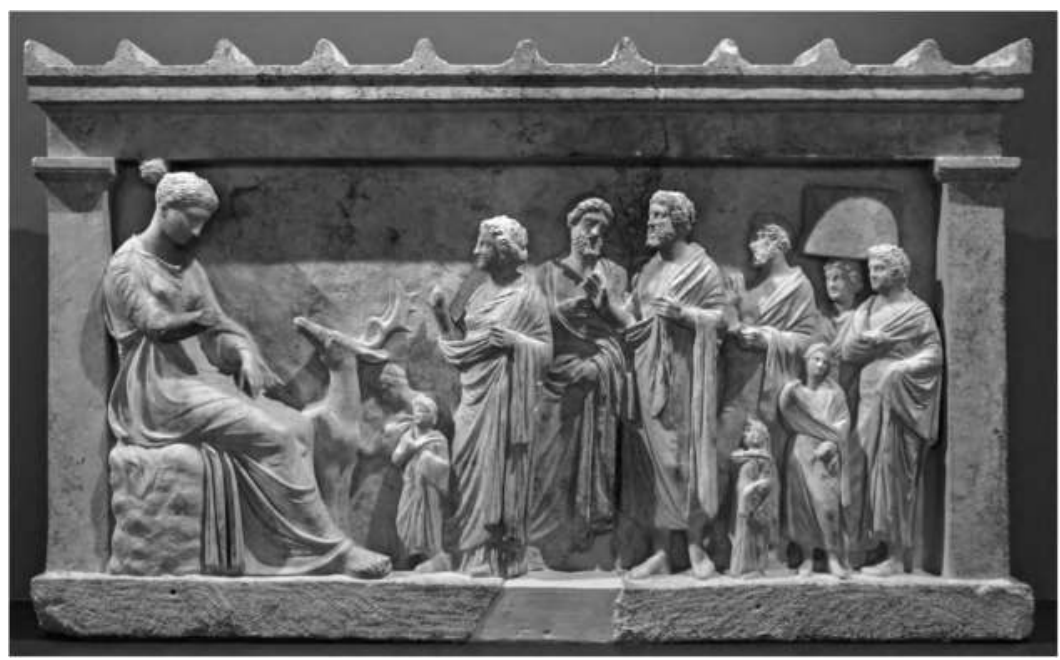

Abb. 1: Votivrelief mit Betenden vor Artemis. Brauron, Arch. Mus. Inv. 1153.

ten bei der Interpretation geführt. Aber in der Masse scheint sich ein antiker Konsens herausgebildet zu haben, der diese spezielle Armhaltung in erster Linie als Beten im Sinne einer Ansprache an die Gottheit auffasst, und in der Fachsprache gewöhnlich als Oransgestus oder Orantengestus bzw. -motiv bezeichnet wird. ${ }^{6}$

Nach dem oben Gesagten ist es nicht weiter erstaunlich, dass wir Figuren von Betenden zunächst vor allem in Heiligtums- und Opferszenen finden, wo sich oft mehrere Personen in einer Art Prozession dem Altar und der Gottheit nähern (Abb. 1). ${ }^{7}$ Sowohl auf attischen Vasen als auch auf zahlreichen Weihereliefs unterschiedlicher Provenienz finden sich solche Szenen seit dem 5. Jh. v. Chr., und häufiger dann seit dem 4. Jh. ${ }^{8}$

Außerhalb solcher narrativen Szenen sind Betende jedoch selten. Wie Carola Reinsberg zuletzt gezeigt hat, sind Darstellungen vereinzelter Betender zudem fast ausnahmslos weiblich, auf Karien und das westliche Kleinasien beschränkt, und auffallend oft mit dem Demeterkult verbun-

\footnotetext{
${ }^{6}$ Strittig ist, ob nur ein Beten mit beiden erhobenen Armen als Oransmotiv bezeichnet werden soll, oder auch das Beten mit einem erhobenen Arm. Ich verwende hier den Begriff für beide Ikonographien.

${ }^{7}$ Brauron, Museum 1153: Comella 2002, 127 Abb. 126; 206 Kat. Brauron 3.

${ }^{8}$ Jakov / Vou'Iras 2005, 137-140 Taf. 16-23 (nicht alle Beispiele sind gänzlich überzeugend); s. auch Vasen: ConNELly 2007, 173-176 mit Abb. 6,5-7; Weihreliefs: Comella 2002, mit zahlreichen Beispielen aus klassischer Zeit; zu Opferbildern auf griechischen Weihreliefs s. auch M. Edelmann, Menschen auf griechischen Weilheliefs. Quellen und Forschungen zur antiken Welt 33 (München 1999), die allerdings nicht eigens auf den Gebetsgestus eingeht.
} 


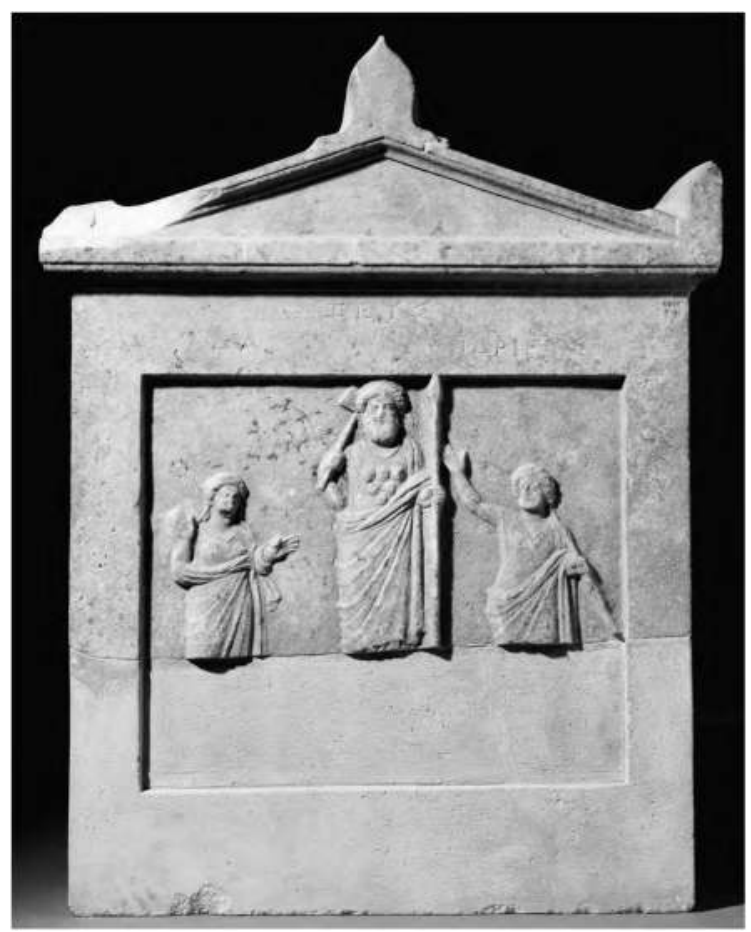

$\Lambda$ bb. 2: $\Lambda$ da und Idrieus vor Zeus Labraundos auf einem Relief aus Tegea. London, BMiIv. 1914.7-14.1.

den. ${ }^{9}$ Besonders zahlreich sind Terrakotten von Betenden, von denen die frühesten dem späten 6 . und frühen 5 . Jh. v. Chr. angehören und aus dem Demeter und Kore Heiligtum von Halikarnass stammen; im Verlauf des 4. Jh.s und im Hellenismus werden Beterinnen in der Koroplastik (Terracottaplastik) dann häufiger und kommen auch andernorts vor. ${ }^{10}$ Angesichts der engen Verbindung der Beterinnenikonographic mit dem Demeterkult, wäre die Beschränkung des Gebetsgestus in der Rundplastik auf Frauen erklärlich, wenn die Figuren sich tatsächlich, wie Reinsberg vermutet, ausschließlich auf die Thesmophorien bezögen, ein Demeterfest, von dem Männer ausgeschlossen waren. ${ }^{11}$ Dies lässt sich jedoch nicht sicher nachweisen und steht im Widerspruch zu den zahlreichen Betenden

\footnotetext{
${ }^{9}$ Reinsberg 2005, 300-302. Von den Ausnahmen in Jakov / Voutiras 2005, 140f. Kat. 83. 87-89, ist m.E. keine völlig überzeugend; zum sog. Betenden Knaben in Berlin s.u. $\Lambda \mathrm{nm}$. 15.

${ }^{10}$ Reinsberg 2005, 302; vg1. Jakov / VoutiRas 2005, 141 Kat. $94-95$ mit $\Lambda$ bb.

11 ReINSberg 2005, 306.
} 
beiderlei Geschlechts auf Weihereliefs, zu den Terrakotten, und zu einem bedeutenden Relief aus Tegea im British Museum (Abb. 2). Es zeigt Ada, eine Schwester des persischen Satrapen und Herrschers über Karien Mausolos, die hier zusammen mit ihrem Ehemann Idrieus, dem Nachfolger des Mausolos, mit erhobenen Armen betend vor einem Bild des Zeus Stratios / Labrandeus (dem insbesondere im Heiligtum von Labraunda verehrten Zeus) erscheint. ${ }^{12}$

Das Relief ist aber noch in anderer Hinsicht von großer Bedeutung: es gibt nämlich eine spezifische Ikonographie und Form der Selbstdarstellung wieder, die offenbar bereits seit dem 4. Jh. v. Chr. für Mitglieder der karischen Herrscherdynastie verwendet wurde und sich vor allem in der kaiserzeitlichen Großplastik größerer Beliebtheit erfreute (Abb. 3). ${ }^{13}$

Sie zeigt eine stehende Frau in langem Chiton und Mantel. Der linke Oberarm liegt relativ eng am Körper an, der rechte ist leicht abgespreizt, die Unterarme sind angewirkelt. Der rechte Unterarm ist aufgestellt, der linke nach vorne gestreckt und leicht nach außen gedreht; beide Handflächen sind üblicher Gebetspraxis entsprechend nach außen gekehrt. Der Typus weist zudem eine charakteristische Gewanddrapierung auf. Der Mantel ist eng um den Unterkörper geführt und zieht sich in eleganten Faltenschwüngen vom rechten Fuß zur linken Hüfte. Um den Oberkörper spannt er sich wie ein Segel auf. Er bedeckt den Hinterkopf der Betenden sowie den rückwärtigen Teil ihrer Schultern, umschlingt den abgespreizten rechten Oberarm und Ellenbogen, bildet vor dem Körper einen faltenreichen Bausch und fällt dann über den angewinkelten linken Unterarm herab.

Wie Reinsberg zu Recht feststellt, ist die enge ikonographische Übereinstimmung zwischen der Relieffigur der Ada und den unten zu besprechenden großsplastischen Wiederholungen nur unter der Annahme eines allen gemeinsam zugrundeliegenden, ebenfalls rundplastischen Originals zu erklären, dass nach seinem Stil zu urteilen im früheren 4 . Jh. v. Chr. entstanden sein muss. ${ }^{14} \mathrm{Ob}$ dieses mit einer der von Plinius als adorantes, admirantes et adorantes, und adorantes sacrificantesque bezeichneten Figuren identisch ist, die er Boidas, Euphranor, Apelles, Bryaxis und Sthen(n)is zuschreibt (Nat. XXXIV 73.78.86.90), muss Spekulation bleiben. ${ }^{15}$ Entschei-

\footnotetext{
${ }^{12}$ So schon JonGKers 1948, 31-33, Abb. $6=$ London, British Museum, Greek and Roman Department, Reg. 1914.7-14.1: WAYwBLL 1993; REINSEBRG 2005, 298f. Die Namen sind beigeschrieben, die Futnktion des Reliefs umstritten. Ada und Idrieus regierten Karien 351/350$344 / 343$ v. Chr.

${ }^{13}$ JoNG KEES 1948.

${ }^{14}$ Grominy 2004, 301f.; Reinsereg 2005, 298. Es kann allerdings keine Rede davon sein, dass in dieser Hinsicht ,Einigkeit' herrsche. Für die bereits von Brbber 1977, 198, geät:ßerte Vermutung, das Original der römischen Replikenreihe sei eine römische Schöpfung in Anlehnung an griechische Vorbilder des 4 . Th.s gewesen, sprechen sich etwa dagegen noch Albxandridis 2004, 79, und Moltesen 2007, 132, aus.

${ }^{15}$ JoNGKens 1948: Bryaxis; R. KABUS-JAHN, Studien zu Frauenfiguren des vierten Jahthunderts vor Christus (Darmstadt 1963) 69f.: Euphranor; gegen eine Zuschreibung schon KLAuser 1959, 125; BIEBER 1977, 198; ditto REINSBERG 2005, 298, und die moderne Forschung generell. Auch ist unklar, wen diese Statuen jeweils darstellten. Plinius' Formulierung lässt vermu-
} 


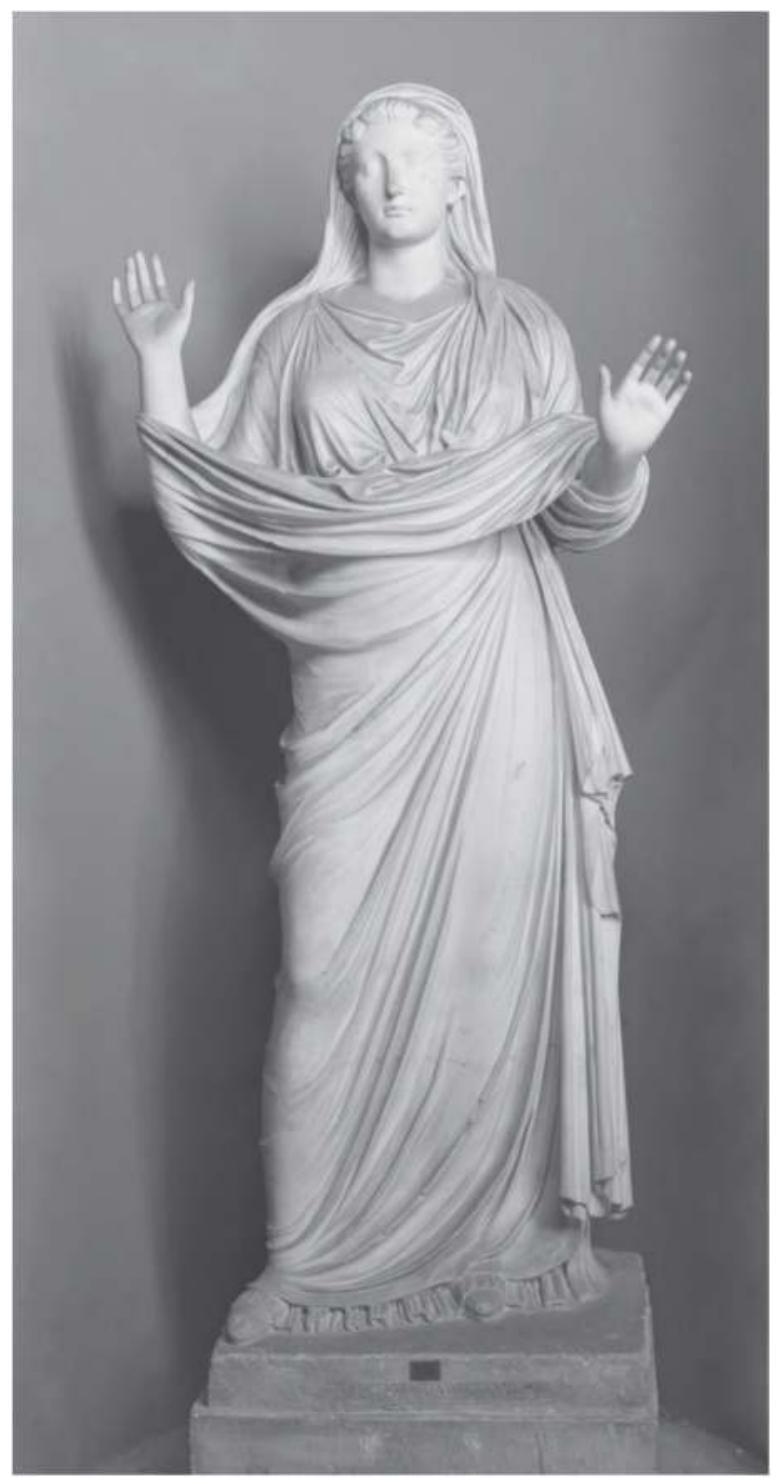

Abb. 3: Statue der Livia als Orans aus Otricoli. Vatikanische Museen, Gall. dei Busti 352.

ten, dass es sich vielleicht nicht um Bilder von Gottheiten handelte, sondern um menschliche Beterinnen. In jedem Fall ist die Boidas-Statue männlich und kommt somit nicht in Frage. Sie wird gelegentlich in dem "Betenden Knaben" in Berlin erkannt (zur Skulptur 
dend ist in unserem Zusammenhang zweierlei: Erstens, dass die Ikonographie nicht nur in der Klein- und Reliefkunst auftrat, sondern bereits im 4. Jh. erstmals auch für großplastische Bilder verwendet wurde, und zweitens, dass sie von den Hekatomnidenfrauen, den weiblichen Angehörigen der im 4. Jh. herrschenden karischen Dynastie, als adäquate Form der öffentlichen Selbstdarstellung gewählt wurde. ${ }^{16}$

Als älteste erhaltene Wiederholung des Oranstypus wird oft die sogenannte Artemisia vom berühmten Mausoleum von Halikarnass angesehen, einem der sieben Weltwunder, das Artemisia II., Schwester und Gemahlin des Mausolos und Vorgängers von Idrieus, für ihren Gatten und zweifellos für die gesamte Dynastie Mitte des 4. Jh.s errichtet ließ. ${ }^{17}$ Die genatue Anbringung der Statue am Mausoleum ist ebenso umstritten wie ihre Identifizierung. Einigermaßen sicher ist aufgrund der Frisur, dass es sich um eine (retrospektive?) Porträtstatue handelt, und gemeinhin wurde angenommen, dass sie Artemisia selbst zeigt. Doch handelt es sich bei der Statue lediglich um eine der besterhaltenen Figuren des Mausoleums, das vermutlich insgesamt 36 kolossale Statuen in den Interkolumnien der umlaufenden Sätlenstellung des Tempelgrabes zeigte, welche vielleicht Vorfahren und zeitgenössische Mitglieder der Hekatomnidendynastie darstellten. ${ }^{18}$ Anders als auf dem Relief der Ada ist allerdings nur der linke Unterarm der Figur leicht aufgestellt, der rechte dagegen horizontal nach vorne gestreckt. ${ }^{19}$ Damit dürfte es sich eher um einen Spendegestus handeln, die Dargestellte also als Opfernde gezeigt sein, die allenfalls nur mit der Linken betet. Waywell weist eine Reihe weiterer Fragmente vom Mat1-

G. Zrmmer, Der Betende Knabe: Original und Experiment [Frankfurt/M. 1997] mit der älteren Literatur), doch hat schon KLAUSER 1959, 123, in ihm ein athletisches Siegerbild erkannt; so zuletzt auch S. LBHManN, "Der Betende Knabe. Zur kunsthistorischen Finordnung und Deutung eines frühhellenistischen Siegerbildes", Jahreshefte des Österreichischen archäologischen Instituts in Wien 66 (1997) 117-128; wieder als Orant angesprochen von REINsBERG 2005, 300 mit Anm. 30.

${ }^{16}$ Die Zunahme der koroplastischen Beterinnen lässt sich daher vielleicht teilweise durch die Prominenz der großplastischen und herrscherlichen Oranten erklären.

${ }^{17}$ Mausolos verstarb $353 \mathrm{v}$. Chr. Zum Monument s. vor allem The Maussolleion at Halikarnassos. Reports of the Danish Archaeological Expedition to Bodrum, 8 Bde. (Copenhagen 19812004); WArwel 1978; B. F. Cook, Relief sculpture of the matusoleum at Halicarnassus (Oxford 2005); W. HoвpFNer, Hatikarnassos und das Maussolleion. Die modernste Stadtanlage und der als Weltwunder gefeierte Grabtempel des karischen Königs Maussollos (Darmstadt / Mainz 2013).

${ }^{18}$ Waywell 1978, 21-25. 40-53. 70-72. 103-105 no. 27 Taf. 13; Waywbll 1993, 80f.; G. B. WAYwBLL, „Sculpture in the Ionian renaissance. Types, themes, style, sculptors. Aspects of origins and influence", in: J. Is AGBR ( $\mathrm{Hg}$ ), Hekatomnid Caria and the Ionian renaissance: acts of the international symposium at the Department of Greek and Roman Studies, Odense University, 28-29 November, 1991. Halicarnassian studies 1 (Odense 1994) [58-72] 63f. 65f. Abb. 13; C. Madgrna, „Die letzten Jahrzehnte der spätklassischen Plastik", in: P. C. Bol (Hg), Die Geschichte der antiken Bildhauerkunst, Bd. II, Klassische Plastik (Mainz 2004) [303-382] 303311.

${ }^{19}$ WAYWell 1978, 104; ReInsBbrg 2005, 299 mit Anm. 22. 
soleum einer kolossalen Opfergruppe $\mathrm{zu}^{20}$ und in diesen Kontext würde auch die sog. Artemisia bestens passen.

Einiges spricht allerdings dennoch dafür, dass auch die Ada-Ikonographie für großplastische Bildnisse der Hekatomnidenfrauen verwendet wurde, möglicherweise sogar am Mausoleum. Auffällig ist nämlich die, abgesehen vom Gestus des rechten Armes und der entsprechend abweichenden Führung des vor dem Oberkörper liegenden Gewandbausches vor allem auf der rechten Seite der Figur, große Ähnlichkeit der sog. Artemisia mit dem Ada-Typus und der Hauptreihe der römischen Repliken, so dass beide Ikonographien als Varianten derselben statuarischen Erfindung angesehen werden können. Angesichts der zahlreichen Fragmente vom Mausoleum, die zu ähnlichen Figuren wie der ,Artemisia' gehören, und des Opferthemas, ist nicht auszuschließen, dass zumindest einige der Statuen Variationen nach einem gemeinsamen Modell waren, tunter denen sich auch eine oder mehrere mit Gebetsgestus befunden haben könnten. In jedem Fall belegen die Figuren vom Mausoleum, dass eine prominente Herrscherfamilie ihre Gottesfürchtigkeit als zentralen Aspekt der dynastischen Selbstdarstellung wählte, und das Adarelief zeigt, dass die in der Kaiserzeit beliebte Ikonographie der Betenden bereits in den 340 er Jahren v. Chr. für eine prominente Angehörige der Dynastie als geeignet angesehen wurde. ${ }^{21}$ Auch ist wahrscheinlich, dass das groß plastische Vorbild der Relieffigur eine Hekatomnide darstellte, die aus chronologischen Gründen dann wohl Artemisia gewesen sein dürfte. ${ }^{22}$ Eine Wiederholung dieser Statue auf dem Mausoleum würde damit weiter an Wahrscheinlichkeit gewinnen. ${ }^{23}$ Die Verwendung des Gebetsmotivs für prominente, großsplastische Porträtstatuen wird schließlich auch durch Plinitus bestätigt, der zwar nicht ausdrücklich von Porträts spricht, dessen Formulierungen aber auch nicht den Eindruck erwecken, er spreche von Götterbildern, deren Namen er sonst wohl genannt hätte.

Angesichts der zunehmenden Präsenz von Frauen im öffentlichen Raum, die seit dem späteren 4 . Jh. hätufiger als selbständige Stifterinnen, meist im Umfeld von Kulten und Festen, im öffentlichen Bereich auftraten

\footnotetext{
${ }^{20}$ WAYWBLL 1978, 44f. $72 \mathrm{f}$

${ }^{21}$ Ein Relief aus Halikarnass in Rom zeigt eine weitere Wiederholung des Typus, doch trägt die Figur hier einen polos, und könnte damit sowohl Demeter als auch eine ihrer Verehrerinnen wiedergeben: A. LAUMONIRR, Les cultes indigènes en Carie. BEFAR 188 (Paris 1958) 627. 636 Taf. 16,1-2.

${ }^{22}$ So W AYwBLL 1993, 81, der an eine Weihestatue im Heiligtum von Labraunda denkt; Reinsberg 2005, 302f., deren Datierung des Urbildes um $370 \mathrm{~m}$. E. mehr überzeugt als diejenige von Gвоміму 2004, 302: um 390.

${ }^{23}$ Dies auch vermutet von WArweLL 1978, 41f, allerdings aufgrund von falschen Voraussetzungen.
} 


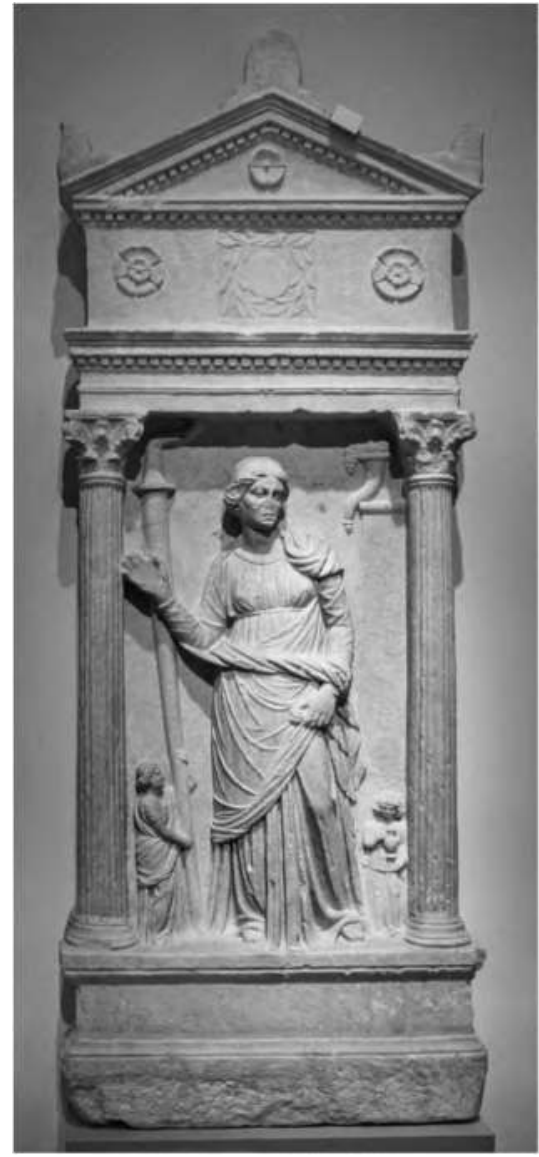

Abb. 4: Grabrelief einer Demeterpriesterin aus Smyrna. Berlin, Staatl. Mus., Antikenslg. Sk 767.

und dafür geehrt wurden, ${ }^{24}$ könnte man erwarten, dass die Ikonographie der Orans für ihre Ehrenstatuen als besonders angemessen erschien. Im

\footnotetext{
${ }^{24} \mathrm{Zu}$ den öffentlichen Rollen von und Ehrungen für Frauen s. R. v. Bremen, The limits of participation. Women and civic life in the Greek East in the Hellenistic and Roman periods. Dutch monographs on ancient history and archaeology 15 (Amsterdam 1996); U. KRoN, "Priesthoods, dedications and euergetism. What part did religion play in the political and social status of Greek women?", in: P. IIELLSTRöm (I Ig.), Religion and power in the ancient Greek world. Boreas 24 (Uppsala 1996) 139-182; J. C. Eule, Hellenistische Bürgerinnen aus Kleinasien. Weibliche Gewandstatuen in ihrem antiken Kontext (Istanbul 2001); M. DiLlov, Girls and women in classical Greek retigion (London / New York 2001) (klassische Zeit); CON NELLY 2007; Mylonopoulos 2013.
} 
erhaltenen vorkaiserzeitlichen Denkmälerbestand sind solche Darstellungen jedoch auf Reliefs beschränkt, die in aller Regel, wie das Ada-Relief, einen klaren Bezug auf einen bestimmten Kult besitzen. Im erhaltenen Statuenbestand ist das Oransschema nicht sicher nachweisbar. ${ }^{25}$ Zwar sind die Arme der Statuen oft gebrochen, aber von den Resten gewinnt man doch den Eindruck, dass selbst für Priesterinnen zumeist Statuentypen ohne spezifisch religiöse Konnotationen verwendet worden sind, ${ }^{26}$ und auf das priesterliche Amt durch die Zufügung von Attributen wie Schlüsseln, paterae (Spendeschalen) oder Kästchen, oder nur durch die Inschrift verwiesen wurde. ${ }^{27}$ Ihre Pietät, die oft als Grund für die Ehrung angegeben wird ${ }^{28}$ ist jedenfalls nicht aus dem ikonographischen Schema, sondern nur ats den, oftmals verlorenen, Attributen erkennbar. Dieser Eindruck wird durch die Mehrzahl der Grabreliefs bestätigt, auf denen Priesterinnen üblicherweise ebenfalls durch Schlüssel oder Kultparaphernalia gekennzeichnet werden. Dennoch mag das Fehlen der Orans teilweise auf die Überlieferungslage zurückzuführen sein, da von den hellenistischen Ehrenmonumenten für Priesterinnen und Euergetinnen zumeist nur die Sockel mit den Inschriften, nicht aber die Statuen selbst erhalten sind. Darauf deuten jedenfalls atuch die von Plinitus erwähnten Beispiele. Und schließlich stellen mehrere kleinasiatische Grabreliefs, vor allem aus Smyrna und Lykien, die Verstorbenen im Gebetsgestus mit einer erhobenen Hand dar $\left(\right.$ Abb . 4). ${ }^{29}$

\footnotetext{
${ }^{25}$ Für Beispiele s. die Literaturr in Anm. 24 und Dillon 2010.

${ }^{26}$ Allerdings ist es möglich, dass Statuentypen von Statuen der Göttinnen abgeleitet sind, denen sich die Dargestellten oder die Dedikanten verbutnden fühlten: zur Angleichung von Priesterinnen an die Gottheiten, denen sie dienen, s. Connelly 2007, 104-115.

${ }^{27}$ Die umfangreichste Dokumentation von Priesterinnenstatuen findet sich ebda.; für weibliche griechische Porträtstatuen insgesamt s. Dillon 2010, 66. 70-75; sie bleibt selbst in Hinblick auf die sog. Artemisia und iht noch am nächsten verwandte Statuen, die sie auf Priesterinnen bezieht, angemessen vage: ,the more active gestures allowed by these statue formats may have been meant to evoke the publicly performed religious duties for which the women were being honored" (66). Die erhaltenen Armstümpfe lassen jedenfalls selten die Rekonstruktion eines Gebetsgestus $\mathbf{z t}$, und deuten eher auf mit einer Hand gereichte oder präsentierte Attribute oder Opfergaben.

${ }^{28}$ Mrlonopoulos 2013, 132f.

${ }^{29}$ E. Pfurl / H. Möktus, Die ostgriechischen Grabreliefs, Bd. 1 (Mainz 1977) 136f. Nr. 405 und 407 Taf. 66, beide 2. Jh. v. Chr.; sowie P. ZANKER, "The Hellertistic grave stelai from Smyma: identity and self-image in the polis", in: A. W. BuLLoch ( $\mathrm{Hg}$.), Images and ideologies. Self-definition in the Hellenistic world. Hellenistic culture and society 12 (Berkeley, CA 1993) [212-230] 226, der auf den statuarischen Charakter der Darstellungen hinweist (215); ConNBLly 2007, 246-253 mit Abb. 8. 19-22. Dass es sich bei diesen wegen der von einer Dienerin gehaltenen Fackel im Hintergrund um Demeterpriesterinnen handelt, wie meist behauptet wird, ist nicht unumstritten. Filges 1997, 195 mit Anm. 933, hat zu Recht darauf hingewiesen, dass die große Zahl der Reliefs in einem relativ kurzen Zeitratum von ca. 170$100 \mathrm{v}$. Chr. ungewöhnlich wäre, sollte es sich bei allen Dargestellten um Demeterpriesterinnen handeln. Er erwägt vielmehr, ob die Fackel nicht in den sepulkralen Zusammenhang gehört.
} 
Bei allen Unsicherheiten ist jedenfalls festzuhalten, dass Ikonographien der Frömmigkeit, die auch Gebetsgesten einschließen, seit dem 4. Jh. v. Chr. eine Form der öffentlichen Selbstdarstellung von Frauen wurden, und dass den Hekatomniden dabei offenbar eine Schlüsselrolle zukam. Als Gründe hierfür darf man sowohl die Tatsache vermuten, dass einerseits Frauen öffentliche Rollen vornehmlich im kultischen Bereich zugestanden wurden, und dass letzterem andererseits eine staatstragende Funktion zukam, welche auch die Bedeutung der den Kult vollziehenden erhöhte.

\section{Kaiserzeitliche Oranten (Beterinnen)}

Außerhalb Kleinasiens hat die Orans erst in der Kaiserzeit größere Bedeutung erlangt. Den Anstoß dazu könnte Livia, die Frau des Augustus, gegeben haben, für die mindestens eine, vielleicht atuch zwei Oransstatuen überliefert sind. Am besten erhalten, wenn auch eher summarisch gearbeitet, ist eine Statue, die 1778 oder 1779 in Otricoli in einem Gebätude gefunden wurde, dessen Funktion nicht eindeutig bestimmbar ist, in dem aber in tiberischer Zeit eine erste Statuengruppe errichtet wurde, die Mitglieder des Kaiserhauses ehrte (Abb. 3). ${ }^{30} \mathrm{Zu}$ dieser Gruppe gehörte, neben einer nackten Statue des Divus Augustus im Diomedestypus, atuch eine Statue des Gaius Caesar, die den zu der Zeit bereits verstorbenen designierten Nachfolger des Augustus als Opfernden capite velato (,mit verhülltem Haupt") und mit Spendeschale zeigt. ${ }^{31}$ Damit ist hier erstmals eine Rollenverteilung belegt, die zwar nicht zwingend war, aber in der Kaiserzeit typisch bleiben sollte, insbesondere dort wo Männer und Fratuen gemeinsam dargestellt waren. Während nämlich Fratuen sowohl als Opfernde mit Spendeschale oder Weihratuchkästchen als auch als Betende gezeigt werden konnten, ${ }^{32}$ ist das bisher einzige Beispiel eines nicht-mythologischen männlichen Oranten ein C. Poppaeus Ianuarius auf einem Grabaltar im Vatikan, der neben einem Tisch mit Opfergaben und einem Schwein steht. ${ }^{33}$

\footnotetext{
${ }^{30}$ Diesen Statuen wurden später weitere hinzugefügt. C. Pietrangrli, Ocriculum (Otricoli). Archaeological monographs of the British School at Rome 22 (Roma 1943), bes. 53-56; Rose 1997, 97f. Kat. 25 Taf. 89; B. Bollmann, Römische Vereinshäuser. Untersuchungen zu den Scholae der römischen Berufs-, Kult-und Augustalen-Kollegien in Italien (Mainz 1998) 409-412 Kat. A 71; Boschung 2002, 67-69. Livia: Vatican Museum-Museo Pio Clementino, Sala dei Busti 637: s. auch BARTMAN 1999, 13. 42. 47. 115. 155-155 Kat. 22 Abb. 9; AlbXANDRIdis 2004, 79. 129 Kat. 33 Taf. 4.2. Bartman 1999, 47 mit Anm. 143, scheint die Ursprünglichkeit der Bethaltung zu bezweifelth, aber die originalen Zugfalten unterhalb des Mantelwulstes auf ihrer rechten Seite lassen angesichts des zur Verfügung stehenden Spektrums kaum eine andere Rekonstruktion zu.

${ }^{31}$ Vatikan, Museo Pio Clementino, Sala dei Busti 199: Rose 1997, 97f. Kat. 25 Taf. 90.

${ }^{32}$ Für Statuen anderen Typs, die auf die pietas von Frauen verweisen, s. AlEXANDRIDIS 2004 , bes. 74-79.

${ }^{33}$ Vatikan, Galleria Lapidaria 9339: KLAuser 1959, 127f.; H. Demisch, Erhobene Hände. Geschichte einer Gebürde in der bildenden Kunst (Stuttgart 1984) 81f.; D. BoschunG, Antike Grab-
} 
Auch ist es sicher kein Zufall, dass zwei der drei belegten my thischen Darstellungen männlicher Oranten ins 1 . Jh. v. Chr. gehören, ${ }^{34}$ während die dritte bezeichnenderweise ein verfehltes Opfer zeigt: Auf der Nebenseite eines Pasiphae-Sarkophages sieht man Minos mit erhobener Rechter vor dem Tempel des Poseidon beten, während hinter ihm eine alte Frau frugale Gaben bringt. Hier handelt es sich demnach um die Verweigerung des Stieropfers, das Poseidon dadurch bestrafte, dass er unter anderem die Frau des Minos, Pasiphae, in Liebe zu ebendiesem Stier entbrennen ließ.$^{35}$

Dass die erhobenen Hände auch in Rom als Gebetsgestus zu lesen sind, belegen Schrift- und Bildquellen ${ }^{36}$ Anders als in Griechenland, wo er wie gesehen in der Regel auf eine konkrete Situation oder Gottheit bezogen gewesen zu sein scheint, tritt dieser Aspekt in den römischen Bildern des Betens (wie des Opferns) aber meist stark in den Hintergrund und die Gesten werden in erster Linie attributiv auf die Dargestellten bezogen. Die Kernbedeutung von Opfern und Beten, wie auch die grundsätzliche Äquivalenz der Handlungen, geht vor allem aus Münzreversen hervor, welche die Personifikation und / oder Göttin Pietas sowohl als Opfernde als auch als Orans darstellen, und sich, beginnend mit Münzen des Galba aus dem Jahr $68 \mathrm{n}$. Chr., mit verschiedenen Variationen bis in die Spätantike fortsetzen. ${ }^{37}$ Pietas war eine der wichtigsten und ältesten römischen Tugenden überhaupt. Sie bezog sich wohl ursprünglich vornehmlich auf die pietas erga parentem, die den Eltern und der Familie gebührende Verpflichtung. In der späten Republik wurden dann, vor allem als politische Tugenden, die pietas gegenüber dem Vaterland (pietas erga patriam) und gegenüber den

altäre aus den Nekropolen Roms. Acta Bernensia 10 (Bern 1987) 114 Nr. 969A; FYntrkoglou / VoutiRAs 2005, 163 f. 178 Nr. 37 Taf. 33.

${ }^{34}$ Eine bärtige männliche Figur auf einem fragmentarischen frühaugusteischen Marmorkrater, die capite velato mit erhobener Rechten einem blutigen Opfer zu Ehren der Athena beiwohnt, wurde als Aeneas gedeutet und ist wohl keine zeitgenössische Gestalt Rom, Museo Nazionale Romano 72257-60: D. GrassinGER, Römische Marmorkratere. Monumenta artis Romanae 18 (Mainz 1991) 198-200 Nr. 39 Textabb. 43-44 Abb. 113-116; FynTIKoglou / Voutiras 2005, 164. $178 \mathrm{Nr} .36 \mathrm{mit} \mathrm{Abb}$. Auf einem wenig früher zu datierenden Relief im Vatikan, Museo Gregoriano Profano 2916, das wohl ebenfalls eine mythische Szene wiedergibt, ist ein Feldherr beim Stieropfer zu sehen, der mit der Rechten über einem Altar libiert und die Lirke betend erhebt. Hier scheint das Betmotiv durch einen zweiten Altar zu seiner Linken bedingt zu sein (vgl. G. KASCHNITZ von WBINBERG, Sculture del magazzino del Museo Vaticano [Città del Vaticano 1937] 189f. Kat. 417-418 Taf. 77; B. M. FelLETTi MAd, La tradizione italica nell'arte romana. Archaelogica 3.1 [Rom 1977] 191f. Abb. 67; REINsEbRG 2006, 73 Anm. 522 mit abweichender Datierung ins 2. Jh. v. Chr.).

${ }^{35} \mathrm{~F}$. BaratTB / C. MetzGer, Catalogue des sarcophages en pierre d'épogues romaine et paléochrétienne (Paris 1985) 64-67 Kat. 22 mit Abb.

${ }^{36}$ Fyntikoglou / Voutiras 2005, $163 \mathrm{f}$.

${ }^{37}$ Galba Münzen: KLauser 1959, 135 Nr. 9; Frntikoglou / Voutiras 2005, Kat. 42-46 Taf. 34; Vollkom Mer 1997, 999 Nr. 7; zu weiteren Pietasmünzen s. ebda. 999-1003 mit Nr. 7-56. Auch zuvor wurde Pietas gelegentlich auf Münzen evoziert, aber nur ihr Kopf dargestellt: ebda. 998 f. 1102 Nr. 1-6. 
Göttern (pietas erga deos) gleichberechtigte Aspekte. ${ }^{38}$ Entsprechend spezifizierte der dem Augustus $27 \mathrm{v}$. Chr. verliehenen clupeus virtutis, der die Haupttugenden des princeps auflistete, pietas als pietas erga deos patriamque. $^{39}$ Wo Beten und Opfern als kontextlose Handlung dargestellt sind, wird den betreffenden Personen somit pietas als hervorragende Tugend zuerkannt, deren spezifischer Charakter sich allenfalls aus dem Zusammenhang ergibt.

Anders als das Opfermotiv für Männer, wird das Oransmotiv für Frauen in Rom erst in der frühen Kaiserzeit, vielleicht zuerst für Livia, eingeführt. Es steht somit, ähnlich wie zuvor in Griechenland, in tunmittelbarem Zusammenhang mit einer neuen, prominenteren Rolle von Frauen im öffentlichen Raum und in öffentlichen Denkmälern. ${ }^{40}$ Hierbei hat die dynastische Rolle der Frauen des Kaiserhauses eine wichtige Rolle gespielt. Vor allem ihnen kam nun die pietas erga familiares als Tugend $\mathrm{zu}$, die nicht nur ein privater Vorzug, sondern auch staatstragend war. Entsprechend werden die Frauen des julisch-claudischen Kaiserhauses auch oft (mehr-

\footnotetext{
${ }^{38}$ Zur römischen pietas allgemein s. J. LIEGLE, "Pietas", in: H. OPPERmann (Hg.), Römische Wertbegriffe (Darmstadt 1967) 229-273; zum beschriebenen Wandel s. jetzt P. Bedronski, "Pietas erga patriam: ideology and politics in Rome in the early first century BC", in: $\mathrm{K}$. Twardowska / M. Salamon / S. Sprawski / M. Stachura / S. Turlej (Hg), Within the circle of ancient ideas and virtues. Studies in honour of Professor Maria Dzilska (Krakow 2014) 143-159, mit der älteren Literatur.

${ }^{39}$ Zum clupeus virtutis s. M. SPANNAGBL, Exemplaria principis. Untersuchungen zu Entstehung und Ausstattung des Augustusforums. Archäologie und Geschichte 9 (Heidelberg 1999) 202f., mit reicher Literatur, P. ZANKER, Augustus und die Macht der Bilder (München 1987) 100f. Abb. 79. Vgl. Cicero, De inventione II 65f.: Religionem eam, quae in metu et caerimonia deorum sit, appellant; pietatem, quae erga patriam aut parentes aut alios sanguine coniunctos officium conservare moneat ( $\mathrm{Als}$ Gottesfurcht (religio) bezeichnet man das, was sich in Furcht vor den Göttern und ihrer feierlicher Verehrung äußert; als Ehrfurcht (pietas) das, was uns mahnt, gegen das Vaterland, die Eltern oder andere durch das Blut mit uns verbundene Menschen die Pflicht zu erfüllen", Übers. Nüßlein). Dazu grundlegend: G. Tномв, Zentrale Wertvorstellungen der Römer. Atxilia 46.2 (Bamberg 2000) 29-49; F.-H. MuTscHLER, "Norm und Erinnerung: Anmerkungen zur sozialen Funktion von historischem Epos und Geschichtsschreibung im 2. Jh. v. Chr.", in: M. BRaun / A. HaLtBnHoff / F.-H. Mutschler (Hg.), Moribus antiguis res stat Romana. Römische Werte und römische Literatur im 3. und 2. Jh. v.Chr. BzA I34 (München 2000) 87-124; M. SPANNAGBL, sZur Vergegenwärtigung abstrakter Wertvorstellungen in Kult und Kunst der römischen Republik", ebda. 237-269, zu den Mürzzen. Bereits spätestens seit dem Ende des 2. Jh.s v. Chr. besaß Pietas in Rom einen eigenen Tempel und Kult, doch wissen wir leider nicht, wie die Kultstatue aussah: $P$. CLancio Rossetto, ,Pietas, Aedes in foro Holitorio / in Circo Flaminio", LTUR IV (1999) 86 mit der älteren Literatur; ReINSBERg 2006, 73 mit Anm. 529.

${ }^{40}$ Klausers Vermutung die Mehrzahl der Oranten stellten die Personifikation der Pietas dar, wird heute nicht mehr geteilt (T. KLAUSBR, ,rStudien zur Entstehungsgeschichte der christlichen Kunst, 3. Schafträger und Orans als Vergegenwärtigung einer populären Zweitugendethik auf Sarkophagen der Kaiserzeit", Jahrbuch für Antzke und Christentum 3 [1960] [112-133] 126f). - Zum Aufkommen von öffentlichen Ehrungen für Frauen in Rom s. bes. Bartman 1999, 57-101, zu Livia; E. A. Hemelrijk, "Octavian and the Introduction of Public Statues for Women in Rome", Athenaeum 93 (2005) 309-317.
} 
heitlich?) als Mitglieder dynastischer Gruppen dargestellt. ${ }^{41}$ Während in letzteren wie üblich die pietas der männlichen Mitglieder durch den Libationsgestus (Spendegestus) ausgedrückt wird, liegt die Vermutung nahe, dass die Orans als spezifisch weibliches Pendant zu diesen Bildern geschaffen wurde.

Beterinnen kommen in der römischen Kunst in verschiedenen Varianten vor, unter denen zwei Reihen von leicht voneinander abweichenden Repliken, die dem auch für Ada verwendeten Vorbild folgen, hervorstechen. Die älteste nachweisbare römische Statue im Oransschema der Ada ist die bereits erwähnte Statue der Livia aus Otricoli. ${ }^{42}$ Es ist vermutet worden, dass der ursprüngliche Anlass für die Schaffung des neuen Typus die Suche nach einer geeigneten Ikonographie für die erste Kaiserpriesterin gewesen sei, sich die Oransikonographie der Livia also ebenso wie die Opferikonographie des Augustus in der berühmten Statue von der via Labicana zunächst auf ein Amt bezog. ${ }^{43}$ Dies ist durchaus möglich, aber nicht beweisbar, und selbst wenn die Ikonographie ursprünglich für die erste Kaiserpriesterin, importiert' worden sein sollte, besaß der Gebetsgestus, wie der Spendegestus des Augustus, vornehmlich attributiven Charakter und kennzeichnete Livia als Trägerin von pietas. Diese Interpretation wird auch dadurch gestützt, dass sowohl Kaiserinnen als auch Privatpersonen sich in aller Regel ohne die typischen Attribute ihres Priesteramtes wie die infula (ein geknotetes Wollband) oder die Priesterkrone darstellen ließen,

\footnotetext{
${ }^{41}$ BarTMAN 1999, 72f.; 78-84; 86-92; 112-114 für Livia; Rose 1997, bes. 52f; S. Wood, Imperial women. A study in public images, 40 B.C.-A.D. 68. Mnemosyne Supplementum 194 (Leiden u.a. 1999) bes. 315-319; D. E. E. KLBINBR, "Family ties: mothers and sons in elite and non-elite Roman art", in: Dies. / S. B. MATHBSoN (Hg.), I Clatdia II: Women in roman art and society (Austin, TX 1996) 43-60; Dies., "Imperial women as patrons of the arts in the early empire", in: Dies. / S. B. MatHBson (Hg.), Women in ancient Rome (Austin, Tex. 1996) 28-41; die Autoren betonen zu Recht, dass die Frauen, nicht zuletzt durch ihre Familienbande, durchaus auch selbst einflussreich waren; zur Bedeutung von Priesterinnen unter öffentlich geehrten Frauen s. E. A. Hemblrijk, "Public roles for women in the cities of the Latin West", in: S. L. JAMEs / S. Dillon (Hg), A companion to wornen in the ancient world (Oxford 2012) 478-490; Dies., "Female munificence in the cities of the Latin West", in: Dies. / G. Woolf (Hg.), Women and the Roman city in the Latin West. Mnemosyne Supplementum 360 (Leiden u.a. 2013) 65-84; Dies., Hidden lives, public personae: women and civic life in the Roman West (Oxford 2015), mit weiterer Literatur.

42 S.o. Anm. 30.

43 Augustusstatue: A. Giultano, Museo Nazionale Romano, Bd. 1,1, Le sculture (Rome 1979) 274-277 Kat. 170 (V. Picciotti Giornetti). Die Statue wird normalerweise als Darstellung des Augustus als Pontifex Maximus gedeutet. Doch während diese Lesart durchaus möglich ist, deutet nichts auf diese spezielle Interpretation hin, und auch das höchste Priesteramt wäre, da ohne jeden anderen Zusammenhang, in erster Linie Ausweis seiner pietas. Kaiserinnen: Moltbsen 2007, 128. 133; E. Talamo in: La Rocca / Parisi Presicce / Lo Monaco 2011, 230f. Die Argumentation Moltesens scheitert jedoch schon daran, dass die Statuen der Agrippina Minor, die sie zum Beleg heranzieht, vermutlich keine Beterin zeigen.
} 
durch welche ihr spezielles Amt leicht hätte kenntlich gemacht werden können. ${ }^{44}$

Echte Repliken des Otricolitypus, die besonders gut an der wie ein Segel um den rechten Unterarm aufgespannten Gewandpartie erkennbar sind, sind. relativ selten und überwiegend (obgleich nicht ausschlieBlich) dem 1. Jh. n. Chr. zuzuweisen, aber weit über das römische Reich verteilt. ${ }^{45}$ Von den Repliken kann die eindrucksvolle Porphyrstatue im Louvre aufgrund des verwendeten Materials einer Kaiserin des 2. Th.s zugewiesen werden. ${ }^{46}$ Die fragmentarische, einstmals hochqualitätsvolle Statue in Cherchell, die zusammen mit einem gleichfalls überlebensgroßen Togatus gefunden wurde, könnte einer weiteren kaiserlichen Gruppe angehören. ${ }^{47}$ Sollte der mittelantoninische Kopf der Statue im Museo Nazionale Romano zugehören, wäre hier jedoch wohl eher eine Privatperson als eine Kaiserin dargestellt. ${ }^{48}$ Für die übrigen Statuen ist wegen fehlender oder nicht bzw. nicht sicher zugehöriger Köpfe eine Zuschreibung an Kaiserin oder Privatperson nicht mehr sicher möglich. Damit entfällt auch jedes weitere Argument, den Typus generell mit dem Kaiserkult zu verbinden. Die Brotzestatue einer Privatperson aus dem Theater in Herculaneum aus tiberischer Zeit folgt dem Typus zwar nicht im Replikensinue, aber in wesentlichen allgemeinen Zügen, und belegt nicht nur, dass die Ikonographie des Betens schon früh von Privatpersonen übemommen wurde, sondern atch, dass sie unabhängig von einer konkret benennbaren Priesterinnenfurktion als allgemeine Chiffre fiur pietas und zur weiblichen Selbstdarstellung im öffentlichen Raum verwendet werden konnte. ${ }^{d 9}$

44 Hemblrijk 2007, 331-337, mit der älteren Literatur; Frlgbs 1997, 195-197.

45 Eine erste Liste bei KLAusBr 1959, 144f.; wichtige Ergärzungen und Korrekturen in

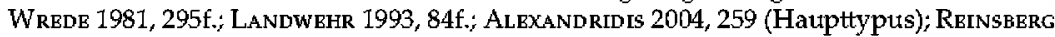
2005, 312f.; zuletzt Moltesen 2007. Zum Typus gehörig sind m.E. die folgenden Statuetr (LANDWEHr 1993= L; AlbXandridis 2004= A; Reinsberg 2005 = R): L $61=$ A A4 = R 3; L A = $\mathrm{A} \mathrm{A} 8=\mathrm{R} 9 ; \mathrm{L} \mathrm{B}=\mathrm{A} A 6=\mathrm{R} 6 ; \mathrm{L} \mathrm{C}=\mathrm{A} A 1=\mathrm{R} 1 ; \mathrm{L} \mathrm{D}=\mathrm{A} \mathrm{A} 3=\mathrm{R} 7 ; \mathrm{L} \mathrm{E}=\mathrm{A}$ Aa5 $=\mathrm{R} 4 ; \mathrm{L} \mathrm{F}=\mathrm{A} 2$ $=R 2 ;$ vielleicht $A$ A5; $A$ A9 $=R$ 8; A A10. Bei A Aa 1 und vielleicht $A$ Aa2 und Aa4 handelt es sich ebenfalls um Oranten, die jedoch einer Variante des Skulpturenschemas folgen.

46 Paris, Louvre 2226: Landwbhr 1993, 84f.; Moltesen 2007, 128; der ideale Kopf gehört nicht dazu. Gegen die von AlbXandrids 2004, 259 Anm. 1121, suggerierte Vermutung, die Statuen seien nur in der frühen Kaiserzeit verwendet worden, sprechen nicht nur die Porphyrstatue, sondern auch die Wiederverwendung der Statue in Chiswick ( $D=A$ A3 $=R$ 7) im 3. Jh. und der von Alexandridis als Nr. A11 geführte Sarkophag mit Reliefdarstellung nach demselben Typus (3. Jh.).

${ }^{47}$ Cherchell, Museum S 14: Landwerr 1993, 83-86 Kat. 61 Taf. 85-87 (2.-3. Viertel 1. Jh. n. Chr.); Reinserrg 2005, 303 mit Anm. 49 (augusteisch). Wenn die Dargestellte tatsächlich einen Nackenzopf trug, wie Landwehr angibt, kann die Statue nicht augusteisch sein und Livia darstellen.

${ }^{43}$ Rom, Museo Nazionale delle Terme 68: A. Guulano, Museo Nazionale Romano, Bd. 1,2, Le sculture (Rome 1981) 6If. Kat. 47 (L. Nista: Fatstina Minor); vgl. ReInsBerg 2005, 298 mit Anm. 9 (Faustina Minor). Doch ist nicht nur unklar, ob der Kopf überhaupt zur Statue gehört, er steht auch in keinem Replikenverhältnis mit den Typen der Faustina: K. FrrTschen, Die Bildnistypen der Faustina minor und die Fecunditas Augustae. Abhandlungen der Akademie der Wissenschaften zu Göttingen, Philologisch-Historische Klasse. Folge 3, 126 (Göttingen 1982) 53 Anm. 33; 80 Anm. 44. Sollte die Statue AlexANdridrs 2004, 259 Nr. A5 in Gerace Marina tatsächlich eine Orans sein, müsste sie wegen ihrer Herkunft aus der Nekropole von Locri wohl ebenfalls eine Privatperson darstellen.

${ }^{49}$ Neapel, Museo Archeologico Nazionale 5589: M. Fuchs, Untersuchungen zur Ausstattung römischer Theater in Italien und den Westprovinzen des Imperium Romanum (Mainz 1987) 28f. C I 2 Taf. 6,2; 7,4-5; spättiberische Datierung ebda. 33. Die dortige Identifizierung als 
Sollte der Statuentypus in Rom zuerst durch Livia eingeführt worden sein, wofür ihre auch sonst zu beobachtende allgemeine Vorbildrolle in Bezug auf kaiserliche wie private Selbstdarstellung spricht, könnten die Hekatomnidenfratuen und möglicherweise die Figuren des Matusoleums von Halikarnass die Wahl des Motivs mit beeinflusst haben. Bei dem Monument handelte es sich um eines der sieben Weltwunder, das auch für Namen und Gestalt des Augustus-Mausoleums Pate stand. Zudem muss die hervorgehobene Rolle der Hekatomnidenfrauen, die sich ebenfalls zumindest teilweise aus ihrer Bedeutung für den Fortbestand der Dynastie ableitete, sie als Modell für die neue Rolle der Livia und anderer Frauen der julischclaudischen Dynastie besonders empfohlen haben. ${ }^{50}$

Wie häufig statuarische Oransdarstellungen generell in der Kaiserzeit gewesen sind, lässt sich nur noch schwer ermessen. Es existieren verschiedene Varianten des Ada-Typus, die aber zumeist den rechten Arm waagerecht vorstrecken, also allenfalls mit einem erhobenen Arm beten. Wie wir aber bereits bei der sog. Artemisia gesehen haben, konnte der Oranstypus, vor allem der eines Variantenstrangs, ${ }^{51}$ bei großer allgemeiner Ähnlichkeit abgewandelt und z.B. durch einen Spendegestus oder ein Attribut in einen Opfertypus umgedeutet werden. Die vorderen Teile der Arme mit den Händen sind bei den Statuen ausnahmslos abgebrochen bzw. verloren, so dass oft nicht mit Bestimmtheit gesagt werden kann, ob ein Gebets- oder Spendegestus wiedergegeben war. Dies betrifft auch die atußerordentlich qualitätsvolle Statue der Agrippina aus dunkler ägyptischer Grauwacke in Rom mit zugehörigem Kopf in Kopenhagen, von der oft vermutet wird, sie habe die Kaiserin und Witwe des Claudius ursprünglich als flaminia im Tempel des Divus Claudius gezeigt. ${ }^{52}$ Wie Moltesens Untersuchungen der Statue ergeben haben, waren beide Unterarme vorgestreckt, und die Rechte hielt vermutlich eine Spendeschale. ${ }^{53}$ Sie ähnelt damit der sog. Ar-

Livia mit guten Gründen abgelehnt von WREDE 1981, 295f., und vor allem BosCHUNG 2002, 124f. mit Anm. 703.

${ }^{50}$ Moltesens Hinweis, dass sowohl Livia als auch Agrippina der Artemisia dahingehend gleichen, dass sie mächtige Frauen waren, die ihre Ehemänner überlebten (MoLTESBN 2007, 132), ist jedoch insofern irreführend, als der Statuentypus, wie gesehen, auch für andere Frauen am Mausoleum verwendet wurde, die Identität der besterhaltenen Statue mit Artemisia nicht gesichert ist, und diese Statue keine Orans darstellte. Zu den Hekatomnidenfraten s. E. D. CARNBY, "Women and Dunasteia in Caria", The A merican Journal of Philology $126(2005) 65-91$.

51 Nach AlexCANDridis 2004, 259.

${ }^{52}$ Rom, Museo Capitolino 1882 und Kopenhagen, Ny Carlsberg Glyptotek 634 (I.N. 753): ebda., 150 Kat. 106 Taf. 26,2. 4; Moltessn 2007; Dies. "The portrait head and its reworking", in: Dies. / Niglsen 2007, 139-148. Zur Auffindung und These der Zugehörigkeit zum Kaiserkulttempel des Claudius: E. TALAMO „I ritrovamenti archeologici sul Celio e la scoperta della statua di Agrippina orante" in: MoltesEn / NIELSEN 2007, 95-111; Dies. in: LA RocCA / Parisi Presicce / Lo Monaco 2011, 230f. Kat. 3.7.

${ }^{53}$ Moltesen 2007, 129f., vergleicht die Statue mit der einer Priesterin aus Pompeji: Neapel, Museo Archeologico Inv. 6044; ebda. P. 10. 
temisia vom Mausoleum. Hier zeigt sich einmal mehr, dass die Römer offenbar keinen grundsätzlichen Unterschied zwischen Bildnissen mit Spendeschale und in Orantenhaltung machten: beide konnten die Dargestellte gleichermaßen als pia kennzeichnen. ${ }^{54}$

Ähnliche Schwierigkeiten ergeben sich für andere Statuentypen, die gelegentlich mit dem einseitigen Betgestus verbunden sind. Für statuarische Privatporträts ist er erstmals in trajanischer Zeit, und zwar für Minia Procula nachgewiesen, die in diesem Schema im Apollon-Heiligtum von Bulla Regia in Nordafrika wiedergegeben war. ${ }^{55}$ Darüber hinaus erscheint Julia Domna mehrfach in diesem Schema. Im Opferrelief des Argentarierbogens in Rom steht die Kaiserin mit betend erhobener Rechten neben ihrem libierenden Gatten, und eine Statue stellte sie in dieser Haltung im Nymphäum von Perge in Kleinasien dar (Abb. 5) ${ }^{56}$ In keinem Fall ist das Geschehen auf eine spezifische Kulthandlung zu beziehen; sie zeichnet die Kaiserin und, im Falle des Reliefs, die kaiserliche Familie durch die Tugend pietas aus.

Im gegebenen Rahmen ist es weder möglich noch nötig, eine umfangreiche Revision der als Beterinnen in Frage kommenden Statuen vorzulegen. ${ }^{57}$ Entscheidend ist vielmehr, dass sowohl der Spende- als auch der

\footnotetext{
${ }^{54} \mathrm{Ob}$ die stark beschädigte Statue der Agrippina (?) aus Cosa dem Opfer- oder Oranstypus folgte, ist heute nicht mehr zu entscheiclen: ebcla., 33. Ähnliche Unklarheiten bestehen auch bezüglich der Agrippinastatue aus Olympia und ihrer Repliken, die von MoLtes BN 2007, 129f,, als Beterin akzeptiert wird; vgl. Olympia, Museum A 143: K. HrTzL, Die kaiserzeitliche Stattuenausstattung des Metroon. Olympische Forschungen 19 (Berlitr / New York 1991) 43-46 Kat. 3 Taf. 14-19. 39b. 40c; Replik aus Atrapalda bei Avellino (Privatporträt) im British Museum GR 1873,8-20.741 und kopflose Statue in Cyrene, Museum 146: BIEBER 1977, 199f. Taf. $140 \mathrm{Abb} .822-823$, die die rechten Arme im Libationsgestus ergänzt.

55 BigerR 1977, 198 Abb. 821; AldXandridis 2004, 80f, mit Anm. 772. Wie Hemblrijk 2007, 332f. mit Anm. 59 feststellt, ist nicht gesichert, dass die Abkürzung "f. p." in der Inschrift (CIL 8.25530) als flaminica perpetua aufgelöst werden muss.

${ }^{56}$ AlEXandridis 2004, 80. 258 Taf. 49, I; ihr ,Typus Magnesia-Borghese' war vielleicht ursprütnglich als Oranstypus entworfen. Ein weiterer Typus, der sich leicht in einen Oranstypus umdeuten ließ, ist ihr Ceres-Typus, bei dem allerdings die Hände des ursprünglichen Entwurfs beide ein Attribut hielten. In mehreren Exemplaren ist der Gebetsgestus modem ergänzt worden und wird von Axel Filges mit vorgestrecktem Arm rekonstruiert: FiLGBs 1997, 13-31, bes. 17 zu Kat. 17. 20. 21.

In Reliefs kann die allein erhobene Rechte aber auch einen Redegestus meinen, vgl. z.B. ein Relief in Ostia: P. ZANKER, Die Maske des Sokrates. Das Bild des Intellektuellen in der antiken Kunst (München 1995) 246 Abb. 140. Wo der Kontext unklar ist, lässt sich die Geste daher nicht mehr sicher bestimmen, z.B. ein hadrianisches Grabrelief, das die Verstorbene im Schema der Venus Victrix, aber mit erhobener Rechter zeigt: H. WREDE, "Die Ausstattung stadtrömischer Grabtempel und der Übergang zur Körperbestattung ", Mitteilungen des Deutschen Archäologischen Instituts, Abteilung Rom 85 (1978) [411-433] 424f. Taf. 133,12, und WREDв 1981, 316 Kat. 310, sieht hier einen Grußgestus, während Reinsberg 2006, 73 Anm. 528, eine Beterin erkennt, was jedoch angesichts der halbnackten Venus Victrix weniger wahrscheinlich erscheint.

${ }^{57}$ Eine bisher unpublizierte Dissertation von Lenaghan sowie eine umfangreichere Pusblikation von Carola Reinsberg werden diese Lücke hoffentlich demnächst schließen.
} 


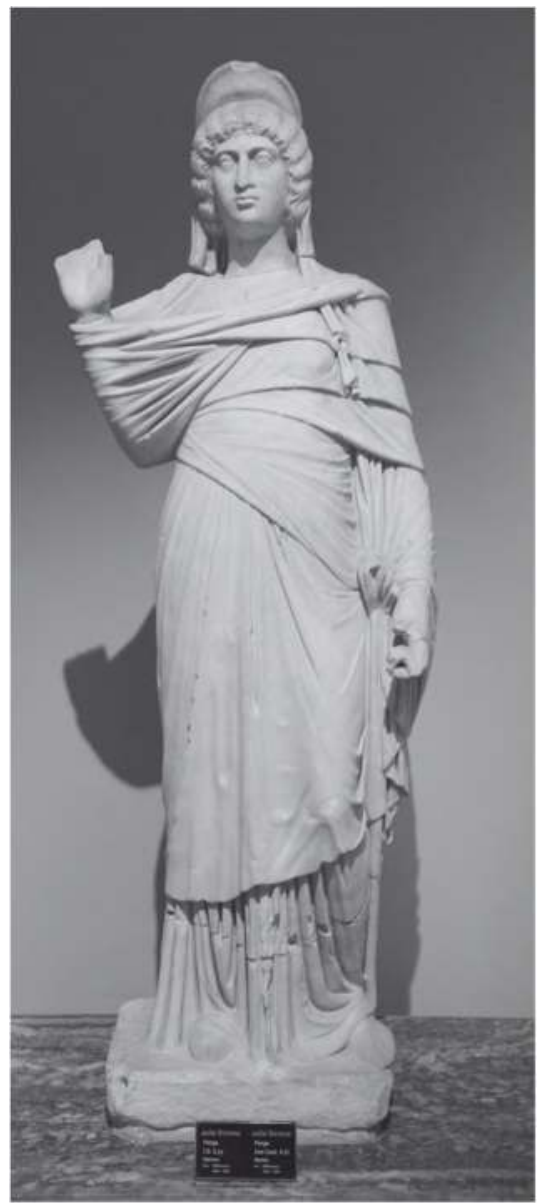

Abb. 5: Julia Domna als Orans vom Nymphäum in Perge. Antalya, Museum Inv. A3262.

Gebetsgestus seit der augusteischen Zeit von Kaiserinnen wie Privatpersonen verwendet wurde, um ihre pietas und gegebenenfalls ein Priesteramt zum Ausdruck zu bringen, und dass diese Tugend auch, aber nicht nur im Falle von Priesterinnen, als besonders hervorhebenswert erachtet wurde. Wie oben bereits angedeutet, spricht einiges dafür, dass die spezifische pietas der Frauen pietas erga parentes und erga familiares war. Auch die Pietas-Münzen beziehen sich oftmals ausdrücklich auf diese dynastische und familiäre pietas, wie u.a. die seit den 80 er Jahren und bis ins 4 . Jh. 
beliebten Münzbilder belegen, in denen Pietas mit einem oder mehreren Kindern dargestellt ist. ${ }^{58}$

Den besten Einblick in die Bedeutung von pietas in nicht-kaiserlichen Familien gewähren Zeugnisse aus dem funerären Bereich. In Grabinschriften werden Verstorbene beider Geschlechter und unterschiedlichen Alters häufig ob ihrer pietas, oft im Superlativ, geehrt. Abgesehen vom allgegenwärtigen bene merens, ist pietas die am dritthäufigsten gelobte Tugend. Nicht von ungefähr werden auf den Grabsteinen in $54 \%$ der Fälle Kinder von ihren Eltern als piissimi oder pientissimi bezeichnet, während der Rest der Beispiele sich fast ausschließlich auf Eltern oder Geschwister bezieht. ${ }^{59}$ Die im Grabbereich gelobte pietas ist demnach, zumindest im Freigelassenenmilieu, aus dem die Grabsteine stammen, pietas erga parentes und erga familiares. ${ }^{60}$ Diese Bedeutung der pietas kommt auch in der Grabkunst zum Ausdruck und wird in verschiedener Weise veranschaulicht. Durch alle Schichten und in allen Genres sind Girlanden, Boukephalia (Stierköpfe), Boukranien (Stierschädel), paterae und andere Kultparaphernalia häufig zu finden. ${ }^{61}$ Die in unserem Zusammenhang interessante Beterin erlangt jedoch erst seit dem späteren 2. Jh. auf römischen Sarkophagen Prominenz. Die ältesten Darstellungen einer Beterin, die hier nur die Rechte zum Gebet erhebt, finden sich auf drei etwa gleichzeitig um 180-190 entstandenen stadtrömischen Sätlensarkophagen. ${ }^{62}$ Hier sind in den beiden mittleren Arkaden der Grabherr und seine Frau im typischen Handschlag des Hochzeitsbildes mit der Personifikation der Concordia im Hintergrund, sowie dasselbe Paar im Opferbild mit dem Mann im Spendegestus und der Frau als Beterin zu sehen (Abb. 6) ${ }^{63}$

Wie Carola Reinsberg zu Recht bemerkt, legen diese Beispiele auch die Deutung einer kopflosen, prominent im Vordergrund des Feldherrenopfers der sog. Feldherrensarkophage stehenden Frau als Grabherrin nahe.

${ }^{58}$ KLAUSER 1959, 117-120. 135-144; VollKommer 1997, Nr. 36-54.

${ }^{59}$ NibLSBN 1997, 176. 193-198, mit ungewöhunlicher Erklärung für den Gebrautch des Epithets für verstorbene Kinder: Zweifellos bezieht es sich nicht auf die Gegenwart oder Zukunft, sondem lobt die pietas der Kinder während sie lebten.

${ }^{60}$ Zur familiären pietas s. besonders R. P. SALLER, "Pietas, obligation and authority in the Roman family", in: P. KndissL / V. Losemann (Hg.), Alte Geschichte tund Wissenschaftsgeschichte. Festschrift für Karl Christ zum 65. Geburtstag (Darmstadt 1988) 393-410.

${ }^{61}$ Zur engen Verbindung von virtus und pietas in Grabmonumenten s. auch A. DARDENAY, "Virtus et pietas du défunt. Quelques hypothèses de lecture de l'iconographie officielle en contexte funéraire" ${ }^{\prime \prime}$, in: Dies. / E. Rosso ( $\mathrm{Hg}$ ), Dialogues entre sphère publigue et sphère privée dans l'espace de la cité ronaine. Vecteurs, acteurs, significations. Ausontus éditions 56 (Pessac 2013) 297-314.

62 Rom, Museo Nazionale:Reinsberg 2006, 218 Kat. 87 Taf. 62,1-2 (um 180); Tipasa: ebda., 233f. Kat. 140 Taf. 32,1-2 (180-190); Rom, Villa Albani: ebda., 227f. Taf. 28,2-3 (180-190).

${ }^{63}$ Zwar fehlt der Kopf der Frau auf dem Sarkophag in Tipasa, doch lassen das Exemplar mit bossiertem Porträt in Rom und die Parallelität der beiden zentralen Bilder kaum Zweifel an der Deutung der Orans als Grabherrin: ebda., 71. An dieser Deutung ist auth nie gezweifelt worden. 


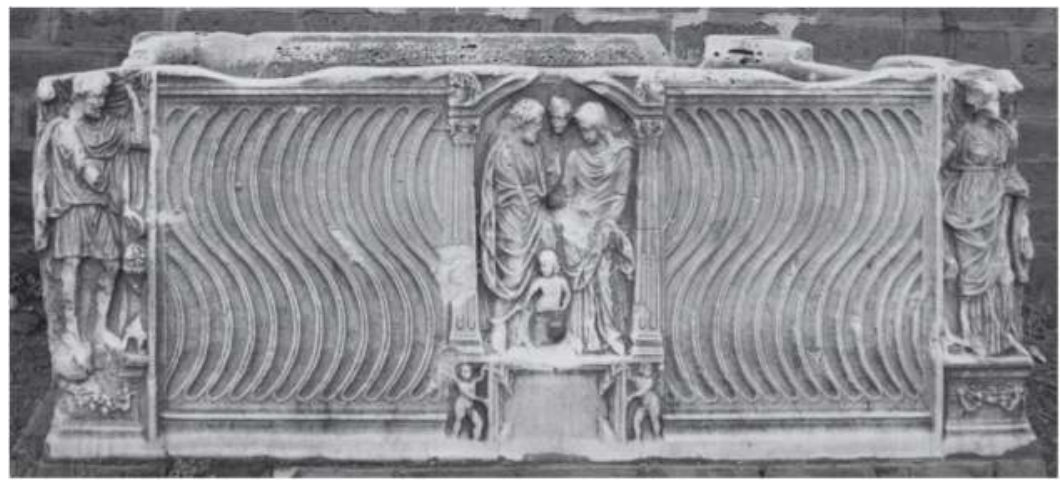

Abb. 6: Sarkophag eines Ehepaars. Rignano Flaminio.

Diese Friessarkophage geben verschiedene idealisierte Ereignisse aus dem Leben des Grabherrn wieder, unter denen sich links Szenen befinden, die mit dem Feldherrenamt des Verstorbenen zusammenhängen, rechts dagegen die Hochzeits-concordia-Szene, die abgekürzt auf den Säulensarkophagen erscheint. ${ }^{64}$ Im Zentrum findet sich das Opfer eines Feldherrn als Staatsakt vor einem Tempel, das sich vielleicht auf das Opfer auf dem Kapitol bezieht, welches üblicherweise vom Inhaber eines Oberbefehls vor Abzug in die Provinz vollzogen wurde ${ }^{65}$ Damit verweist die Darstellung auch auf das bedeutende Amt des Verstorbenen. Die prominente Position dieser Szene im Zentrum der Sarkophagfront macht aber auch die Bedeutung der durch diese veranschaulichten pietas deutlich, die man dem Kontext entsprechend wohl als pietas erga deos und erga patriam nach dem Vorbild des Kaisers interpretieren darf. ${ }^{66}$ Auf drei oder vier solcher Sarkophage findet sich in dieser Szene auch eine Beterin, die mit einer Ausnahme als die Ehefrau des Feldherrn zu deuten ist. ${ }^{67}$

Auf allen Sarkophagen stellt die Beterin das weibliche Pendant zum Opfernden dar. Dabei ist höchstwahrscheinlich nicht eine spezifische Rolle

\footnotetext{
${ }^{64}$ S. allgemein WREDE 2001, 21-60; S. MUTH, „Drei statt vier: Zur Deutung der Feldherrensarkophage“, Archäologischer Anzeiger (2004) 263-273; ReINSBERg 2006, bes. 61-109.

${ }^{65}$ WREDE 2001, 27-30; ReINSBERg 2006, 66-70.

${ }^{6 i}$ Dies erklärt wohl auch die Darstellung des Opfernden auf dem bekannten Sarkophag in Mantua, dessen jugendliches Alter den realen Vollzug eines solchen Staats- und/oder Profectio-Opfers ausschlicßt: ReINSBERG 2006, 70.

${ }^{67}$ Wrede 2001, 29f.; ReINsberg 2006, 70f. 196f. Kat. 15 Taf. 13,2; 16,2; 70-71; 198 Kat. 20 Taf. 20,2-3; 192 Kat. 6 Taf. 21,1; hierzu kommt vermutlich das heute nicht mehr auffindbare Fragment ebda., 71. 214f. Kat. 76 Taf. 16,4. Einzig der sog. Rinuccini-Sarkophag in Berlin lässt eindeutig erkennen, dass es sich bei der Orans um die Personifikation der Pietas handelt, da der Kopf ausreichend gut erhalten und als der einer Idealfigur bestimmbar ist. Doch befindet sich die Pietas, wie üblicherweise Concordia in der Hochzeitsszene, weit im Hintergrund und nicht auf einer Ebene mit dem Opfernden, wie in den anderen Beispielen, und ist daher als Ausnahme anzuschen.
} 
in einem konkreten Ereignis gemeint. Auch wenn die Feldherrenkleidung des Opfernden der Friessarkophage und zwei der drei Sätulensarkophage auf ein Feldherrenopfer, möglicherweise das profectio-Opfer, anspielen, hatten deren Ehefrauen bei dieser Gelegenheit zweifellos keine entsprechend prominente Rolle inne. ${ }^{68}$ Ihre realitätsferne Einführung in diese Bilder sowie ihre Einbeziehung in die unspezifischen Opferbilder sind daher zum einen auf ein Bedürfnis zurückzuführen, beide Ehepartner gleichberechtigt darzustellen, zum zweiten auf die besondere Eignung des Pietaslobes für beide Partner, und zum dritten auf die Wichtigkeit der pietas als Tugend generell. Dies bestätigt sich schließlich an den im 3. Jh. weiterlatufenden Riefel- und Säulensarkophagen, welche die Opferszene teilen und auf die beiden Eckfelder verteilen: das eine zeigt die Libation des Ehemannes, das andere die Ehefrau in Gebetshaltung (Abb. 6). Auf diese Weise werden Gebets- und Opferszenen oft gänzlich aus ihrem Kontext isoliert, und die Militärtracht kann durch die Toga ersetzt werden. Der Akt des Opferns wird damit zum reinen Zeichen und Ausweis der Tugend und Pflichterfüllung des Dargestellten, von denen man aber sicher weiterhin annehmen darf, dass sie sich auf die Götter und den Staat bezieht. ${ }^{69}$

Gelegentlich ist der Gebetsgestus beidarmig ausgeführt, und in einem Fall sogar das Otricoli-Schema kopiert; in der Mehrzahl der Bilder ist er einarmig, wobei aber in aller Regel auch ein brennender Klappaltar dargestellt ist. ${ }^{70}$ Dieser macht nicht nur die Bedetutung der Geste klar, sondern verdeutlicht auch, dass es sich hier nicht um kontemplative Anbetung handelt, sondern um Teil des Opfergeschehens. ${ }^{71}$

${ }^{68}$ E. A. Hem BLRIJK, "Women and sacrifice in the Roman empire", in: O. HeKSTER / S. SCHMidT-Horner / C. WITSCHRL (Hg.), Ritual dynamics and religious change in the Roman Empire. Proceedings of the Eighth Workshop of the International Network Impact of Empire (Heidelberg, July 5-7, 2007). Impact of Empire 9 (Leiden 2009) 253-267 hat überzeugend dargelegt, dass die verbreitete Vorstellung, Frauen seien von blutigen Opfern grundsätzlich ausgeschlossen gewesen, verfehlt ist. Doch waren Frauen von bestimmten Opfern ausgeschlossen, und im realen Feldherrenopfer stand eindeutig der in den Krieg ziehende Feldherr im Vordergrund, auch wenn nicht ausgeschlossen werden kann, dass seine Frau anwesend sein durfte.

${ }^{69}$ Dies gilt auch, wenn die opfernden Militärs noch auf das konkrete Opfer der Friessarkophage hinweisen sollten: Durch die Ausblendung des Kontexts wird die Bildaussage auf das Wesentliche fokussiert, das nun offensichtlich die pietas war.

${ }^{70}$ Reinserrg 2006, 71f. mit Beispielen. Beidarmig: ebda. Kat. 138; 151; 25; im Ada-Schema: A. Giuldano, Museo Nazionale Romano, Le sculture, Bd. 1,8/1, Le Aule delle Terme (Roma 1985) 5-10 Nr. I,2 (M. Bertinetti); ALEXANDridis 2004, 259 Nr. 11; die Linke hälthier eine Buchrolle. Auf dem Sarkophag in Cordoba Reinsberg 2006, Kat. 11 fehlt der Altar und die Verstorbene hält eine Buchrolle in der Hand und wird von einer weiteren Frau begleitet. Hier ist die erhobene Rechte vielleicht als Redegestus zu deuten, wie es in Darstellungen des späteren 3. und des 4. Th.s dann öfter vorkommt.

${ }^{71}$ Reinsberg 2006, 72f. F. Matz, „Das Problem der Orans und ein Sarkophag in Córdoba", Madrider Mitteilungen 9 (1968) 300-310, deutete den Gebetsgestus der Sarkophage, aber auch anderer Monumente, als einen Hinweis auf die Apotheose der Dargestellten. Dem ist 
Die Verteilung der Ikonographien auf die Geschlechter erklärt Reinsberg damit, dass sich das Rollenbild des opfernden Mannes an der Realität der Staatsopfer orientierte: Der Opferherr wird bei der das Opfer normalerweise einleitenden Libation gezeigt, während der popa (Opferdiener) den Stier tötet, der den Charakter des Opfers verdeutlicht. ${ }^{72}$ Wie die pietas Augusti sich auf die Götter und den Staat richtet, so auch die des Grabherrn. Einen entsprechenden Staatsakt, an dem die Ikonographie der Fratuen sich ausrichten konnte, gab es nicht. ${ }^{73}$ Doch ist es hier wohl nicht nur das Vorbild der Priesterin und die Pietasikonographie der Münzen gewesen, die die Wahl angeregt haben, sondern, wie im männlichen Opferbild auch, das kaiserliche Vorbild. ${ }^{74}$ So wie die Kaiserin speziell die für den Fortbestand der Dynastie so wichtige pietas gegenüber der Familie verkörperte und somit das Spektrum der geforderten pietas des Kaiserpaares abrundete, so stand auch die Frau auf den Sarkophagen der Oberschicht für die pietas erga familiares, und ergänzte den Mann beim Staatsakt.

\section{Christliche Oranten (Beterinnen)}

Vor diesem Hintergrund ist auch die Übernahme der Oransfigur in die christliche Kunst zu sehen, wobei ihre Prominenz sich zunächst daraus ergeben haben muss, dass das bis dato beliebtere Opferbild im christlichen Kontext obsolet geworden war. Wie zuvor konnte der Gebetsgestus sowohl im Handlungskontext als auch isoliert vorkommen. In den frühen Darstellungen Daniels in der Löwengrube oder der drei Jünglinge im Feuerofen bringen die erhobenen Arme das Gebet zu Gott um Errettung aus der Not zum Ausdruck. ${ }^{75}$ Sie knüpfen damit inhaltlich unmittelbar an die Tradition des nicht-christlichen Bittgebets an, das nun erneut zum Darstellungsthema erhoben wird.

Umstritten ist die Bedeutung der Orans jedoch, wo sie außerhalb eines narrativen Zusammenhangs begegnet: großformatig in der Katakombenmalerei (Abb. 7 und 8$)^{76}$ oder kleinfigurig auf Sarkophagen ${ }^{77}$ und in unbeholfenen Ritzzeichnungen auf den Verschlüssen der loculi (Wandni-

jedoch zu Recht widersprochen worden: Wrede 1981, 205f.; ReInsebre 2006, 70 Anm. 495; AlbXandridis 2004, 79 mit Arm. 760.

${ }^{72}$ ReINSBRrg 2006, 73; dass es sich um ein Staatsopfer handelt, ist immer gesehen worden.

${ }^{73}$ Ebda.

${ }^{74}$ Anders ebda., 73f. Auf den Vorbildcharakter der Kaiserinnen im provinzialen und munizipalen Kaiserkult hat atch HeмвLRIJK 2007 hingewiesen.

${ }_{75}$ Hierzu STudER-KarLen 2012, 121 mit Bibliographie.

${ }^{76}$ A. Nestori, Repertorio topografico delle pitture delle catacombe romane (Roma 1993) 207f; ZimMERMANN 2007, 168-171; DresKEN-W BILANd 2010, 38-76.

77 STUDBR-KARLEN 2012, 117-170. 
schen für Bestattungen). ${ }^{78}$ Interessanterweise sind auch christliche Oran$\operatorname{ten}^{79}$ hier vornehmlich, wenn auch nicht mehr ausschließlich, weiblich, auch wo sie gelegentlich auf Gräbern von Männern erscheinen. Seit langem sind zwei Erklärungen vorherrschend, die Oranten stellten entweder die Verstorbenen oder die zu Gott betende Seele der Verstorbenen dar, wobei letzteres die fast ausschließliche Verwendung der weiblichen Orans erklären soll: die Seele sei im Falle von Verstorbenen beider Geschlechts weiblich, weil das Substantiv für Seele im Lateinischen wie im Griechischen weiblich ist (anima / psychē). Ob es sich bei den Gebeten um Bittgebete oder kontemplative Anbetung handelt, ist dabei umstritten. ${ }^{80}$ Dies ist nicht der Ort, die Diskussion völlig neu aufzurollen, nicht zuletzt, da die Orans insbesondere seit dem 4. Jh. in sehr unterschiedlichen Kontexten erscheint. Ich will mich daher auf einige Bemerkungen beschränken, und vor allem auf das Fortleben der vorchristlichen Vorstellungen konzentrieren.

Zunächst ist festzuhalten, dass viele Oranten Porträtzüge und Modefrisuren tragen und daher spezifische Personen meinen. Für diese ergibt sich lediglich die Frage, ob sich der Sinn des Gebetsgestus näher spezifizieren lässt. ${ }^{81}$ Daneben gibt es viele nicht eindeutig individualisierte Oranten, die theoretisch als Darstellungen der Seelen auch männlicher Verstorbener, oder als betende Seelen sui generis in Frage kämen. Letzteres ist m.E. nicht völlig auszuschließen, da die Orans oftmals als Pendant zum,Guten Hirten' erscheint, der niemals individualisiert ist und nach übereinstimmender Meinung nie einen Verstorbenen meint. ${ }^{82}$ Andererseits finden sich in dieser Position auch eindeutig individualisierte Oranten ${ }^{83}$ sowie Verstorbene mit Bildungsattributen, für die keine vergleichbare symbolische

\footnotetext{
${ }^{78} \mathrm{~F}$. BisconTI, "La rappresentazione dei defunti nelle incisiont stlle lastre funeratie paleocristiane aquileiese e romane", Antichità Altoadriatiche 30 (1987) 289-308.

${ }^{79}$ Ich itbergehe hier die Frage, ob alle in der Literatur in unserem Zusammethang diskutierten Bilder tatsächlich christlich sind. Für eine nennenswerte Anzahl lässt sich dies mangels eindeutiger Indizien nicht beweisen. Für die hier angestellten Überlegungen ist jedoch eine Festlegung im Einzelfall nicht entscheidend.

${ }^{80} \mathrm{~S}$. den Überblick in STUDER-KARLEN 2012, 117-119.

${ }^{81}$ Insofern ist es nicht gänzlich müßig, im Falle weiblicher Verstorbener zu fragen, ob es sich um diese selbst oder ihre Seele handelt (so ebda., 118 mit Berufung auf ältere Literatur): Nur wenn und wo man das Beten im Jenseits ansiedelt, wird dieser Unterschied unerheblich.

${ }^{82}$ Seine Bedeutung ist ebenfalls umstritten, aber hier nicht zentral; vgl. N. HIMm RLMANN, Über Hirten-Genre in der antiken Kunst. Abhandlungen der Rheinisch-Westfälischen Akademie der Wissenschaften 65 (Opladen 1980) 138f.; J. EngBmann, "Hirt”, RAC 15 (1991) 577-607; B. C. EwALD, Der Philosoph als Leitbild. Monographische Untersuchungen an römischen Sarkophagreliefs. Mitteilungen des Deutschen Archäologischen Instituts, Römische Abteilung 34 (Mainz 1999) 64-69; DresKen-W EILAND 2010, 77-95.

83 Z.B. B. Christbrn-Bribsenick / G. Bovini / H. Brandenburg, Repertorium der christlichantiken Sarkophage, Bd. 3, Frankreich, Algerien, Tunesien (Mainz 2003) Nr. 33; STUdgr-KarLen 2012, 81 mit Abb. 67; 158 mit Abb. 122.
} 
Bedeutung vorgeschlagen wird, ${ }^{84}$ so dass das Argument nicht zwingend ist. Auch ist zu bedenken, dass das Fehlen einer deutlicheren Individualisierung oft schlicht durch die kursorische Arbeit der Steinmetze erklärt werden kann. Jedenfalls ist mir keine nicht-individualisierte Orans auf einem handwerklich hochstehenden Sarkophag bekannt, und solche scheinen auch in anderen Kunstgenres zu fehlen. Insofern ist es überzeugender, in allen Oranten intendierte Porträtdarstellungen, d.h. Darstellungen von spezifischen Menschen zu erkennen, womit auch die Idee, weibliche Oranten stellten die Seelen männlicher Verstorbener dar, obsolet wäre. ${ }^{85}$

Für diese letzte Annahme gibt es m.E. aber auch keine Notwendigkeit, wenn man einmal von der Vorstellung abrückt, Männer müssten grundsätzlich im Vordergrund gestanden haben, oder die Geschlechter müssten zumindest immer gleichermaßen prominent erschienen sein, denn die traditionelle Grundbedeutung der Orans lebt im Christentum nachweislich fort. Auch im 3. und 4. Jh. spielt die weibliche Verpflichtung gegenüber der Familie noch eine große Rolle, und wird mit dem Terminus pietas bezeichnet. Dies zeigen nicht zuletzt die Münzen, welche das beliebte Motiv der Pietas mit Kind(ern) noch bis in die Mitte des 4. Jh.s, und weiterhin vornehmlich auf Münzen der Kaiserinnen, wiedergeben. ${ }^{86} \mathrm{Im}$ funerären Kontext war auch die Grabpflege (und somit die Sorge für die Vorfahren) Teil der weiblichen pietas, ${ }^{87}$ ein Aspekt, zu dem unter Christen auch die Fürbitte für den Verstorbenen gehört haben dürfte. Insofern ist es im Falle

\footnotetext{
${ }^{94}$ Z.B. Bovini / Brandeneurg / Ulbert / Deichmann 1967, 68f. Nr. 80 Taf. 24.

${ }^{85}$ Die zitierten ,Belege' für weibliche Oranten als Seelen männlicher Verstorbener sind m.E. nicht schlitssig, und ich netune hier nur ein Beispiel. Ein Sarkophag im vatikanischen Museo Pio Cristiano (ebda., Nr. 6; Studer-Karlen 2012, 164 Abb. 99 und 125) ist einem gewissen Sabinus gewidmet, der attf dem Deckel in einer Büste vor Parapetasma dargestellt war. Auf dem Kasten befindet sich in zentraler Stellung eine Orans zwischen biblischen Szenen. Es ist jedoch keineswegs ausgeschlossen, und in der Tat sehr unwahrscheinlich, dass nur Sabinus in dem Sarkophag beigesetzt war oder werden sollte: der Sarkophag wurde ihm von seiner Frau gesetzt, die zweifellos ebenfalls dort bestattet werden wollte. Ehepaare wurden traditionell sehr häufig, wenn nicht ganz überwiegend, zusammen bestattet. Auch sind Inschriften häufig komplementär zu den Bildern zu lesen, und listen keineswegs immer vollständig alle Bestatteten auf. Im vorliegenden, wie auch in den weiteren Fällen von nicht umgearbeiteten Sarkophagen, ist vielmehr dem Repräsentationsbedürfnis des Mannes durch die Inschrift (und in einigen Fällen seine Büste auf dem Deckel) genüge getan, während die Frau als Orans erscheint.

${ }^{86}$ KLAUSER 1959, 143f.; J.-P. CALLU, "Pietas romana. Les monnaies de l'impératrice Théodora", in: P. Boyancí (Hg.), Mélanges de philosophie, de litterature et d'histoire ancienne offerts à Pierre Boyancé. Collection de l'École française de Rome 22 (Rome 1974) 141-151; VollkomMBR 1997, Nr. 40, 41, 49, 50 .

${ }^{37}$ RerNsebrG 2006, 153f., liest die Oranten der vita htamana Sarkophage attch als exempla für die Hinterbliebenen, welche den Grabkult zu vollziehen haben; zum Grabkult als Akt der Pietas s. NizLSEN 1997, 195f.; zur Grabpflege als familiärer Aufgabe im Christentum s. É. Rebillard, The care of the dead in Late antiguity. Cornell studies in classical philology 59 (Ithaca / NY 2009) 20f. 26f. 160f. 174f.; Frauen als Euergeten im funerären Bereich: C. Osirk, "Roman and Christian burial practices and the patronage of women", in: L. BrinK /
} 
der meist isolierten Ritzzeichnungen der Lokulusverschlüsse vielleicht am ehesten denkbar, dass nicht eine Verstorbene, sondern eine Hinterbliebene gemeint ist, insbesondere dort, wo sie sich auf dem Grabverschluss eines männlichen Verstorbenen befindet. ${ }^{88}$

Wo die Orans hingegen die weibliche Verstorbene meint, und dies scheint in der Tat zumindest auf Sarkophagen und in der Katakombenmalerei der Fall zu sein, wird sie in der einschlägigen Literatur in der Regel im Jenseits oder Paradies verortet. Manche Darstellungskontexte, vor allem in späteren Bildern, legen diese Deutung durchatus nahe, wie Dresken-Weiland gezeigt hat. ${ }^{89}$ Doch ist es unwahrscheinlich, dass diese Deutung verallgemeinert werden kann.

Auf Sarkophagen finden sich außer Oranten weiterhin die Gebildeten mit Buchrolle und die ihrem Ehemann im Handschlag verbundene Ehefrau. ${ }^{90}$ Dies unterstreicht, dass die traditionellen Tugenden von ehelicher concordia, von paideia (Bildung), und von pietas weiterhin Geltung besaßen. Auch legt die - ebenfalls traditionelle - Isolierung der Chiffren für diese Tugenden von einem konkreten Handlungsgeschehen die Annahme nahe, es sei weniger eine spezifische Art oder ein spezifischer Inhalt des Betens gemeint, sondern die pietas als Charaktereigenschaft tund Tugend der Verstorbenen. Aus dieser können sich natürlich konkrete Akte der pietas implizit ableiten, die sich sowohl auf soziale als auch auf religiöse Inhalte beziehen. Zumindest für solche Sarkophage, wo die Orans von eindeutig christlichen Gestalten oder biblischen Szenen umgeben ist, wird man voraussetzen dürfen, dass ihre pietas nun auch die pietas erga Christum mit einschlieBt ${ }^{91}$ Hier wie auch im Falle der Oranten im Jenseits wäre tatsächlich zu überlegen, ob sich nun, d.h. im 4. Jh., erstmals in der Bildkunst das kontemplative Beten nachweisen lässt, obgleich die Tatsache, dass Sarkophage mit der Anbetung Christi niemals das Oransschema zeigen, vielleicht eher dagegen spricht. In jedem Fall sind die Darstellungen hier jedoch weiterhin in erster Linie als Charakterbilder und Tugendlob zu verstehen, und nicht auf eine konkrete Situation bezogen. ${ }^{92}$ Damit ist, sofern nicht ein-

D. GRBEN (Hg.), Commemorating the Dead: Texts and Artefacts in Context. Studies of Roman, Jewrish, and Christian Burials (Berlin 2008) 243-272.

${ }^{88} \mathrm{Zu}$ vereinzelten epigraphischen Zetgnissen für diesen Gedanken s. J. DREsKENW BLLAND, ,Vorstellungen von Tod und Jenseits in den frühchristlichen Grabinschriften des 3.-6. Th.s in Rom, Italien und Afrika", Römische Quartalschrift für christliche Altertumskunde und Kirchengeschichte 101 (2006) [289-312] 301; zu solchen Fürbitten allgemein A. MвRкт, Das Fegefeuer. Entstehung und Funktion einer Idee (Darmstadt 2005) 57-64.

${ }^{89}$ DrbsKen-Weiland 2010, 40-76.

${ }^{90}$ STUDER-KaRLEN 2012, passim, zusammenfassend 38-40.

${ }^{91} \mathrm{Zu}$ diesen ebda., 121-126. 132-138. Meine Deutung der Orans primär als Ausdruck einer weiblichen Tugend steht nicht unbedingt im Gegensatz zu den Deutungen dieser Autorin

${ }^{92} \mathrm{~S}$. BIRK, Depicting the dead. Self-representation and commemoration on roman sarcophagi with portraits. ASMA 11 (Aarhus 2013) 89-91, möchte die Orans der Sarkophage als ei- 


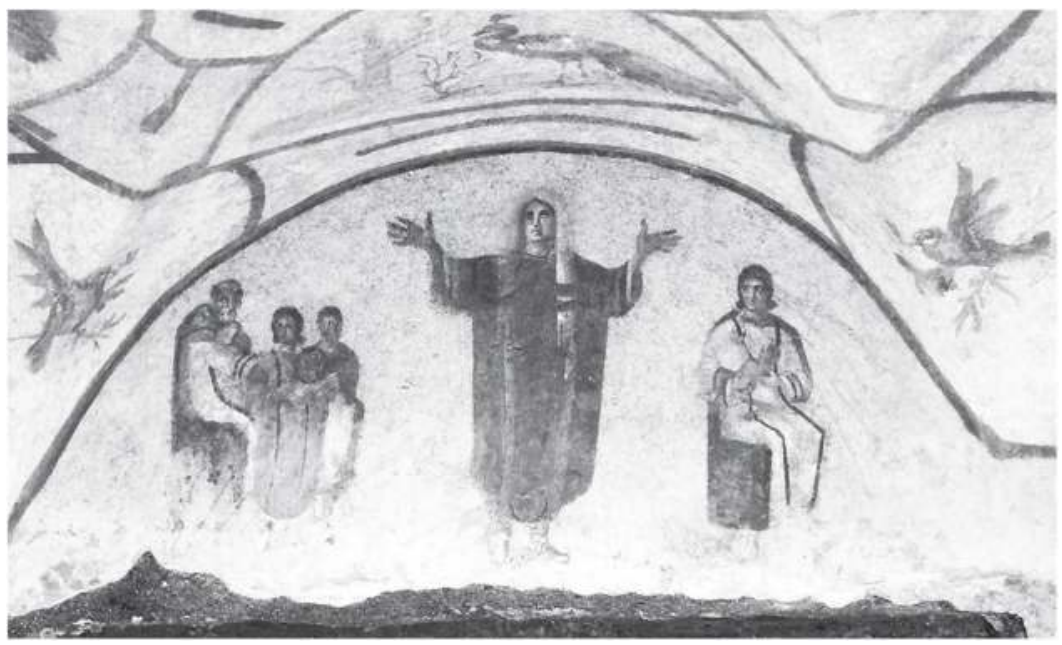

Abb. 7: Sog. Velata-Cubiculum, Rom, Priscilla Katakombe.

deutige Hinweise hinzutreten, auch offen gelassen, ob es sich bei diesen Darstellungen von Verstorbenen auch um Darstellungen als Verstorbene, d.h. in einem jenseitigen Zustand handelt. Tugendlob als solches hat den Vorzug, dass es sich sowohl auf die positiven Eigenschaften einer Person in der Vergangenheit als auch auf ihre Haltung in Gegenwart und Zukunft beziehen kann. Eine solche Zurschaustellung von Tugenden fügt sich nicht nur bestens in die gesellschaftliche Tradition ein, sondern auch in die verschiedentlich nachweisbare Vorstellung, dass die Christen ihr jenseitiges Schicksal ihrer diesseitigen Tugendhaftigkeit zu verdanken haben. ${ }^{93}$

Dieser Eindruck bestätigt sich in den großformatigen Wandmalereien, wo ebenfalls biblische Bilder mit solchen der privaten Selbstdarstellung in traditionellen Rollen verbunden sind. Im sogenannten Velata-Cubiculum der Priscillakatakombe aus dem dritten Viertel des 3. Jh.s zum Beispiel sieht man in der Lünette der Rückwand eine weibliche Orans im Zentrum, die eine zeitgenössische Modefrisur trägt und daher die Grabherrin meint

ne Variante der gelehrten Frau erklären. Doch während die Orans tatsächlich gelegentlich auf Sarkophagen mit Bildungsthematik erscheint, sind diese Fälle doch äußerst selten (vgl. ihren Appendix C). Auch beachtet sie nicht, dass die erhobene Rechte nun auch vermehrt als allgemeiner Redegestus fungiert, wie aus manchen Kontexten eindeutig hervorgeht. Im Übrigen weisen Frntikoclou / Voutiras 2005, 164, mit Berufung auf F. Fless, Opferdiener und Kultmusiker auf stadtrömischen historischen Reliefs. Untersuchungen zur Ikonographie, Funktion und Benennung (Mainz 1995) 34-36, darauf hin, dass Betende und Opfernde gelegentlich Buchrollen in den Händen halten, die auf die schriftlich vorgegebenen und u.U. durch einen Vorsprecher vorgelesenen Gebete verweisen.

${ }^{93} \mathrm{~J}$. DRESKEN-WEILAND, "Vorstellung von Tod und Jenseits in den Frühchristlichen Grabinschriften der Oikumene", Antiquité Tardize 15 (2007) 285-302; Dies. 2010, $50 f .67$. 
(Abb.7). Sie wird auf der linken Seite flankiert von einer Unterrichtsszene, in der dieselbe Person vor einem sitzenden, älteren Mann mit Buchrolle steht. Rechts ist dieselbe Frau ein drittes Mal dargestellt, diesmal sitzend mit einem Kleinkind auf den Armen. ${ }^{94}$ Ähnliche idealtypische Szenen aus dem Leben der Verstorbenen finden sich auf traditionellen römischen vita privata Sarkophagen ebenfalls. Sie beschreiben die Tugenden der Verstorbenen: sie ist gebildet, eine gute Mutter, und piissima. Ihre pietas ist daher sicher wie in den gleichzeitigen nichtchristlichen Sarkophagdarstellungen zunächst attributiv im Sinne eines recht umfassenden Tugendlobes zu verstehen, auch wenn hier vielleicht die konkretere, im eigentlichen Sinne religiöse Frömmigkeit des Betens zu Christus oder Gott hinzugekommen sein mag. In diesem Sinne ist es wohl auch zu verstehen, wenn sich direkt vor einer reich geschmückten und gekleideten Beterin an gleicher Stelle im Cubiculum C des Coemeterium Maitus ihr Sohn befindet (Abb. 8). Die Darstellung wurde gelegentlich als die der Madonna gedeutet, doch sind Porträtzüge und Modefrisur der Frau detutlich zu erkennen. ${ }^{95}$

Insofern ist es auch zunächst ein traditioneller $Z \mathbf{u g}$, dass die pietas fast ausschließlich als weibliche Tugend präsentiert wird. Im ersten Band des Repertoriums der christlichen Sarkophage aus Rom und Ostia stehen 121 weiblichen nur 10 männliche Oranten gegenüber, die zudem ganz überwiegend (sehr) jugendlich sind ${ }^{96}$ Dies legt den Eindruck nahe, dass pietas eine beliebte Tugend jener Personen sein könnte, die bestimmte andere Leistungen wie öffentliche Ämter nicht vorztweisen haben. Die besondere Prominenz der Orans auf diesen Sarkophagen, sowohl hinsichtlich ihrer Hätufigkeit als atuch hinsichtlich ihrer zentralen Stellung in den Dekorationen, bedarf allerdings näherer Erklärung, denn es fehlen weitgehend nicht nur männliche Oranten, sondern männliche Porträtfiguren überhaupt. ${ }^{97}$

\footnotetext{
${ }^{94}$ F. Bisconti / D. Nuzzo, "Scavi e restauri nella regione della, Velata in Priscilla", Rizista di archeologia cristiana 77 (2001) [7-95] 70-77; F. BisconTL, Le pitture delle catacombe romane (Todi 2011) 113-154; B. E. Borc, Crisis and ambition. Tombs and burial customs in third-century AD Rome (Oxford 2013) 254f. mit ausführlicher Begründung für die von der gängigen Interpretation abweichende Deutung und Bibliographie.

${ }_{95}$ Madonna: U. M. FAsOLA, „Topographische Argumente zur Datierung der ,Madonna orans" im Coemeterium Majus ${ }^{\prime \prime}$, Römische Quartalschrift für christliche Aitertumskunde und Kirchengeschichte 5.1 (1956) 137-147; Verstorbene: ZimmbrmanN 2007, 177 mit Taf. 26d; STUDER-KARLEN 2012, 115 Anm. 763.

${ }^{96} \mathrm{Vgl}$. LANGE 1996. Die Jugendlichkeit der männlichen Oranten wurde auch bemerktvon STUDER-KarLEN 2012, 158-164, die das Phänomen aber nicht weiter erläutert. Die Seltenheit männlicher Oranten erklärt sie wie ihre Vorgänger durch das weibliche Geschlecht der Termini für Seele (ebda. 158 mit Anm. 1144). Die männlichen Oranten erklärt sie mit dem vereinzelten Wunsch der zumindest geschlechtsmäßigen Präzisierung der Aussage. Hinzu kommen einige männliche Oranten in der Katakombenmalerei: ebda., 159 Anm. 1145.

${ }^{97}$ Nur sehr gelegentlich erscheinen hier männliche Figuren im Bildungstypus, wie etwa der clarissimus puer auf einem Sarkophag des frühen 4 . Jh.s aus der Prätextatkatakombe: Bovini / Brandengurg / Ulbert / Deichmann 1967, 233f. Nr. 564 Taf. 87. Wie dieser, sind jedoch auch die übrigen tendenziell früh und nicht eindeutig christlich. $\mathrm{S}$. aber den noch
} 


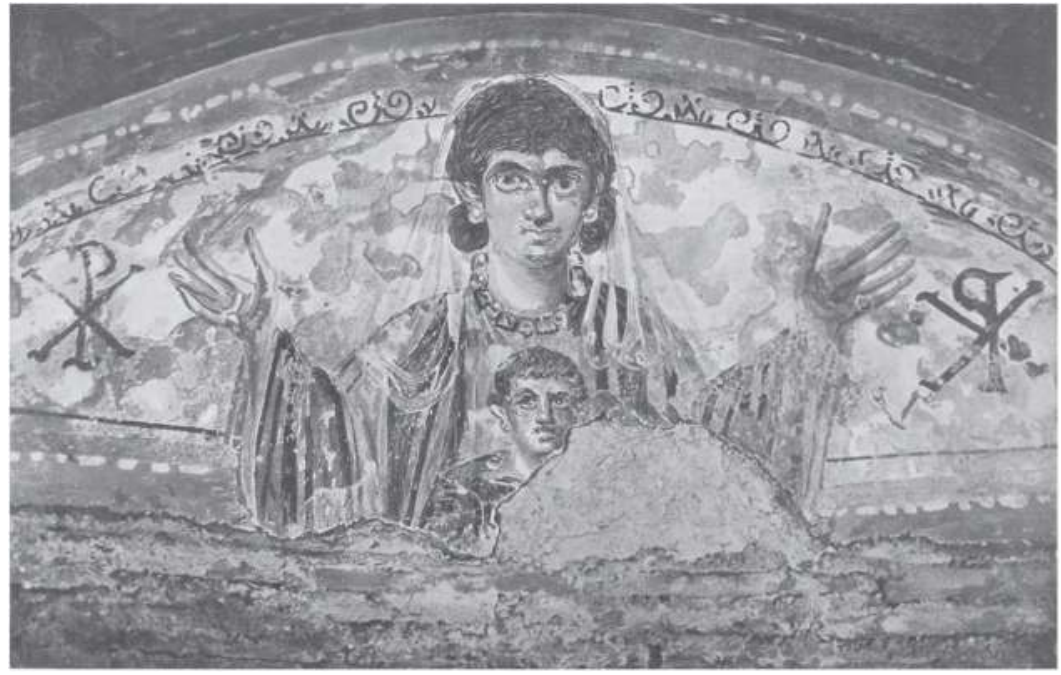

Abb. 8: Orans mit Kind aus dem sogenannten Cubiculum della Madonna, Rom, Coemeterium Maius.

Wo in entsprechender Position, etwa in den Seitenpanelen von Strigilissarkophagen, Männer erscheinen, handelt es sich in erster Linie um den ,Guten Hirten', dann auch um Männer in Himation (griechischem Mantel) und mit Buchrolle. Diese tragen jedoch in aller Regel keine Porträtzüge und sind oft gedoppelt, so dass es sich entweder um generische Gelehrte oder aber um Apostel handeln muss. ${ }^{98}$ Im Zentrum der Kompositionen kommen, von wenigen meist nicht eindeutig christlichen Ausnahmen abgesehen, ${ }^{99}$ sogar ausschließlich der ,Gute Hirte' und später Christus vor. Männliche Porträts finden sich fast ausschließlich als Büsten in Clipei (Rundschilden) oder vor einem Parapetasma (Vorhang) auf den Deckeln in den seit dem 2. Jh. bekannten Ikonographien, sind aber auch dort leicht in der Minderheit. ${ }^{100}$ Dieses Ungleichgewicht ${ }^{101}$ lässt sich weder durch das verständliche Verschwinden des Opfernden erklären, noch durch den

dem 3. Viertel des 3. Jh.s angehörigen Sarkophag in Santa Maria Antiqua, der auf der Front mit biblischen Szenen im Zentrum die Orans dem lesenden pepaideumenos gegenüber stellt: ebda., 306f. Nr. 747 Taf. 117.

${ }^{98}$ STUDER-KARLEN 2012, 126-132.

${ }^{99}$ S. LANGE 1996, 109, mit 8 Exemplaren. Von diesen sind aber die meisten nicht als christlich zu erweisen und / oder zu fragmentarisch, um eine Aussage zuzulassen.

${ }^{100} \mathrm{~S}$. die Listen in ebda. Porträtclipei: 23 Ehepaare, 13 Männer, 15 Frauen (einmal mit Kind) ${ }_{r}$ und 8 Kinder. Büsten vor Parapetasma: 28 Frauen (einmal mit Kind) stehen 17 Männern gegenüber, wobei auf einigen Sarkophagen beide als Pendants erscheinen.

${ }^{101}$ Es würde auch in dem Falle bestehen, wenn wir weibliche Oranten als Seele männlicher Verstorbener akzeptieren würden. 
Rückgang an pepaideumenoi (Gebildeten). ${ }^{102}$ Angesichts des weiterhin relevanten Bildungsideals, das sich ja auch in den erhaltenen Männerporträts niederschlägt und nach Bedarf leicht christlich auszudeuten wäre, ist vielmehr dieser Rückgang selbst ebenso zu erklären, wie die Tatsache, dass die Oransikonographie nur extrem vereinzelt und spät für erwachsene Männer übernommen wurde. ${ }^{103}$ Wir sind demnach mit der überaus interessanten Tatsache konfrontiert, dass Fratuen in der frühchristlichen funerären Bildkunst generell eine heratusragende Position einnehmen, die nicht durch die wenig überzeugende Umdeutung weiblicher Oranten in männliche Seelen hinwegerklärt werden kann und sollte. Vielmehr steht zu vermuten, dass die Bilder gesellschaftliche Phänomene spiegeln, die wohl nur im weiteren sozio-historischen Kontext erklärt werden können und einer eigenen Untersuchung bedürfen. ${ }^{104}$

\section{Fazit}

Beten als Kommunikation mit einer Gottheit ist während des gesamten hier betrachteten Zeitraums ein zentrales Element der nicht-christlichen wie christlichen Religion. Anders als philosophische und theologische Traktate wie der in diesem Band im Zentrum stehende Maximos-Text vermuten lassen, handelte es sich dabei jedoch in erster Linie um Bitten um Rettung oder Vergünstigungen, und in zweiter Linie um Dank für ebendiese an die Gottheit, während die kontemplative Anbetung und spirituelle Begegnungen extrem selten gewesen zu sein scheinen, und sich erst im Christentum langsam durchsetzen. So jedenfalls lassen die epigraphischen und bildlichen Zeugnisse vermuten. Daratus erklätt sich atıch die gesellschaftliche Bedeutung des Betens: Nur mit Unterstätzung der Gottheit oder zumindest ohne ihren Widerstand - lassen sich Wohlergehen und Fortbestand von Familie wie Staat sichern. Dies dürfte auch erklären, warum die Demonstration von Frömmigkeit zu einem wichtigen Element der bürgerlichen wie herrscherlichen Selbstdarstellung werden konnte. In vorchristlicher Zeit scheint das Beten als rein verbale Kommunikation nach dem Opfer als Akt des Gabentausches die zweite Stelle eingenommen zu haben, weshalb seine Darstellung - wenn auch nicht die Praxis! - weitgehend auf Frauen beschränkt war. Die spezifische Ikonographie der Orans mit beidarmigem oder einarmigem Gebetsgestus wurde somit vor allem für die Selbstdarstellung von Fratuen erfunden und verwendet. Spätestens in der römischen Kaiserzeit verselbständigte sich die Oransikonographie,

\footnotetext{
${ }^{102}$ Wie etwa Studer-KarLen 2012, 160 mutmaßt.

${ }^{103}$ Zu diesen späten Einzelstücken s. ebda., 161.

${ }^{104}$ Der Hinweis auf die - angebliche oder tatsächliche - schnellere Verbreitung ces Christentums unter Frauen (so z.B. ebda., 34) scheint mir als Erklärung unzureichend.
} 
die nun nicht mehr (nur) den Akt des Betens und die Kommunikation mit einer Gottheit zum Ausdruck brachte, sondern als allgemeines Zeichen der pietas, welche sich im Falle der Frauen in erster Linie auf die Familie bezog, zum weiblichen Tugendlob eingesetzt wurde. In dieser Funktion dürfte sie auch in die christliche Ikonographie übernommen worden sein. Abgesehen von einigen biblischen Szenen, in denen männliche Protagonisten um Errettung aus einer konkreten Notlage bitten, und obgleich das traditionelle männliche Pendant zur Orans, der Opfernde, aus offensichtlichen Gründen nicht mehr darstellungswürdig war, sind es weiterhin fast ausschließlich Frauen, die als Oranten dargestellt werden. 


\title{
Religionsphilosophische Meditationen über Ödipus und Jesus im Gebet
}

\author{
Vincenzo Vitiello
}

\section{Vorbemerkung}

Die Frage, um die es im Folgenden geht, ist keine historische, obwohl sie sich aus geschichtlichen Entwicklungen heraus ergibt. Vielmehr geht es um eine theoretische, spekulative Frage. Sie soll am Beispiel zweier unterschiedlicher Gestalten behandelt werden, anhand derer sich die Beziehung des Menschen zu Gott, insbesondere im Bereich des Gebets, erläutern lässt. Die Wahl von Ödipus und Jesus hat sich dabei wie von selbst ergeben. Sie sind die exemplarischen Vertreter zweier religiöser Traditionen, der heidnischen und der christlichen, die zwei sehr verschiedene Konzeptionen des Verhältnisses von Mensch und Gott repräsentieren. Aufgrund dessen kann die theoretische, seinsgeschichtliche Analyse ihrer Verschiedenheit, auch gerade weil diese Religionen die ganze Geschichte Europas geprägt haben, zum besseren Verstehen unserer Zeit, nicht nur ihrer religiösen Aspekte, beitragen. Das Ziel dieses Essays ergibt sich somit aus der Überzeugung, dass philosophische Betrachtungen einen bedeutungsvollen Verständnishorizont für die Geschichte ebenso wie für die je eigene Zeit eröffnen.

\section{Die Sprache des Gebets}

„Mensch so du GOtt noch pflegst umb diß und das zudanken, Bistu noch nicht versetzt auß deiner schwachheit schranken. ${ }^{\prime 1}$

Beten bedeutet anrufen, flehen, danken. Sprechen also. Insgeheim zum eigenen Herzen - allein; oder gemeinsam mit anderen - indem man einen Lobgesang anstimmt. Beten bedeutet auch Zuhören oder auch nur auf das Wort des Anderen zu warten. Es könnte indes übertrieben erscheinen, wenn man beim Beten nur auf das Wort des Anderen wartet. Nicht, weil man beabsichtigt, das Schweigen des Anderen zu respektieren, sondern

\footnotetext{
* Aus dem Italienischen übersetzt von Simone Seibert unter Mithilfe von Andrea Villani und Rainer Hirsch-Luipold. Anmerkungen von Simone Seibert.

${ }^{1}$ L. GNÄDINGER (Hg), Angelus Silesius (Johannes Scheffler). Cherubinischer Wandersmann (Stuttgart 1984) I 91, 40 .
} 
weil schon allein das Anrufen, das Flehen um ein Wort, als ein Akt der Überheblichkeit empfunden werden kann als ob man durch das Beten den Anderen - unter Einsatz des Wortes - an sich binden wollte. Aber wenn es der Andere ist, der auf das Wort eingeht? Der geheimnisvollerweise auf das Wort eingeht? Freilich kann man sich nicht unvorbereitet dem $\mathrm{Zu}$ hören stellen. Beten bedeutet, sich auf das Zuhören einzulassen. Auch in Abwesenheit des Wortes.

Beten bedeutet anrufen, flehen. Bitten also. Aber nicht, um etwas zu bekommen. Nicht einmal das Wort. Nicht einmal Vergebung. Aber was für ein Bitten wäre das, das sich nichts "wünscht"? Ist nicht in allen Gebeten der Wunsch nach "etwas" präsent? Bitten ohne etwas zu wollen? Ohne etwas zu erbitten? Wenn man Gott anruft, erbittet man tatsächlich von ihm Gehör, Schutz, Rettung, Trost. Vergebung. Um zu bitten, dass er spricht, wendet man sich ihm zu, tritt an ihn heran. Man bittet - tum etwas zu bekommen. Weil man etwas "will". Und trägt nicht vielleicht dieses Bitten das Merkmal, das das dem Beten von Anfang an innewohnt, nämlich das Eingestehen der eigenen Bedürftigkeit, die Selbsterniedrigung - $m i$ nus quam cogitari potest ${ }^{2}-$ angesichts des Größeren, des Allergrößten? Ist es nicht ein Akt des Hochmuts, nicht zu bitten? Nicht bittet, wer die Gefahren, die Krisen, die Nöte des Lebens allein zu meistern versteht. Wer sich nicht für hilfsbedürftig hält.

Nein: Wunschloses Bitten bedeutet etwas anderes. Es bedettet, um das zu bitten, was ohnehin gewährt wird. Da quod iubes. ${ }^{3}$ Mehr noch: um das zu bitten, was bereits gewährt wurde. Darum zu bitten, obwohl es bereits

\footnotetext{
${ }^{2}$ Anselm von Canterbury, Proslogion, P5, I 104,11-17: Quid igitur es. Domine Deus, quo nihil maius valet cogitari? Sed guid es, nisi id guod summum omnium solum existens per seipsum, omnia alia fecit de ninilo? Quidguid enim hoc non est, minus est quam cogitari possit; "Was also bist Du, Herr-Gott, ,über dem nichts Größeres gedacht werden kartr'? Aber was bist du, wenn nicht das, was als das Höchste von allem allein durch sich bestehend, alles andere aus dem Nichts geschaffen hat? Denn alles, was das ticht ist, ist weniger als was man sich denken kann." Text und Übersetzung aus: P. Franciscus Salbsius Schmitr O. S. B. Abtei Wimpfen (Hg.), Anselm von Canterbury. Proslogion. Untersuchungen. Lateinisch-c.eutsche Ausgabe (Stuttgart / Bad Cannstatt 1962) 90. Das Zitat ist Teil von Anselms Gottesbeweis, der später als ontologischer Gottesbeweis in der Philosophiegeschichte ausführliche Beachtung fand: Aus den Annahmen, dass nichts Größeres als Gott gedacht werden kann und dass in Wirklichkeit zu existieren etwas Größeres ist, als lediglich im Verstand zu existieren, wird darauf geschlossen, dass Gott nicht nur im Verstand, sondern auch in Wirklichkeit existiert. Vgl.dazu R. WIMMBR, „Gottesbeweis, ontologischer“, Enzyklopädie Philosophie und Wissenschaftstheorie 1 (1995) 800-804. Siehe auch unten, S. 185 und 186-187.

${ }^{3}$ Augustinus, Confessiones $X 29,40 ; 31,45 ; 37,60$ und $D e$ dono perseverantiae $20,53: D a$, quad itubes, et itbe, quod vis; "Gib, was du befiehlst und befiehl, was du willst." Text und Übersetzung aus: W. Thiмmв ( $\mathrm{Hg}$ ), Aurelizus Augustinus. Confessiones. Bekenntnisse (Düsseldorf / Zürich 2004). Kernsatz der augustinischen Gnadenlehre: Ohne Gottes Gnade ist es dem Menschen nicht möglich, einem sündigen Lebenswandel zu entgehen. Gott muss also selbst dem Menschen die Gnacle der Tugendhaftigkeit verleihen, damit dieser den Wünschen Gottes nach einem tugendhaften Leben entsprechen kann.
} 
gewährt wurde, bleibt immer "möglich", weil es denjenigen, der gewährt, nie bindet. Bitten bedetutet hier: danken. Danken für das, was bereits gegeben wurde, nicht nur "bevor" wir darum gebeten haben, sondern "darüber hinaus" und unsere Bitte "übersteigend". Armselig ist unsere Bitte, allzu armselig im Hinblick darauf, was schon gegeben wurde, geschenkt wurde, und im Hinblick auf die Möglichkeit, dass überhaupt etwas gegeben und geschenkt wird. Beten bedeutet, im Flehen zu danken.

Flehen ist Beten in völliger Selbsterniedrigung, in einer absoluten Entäußerung des Selbst, des eigenen Seins. Kenose ${ }^{4}$ unendlich weit entfernt vom Tod und von jeder Todessehnsucht. Wir wollen hier nicht atuf den Tod eingehen, den sich der Mensch selbst geben kann (was in unserem Zusammenhang auch überflüssig ist); denn das wäre keine Selbstentäußerung, sondern der höchste Ausdruck von Gottlosigkeit, die radikale Missachtung der eigenen Endlichkeit und des Andersseins des Anderen; jene extreme Form der hybris, die das Subjekt als absolute Monade setzt, gänzlich losgelöst, völlig sein eigener Herr, des eigenen Lebens und des eigenen Todes. Nein: Hier geht es um den erflehten Tod, um das nunc dimitte servum tuum ... . Solches Flehen ist auch unendlich weit entfernt vom Bitten um den Tod, ut Unum simus, ${ }^{6}$ um sich mit Gott zu vereinigen. Denn auch in diesem Bitten steckt eine hybris, die Überheblichkeit des Urteilens, die es wagt, Präferenzen ztu setzen: vom Selbst atusgehend und in Bezug atuf das Selbst. Eine hybris, die atus der philautia erwächst: aus der Selbstliebe. Und auf der Basis dieser Liebe sich anmaßt, das Werk Gottes zu beurteilen. Beten bedeutet demgegenüber, dankend zu flehen. Dankend für das, was

\footnotetext{
${ }^{4}$ "Entäußerung" in Phil 2,6f.: „Er war Gott gleich, hielt aber nicht daran fest, wie Gott zu sein, sondern er entäußerte sich selbst und nahm Knechtsgestalt an, und wurde den Menschen gleich." Die Kenose wurde im Rahmen der Zweinaturen-Lehre bereits in der Patristik diskutiert, dann von der lutherischen Theologie des 17. und 19. Th.s als Begriff für ein bestimmtes Moment der Menschwerdung des Gottessohnes etabliert. Vgl, dazu M. SeILs, "Kenose", Historisches Wörterbuch der Philosophie 4(1976) 813-815. Siehe unten, S. 184-187.

${ }^{5}$ Lk 2,29-32 (Lobgesang des Simeon; einer der drei Lobgesänge im Lukasevangelium): Nunc dimittis servum tuum Domine, secundum verbum tuum in pace; ${ }_{\text {Herr, }}$ nun lässt du deinen Diener in Frieden fahren, wie du gesagt hast" (Teil des Komplet). Simeon hatte die Prophezeiung erhalten, dass er erst dann sterben werde, wenn er den Messias gesehen habe. Als der acht Tage alte Jesus zur Beschneidung in den Tempel von Jertsalem gebracht wird, erkennt ihn Simeon als Messias und weiß, dass er nun in Frieden sterben kann.

${ }^{6}$ Vor allem in einigen Strömungen der Mystik findet sich die Vorstellung vom Tod als herbeigesehnte Vereirigung der Seele mit Christus und Gott (mors mystica / unio mystica). In Joh 17,11 hingegen bittet Jesus in seiner Fürbitte an die Jünger, dass sie auch nach seinem Tod in der Vereinigung mit ihm leben sollen, um das Wort Gottes zu verbreiten: et iam non sum in mundo et hii in mundo sint et ego ad te venio Pater sancte serza eos in nomine tuo quos dedisti mini custodivi et nemo ut sint unum sicut et nos; "Ich bin nicht mehr in der Welt, sie aber sind in der Welt, und ich komme zu dir, Heiliger Vater, erhalte sie in cleinem Namen, den du mir gegeben hast, damit sie eins sind wie wir."
} 
ist und was geschieht. Für alles, was ist und was geschieht - ohne Unterschied. Für alles, was als Seiendes stets möglich bleibt.

Aber wenn wir beim Beten anrufen, flehen, danken, wie wenden wir uns, die wir Menschen sind, an den ganz Anderen? In der zweiten Person richten wir uns an den Anderen wie an ein Du. Aber wir sind es, es ist unser Denken, das den Anderen als "Du" benennt und definiert. Ein Du, das eigentlich über jedes andere Du hinatusgeht, das jeden Namen und jede Definition übersteigt. Ein Du, das anders ist, radikal anders, und trotzdem "unseres". Gerade weil es, dieses radikal andere Du, "in Beziehung" zu uns als "Du" steht, ist es ein Du. "In Beziehung" zu uns bedeutet nicht, dass es "für" uns ist. Aber sogar das mag zu viel sein. Das Du kann für sich selbst ein solches sein. Weil der Andere sich auf uns einlassen kann, als Anderer, als "Du". Wie gesagt: Aus dem Schweigen kann das Wort auf geheimnisvolle Weise kommen. Und es hieße, dieses Geheimnis zu verraten, wenn man etwas für sich selbst bitten wollte: Das Wort kommt zu uns von Ihm her, das Undenkbare, das Unverstehbare. Quiddam maius quam cogitari potest. ${ }^{7}$

Die Sprache des Betens ist die Sprache, die sich der Endlichkeit bewusst

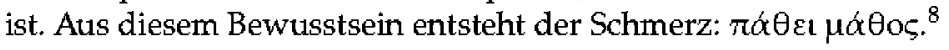

Zeus, wer immer es ist -

Läßt gern bei diesem Namen sich nennen, ...

Doch preist man getrost mit Liedern des Sieges Zeus,

gewinnt man als Krone des Wissens,

dass er den Menschen den Weg gewiesen

zum Denken, dass er durch Geltung erhoben

den Satz: Durch Leiden lernen! $!^{9}$

\section{Das pagane Gebet}

"Freilich die Sehergabe, nach der du, trefflicher Zeussohn, Fragst, zu erlemen, ist so wie den andern Unsterblichen dir auch Nicht von den Göttern bestimmt [...]

Es soll von den ewigen Göttern kein andrer Außer mir wissen, was Zeus entschlossen will [...] Doch von den Menschen vernicht ich die einen, den anderen nütz ich, Führe der heillosen Menschen Geschlechter auf mancherlei Umweg. Vorteil von meinem Verkünden wird allen, die zu mir kommen, Wenn nichts fehlt an der Vögel Stimmen und. Flügen; sie werden Vorteil haben von meinem Verkünden und keine Enttäuschung.

Wer aber Vögeln vertraut, die Eitles verlauten, wer ohne Klare Einsicht versucht mein Orakel zu fragen, wer etwa

\footnotetext{
${ }^{7}$ Siehe oben Anm. 2.

8 "Durch Leiden lernen", Aischylos, Agamemnon 177, siehe das folgende Zitat.

${ }_{9}^{9}$ Aischylos, Agamemnon 159f. und 173-177 (Übers. Ebener).
} 
Weiter zu sehen versucht als die ewigen Götter, dem sag ich: Nutzlos geht er seinen Weg, seine Gaben freilich empfang ich. ${ }^{\text {.10 }}$

Welches ist das höchste pagane Gebet? Welches drückt auf nobelste Weise die heidnische Religiosität aus, die Niedrigkeit und die Selbsterniedrigung des Menschen angesichts seines Gottes, seiner Götter? Und zeigt zugleich, wie hart und schwierig es ist, zu beten? Wie ungewiss ist nämlich das Beten, weil es auf einer unsicheren Schwelle steht, die trennt und vereint, teilt und zusammenfügt Diesseits und Jenseits, das irdische Schicksal des Menschen und das Andere, und, darüber hinatus, den Menschen und seine Selbsterniedrigung? Welches also ist das nobelste pagane Gebet?

\subsection{Der Ödipus auf Kolonos von Sophokles}

Die Tragödie macht zuallererst Folgendes deutlich: dass das Wort des Gebets nicht nur Stimme ist, sondern zugleich auch eine Geste, eine Handlung. Sie ist zwar eine ganz besondere - sowohl durch die Form, das Ritual, als auch dadurch, dass es ein Einzelner ist, der die Geste in die Tat umsetzt - und trotzdem steht sie nicht isoliert. Das Gebet ist Singular und Plural zugleich: von einem Einzelnen, sogar einem völlig Vereinzelten, und zugleich chorisch.

Der Auftakt dieses tragischen Gebets ist Ödipus' Betreten eines heiligen Ortes. Ein Akt des Sakrilegs, das Ödipus unbewusst begeht. Müde vom Alter und vom langen sich Hinschleppen, als Verbannter, von Stadt zu Stadt, setzt er sich auf einen Stein im heiligen Bezirk, der Poseidon und Prometheus geweiht ist, bei der "ehernen Schwelle", 11 einem Bollwerk der Athena. Ödipus wendet sich an die "holden Töchter der uralten Nacht" (àexaíov okótov, 106) und an Athena: Er bittet um Mitleid - er ist nicht mehr der Ödipus, der er einst war. Auch alle Bewohner des Ortes bittet er, Mitleid mit ihm zu haben. Durch die Weissagungen und Zeichen der Götter, besonders von Apollon, weiß er, dass er an den Ort gelangt ist, wo seine Tage und seine Leiden enden werden. Er bittet, dass sie ihn nicht vertreiben und ihm erlauben mögen, mit Theseus, ihrem König, zu sprechen. Ödipus steht bereits jenseits seiner Handlungen und seines Schicksals. Er weiß, dass er seine Handlungen mehr erlitten als verübt hat. Sein Leben lag weniger in seiner als in der Hand des Schicksals: "Nichts tat aus eigenem Entschluss ich" (523), sagt er. Jetzt ist er nicht mehr derselbe, jetzt ist er nicht länger der Ödipus, der er einst war, er ist "heilig und fromm" (ígò $\zeta \varepsilon u \sigma \varepsilon \beta \dagger\rceil \zeta ~ \tau \varepsilon, 287$ ), "dem Gesetz nach schuldlos" (vó $\omega \omega$...

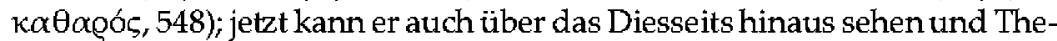
seus gegenüber vorhersagen: „du selbst und dieses Land und die dir un-

\footnotetext{
${ }^{10}$ Hymnos auf Hermes 533-549 (Übers. Weiher).

${ }^{11}$ Sophokles, Ödipus auf Kolonos 57 (Übers. Willige, Überarb. Bayer, wie im Folgenden).
} 
tertan, ihr möget glücklich werden, und im Wohlergehn gedenket mein, des Toten, immerdar beglückt!" (1553-1555). Aber gerade in eben diesem "Jetzt", als er, obwohl noch im Diesseits, bereits außerhalb des Diesseits steht, kehrt ungestüm das Diesseits zurück, um ihn einzunehmen, in Figur von Ismene, der Tochter-Schwester. Ismene erzählt Ödipus die letzten Ereignisse, den tödlichen Bruderkrieg unter seinen beiden männlichen Nachkommen, Eteokles und Polyneikes, die gegeneinander um den Thron von Theben kämpfen. Wieder bricht die Vergangenheit über ihn herein. Aber es ist nicht nur die Erinnerung an den Vatermord und die inzestuöse Hochzeit. Es ist die Erinnerung an eine kürzer zurückliegende Vergangenheit, die Ödipus überwältigt: die Erinnerung aus der Stadt von Kreon vertrieben worden zu sein, ohne dass seine männlichen Nachkommen, allein begierig, ihm auf dem Thron zu folgen, ihn verteidigt hätten. Als Gefangener des Diesseits wird Ödipus erneut zur Beute des Hasses. Er bittet um Mitleid für sich selbst, ist aber mitleidlos gegenüber den anderen, gegenüber seinen eigenen Söhnen-Brüdern. Er sieht nicht, dass es sein eigenes Unglïck ist, sein eigenes Schicksal, das sich über sie ergießt. Er wiederholt zu seiner eigenen Entlastung die Worte von Antigone - "denn keinen Sterblichen wirst du erblicken, der, bedrängt ihn ein Gott, ihm entrinnen könnte" (252-254). ${ }^{12}$ Aber er tut es nicht für Polyneikes, obwohl dieser ge-

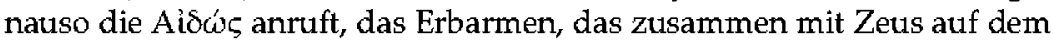
Thron sitzt (1267f.), nicht für Polyneikes, obwohl dieser zwar weiß, aber gegen den Erzeuger nicht einwendet, dass sein eigener Weg, "schicksalsschwer und unheilvoll" (1433), ihm zuteil wurde "durch diesen Vater und die Rachegöttinnen" (1434). Vom übermächtigen Diesseits hergeschleppt wird Ödipus wieder zu dem Ödipus, der er einst war, und jagt den Sohn davon. Er beginnt wieder, sich mit seinem weltlichen Schicksal zu identifizieren.

Die Tragödie spielt sich auf zwei Ebenen ab: der menschlichen und der göttlichen. Das Beten bildet den Übergang von der einen zur anderen. Den Übergang, der sich innerhalb des Diesseits ereignet. Denn es geschieht im Diesseits, dass das Diesseits überholt, übertroffen wird. Im Diesseits: Das Beten bleibt daher immer den Fallstricken des Diesseits ausgesetzt. Ödipus, der betende Ödipus, der heilige und fromme, dem Gesetz nach schuldlos, ist immer in Gefahr, eben das Göttliche zugunsten des Menschlichen aus dem Blick zu verlieren. Eine Gefahr, die umso größer ist, je näher Ödipus davor steht, sie zu überwinden.

Der betende und flehende Ödipus weiß, dass alles in der Hand der Götter liegt: Sein eigenes Betreten von Kolonos, dem heiligen Bezirk, die Gastfreundschaft des Theseus, sein naher Tod - so wie sein eigenes vorïbergegangenes Leben. Er weiß es und verkündet es; er sagt es zu Theseus, dem er

\footnotetext{
${ }^{12} \mathrm{Vgl}$. auch 997f.: „Nun, in solch Unheil lief ich selber auch hinein, geführt von Göttern...".
} 
die Geheimnisse offenbaren muss, die er ihm in den letzten Augenblicken seines Lebens mitteilt. Er bittet darauf die Töchter, ihn zu waschen und zu kleiden mit dem unbefleckten Kleid, dann schickt er sie weg. Allein Theseus, der schon einmal in die Unterwelt gestiegen war, um Persephone zu rauben, begleitet ihn. Aber auch er bedeckt am Ende die Augen, als er vom allzu starken Licht geblendet wird - "Licht ohne Licht" ( $\phi \tilde{\omega} \zeta \dot{\alpha} \phi \varepsilon \gamma \gamma \varepsilon \dot{\varepsilon} \zeta$, 1549) - und, ausgestreckt auf der Erde, betet er "mit ein und demselben Gebet $^{\prime \prime}$ ( $\left.\dot{*} v \tau \alpha v \tau \bar{\omega} \lambda{ }^{\prime} \gamma \omega, 1655\right)$ zu Gaia (der Erde) und den olympischen Göttern.

Ödipus stirbt allein. Eine schwer zu ertragende Einsamkeit - auch wenn er so lange gezögert hat. „Ödipus, was zögern wir zu gehen? Du hast nun allzu lange schon gesäumt" (1627f.). Aber auch nach den Worten des Gottes wendet sich Ödipus an die Welt: Der Gedanke an die Töchter lässt ihn nicht los; er bittet Thesetus, das Versprechen, sie zu schützen, zu erneuern. Endlich macht er sich zum letzten Schritt auf. Ohne Stöhnen, ohne Schmerzen: "wunderbar, wie sonst kein Mensch" (1664f.) - nach der Erzählung des Boten. Wie er gestorben ist, kann keiner sagen, außer Theseus. Aber was sagt Theseus? An die weinenden Töchter, die der Chorführer schon versucht hatte zu trösten, indem er sie aufforderte, das göttliche Schicksal edel zu tragen und daran zu denken, dass sie sich nichts vorzuwerfen haben, richtet Theseus den Vorwurf, dass sie sich beklagen: "Denn wo als eine Gnade die Nacht drunter gewähtt ist, da trauert man nicht: es ist unrecht" (1751-1753). Der Chorführer betrachtet es mit den Augen der Welt, Thesetus mit göttlichen. Thesetus sagt dasselbe, was vorher bereits der Chor ausdrückte, mit den Worten, die die ganze Kultur Griechenlands prägen: "Nicht geboren zu sein, das geht über alles; doch, wenn du lebst, ist das zweite, so schnell du kannst, hinztugelangen, woher du kamest" (12241227).

Die Begräbnisriten zeigen die Notwendigkeit, sich vom Selbst zu reinigen, von der Endlichkeit und der Negativität des "Selbst". Der Tod bedeutet zum gewesenen Schatten zurückztıkehren, zum Heiligen - jenseits des Menschen und jenseits des Göttlichen. Das pagane Gebet gibt dieser Sehnsucht eine Stimme.

Es erklärt hingegen nicht die menschlichen, allzı menschlichen Tränen von Antigone und Ismene. Aufs Netue wendet sich die Demut in ihr Gegenteil, in eine hybris, zur Welt zu sprechen mit der Stimme des Gottes. Theseus, der die unglücklichen Töchter von Ödipus tadelt, ist weniger pietätsvoll als der Chorführer, der menschliche Worte spricht. Menschlich, aber nicht nur menschlich. In der Tat, das pagane Gebet verrät die Endlichkeit des Endlichen genatu an dem Punkt, an dem es sie einzuholen scheint. Die griechische Kultur - und damit auch ihr Beten - kennt die Endlichkeit des Lebens nur als Moment oder als Teil des unendlichen Lebens. 


\section{Das christliche Gebet}

"Wahrlich, er wendet sich dir dann zu, wenn du ihn selbst stchst, nicht, wenn du durch ihn etwas anderes suchst. ${ }^{.13}$

Nach Getsemane geht Jesus um zu beten. Das Beten verlangt Einsamkeit - er selbst hatte gemahnt, im Verborgenen zu beten -; aber obwohl er sich jetzt zurückzieht, will er seine Jünger bei sich haben; bei ihm bleiben Petrus und die beiden Söhne des Zebedäus. Bevor er auch sie zurücklässt, sagt er: "Meine Seele ist zu Tode betrübt; bleibt hier und wacht mit mir" (Mt 26,38). Dann, hingestreckt auf der Erde, fleht er: "Mein Vater, wenn es möglich ist, lass diesen Kelch an mir vorübergehen. Aber nicht nach meinem Willen, sondern nach deinem" (Mt 26,36-39). Es ist der Menschensohn, der so betet. Der Sohn, der - um Paulus noch einmal zu zitieren "Gott gleich war, aber nicht daran festhielt, wie Gott zu sein, sondern er entäußerte sich selbst und nahm Knechtsgestalt an, und wurde den Menschen gleich" (Phil 2,6f.). Das Menschsein von Christus ist total: Er legt sich auf die Erde, er erniedrigt sich vor dem Vater. Er entäußert sich so gänzlich seiner göttlichen Natur, dass er auch dem Vater einen menschlichen Charakter zuschreibt: den Willen. Und von diesem Willen befreit er sich jetzt. Er will sich befreien. Es ist die zweite und schwierigere Kenose. Nicht der Rückzug aus der Welt - die Versuchung durch den Satan ist schon lange her - sondern der Rüickzug vom eigenen Willen. Vom eigenen Selbst. Dass diese zweite Kenose, diese Entäußerung der Kenose selbst, hart und schwierig sein mag, das zeigt die Tatsache, dass er sogar dreimal zum Vater betet, hingestreckt auf der Erde. Die Nähe der Jünger ist ihm ein Trost, sie sind das Zeugnis seiner Menschlichkeit. Aber die Jünger geben sich dem Schlaf hin. "Ihr Geist ist willig, aber das Fleisch ist schwach" (Mt 26,41). Jesus spricht natürlich zu den Jüngern, aber ihre Nähe hätte keine Bedeutung, wenn Jesus nicht auch zu sich selbst spräche. Er wäre nicht vollkommen Mensch, wenn die Bemerkung nicht auch für ihn gelte, für Jesus. Im Gebet zeigt sich mit Schmerz, im Schmerz, dass die Vereinigung des Geistes mit dem Fleisch unvollkommen, inkomplett ist. Im Übergang vom Diesseits zur Ewigkeit widerstrebt die Zeit, erhält Gewicht. Und das Gebet ist die Überwindung des Diesseits im Diesseits. Jesus, der göttliche Sohn, der Mensch geworden ist, ist das höchste Zeugnis, dass man nicht "in" Gott betet. Daher ist sein Leiden real. Man betet im Diesseits; außerhalb won Gott. Und doch auf das Jenseits hin ausgerichtet. Dieses Gerichtetsein ist noch nicht das Jenseits, auch wenn es das Jenseits von außerhalb vorwegnimmt. Im christlichen Gebet sind die menschlichen, allzu menschlichen Tränen von Antigone und Ismene vollständig angenommen und

${ }^{13}$ Vere tunc tibi adtendit, quando ipsum quaeris, non quando per ipsum aliud quaeris: Augustinus, In Psalmos enarrationes 76, 2,23-25. 
verstanden. Menschlich, vollkommen menschlich, aber nicht „zu menschlich": denn er vergisst Gott um des Menschlichen willen nicht.

Am Kreuz war das letzte Wort ein Schrei. Das Letzte, das eschaton, nimmt den Anfang wieder auf, das Geheimnis des Ursprungs: das Verlassensein. Auch die Form des Ausrufs - der Schrei - ist bedeutsam. Er verweist auf das Anfangswort, das erste Wort, das nicht dazu gedient hatte, zu kommunizieren; es war ein Ausdruck der Verwunderung gewesen, des Staunens: Das Staunen über das Dasein, über das eigene Sein: Gott, anders als Gott. Ein Schrei: Mehr als eine im Diesseits veränderte Stimme. Der Donner, der das Schweigen des Heiligen bricht, der das Unteilbare teilt.

Das pagane Gebet feiert die Rückkehr zur Ununterschiedenheit des Heiligen. Das christliche Gebet durchleidet das Geheimnis der Geburt Gottes und seiner Dreieinigkeit noch vor der Geburt des Kosmos. Mit dem Sohn nämlich wurde die Dreieinigkeit geboren. Und der Schrei zur neunten Stunde enthält, trägt in sich, sowohl den Schmerz der Geburt, als auch die Freude über die Rettung. Auch nach der Kenose der Kenose, nach dem Verzicht des Sohnes auf sich selbst, bleibt das Verlassensein. Es bleibt der Sohn, das Menschsein des Sohnes. Das Aufheben der Tränen von Antigone und Ismene. Das Zeugnis, dass Weinen und Schmerz über den Tod keine Schande sind.

Das Letzte, das eschaton, nimmt den Anfang wieder auf; jedoch nicht als Wiederholung. Im Anfang war die Kenose, nicht die Kenose der Kenose. Das Letzte beinhaltet und bewahrt den Unterschied zwischen dem Größtmöglichen - quiddam maius quam cogitari potest - und dem Kleinstmöglichen - quiddam minus quam cogitari potest. ${ }^{14}$ Deshalb ein Schrei des Leidens, nicht nur der Freude. Die Freude über das Bewahren, über die Rettung des Endlichen - genatu dieselbe Fretude und keine andere - ist das Leiden am Endlichen: denn das, was bewahtt wurde, ist das Endliche, die Unvollkommenheit, und sogar das Böse, das aus dem Endlichen und der Unvollkommenheit kommt.

Diese untrennbare Einheit von Freude und Schmerz, von Schmerz und Freude, prägt das christliche Gebet, das menschliches Wort ist und bleibt, was das Diesseits überschreitet, aber innerhalb des Diesseits bleibt, also immer im Abstand von der Wahrheit. Unendlich fern. Niemals ein Wort der Wahrheit. Oder besser ausgedrïckt: nur insofern ein Wort der Wahrheit, als es den Abstand zur Wahrheit erkennbar macht. Die Wahrheit ist das Ziel, der Zweck, die Vollendung des Wortes. Der Genitiv bleibt Objekt, er wird nicht zum Subjekt. ${ }^{15}$

\footnotetext{
${ }^{14}$ Siehe oben Anm. 4.

${ }^{15}$ Das Lateinische unterscheidet zwischen Subjektsgenitiv (Genitiv der Herkunft), der wie im Deutschen angibt, von wem eine Handlung o. ähnl. ausgeht (Bsp. die Liebe der Eltern) und den Objektsgenitiv (Genitiv des Ziels), der das Objekt bezeichnet, auf das sich
} 
Fromm ist nur das Wort, das sich immer als fern vom Wahren versteht und trozdem in engster Nähe zu ihm steht; ruchlos ist das Wort, das glaubt, die Wahrheit zu sein.

$\mathrm{Zu}$ finden ist hier vielleicht die Antwort auf die Frage mit der wir das Kapitel über die Freiheit und die Knechtschaft geschlossen haben: ${ }^{16}$ wieso Mt 10,34-39 auf Mt 5,45 folgt? Wieso nach der Aufnahme von allen, der Guten wie der Schlechten, der Gerechten wie der Ungerechten, unter einem gemeinsamen Himmel das Schwert folgt, das die Tochter von der Mutter trennt, den Sohn vom Vater, die Schwiegertochter von der Schwiegermutter? Wieso nach der Liebe, die sich in der vollständigen Versöhnung äußert, noch der Hass folgt, der entzweit, und sei es nur der Hass des Hasses, die Entzweiung der Entzweiung?

Die Aufnahme, sei sie auch noch so weitreichend, bleibt immer mangelhaft. Denn mangelhaft ist das Endliche. Und auch wenn die ganzen Endlichkeiten in einer einzigen harmonischen und versöhnlichen Totalität zusammenkämen, blieben alle endlich und die Totalität selbst wäre, wenn auch perfekt, doch die Summe aller Unvollkommenheiten: das Unvollkommenste. Vollkommen ist nur das Unendliche - aber vom Unendlichen können wir nur eine negative Vorstellung haben. Denn vom Unendlichen als solchem gibt es keine Vorstellung, kein Bild, keine Ikone. Das Unendliche hat keine Form, die sich begreifen ließe.

Und doch wird die Vorstellung, die Form, die endliche Ikone des Unendlichen, auch wenn sie zurückgewiesen wird, vollkommen angenommen und gefeiert und gepriesen im christlichen Gebet, das für das Heilige das Göttliche nicht vergisst - wie es für das Göttliche das Heilige nicht vergisst. ${ }^{17}$

Aber die Kenose wäre keine Kenose, wenn der Sohn, in seinem vollständigen, vollkommenen Menschsein, nicht gleichzeitig ( $\alpha \mu \alpha$, simul) Sohn Gottes wäre, eben Gott selbst. Sein Gebet - das Gebet des Menschensohnes - kann nicht abgespalten werden von seinem Wort, von sich selbst als Wort Gottes. Und hier in der unendlichen Verschiedenheit zwischen dem quiddam maius quam cogitari potest und dem quiddam minus quam cogitari po-

eine Handlung richtet (Bsp. die Liebe zu den Eltern). Insofern bedeutet hier "Wort der Wahrheit ${ }^{\prime \prime}$, dass keine Wahrheit ausgesagt wird, sondern dass das Wort lediglich auf die Wahrheit gerichtet ist, sie aber selbst nicht beinhaltet.

${ }^{16}$ Siehe V. VItrello, Il Dio possibile. Esperienze di cristianesimo (Roma 2002) Kap. 2.2, 152158; und auch Ders., E pose la tenda in mezzo a noi... (Milano 2007) I, "La Trinità e il Sacro. La trascendenza del corpo", 17-48, insbesondere 40f.; Ders., Ripensare il Cristianesino. De Europa (Torino 2008) I/III, "Accoglienza e abbandono", 47f.

${ }^{17}$ Siehe oben S. 182-183: Das pagane Gebet gibt der Sehnsucht Ausdruck, zum Schatten, zum Heiligen, jenseits des Menschlichen und Göttlichen zurückzukehren. Das christliche Gebet dagegen schließt das Heilige wie das Menschliche und Göttliche mit ein. Siehe auch unten S. 187: Der Schatten des Heiligen umfasst Gott und den Menschen. 
test, ${ }^{18}$ zwischen dem Größtmöglichen des Allergrößten und dem Kleinstmöglichen des Allerkleinsten, lässt sich das geheimnisvolle Band erkennen, die unbegreifbare Identität. Christus ist mehr als die Identität der zwei Naturen, der zwei Substanzen, der zwei Personen: Er ist die Identität der äußersten Vollkommenheit und der äußersten Erniedrigung. Identität der Differenz. Und das heißt: Wahrheit, absolute Wahrheit - aber als Frage. Der göttliche Sohn, die Wahrheit des Vaters, zeigt sich dem Menschen durch Fragen, in dem er sich selbst befragt und die anderen über sich selbst: „Und für wen haltet ihr mich?" (Mt 16,15).

Es ist die Frage, die zuerst darum bittet, Gehör zu erhalten. Es ist keine menschliche Überheblichkeit, sich darauf einzulassen, dem Wort zuzuhören, denn Gott verlangt das Zuhören, indem er seine Wahrheit und damit sich Selbst in Form einer Frage zeigt. Es ist auch keine menschliche Überheblichkeit zu bekräftigen, dass das Zuhören von Gott verlangt wird, der sich in Form einer Frage zeigt - denn diese Frage nach dem Zuhören ist nicht tröstend, sondern beunruhigend. Beunruhigend genau da, wo sie tröstet, weil sie nämlich jede Gewissheit in Frage stellt und ebenso jeden Zweifel, weil sie eine Sicherheit ist, die sicherer ist als jede Sicherheit, und ein Zweifel, der zweifelhafter ist als jeder Zweifel. Wer diese Frage versteht, wenn er ihr zuhört, ist nicht mehr derselbe, der er vorher war. Die Frage nimmt ihn ein, entfremdet ihn vom Selbst. Diese Frage betunruhigt das ganze Wesen des Zuhörers.

In Christus zu beten bedeutet, einer solchen Unruhe zu entsprechen. Es bedetutet, sich betunruhigen $\mathrm{zu}$ lassen von einer solchen Unruhe.

Sich beunruhigen lassen oder beunruhigt werden?

Gewiss: die Frage Jesu, aber nicht weniger sein Zuhören, stehen nicht in unserer Macht. Wir können sie Mal um Mal gehört haben, diese Frage, ohne jemals wirklich zugehört zu haben. Wir können uns dem Zuhören zugewandt haben, mit den besten Absichten, unseren Absichten, und doch nicht gehört haben. Und daher: Wer betet im Gebet?

Der mögliche Gott ${ }^{19}$ kann keine Ruhe lassen, keine Sicherkeit geben, keine Identität. Auch nicht die des Ich, das sagt: "Du". Ist das "Du“ ausgesprochen, dieses Du, wird das betende Ich eine Frage an sich selbst. Welche Intimität mit dem "Ich" hat das "Du" erreicht? Der Schatten des Heiligen umfasst nicht nur Gott, sondern auch den Menschen: dem Deus absconditus ${ }^{20}$ entspricht das ego absconditus.

Die Frage Jesu bringt die Annäherung Gottes an den Menschen zur Sprache und gleichzeitig die unüberbrückbare Distanz zwischen Mensch und Gott. Es ist das Wort Gottes, das dem Menschen das Bewusstsein sei-

\footnotetext{
${ }^{18}$ Siehe oben Anm. 2.

${ }^{19}$ Siehe die Literaturangabe oben Anm. 16.

${ }^{20}$ Jes 45,15: "Fürwahr, du bist ein verborgener Gott, du Gott Israels, der Heiland." Im Gegensatz zu den heidnischen Götzenbildern ist der christliche Gott nicht sichtbar.
} 
ner eigenen Endlichkeit schenkt. Es ist Gott, der sich dem Menschen enthüllt, in der Not, in der Bedürftigkeit. Die Gegenwart Gottes, des möglichen Gottes, ist die Gegenwart nicht einer Abwesenheit, sondern die eines Mangels - und die eines Leidens. Einer unendlichen Sehnsucht. Aber es ist diese Sehnsucht, die uns "rettet". Die unsere "Endlichkeit" rettet: Die diese Endlichkeit erhält, bewahrt und sie befreit - sie befreit in ihrer immanenten "Negativität". Die sie nicht erlöst, sondern befreiend bewahrt. Und so rettet sie "uns": Sie rettet "uns" auch vor der tröstenden Gewissheit - menschlich, allzu menschlich: noch eine Form der hybris - vor der Eschatologie der Erlösung.

Was wollen wir damit sagen?

Dass Christus eine Schwelle ist; auch wenn man sie überschreitet, bleibt die Schwelle. Kein Weg im Gebet ist endgültig, weder im Aufstieg (vom Menschen zu Gott), noch im Abstieg (vom Gott zum Menschen). Der mögliche Gott bleibt möglich. Auch im Sein, im sich Hingeben - im Kommen zum Menschen in Form einer Frage, und, eben deshalb, im Bitten und im Gehör schenken. Im Hören auf seine Worte: Und für wen haltet ihr mich? 
D. Anhang 



\title{
Literaturverzeichnis
}

\section{Abkürzungen}

$\begin{array}{ll}\text { ANRW } & \text { Atyftieg tund Niedergang der Römischen Welt } \\ \text { BKV } & \text { Bibliothek der Kirchenväter } \\ \text { BSLK } & \text { Bekenntnisschriften der evangelisch-lutherischen Kirche } \\ \text { CCSL } & \text { Corpus Christianorum. Series Latina } \\ \text { CIL } & \text { Corpus Inscriptiontum Latinarum } \\ \text { CSEL } & \text { Corpus Scriptorum Ecclesiasticorum Latinorum } \\ \text { DK } & \text { Diels / Kranz (Hg.), Die Fragmente der Vorsokratiker } \\ \text { FC } & \text { Fontes Christiani } \\ \text { GNO } & \text { Gregorii Nysseni Opera } \\ \text { JAC } & \text { Jahrbuch für Antike und Christentum } \\ \text { ILA } & \text { Inscriptions latines de l'Algérie } \\ \text { LIMC } & \text { Lexicon Iconographicum Mythologiae Classicae } \\ \text { LTUR } & \text { Lexicon Topographicum Urbis Romae } \\ \text { OWD } & \text { Origenes Werke mit detutscher Übersetzung } \\ \text { RAC } & \text { Reallexikon für Antike und Christentum } \\ \text { SVF } & \text { Stoicorum Veterum Fragmenta }\end{array}$

\section{Ausgaben, Kommentare und Übersetzungen}

\author{
Maximos von Tyros, Dissertationes
}

KonLARIS 1995

TrapP 1994

Trapp 1997a

VAN DER HORST 1996
G. L. Kontaris ( $\mathrm{Hg}$ ), Maximus Tyrius. Philosophumena. Texte und Kommentare 17 (Berlin u.a. 1995)

M. Trapr (Hg.), Maximus Tyrius. Dissertationes (Stuttgart/ Leipzig 1994)

M. Trapp (Übers.), Maximus of Tyre. The Phitosophical Orations (Oxford u.a. 1997)

P. W. vAN DER HoRst (Übers.) , "Maximus of Tyre on Prayer. An Annotated Translation of EL $\delta \varepsilon \overline{\mathrm{L}} \varepsilon v \operatorname{x} \chi \varepsilon \sigma \theta \alpha \mathrm{L}$ (Dissertatio 5)", in: H. CanciK / H. Lichtennerger / P. Schäfrer (Hg.), Geschichte-TYadition - Reflexion. Festschrift Martin Hengel, Bd. 2 (Tübingen 1996) $323-338$ 


\section{Sekundärliteratur (und Ausgaben anderer Autoren)}

AlbXANDR IDIS 2004

BaLthes 2004

BARTMAN 1999

Beibrwaltes 1979

BendinglLi 1997

BiBBBR 1977

BOSCHUNG 2002

Le Boullubc 2003/2006

A. AlbXandridis, Die Frauen des römischen Kaiserhauses: eine Untersuchung ihrer bildichen Darstellung von Livia bis Iulia Domna (Mainz 2004)

M. Balthis u.a. (Hg.), Apuleitus. De Deo Socratis - Der Gott des Sokrates. SAPERE 7 (Tübingen 2004)

E. Bartman, Portraits of Livia: imaging the imperial woman in Augustan Rome (Cambridge 1999)

W. Bigrwaltbs, Proklos. Grundzüge seiner Metaphysik (Frankfurt a.M. ${ }^{2} 1979$ )

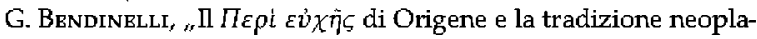
tonica", in: CocCHINI 1997, 33-52

M. BIrber, Ancient copies: contributions to the history of Greek and Roman art (New York 1977)

D. Boschung, Gens Augusta. Untersuchungen zu Aufstellung, Wirkung und Bedeutung der Statuengruppen des julisch-claudischen Kaiserhatses. Monumenta artis Romanae 32 (Mainz 2002)

A. Le Boullubc, "Les réflexions de Clément sur la prière et le traité d'Origène", in: L. Perrone $(\mathrm{Hg}$.), Origeniana Octava. Origen and the Alexandrian Tradition. BEThL 164 (Leuven 2003), Bd. 1, 397-407 (= Ders., Alexandrie antique et chrétienne. Clément et Origène. Collection des Études Augustiniennes. Série Antiquité 178 [Paris 2006] 137-149)

Bovini / Brandenburg / G. Bovini / H. Brandengurg / T. Ulebrt / F. W. Deichmann, ReUleert / Deichmann pertorium der christlich-antiken Sarkophage, Bd. 1, Rom und Ostia 1967 (Mainz 1967)

Boys-Stongs 2001 G. R. Boys-Stones, Post-Hellenistic Philosophy. A Study of its Development from the Stoics to Origen (Oxford 2001)

Campi / Grane / Rittrr E. Campi / L. Grane / A. M. Ritter (Hg.), Oratio. Das Gebet in pa1999

Chang 2010 tristischer und reformatorischer Sicht. FKDG 76 (Göttingen 1999) Y. J. Chanc, Origenes: Über das Gebet ( $\pi \varepsilon \rho t \varepsilon \dot{v} \chi \tilde{\eta} \zeta$ ). Studien zur Theologie und Frömmigkeit in der friihen Kirche (Diss. masch. Marburg 2010)

CLAy 1979

D. ClAY, ,Socrates' Prayer to Pan", in: G. W. Bowbrsock u.a. (Hg.), Arktouros. Festschrift B.M.W. Knox (Berlin 1979) 345-353

Cocchini 1997

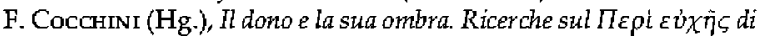
Origene. SEAug 57 (Rom 1997)

Comblla 2002

A. CoMblla, I rilievi votivi greci di periodo arcaico e classico: diffusione, ideologia, committenza. Bibliotheca archaeologica 11 (Bari 2002)

CONNELLY 2007 J. B. ConNBlLy, Portrait of a priestess. Women and ritual in ancient Greece (Princeton, N.J. 2007)

Crouzbl /

Quacouarelli 1980

Druse 1983

H. Crouzbl / A. Quacouarbll (Hg.), Otigeniana Secunda. QVetChr 15 (Rom 1980)

W. DeusB, Untersuchtungen zur mittelplatonischen und neuplatonischen Seelenlehre (Wiesbaden 1983)

DiHLe 1999

A. Dirle, "Das Gebet der Philosophen", in: CAMPI / GRane / RrTTER 1999, 23-41

Dillon 1996

J. Dillon, The Middle Platonists. A Study of Platonism 80 B.C. to A.D. 220 (London 1996; ${ }^{1} 1977$ ) 
DILLON 2016

Dillon / Timotin 2016 J. Dillon / A. Timotin (Hg), Platonic Theories of Prayer (Leiden / Boston 2016)

Dillon 2010

DoNINI 1982

DöRRIB 1977

Dresken-WeILAND 2010 J. DreskBn-W biLAND, Bild, Grab und Wort. Untersuchungen $z u$ Jenseitsvorstellungen von Christen des 3. und 4. Jahrhunderts (Regensburg 2010)

FELDMBIBR 2016

FILGBs 1997

Flashar 2006

FöRSTER 2007

FürsT 2014

A. Fürst, "Origenes", RAC 26 (2014) 460-567

Fyntikoglou / Voutiras V. Fyntikoglou / E. Voutiras, "Gebet, Gebärden und Handlun2005

Gente 1903

Grominy 2004

Gessel 1975

HALFWASSEN 2015

Helmig 2013

HвмBLRIJK 2007

HirsCH-LuIPOLD 2002

J. Dillon, "The Platonic Philosopher at Prayer", in: Dillon / Trmotin 2016, 7-25 (bereits erschienen in: T. Kobusch / M. ERLER (Hg.), Metaphysik und Religion. Zur Signatur des spätantiken Denkens. Beiträge zur Altertumskunde 160 [München / Leipzig 2002] S. Dillon, The female portrait statue in the Greek world (Cambridge 2010)

P. L. Donins, Le scuole, l'anima, l'impero: la filosofia antica da Antioco a Plotino (Torino 1982)

R. FbldmbigR, "Geheiligt werde dein Name", in: F. Wilk (Hg.), Das Vaterunser in seinen antiken Kontexten. FRLANT 266, Göttingen $2016,25-82$

A. FILGEs, Standbilder jugendlicher Göttinnen. Klassische und frithhellenistische Gewandstatuen mit Brustwulst und inre kaiserzeitliche Rezeption (Köln / Weimar / Wien 1997)

H. Flashar u.a., Aristoteles. Fragmente zu Philosophie, Rhetorik, Poetik, Dichtung. Aristoteles Werke in deutscher Übersetzung 20/1 (Berlin 2006)

N. Förster, Das gemeinschaftliche Gebet in der Sicht des Lukas. Biblical Tools and Studies 4 (Leuven 2007) gen des Gebets: Das römische Gebet", in: V. LambrinoudakIs / J. C. BALTY (Hg.), Thesaurus cultus et ritutum antiguorum (ThesCRA), $\mathrm{Bd}$ 3, Divination, prayer, veneration, hikesia, asylia, oath, malediction. profanation, magic rituals and Addendum to vol. II consecration (Los Angeles 2005) 151-179

D. GnNET, L'enseignement d'Origène sur la prière (Cahors 1903)

W. Grominy, "Die Zeit von 390 bis 360 v. Chr.", int P. C. Bol, Die Geschichte der antiken Bildhauerkunst, Bd. II, Klassische Plastik (Mainz 2004) 259-302

W. Gessen, Die Theologie des Gebetes nach, De Oratione' von Origenes (München u.a. 1975)

J. HALFWAssen, „Der, göttliche Platon' - Gründer einer philosophischen Religion?", in: T. Ggorges / J. Scheingr / I. TANASBanuDöвLER (Hg), Bedeutende Lehrerfiguren. Von Platon bis Hasan alBanna (Tübingen 2015) 17-36

C. Helmic, "Hilfe der Götter für das gute Leben - Die Rolle der Religiosität in der Ethik des antiken Platonismts", in: PIETsCH 2013a, 237-258

E. A. HвмвLRIJK, ,Local empresses: priestesses of the imperial cult in the cities of the Latin West", Phoenix 61 (2007) 318-349

R. Hirsch-Luirold, Plutarchs Denken in Bildern. Studien zur literarischen, philosophischen und religiösen Funktion des Bildhaften. STAC 14 (Tübingen 2002) 
Hirsch-Luirold 2009

Hirsch-LuIPOLD 2013

Hirsch-Luipold /

GörgEMANNs / von

Albrecht 2009

JAKOV / VoutiRas 2005

JONGKBES 1948

KLAuser 1959

Koniaris 1982/1983

LANDWBHR 1993

LANGE 1996

LANZI 2000

La Rocca / ParisI

Presicce / Lo Monaco

2011

LÖHR 1999

MoLtesen 2007

MoltesEn / Nielsen

2007

Mylonopoulos 2013

NIbLSEN 1997

OOBRLAN 2016
R. HIRsch-LuIPold, "Die religiös-philosophische Literatur der frühen Kaiserzeit und das Neue Testament", in: Hirsch-Luirold 2009, 117-146

R. Hirsch-Luipold, ",The Most Ennobling Gift of the Gods - Religious Traditions as the Basis for Philosophical Interpretation in Plutarch", in: P. Volpe Cacciatore (Hg.), Plutarch's Writings: Transmission, Translation, Reception, Commentary (Napoli 2013) 203-217

R. Hirsch-Luipold / H. Görgbmanns / M. von Albrbcht (Hg.), unter Mitarbeit v. T. Thum, Religiöse Philosophie und philosophische Religion der frühen Kaiserzeit. Literaturgeschichtliche Perspektiven. Ratio Religionis Studien I, STAC 51 (Tübingen 2009)

D. Jakov / E. VoutrRas, "Gebet, Gebärden und Handlungen des Gebetes: Das Gebet bei clen Griechen", in: V. LAMbrinoudakis / J. C. BALTY ( $\mathrm{Hg}$.), Thesaurus cultus et ritum antiquorum (ThesCRA), Bd. 3, Divination, prayer, veneration, hikesia, asylia, oath, malediction, profanation, magic rituals and Addendum to vol. II consecration (Los Angeles 2005) 105-141

J. H. JonGKEBs, "New Statues by Bryaxis", The Journal of Hellenic Studies 68 (1948) 29-39

T. KLAUSER, "Studien zur Entstehungsgeschichte der christlichen Kunst II.6. Heidnische Vorläufer des christlichen Oransbildes", JAC 2(1959) 115-145

G. L. Kontaris, „On Maximus of Tyre: Zetemata (I) (II)", Classical Antiquity 1 (1982) 87-121; 2 (1983) 212-250

C. LANDWBHR, Die römischen Skulpturen von Caesarea Mauretaniae: Idealplastik, weibliche Figuren benannt. Archäologische Forschungen 18 (Berlin 1993)

U. LANGB, Ikonographisches Register fuir das Repertorium der christlich-antiken Sarkophage: Rom und Ostia (Dettelbach 1996)

S. LanzI, Theos Anaitios. Storia della teodicea da Omero ad Agostino. Biblioteca di storia delle religioni 2 (Roma 2000)

E. La Rocca / C. Parisi Presicce / A. Lo Monaco (Hg.), Ritratti. Le tante facce del potere (Roma 2011)

W. A. LöHR, „Argumente gegen und für das Gebet. Konturen einer antiken Debatte (im Anschluß an Origenes und Porphyrios)", in: CAMPI / Grane / RrTTER 1999, 87-95

M. Moltesen, „Agrippina Minor in the Montemartini: the statue type", in: Dies. / NirLsEn 2007, 123-136

M. Moltesen / A.M. Nielsen (Hg.), Agrippina minor. Life and afterlife; liv og eftermale (Kopenhagen 2007)

J. MrLonopoulos, "Commemorating pious service: images in honour of male and female priestly officers in Asia Minor and the Eastern Aegean in Hellenistic and Roman times", in: M. HorsTRR / A. KLö́ckner ( $\left.\mathrm{Hg}_{\mathrm{g}}\right)$, Cities and priests. Cult personnel in Asia Minor and the Aegean islands from the Hellenistic to the Imperial period. RGVV 64 (Berlin 2013) 121-133

H. S. NIELSEN, "Interpreting epithets in Roman epitaphs", in: B. Rawson / P. W Baver (Hg.), The Roman family in Italy. Status, sentiment, space (Carberra 1997) 169-204

C. O'Brian, "Prayer in Maximus of Tyre", in: Dillon / Timotin 2016, 58-72 
PERRone 2001

Pgrrone 2011a

Perrone 2011b

Pigtsch 2013a

РigTsCh 2013b

Pizzolato / Rizzi 2001

REINSBBRG 2005

REINSBERg 2006

RoHDICH 1879

Rose 1997

Russell 1983

VON SEviRus 1972

SOURY 1942

VON STRITZKY 1989

VON STRITZKY 2014

STUDER-KARLEN 2012

SzARMACH 1985

TIMOTIN 2012

Timotin 2016

Trapp $1997 \mathrm{~b}$

TRAPP 2007
L. PrRrong, "Prayer in Origen's Contra Celsum. The Knowledge of God and the Truth of Christianity", Vigiliae Christianae 55 (2001) 1-19

L. Perrone, La preghiera secondo Origene. L'impossibilitì donata. Letteratura Cristiana Antica N.S. 24 (Brescia 2011)

L. PERrone, "Chasser les chiens au moment de la prière. L'image de l'orant entre les démons et les anges: d’Origène à Évagre le Pontique", in: Y.-M. Blanchard / B. Pouderon / M. Scopello (Hg.), Les forces du bien et du mal dans les premiers siècles de l'église. Théologie historique 118 (Paris 2011) 157-185

C. PIRTsCh $(\mathrm{Hg})$, Ethik des antiken Platonismus. Der platonische Weg zum Gliick in Systematik, Entstehung und historischem Kontext. Philosophie der Antike 32 (Stuttgart 2013)

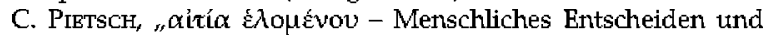
Handeln zwischen Freiheit und Determination im Platonismus der Kaiserzeit", in: PIETsCH 2013a, 191-218

L. F. Pizzolato / M. Rizzi (Hg.), Origene maestro di vita spirituale. SPMed 22 (Mailand 2001)

C. ReINsebrg, "Demeter, Artemisia und die Pietas Augustae zur spätklassischen Statue der ,Orans ${ }^{\prime \prime \prime}{ }^{\prime \prime}$, in: M. ŞAHIN / I. H. MeRT / H. MerT (Hg.), Ramazan Özgan'a armă̆an. Festschrift fiir Ramazan Özgan (Istanbul 2005) 297-316

C. ReInsberg, Vita-Romana-Sarkophage. ASR 1.3 (Berlin 2006)

R. Roнdich, De Maximo Tyrio Theologo (Breslau 1879)

C. B. Rose, Dynastic commemoration and imperial portraiture in the Jutio-Claudian period (Cambridge 1997)

D. A. Russell, Greek Declamation (Cambridge 1983)

E. von Severus, "Gebet I", RAC 8 (1972) 1134-1258

G. Soury, Aperçus de philosophie religietuse chez Maxime de Tyr, platonicien éclectigne. La prière-la divination-le problème du mal. Collection d'études anciennes (Paris 1942)

M.-B. von SтRпZKк, Studien zur Überlieferung und Interpretation des Vaterunsers in der frühchristlichen Literatur. MBTh 57 (Münster 1989)

M.-B. von Stritzky, Origentes. Über das Gebet. OWD 21 (Berlin u.a. 2014)

M. STUDER-KARLEN, Verstorbenendarstellungen auf frühchristlichen Sarkophagen. Bibliothèque de l'antiquité tardive 21 (Turnhout 2012)

M. Szarmach, Maximos von Tyros. Eine literarische Monographie (Torun 1985)

A. Trmotin, La démonologie platonicienne. Histoire de la notion de daimôn de Platon atx derniers néoplatoniciens. PhA 128 (Leiden / Boston 2012)

A. Trmotrn, "Le discours de Maxime de Tyr sur la prière (Dissertatio V) dans la tradition platoniciennes, int: F. FAuquIER / B. PÉrbz-JBAn (Hg.), Maxime de Tyr, entre rhétorigue et philosophie au IIe siècle de notre ère (Montpellier 2016) 163-181

M. B. TrapP, "Philosophical Sermons. The "Dialexeis" of Maximus of Tyre", ANRW II 34.3 (1997) 1945-1976

M. B. Trapp, Philosophy in the Roman Empire. Ethics, Politics and Society (Ashgate 2007) 
VERSNEL 1981

VOLLKOMMER 1997

VöLKER 1931

WALTHER 1914

WAYWELL 1978

WAYWBLL 1993

WHITTAKER 1974

WHITTAKER 1987

WOLTER 2008

WREDE 1981

WREDE 2001

ZIMMBRMANN 2007

Abb. I (S. 40)

Abb. 2 (S. 40)

Abb. 1 (S. 149)

Abb. 2 (S. 150)

Abb. 3 (S. 152)

Abb. 4 (S. 155)
H. S. VBRSNBL, "Religious mentality in ancient prayer", int H. S. VBRSNBL ( $\mathrm{Hg}$.), Faith, hope, and worship: aspects of religious mentality in the ancient world. SGRR 2 (Leiden 1981) 1-64

R. VollKommer, "Pietas", LIMC VIII Suppl. (1997) 998-1003

W. VöLkRR, Das Vollkommenheitsideal des Origenes. Eine Untersuchung zur Geschichte der Frömmigkeit und zu den Anfängen christlicher Mystik. BHTh 7 (Tübingen 1931)

G. WALTHER, Untersuchungen zur Geschichte der griechischen Vaterunser-Exegese. TU 40/3=3. Reihe 10/3 (Leipzig 1914)

G. B. WAYweLL, The free-standing sculptures of the Matusoletim at Halicarnassus in the British Museum: a catalogue (London 1978)

G. B. WAYWBLL, "The Ada, Zeus and Idriets relief from Tegea in the British Museum", in: O. Palagia/ W. Coulson (Hg.), Sctilptitrefrom Arcadia and Laconia: proceedings of an international conference held at the American School of Classical Studies at Atherts, April 10-14, 1992. Oxbow monograph 30 (Oxford 1993) 79-86

J. WhITTAKER, ,Parisinus Graecus 1962 and the Writings of Albinus", Phoenix 28 (1974) 320-357

J. WhitTaker, "Platonic Philosophy in the Early Centuries of the Empire", ANRW II 36.1 (1987) 81-123

M. Wolter, Das Lukasevangelium. Handbuch zum Neuen Testament 5 (Tübingen 2008)

H. WREDE, Consecratio in formam deorum. Vergöttlichte Privatpersonen in der römischen Kaiserzeit (Mainz 1981)

H. WREDE, Senatorische Sarkophage Roms. Der Beitrag des Senatorenstandes zur römischen Kunst der hohen und späten Kaiserzeit. Monumenta artis Romanae 29 (Mainz 2001)

N. Zimmbrmann, „Verstorbene im Bild. Zur Intention römischer Katakombenmalerei", JAC 50 (2007) 154-179

\section{Abbildungsnachweis}

\section{a. Einführung}

Bibliothèque nationale de France, Paris. gr. 1962, f. 36r, oberer Rand

Bibliothèque nationale de France, Paris. gr. 1962, f. 36r, unterer Rand

\section{b. Ikonographie des Betens}

Votivrelief mit Betenden vor Artemis. Brauroth, Archäologisches Museum inv. 1153. Photo: Wikimedia Commons License Ada und Idrieus vor Zeus Labraundos auf einem Relief aus Tegea. London, British Museum inv. 1914.7-14.1. Photo: @ The Trustees of the British Museum

Statue der Livia als Orans aus Otricoli. Vatikan, Vatikanische Museen, Museo Pio Clementino, Galleria die Busti 352. Photo: C. Rossa, neg. D-DAI-ROM-78.75.

Grabrelief einer Demeterpriesterin aus Smyrna. Berlin, Staatliche Museen Preußischer Kulturbesitz, Antikensammlung Sk 767. Photo: Ophelia2 Creative Commons License 
Abb. 5 (S. 164)

Abb. 6 (S. 166)

Abb. 7 (S. 172)

Abb. 8 (S. 174)
Jutia Domna als Orans vom Nymphätm in Perge. Antalya, Museum Inv. A3262. Photo: Gregor Borg

Sarkophag eines Ehepaars. Rignano Flaminio (RM). Photo: S. Steingräber, neg. D-DAI-ROM-79.1464

Sog. Velata-Cubiculum, Rom, Priscilla Katakombe. Photo: Stephen Zucker, Creative Commons License

Orans mit Kind aus dem sog. Cubiculum della Madonna, Rom, Coemeterium Maius. Photo: J. Wilpert, Die Malereien der Katakomben Roms, Tafelband (Freiburg i.Br. 1903) Taf. 207 



\section{Stellenregister (in Auswahl)}

\begin{tabular}{|c|c|c|}
\hline Aischylos & Ps & $18,9: 102$ \\
\hline Ag. & $58,4: 135$ & $18,9-14: 102$ \\
\hline 159f.: 180 & Weish & $18,10-13: 102$ \\
\hline $173-177: 180$ & 9,16: 121 & 18,11f.: 103 \\
\hline $177: 180$ & $11,25: 131$ & 18,13: 103 \\
\hline Alexander von & Jes & $18,14: 103$ \\
\hline Aphrodisias & $45,15: 187$ & $18,19: 105$ \\
\hline Fat. 20,190f.: 137 & Netres Testament & $22,39-46: 105$ \\
\hline Alkinoos & Mt & Joh \\
\hline Didasc. & $5,45: 185$ & $1,26: 128$ \\
\hline $10,7: 98$ & $6,5-15: 126$ & $6,51: 127$ \\
\hline $179,1-33: 89$ & $6,6: 126,128$ & $15,15: 146$ \\
\hline Anselm von Canterbury & $6,7: 95,126$ & $17,11: 179$ \\
\hline Prosl. P5, I 104,11-17: & $6,8: 95,145$ & Röm \\
\hline 178 & $6,10: 128$ & $8,26: 122 \mathrm{f}$. \\
\hline Apuleius & $6,11: 126$ & 9,11-13: 135 \\
\hline Apol. 1-16: 24 & $10,34-39: 185$ & 1 Kor \\
\hline Aristippos & $16,15: 186$ & $13,12: 8$ \\
\hline fr. 132 Giannantoni: & $26,36-39: 183$ & $15,49: 128$ \\
\hline 131 & $26,38: 183$ & 2 Kor \\
\hline Aristoteles & $26,41: 183$ & $12,4: 124$ \\
\hline fr. 49 Rose: 117 & $\mathrm{Lk}$ & Gal \\
\hline Met. 1032a12-32: 66 & 1,51-53: 106 & $1,15: 135$ \\
\hline Ps-Aristoteles & $2,29-32: 179$ & Eph \\
\hline Mund. 400b12: 35 & $6,36: 107$ & $1,4: 136$ \\
\hline Augustinus & $7,4: 102$ & Phil \\
\hline Civ. VI 10: 145 & $7,6 f .: 102$ & $2,6 f .: 179,183$ \\
\hline Conf. & $7,9: 102$ & 1 Thess \\
\hline$\times 29,40: 178$ & $7,36-50: 102$ & $4,13: 71$ \\
\hline$\times 31,45: 178$ & $11,1: 94,105,125$ & 2 Thess \\
\hline$\times 37,60: 178$ & $11,1-4: 126$ & $2,9: 129$ \\
\hline ep. & $11,2: 104,128$ & Boethius \\
\hline $130,1: 125$ & $11,3: 126$ & Cons. phitos. V \\
\hline $130,2-8: 125$ & $11,5-8: 95$ & $3,1-6,48: 139$ \\
\hline $130,9-30: 125$ & $11,5-13: 65,95$ & \\
\hline $130,21: 125$ & $11,8: 104,107$ & Chalcidius \\
\hline In Psalm. 76 2,23-25: & 11,9f.: 103 & In Tim. 183,6f. \\
\hline 183 & 11,11f:: 95,104 & Waszirk: 84 \\
\hline \multirow[t]{2}{*}{ Persev. 20,53: 178} & 11,13: 104f. & Cicero \\
\hline & 16,19-31: 107 & Inv. II 65f.: 159 \\
\hline Bibel & $18,1: 106,110$ & \\
\hline Altes Testament & $18,2: 106 \mathrm{f}$ & Diogenes Laertios \\
\hline Gen & 18,2-8: 102,106 & III $59,2: 7$ \\
\hline $1,26: 128$ & $18,4: 106$ & III 96: 133 \\
\hline $\mathrm{Ex}$ & $18,5: 106$ & Dionysios Areopagites \\
\hline $3,14: 126$ & $18,7 f .: 106$ & Div. nom 3,1: 144 \\
\hline
\end{tabular}




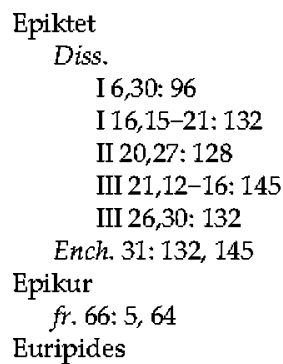

Tro. 1280f.: 131

Eusebios

Hist. eccl. VI 18,1: 129

Praep.ev. V 10,8: 124

\section{Gregor von Nyssa \\ Orat. dom. hom. 1: 146}

\section{Heraklit \\ Herodot \\ I 50-53: 18 \\ I 53,3:64 \\ VI 86: 122}

DK 22 B 5: 122

Homer

$n$.

I 35-42: 18, 64

I 39: 70

II $112 f .:$ 18, 64

IV 31-49: 18

VI $46: 18,68$

VI 196-199: 68

VII 175-184: 18

VII 179f.: 64

VII 182f.: 64

IX 497: 18, 26, 64

XVI 43f.: 18

XVIII 54: 18

Od. IV 341: 71

Hymnos auf Hermes

533-549: 181

Jamblich

Myst.

I 15: 124

I $47 \mathrm{f}: 141$

V 238-240: 141

Johannes Cassianus

Conl. IX 18,1: 144

Joseph und Aseneth

8,9: 112

$9,5: 112$ 10,3f:: 110

10,8: 111

10,10: 111

10,11-13: 111

10,14: 111

11,3: 111

$11,3-5: 111$

11,9: 111

11,10: 112

11,15: 112

11,16-18: 112

11,17: 112

11,19: 112

12,5: 112

$12,8: 112$

Juvenal

$10,12-27: 62$
$10,347-349: 133$
$10,349: 65$
$10,350: 65$
$10,354-362: 133$
$10,357: 133$
$10,357-360: 71$
$10,363: 71,133$

Klemens von Alexandria

Strom.

I 23,155:71

VI $29,3: 124$

VI 104,1: 143

VII 35,6: 143

VII 35-49: 143

VII 39,6: 143

VII $40,3: 143$

VII 41,If.: 130

VII $41,3: 138$

VII $41,5-7: 135$

VII $42,3: 143$

VII $42,4: 138$

VII 42,5: 138

VII $42,6: 138$

VII $49,3: 143$

VII $49,4: 143$

Lukian

Dem. 27:3

Icarom. 25: 5, 64

Sacr. 3: 64

Tim. 31-33: 63

Mark Aurel

V 7:8, 132

V 8: 132
IX 11:98

IX 40:98, 132

Maximos von Tyros

or.

$1: 13,17,19,25$,

$28 \mathrm{f}$.

1,1: 25

1,1f.: 25

$1,3: 13,20,71$

1,4-6: 25

1,5: 14

$1,7: 14,25$

1,8: 13f., 17, 68

1,9: 14

1,10: 21,25

2: $4,17,28 \mathrm{f} ., 31$

2, I: 29

2,2: 29

2,3: 30

$2,4: 30$

2,5: 30

$2,6-8: 30$

$2,9: 30$

2,10: 30

3: 22

3,3: 70

$3,6: 31$

$3,8: 32$

$4: 19,24,28,30,35$

$4,3: 24,31$

$4,4: 24,62$

4,5: 31

$4,8: 31,35$

$4,9: 24$

5: 6, 11f., 16-20, 22f., 28, 31f., $34-36,39,4 \mathrm{If}$. 97

5,I: $62,82 f$.

5,1f.: 26, 123

5,2: 18,100

$5,2 \mathrm{f}: \mathrm{i7}$

$5,3: 19,26,40,84$, 98-100, 105, 109, 123,135

$5,4: 26,40,43,66$, 86f., 110,133

5,4-6: 27,98, 133

$5,5: 18,99$

$5,6: 90$

$5,7: 17 f ., 27,43,96$, $99,111,113,134$ 
5,8: 4, 21f., 24, 27,

$30,33,41,66,90$, $96 f ., 99,141$

$6,1: 91$

$6,5-7: 32$

$6-10: 37$

$7: 32 f$.

7,1: 28

$7,5: 28$

8,1-6: 22

$8,7: 33,83$

8,8: 33

$8-9 ; 28,32$

9. 21,40

10: 15f, 20f, 33,

40

$10,1: 63$

10,2: 21

$10,9: 20,33$

$11: 20 f, 23,28,33$,

$35 f$.

11,1:72

11,2:34

$11,3: 34$

$11,5: 34$

$11,6: 34$

11,7-12: 34

11,8:76

11,9: 34

$11,11: 8,20,34$

11,11f.: 35

$11,12: 34 \mathrm{f}$.

12: $16,20,33,37$

12,8: 22

13: 16, 23, 28 ,

33-35

$13,7: 21,66,133$

15,8: 21

16: 17,20

$16,5: 21$

18,5: 63

18-21: 16, 22, 28 , 35

$21: 23,34$

21,4f.: 21

$21,7: 22$

21,7f.: 35

22: 16, 19, 25

$22,7: 8,28,36,64$

25: 25

25,2: 21

25,4: 24

$25,7: 17$
26: $19,24,35$

26, 1: 20, 37

26,2: 24

26,3: 24

26,5:21

26,5f.: 19

27: $16,35,40$

27,5: 15, 21, 24

$29,5: 21,72$

29,6: 20

$29,7: 21,24$

29-33: 35

32, I: 63

33,3:24

34: 21

$34,9: 21$

35: 20

$35,1: 32$

35,2: 32

35,8: 32

36: 37

37: 25

37,4: 62

$37,5: 21$

$38: 21,28$

$38,1: 32$

38,5-8: 32

$39,5: 36$

39-41: 32

40,5: 69

$41: 20,23,28,34 f$.

82

41,2: 24

41,4: 67,82

Menander

$f r .363$ K.-A.: 18,69

Nag-Hammadi

Ev. Phil. 7: 129

Ev. Thom. 14: 129

Nemesios

Nat. hom 35,289:131

Numenios

fr. 11 des Places: 120

fr. 52,95 des Places: 83

Origenes

Cels.

V 11: 144

VI 17: 145

VII 44: 124, 143

VIII 66f.: 144

In Gen. hom. VII 4: 146
In Toh. comm.

I 15,89: 121

$\times \times 13,107: 126$

In Lev. hom. XVI 6:

140

In Rom. comth.

VII 6,5: 138

X 15,2: 121

Orat.

1: $121,123,146$

If.: 120

1-17: 118

2,I: 12If., 129

2,2: 122,124

2,3: 122-124

2,4: 121, $124 \mathrm{f}$.

2,5: 125

2,6:121

5,1: 130,135

5,1f.: 134

5,2: 130f, 134f.

5,3:135

5,4: 135

5,4f: 135

5,5: 136

$5,6: 129$

6,1: 136

6,2: $136 \mathrm{f}$.

6,3: 139

6,4f.: 138

8-10: 128

9,2: $143 \mathrm{f}$.

10,2: 128,144

11,1: 124

11,3: 124

11,4: 124

11,5: 124

$13,1: 125$

14, I: 144

16,2: 144

17,1: 144

17,If:: 144

18,1: 122

18-30: 118

$20,2: 126,128$

21,2: 126, 145

$22,4: 126$

22,5: 128

23: 126

24,2: 126

24,3: 126

$25,1: 126,128$

25,3:126 
$26,5: 126$

$26,6: 126$

$27,7: 126$

27,7-12: 126

$27,8: 127$

27,9:127

27, $13: 126$

29,13: 126

29,15: 126

29,19: 126

$30,1: 126$

31,1: 122

31,5: 124

34: 121f.

Philoc. 23,8: 138f.

Princ.

II $9,5: 135$

III 1,2: 136

III 1,6-24: 135

Ovid

Met. XI 90-93: 62

\section{Philostrat \\ V. Ap. I11(=IV 40): 65} Platon

Euthyphr.

14e: 86

Eutyphr.

14c: 64

$14 \mathrm{~d}-\mathrm{e}: 122$

14e: 64

Leg.

$716 \mathrm{c}-\mathrm{d}: 140$

IV 709a-c: 66

IV 709b-c: 133

VII 801a-b: 6, 81

X 885b: 85

X900c-d: 67

X902e-903a: 87

$X$ 903b: 87

$\times 903 b-d: 87$

$X 903 \mathrm{c}-\mathrm{d}: 87$

X 905d: 86

$X 907 \mathrm{~b}: 86$

Phaedr. 279b-c: 6

Prot.351b-357e: 99

Rep.

I 327a: 70

I354a: 70

II 379a-383a: 82

II 379a-c: 82

II $379 \mathrm{~d}: 63 \mathrm{f}$.

II $380 \mathrm{c}: 65$
II 381c: 64

III $388 \mathrm{c}-\mathrm{d}: 68$

VIII 565a-IX 580c:

67

X 617b-e: 67

X 620d-e: 68

Symp.

202d-203a: 32

203a: 90

230b-c: 62

Tim.

27c: 6

$28 \mathrm{c}: 30,131$

Ps.-Platon

Alk. 2

138b: 81,122

138b-143a: 67

141a: 63

141a-143b: 123

142e: 123

143a: $8,67,81$

148a-b: 62

$148 \mathrm{~b}: 67,123$

$149 \mathrm{c}: 123$

149d-150a: 5

149e: 123

150a-b: 85

150c: 123

150d: 7

Epin. 984b-d: 32

Plotin

III 2,8,37-40: 134

III 2,9,10-12: 134

IV 4,40-44: 142

IV 8,1,1: 141

V 1,6,7,8-10: 141

V 1,6,9-12: 141

$\mathrm{V} 1,6,12: 141$

V 8,9,1-13: 141

V 8,9,13-18: 141

VI $9,11,51: 139$

Plutarch

Adv. Col. 3I,

1125D-E: 3

De E 17, 392A: 7, 114

De genio 22, 592A-B:

67

De Is.

1, 351C-D: 32,113

$78,382 \mathrm{E}-383 \mathrm{~A}$ :

113

De sera 3, 549C-D: 67

Praec. coní. 138B: 113
Quaest. conv.

I 1, 613B: 69

IX 5,740C: 133

Quaest. Rom. 10,

266C-D: 114

V. Num. 14: 114

Ps.-Plutarch

Fat. 570B-C: 89

Plac. Phil.

885C: 133

885C-D: 88

Porphyrios

Abstin.

I 30: 143

II 34: 143

In Tim. Plat. II: 133f., $141 \mathrm{f}$.

Marcell. 31: 143

Regress. an. fr. 2: 142

Seneca

Bentef.

I 6,3: 145

V 25,4: 132

ep.

10,4: 132

31,5: 132

$41,1: 3,69,109$,

132

41,2: 96

90,28: 145

95,47f: 145

95,49f:: 82

107,11: 67

Nat. quaest.

II $35,1: 132$

II $37,1-3: 132$

II 45: 66

Sextus Empiricus

Adv. math.

VII 401: 145

IX 61: 145

Silesius, Angelus

Cherubinischer

Wandersmann I 91:

177

Sophokles

Oed. C.

57: 181

106: 181

252-254: 182

287: 181

523: 181 
997f.: 182

1224-1227: 182

1267f.: 182

1433: 182

1434: 182

1549: 182

1553-1555: 181 1627f.: 182

1655: 182

1664f.: 182

1751-1753: 182

Stobaios

I 5,15: 68

I7,10: 133
Tabula Cebetis

7,1-3:69

Tertullian

Orat. 1,6: 125

Thukydides

IV 27-41: 70 



\section{Namens- und Sachregister}

Acciaituoli, Zanobi: 68

Achilles: 18, 64

Ada: 151, 153f., 156, 160, 162, 167

Adiaphora: 65

Adrestos: 18

Aeneas: 158

Aesop: 63

Aetios: 88

Agamemnon: 18, 64

Agrippina: 162

Agypter: 17,30

Aischines: 14f.

Aktaion: 16

Albinos: 9,75

Alexander der Große: 15, 18

Alexander von Aphrodisias: 137f.

Alexandria: 129

Alkibiades: 7, 14, 32, 62, 123

Alkinoos (König): 16

Alkinoos (Philosoph): 9, 19, 75, 77, 79, 98

Allegorie: 35

Ambrosios: 129

Ammonios: 7, 114

Anamnesis: siehe Wiedererinnerung

Anaxagoras: 15, 88

Anaximenes: 15

Anbetung: 147

- Anbetung Christi: 171

- kontemplative Anbetung: 168f., 175

Anselm von Canterbury: 178

Anthropologie: 31, 103, 110, 117

Antigone: 181f., 184

Antiochos von Askalon: 79

Antisthenes: 14f.

Apatheia: 71

Apelles: 151

Apollon: 8, 18, 27, 30, 37, 97f., 100, 113, 163, 181

Apologetik: 130

Apostel: 174

Apostoles, Michael: 42

Apuleius: 19, 24, 75

Aristeas von Prokonnesos: 16

Aristippos: 14f., 131

Aristogeiton: 16

Aristophanes: 63,70
Aristoteles: 6, 10, 15, 24, 79f., 117

A ristotelismus: 79

Armut/Penia: 62f.

Artemidor: 9

Artemisia: 153f., 156, 162f.

Arzt: siehe atth Gott (als Arzt), 26, 87, 109

- Arztmetaphorik: 131

Aseneth: 70, 110-113

Asklepios: 3

Ataraxia: 71

Atheisten: 34,130

Athen: 96, 16, 22, 32, 68

Athena: 27, 30, 97, 158, 181

Athener: 8, 32, 67, 70

Atrapalda: 163

Atropos: $67 \mathrm{f}$.

Attikos: 79,84

Aufklärung: 39

Augustinus: 125, 145

Augustus: 157, 159f.

Augustus-Mausoleum: 162

Ausbildung: siehe auch Bildung

- grammatisch-rhetorische Ausbildung: 15

- religiöse Ausbildung: 71

Auslegung

- spirituelle Auslegung: 127

- wörtliche Auslegung: 127

Avellino: 163

Bari: 119

Barmherzigkeit: 100, 107

Basileios von Caesarea: 144

Begierde: 21, 133

Bendideia: 70

Bendis: 70

Benson, George: 41

Beredsamkeit: 17

Berlin: 150, 152, 166

Bescheidenheit: 65

Bessarion: 41f.

Beten: siehe Gebet

Bewegungslehre : 136f.

Bibel: $119,124,128,135,146$

Bildkunst: 171 
- funeräre Bildkunst: 175

- römische Bildkunst: 148

Bildung: siehe atch Ausbildung, 18, 75, 78,171

- Bildungsideal: 175

- griechische Bildung: 14, 25

- philosophische Bildung: 71

- philosophisch-ethische Bildung: 24

- religiöse Bildung: 71

Bittgebet siehe Gebet

Boethits: 139

Boidas: 151f.

Brot: 126f.

- Brotbitte: 95, 104f., 127

- substantielles Brot: 126

Bryaxis: 151

Bulla Regia: 163

Cassianus: 143

Cassius Maximus: 9

Chalcidius: 83

Cherchell: 161

Chiasmus: 66

Chieti: 119

Christen: 71, 93, 108, 134, 145, 170, 172

Christentum: 121, 170, 175

- frühes Christentum: 101

Christus: siehe atch Jests, $71,121,129$, 173f., 179, 183, 186f.

Chryse: 8,64

Chryseis: 64

Chryses: $8,16,18,27,64,98,100,123$

Chrysipp: 15, 24, 68

Cicero: 88

Claudius: 162

Commodus: $8 \mathrm{f}$.

Concordia/concordia: 165, 167, 171

Cordoba: 167

Cornutus: 31

Cosa: 163

Cyprian: 125,146

Cyrene: 163

Daimon/Daimones: $32,40,62,121,142$

- als Zwischenwesen: 33, 62

Daimonion: 22

- Daimonion des Sokrates: 28, 33, 77

Daimonologie: 21, 31, 76

- mittelplatonische Daimonologie: 33

Daniel: 168

Dankgebet: siehe Gebet

Davies, John: 39,43

Deklamation: 12
Delphi: 18, 33, 37, 108, 113

Demeter: 63, 150, 154

Demiurg: 77

Demokrit: 15, 34

Demonax: 3

Demosthenes: 14

Determinismus: 89, 129f., 132, 135, 137f.

Diagoras: 34

Diatribe: 78

Dichter: $8,14,17,19,28,31,34,63,67,81$

Dichtung: 17, 19f, 24, 30, 63

- homerische Dichtung: 37, 82, 131

Diogenes Laertios: 7

Diogenes von Apollonia: 15

Diogenes von Sinope: 14f., 21, 70

Dion Chrysostomos: 19, 24, 32, 34, 37

Dionysios: 18

Dionysios Areopagites: 144

Dionysios von Syrakus: 68

Divination: $28,33,36$

Dualismus: 83

Einsamkeit: 182f.

Eklektizismus: 23

Ellipse: 68

Empedokles: 15

Engel: 124

- Schutzengel: 124

England: 41

enkyklia mathemata: 25

Entäußerung/Kenose: 179, 183f., 186

Ephesos: 9

Epik: 85

Epiktet: 96, 115, 128, 132, 145

Epikur: 5, 15, 24, 34, 64

- als Atheist: 24

- als Hedonist: 24

Epikureer: 78, 130, 135, 145

Epikureismus: 10

Epimenides: 16

Epistemologie: 33, 78

Erkenntnis: siehe auch Gott, 7, 30, 36, 39,

$91,113,126,139,142$

- Erkenntnis der Wahrheit: 24

- Erkenntnistheorie: 11

Eros: $22,28,62,90$

Esau: 135

Eschatologie: 187

Eschaton: 184

Eteokles: 181

Ethik: 11, 31, 70, 77f

- sokratische Ethik: 81

Etymologien: 63, 68 
Ettböa: 68

Eucharistie: 129

Eudaimonia: siehe Glückseligkeit

Eudoros: 77,79

Euphranor: 151

Euripides: 131

Europa: 177

Euseb von Cäsarea: 8f., 62

Evagrios Pontikos: 143

Evargelitum: 102-104, 107, 121

- Johannesevangelium: 7

- Lukasevangelium: 65, 100, 105, 107f., 125,179

- Matthätsevangelitum: 105

Ewigkeit: 32, 139, 183

Exegese: 127

Fabel: 63

Faustina: 161

Favorinus: 117

Florenz: 39

Frankreich: 41

Freiheit siehe atch Gebet (als Akt der Freiheit), Metaphysik, 28, 34, 38, 89, $117,126,137-140,144,146,185$

- Freiheit der Liebe: 146

- Freiheit Gottes: 140

- Freiheitslehre: 135t., 138

Frömmigkeit: siehe auch pietas, 7, 27,86, 114, 122f., 141, 145, 157, 173, 175

- stoische Frömmigkeit: 132

Fürbitte: 97, 171, 179

Gaia: 182

Gaits Caesar: 157

Galba: 158

Gebet: $3-8,17,19,22,26-28,31 f, 36-38$, $41,62,64-66,69-71,79-81,85 f ., 88-90$, 93-95, 97f., 100f., 103-105, 107-114, 116-125, 128-136, 138-140, 142-148, $158,165,167-169,171-173,175-178$, 180-184, 186f.

- als Akt der Freiheit: 118, 146

- als geistiges Opfer: 143

- als Gespräch mit Gott: 27, 70, 90f, 96, $105,115,140 f ., 143-147,149,175$

- Bittgebet: 3-5, 8, 18, 26t., 32, 64, 70t, 90, 94-101, 103-107, 109, 113, 115, 122f., 130-133, 140-142, 144, 147, I68f,. $175,178 \mathrm{f}, 187$

- christlidies Gebet: 97, 107, 118, 183-18.5

-Dankgebet: 3, 97, 102, 132, 147, 175
- falsches Gebet: 63

- Gebet Jesu: 125

- Gebetserfülltung: 5, 26, 40, 64, 95,98f., 102-104, 106

- Gebetsgegner: 130, 136

- Gebetskritik: 4, 130, 134

- Gebetslehre: 141

- Gebetsliteratur: 120

- Gebetsphilosophie: 140

- Gebetspraxis: 4, 6, 27, 95-97, 115, 122f., $132,134,145,147,151$

- Gebetssprache: 177, 180

- Gebetstheologie: 70

- Gebetstheorie: 6, 65, 95, 101, 107, 115, $119,130,145$

- Gebetsverständnis: 4, 7, 64, 94, 100,112

- Klagegebet: 3

- kontemplatives Gebet: 171

- magisches Gebet: 142

- Möglichkeit des Gebets: 118, 121, 124, $128,131-133$

- Mustergebet: 8, 67, 71, 94f, 105

- mystisches Gebet: 142

- Nützlichkeit des Gebets: 80, 132, 134

- Nutzlosigkeit des Gebets: $82,84-86,88$

- paganes Gebet: 105, 180-182, $184 f$.

- philosophisches Gebet: 6-8, 20f., 27, 33, 71, 97, 141

- Preisgebet: $3,132,147$

- problematisches Gebet: 64

- richtiges Gebet 124

- Sinn des Gebets: 117f, 120, 135, 139, 146

- sirnvolles Gebet: 20

- sinvolles Gebet: 118, 138f.

- theurgisches Gebet: 141

- törichtes Gebet: 123

- unbedachtes Gebet: 62f.

- unvernünftiges Gebet: 42, 63

- verfehltes Gebet: 26, 97

- vernünttiges Gebet: 96

- wahres Gebet: 91

Gebote: 138

Geist. 20, 25, 121, 123f., 127f., 135, 144, 183

- Geist Gottes: 121

- Heiliger Geist: 104, 121

- menschlicher Geist: 29,32

Gelassenheit: 65

Genealogie: 91

Geometrie: 25

Gerace marina: 161 
Gerechtigkeit: siehe auch Gott, 7, 16, 33, $85 f ., 103,105,123$

Geschichte: 17, 25, 32, 38, 138f., 177

- griechische Geschichte: 68

- römische Geschichte: 62

Getsemane: 105, 183

Giraldi, Giglio Gregorio: 42

Glatube: 102, 110, 142

- christlicher Glaube: 119

Glaukon: 70

Glück: $63,65 f ., 69,90,98,115,132,141$

Glückseligkeit/Eudaimonia: 63, 90, 141

Grade: 18,100

- Gnadenlehre: 178

Gnosis: 129

Gnostiker: 129, 138, 143

Gott: 3-5, 7f., 17, 20, 22f, 26, 28-36, 38, $40,62-67,69,71,76,81-83,85-87,91$, 94-96, 98-100, 102, 104, 106-117, 120f., 123f., 126-130, 133-136, 138-141, 143f., 147, 168f., 173, 177-179, 181-184, 186f.

- Allmacht Gottes: 4, 6

- Allwissenheit Gottes: 97

- als Arzt: 67, 99, 109

- als Geist: 117

- als Urheber des Guten: 65

- als Urheber des Rechts: 33

- als Ursache des Guten: 80-82

- als Vernunft: 76

- als Weltvernutift: 33

- Angleichung an Gott: 32, 91, 108, 140, $142 \mathrm{f}$.

- antropomorphes Gottesbild: 34

-Betrachtung Gottes: 143

- erster Gott: 77

- Existenz Gottes: 38, 145

- Geist Gottes: 144

- Gerechtigkeit Gottes: 4, 6, 33, 38, 97-99, 107, 115

- Gottesbegriff: 3, 6f., 26, 29, 33, 36, 76, 101, 115f.

- Gottesbeweis: 178

- Gottesbild: 4, 107f., 112, 115

- Gottesbilder: 31, 34, 111

- Gotteserkenntnis: 7, 29-31, 113, 121, 124,126

- Gottesgedanke: 4, 23, 27

- Gottesgnade: 121, 178

- Gotteshandeln: 67f., 85f., 110

- Gotteslehre: 6, 65, 68, 93, 96

- Gottesmacht: 38, 114

- Gottesverehrung: 30, 140

-Gottesvorstellung: 7, 31, 97, 115
- Gotteswesen: 21, 31, 65, 109, 115

- Gotteswille: 35, 41, 85, 124, 126, 129, 131,139

- Gotteswort 127f., 144, 179, $186 \mathrm{f}$.

- Gott Israels: 70, 107, 110, 187

- Güte Gottes: 4, 6, 32, 82, 132

- Heiligkeit Gottes: 119

- höchster Gott: 68, 113

- Körperlosigkeit Gottes: 126

- Transzendenz Gottes: 121, 124, 144

- Unbeeinflussbarkeit Gottes: 85, 97

- Unfehlbarkeit Gottes: 109

- Unveränderlichkeit Gottes: 85, 97, 115, 126, 136

- Unwanclelbarkeit Gottes: 6, 98

- Vollkommenheit Gottes: 32

- Weisheit Gottes: 32, 121, 144

- Zorn Gottes: 112

- zweiter Gott: 77

Götter: 7f., 17f., 28-31, 35, 64f., 67, 69, $80-82,85 \mathrm{f}, 90,98,111,113,120,122 \mathrm{f}$, $131-134,137,140 f ., 145,148,159,167 \mathrm{f}$, 180-182

- Götterbilder: 17, 29, 31, 34, 122, 154

- Götter der Philosophie: 17

- Götterverehrung: 29

Gottlosigkeit: 85, 134, 179

Grammatiklehrer: 10

Gregor von Nyssa: 125, 146

Griechen: 9f., 17, 30, 64, 93, 108, 148

Griechenland: 14, 17f., 123, 158f., 182

Griechisch: 9, 11, 62, 67, 169

Hadrian: 9

Halikarnass: 150,154

Hancleln: siehe auch Gott, 42, 66, 69f., 132f., 137, 139

- tugendhaftes Hatrdeln: 12

Hanna: 125

Harmodios: 16

Harmonie: 21, 96

Hedonismus: 78

Heimarmene: siehe Schicksal

Hekatomniden: 157

Hekatomnidenfrauen: 153f., 162

Hektor: 18

Hellenismus: 10, 150

Hera: 68

Heraklit: 15, 122

Herculane um: 161

Herodot: 18, 64, 122

Herophilos: 127

Hesiod: 24, 63, 82 
Hipponikos: 32, 69

Hoffnung: 71, 112, 142

Homer: siehe auch Dichtung, 15, 18f, 22, $24,30,35,37,63 f ., 68,79,98-100$

- als Philosoph: 19f.

- Homerkritik: 31

homoiosis theo: siehe Gott (Angleichung an)

hybris: 179, 182, 187

Ideenlehre: 23

Idrieus: 151, 153

Ikaromenipp: 5

Ikonographie: 36, 38, 69, 149, 151, 153f., $157,160,168,174$

- Beterinnenikanagraphie: 150

- christliche Ikonographie: 176

- Gebetsikonographie: 148, 161

- Opferikonographie: 160

- Oransikonographie: 154f., 160, $175 f$.

- Pietasikonographie: 168

Inder: 30

Ismene: 181f., 184

Israel: 102

Italien: 39

Jakob: 135

Jamblich: 117, 141

Jenseits: $169,171,181,184$

Jerusalem: 179

Jesus: siehe auch Christus, 32, 94f., $102-105,109,121,125,177,179,183$, 186

Johannes Chrysostomos: 144

Johannes der Täufer: 94

Johannes Klimakos: 144

Johannes Skytariotes: 41

Joseph: 110f.

Joseph und Aseneth: 70, 95, 100, 110, 116

Juden: 93, 108

Judentum: 95

Julia Domna: 163

Jupiter: siehe Zeus

Juvenal: 4, 62, 65, 71, 117, 132

Kalbenos Tauros: 19,75

Kallias: 14,70

Kant, Immanuel: 4

Kapernaum: 102, 110

Kapitol: 166

Karien: 149,151

Karneades: 15, 131

Katakomben
- Prätextatkatakombe: 174

- Priscillakatakombe: 173

Kelsos: 122

Kelten: 30

Kenose: siehe Entäußerung

Kirche

- christliche Kirche: 94

Klagegebet: siehe Gebet

Klaros: 33

Kleanthes: $84,108,132$

Kleinasien: 149, 157, 163

Kleitomachos: 15, 24

Klemens von Alexandria: 71, 80, 124, $130,135,138,143 f ., 146$

Kleon: 70

Klotho: 67f.

Kolonos: 182

Kontemplation: 20, 115, 147

- philosophische Kontemplation: 17

Kopenhagen: 162

Kore: 150

Korinth: 16

Kosmologie: 78

Kosmos: siehe auch Welt, 33, 184

Kreon: 181

Kritias: 14, 32

Kroisos: 16, 18, 27, 64, 97, 123

Kult: 154, 156f., 159

- Demeterkult: $149 \mathrm{f}$.

Kultur: 18, 182

- antike Kultur: 146

- christliche Kultur: 145

- europäische Kultur: 43

- griechische Kultur: 39, 147, 182

- philosophische: 36

- religiöse Kultur: 36

- römische Kultur: 147

Kunst

- christliche Kunst: 148, 168

- Grabkunst. 165

- griechische Kunst: 148

- römische Kunst: 160

Labraunda: 151, 154

Lachesis: 67f.

Laodameia: 68

Latein: 9

Lateinisch: 169, 185

Lazarus: 107

Leben: 6, 8f., 13f., 16f., 20f., 23, 25, 27 , 29 ., 36, 38-40, 63, 66, 71, 96-98, 103 , 108, 111-115, 131-133, 146, 178f., 181f.

- ethisches Leben: 69, 101 
- glückliches Leben: 12f., 20, 36, 69, 140

- gottgleiches Leben: 32

- harmontisches Leben: 37

- heiliges Leben: 90

- moralisches Leben: 78

- philosophisches Leben: 21, 71

- religiöses Leben: 145

- tugendhaftes Leben: 14, 20 f., 92

- tunendliches Leben: 91, 183

- veranwortliches Leben: 25

Lebewesen: 136

Leidenschaften: $25,35,64$

Leukipp: 15, 34

Libyer: 30

Liebe: 35f., 38, 65, 142, 158, 179, 185

- sokratische Liebe: 28

Literatur: 10, 15f., 69, 94f.

- altchristliche Literatur: 125

- christliche Literatur: 118

- doxographische Literatur: 66

- griechische Literatur: 64, 123

- häresiologische Literatur: 129

- klassische Literatur: 67

- pagane Literatur: 105

- religiös-philosophische Literatur: 68

- stoische Literatur: 108

Livia: 157, 159f., 162

Lobgesang: 177, 179

Locri: 161

Logik: 11

Logos: 7, 85, 108, 113, 128

London: 151

Lukas: 94f., 101f., 104f., 107, 109f., 112, 115

Lukian: $3-5,26,64$

Lust: 35

Luther: 100, 104

Lykien: 156

Madonna: 173

Mantua: 166

Mark Aurrel: 8, 10, 98, 132

Materialismus: 78

Materie: 83

Matthäus: 95, 105

Mausoleum von Halikarnass: 153f., 162f.

Mausolos: 151, 153

Maximos Confessor: 144

Maximos von Tyros: $4,6-8,10-18$, $20-22,24,26,28-31,33,35-38,41 f$, 62-64, 66-68, 70f., 75-78, 80-91, 93-95, 97-100, 102-109, 111, 113-115, 117. $123,132-135,138,141,147,175$
- als Eklektiker: 22

- als Halbphilosoph: 19

- als Lehrer: 9

- als Philosoph: 9, 75-77

- als philosophischer Lehrer: 20, $36 f$.

- als Platoniker: 9, 22f., 77-79

- als Redner: 9, 76

- als Sophist: 19

- als Stoiker: 78

Mead, Richard: 39

Meletos: 70

Menander: 18

Menelaos: 18

Metapher: 68,71

Metaphorik: 67, 71, 131

Metaphysik: 78

- Freiheitsmetaphysik: 118, 139

Midas: 16, 26, 42, 62f., 97, 123

Minia Procula: 163

Minos: 158

Mittelplatoniker: 84,89

Mittelplatonismus: 79, 131

Moiren: 67f.

Mose: 143

Musik: 25, 62

Mystik: 179

Mythologie: 25

Mythos: 17, 31, 36, 42, 63

Natur: 71,138

Nemea: 32

Nemesios: 131

Neues Testament: $34,67,94 f, 102$

Neuplatoniker: 124

Neuplatonismus: 38, 80, 141

Nikephoros Gregoras: 39

Nikolaus V.: 41

Nordafrika: 163

Notwendigkeit: $34,40,88$, $133 \mathrm{f}$.

Numa: 114

Numenios: $75,77,79,83,91,120$

Ödipus: 63, 177, 181f.

Odysseus: 16,19

Offenbarung: 120

- christliche Offenbarung: 41

Olympia: 5, 32, 163

Opfer: $3-5,38,64,98,122,131,148,158$, $166,168,176$

Orakel: 16, 33, 180

Origenes: $7,80,101,118-131,134-139$, $143 f ., 146$

-Origenes' Theologie: 120f. 
Orpheus: 24

Ostia: 163, 173

Otricoli: $157,160,167$

Ovid: $62 \mathrm{f}$

Paideia: siehe Bildung

Paradies: 171

Parmenides: 15

Pasiphae: 158

Patristik: 179

Paulus: 7, 71, 122, 124, 183

Peisistratos: 18,67

Peria: siehe Armut

Perge: 163

Periander: 16, 18, 68

Perikles: 32

Peripatetiker: 130,133

Persephone: 182

Perser: 16, 30

Petrus: 183

Phidias: 17,30

Philon von Alexandria: 37

Philosophen: 10, 20-22, 24, 28, 31, 34, 70, $91,93,102,117,133 \mathrm{f} ., 140,147$

- als religiöse Menschen: 118

Philosophie: 6, 10, 13-15, 17-21, 24f., 27f., 30f., 35-37, 39, 69, 71, 75f., 78, 80, $90,94,118 f ., 121,124,139,143$

- als ars vitae: 38

- als Licht: 71

- als Praxis der Tugend: 91

- antike Philosophie: 120, $130 f$.

- anti-skeptische Philosophie: 91

- ethische Philosophie: 62,70

- griechische Philosophie: 80

- neuplatonische Philosophie: 124

- philosophische Schulen: 10, 36, 76, 88

- platonische Philosophie: 37, 80, 90, II9, 126

- religiöse Philosophie: $36,38,70,93,100$

- Schulphilosophie: 22,75

- stoische Philosophie: 126, 131

- theurgisches Philosophie: 142

Philostrat: 65,76

Phoenix: 18, 26

Physik: 93

Pietas/pietas: 157f., 160f., 164-166, 168, 170f., 173, 176

- als Tugend: 159, 163, 165, 167

- pietas Augusti: 168

Pindar: 16

Piräus: 70
Platon: 6, 10, 15f., 21-24, 27f., 30, 33, 35 , $38,42,62,64-70,72,78-80,82 f ., 85-87$, $90 f, 94,117,122 f_{1}, 140 f$.

Platoniker: 63, 76-78, 86, 91, 94, 108, 130, 133,145

- christliche Platoniker: 143, 145

Platonismts: 7, 10, 2I-23, 38, 78-80, 82f., $91,121,131,139,141$

- aristotelisierender Platonismus: 79

- dogmatischer Platonismus: 80

- pythagoreisierender Platonismus: 79

- religiöser Platonismus: 22f., 28, 71, 95

- stoizierender Platonismus: 79

Plinius der Ältere: 151, 154, 156

Plotin: 134, 139, 141-143

Plutarch: 3, 7f., 23f., 37, 66f., 71, 75, 77, $79,84,89,91,95,97,100,108,113-115$

Politik: 11

Polyneikes: 181

Poppaets Ianuaritus: 157

Porphyrios: 9, 117, 133f, I4If.

Poseidon: 158, 181

Prädestination: 135

Preisgebet: siehe Gebet

Priamos: 18, 123

Prodikos: 130

Proklos: 133f, 141f., 145

prolalia: 12

Prometheus: 181

Pronoia: siehe Vorsehung

Prophetie: 16, 23, 34

Protagoras: 34

Protreptik: 13

Psychologie: 11, 78

Pyrrhon: 5

Pythagoras: $15 f_{1}, 21 f ., 24,27,70,83,91$, 141

Rechtfertigung: 100

Redekunst

- philosophische Redekunst: 17

- sophistische Redekunst: 25

Reiske, Johann Jakob: $39,43,70$

Religion: 28, 79f, 94, 105, 118, 145, 177

- antike Religion: 42

- christliche Religion: 175

- gelebte Religion: $28,30,36,38,94$

- nicht-christliche Religion: 175

- philosophische Religion: 118

- polytheistische Religion: 93

- Religionsgeschichte: 94

- religiöse Praxis: 3f., 91, 94, 115

- Vernunftreligion: 41 
Religiosität: 3, 93, 116

- heidnische Religiosität: 181

Renaissance: 39

Rhetorik: 9, 16, 100

Rhetoriklehrer: 10

Riten: 36

Ritual: 3, 181

Rom: 8f., 12, 154, 158f., 162, 165, 173

Römer: 9, 148, 163

Sabinus: 170

Sachverstand: 26, 34, 65f., 69, 86, 88f., 98, 133

salus publica: 67

Sardis: 63

Sarpedon: 18,68

Satan: 183

Satire: $4,62,117$

Schamlosigkeit: 107

Schicksal: siehe auch Tyche, 18, 21, 26, $34,40,64-68,83 \mathrm{f} ., 86,88 \mathrm{f}, 96-98$, 131-134, 139, 172, 181f.

Schönheit: 22, 25, 35, 132, 142

Schöpfung: 100, 136, 139

Seele: 8 , 13f., 17, 20, 24f., 27, 30-32, 62, 64, 82, 124, 126f., 141-143, 169f., 173, $175,179,183$

- Aufbaut der Seele: 21

- betende Seele: 169

- Reise der Seele: 17

- Seelenlehre: 31,33

- Unsterblichkeit der Seele: 21

- vorkosmische Seele: 84

- Wahrnehmungen der Seele: 21

- Weltseele: 77

-Zweiteilung der Seele: 15, 21

Selbstbestimmung: 136f.

Selbstbewusstsein: 10, 65

Selbstkontrolle: 25

Selbstvergessenheit: 25

Seleukiden: 9

Seneca: 67, 69, 90, 96f., 109, 115, 132f., 145

Silen: 62

Simeon: 179

Simplikios: 6

Sinai: 107

Skepsis: 15

Skeptiker: 135, 145

Skeptizismus: 10,78f.

Smyrna: 9,156

Sokrates: 7f., 10, 14-16, 21, 24, 27, 31, 42, $62,67,69 f ., 81 f ., 84,90 f ., 123,141$
Sparta: 32

Sphakteria: 70

Spiritualität: 119

- christliche Spiritualität: 143,145

- monastische Spiritualität: 143

Sprache: 137, 177

- bildhafte Sprache: 24,107

- Sprachtheorie: 11

Stesichoros: 62

Sthen(n)is: 151

Stoa: $10,23,78,80,84,93$

Stobaios: 62

Stoiker: 63, 65f., 88f., 108f., 130, 132, 145

Straton: 15,34

Symbolik: 38

sympatheia: 109

Synkretismus: 23

Syrien: 9

Tatiana: 129

Taufe: 129

Techne: siehs: Sachverstand

Tegea: 151

Tempel: 3, 8, 108, 113, 158f., 162, 166, 179

Tertullian: 125,146

Thales: 15

Theben: 181

Theodizee: $35,64,66 f ., 82$

Theodoros Metochites: 39

Theologen: 127

- christliche Theologen: 117, 146

Theologie: 4, 6, 11, 28f., 31, 33, 36, 78, 82, 107, 109, 113, 117f., 139, 179

- christliche Theologie: 120

- dialektische Theologie: 114

- Geschichtstheologie: 31

- homerische Theologie: 35

- Kosmotheologie: 34

- mittelplatonische Theologie: 77

- philosophische Theologie: 93

Theseus: 181f.

Thesmophorien: 150

Thessalonich: 71

Thetis: 18

Thrasybulos: 18,68

Thukydides: 18,70

Tierverehrung: 30

Tipasa: 165

Tod: 18, 32, 38, 71, 111, 133, 179, 182-184

Tradition: $8,24,63,79 \mathrm{f}, 95,122,168,172$

- biblische Tradition: 108, 114

- Bildungstracition: 23

- christliche Tradition: 71, 120, 144 
- griechische Tradition: 143

- philosophische Tradition: 96, 1266., 136

- platonische Tradition: 6, 33, 99, 127, 142

- pythagoreische Tradition: 91

- religiöse Tradition: $28,36,38,63$, $113 \mathrm{f}$., 118f., 145, 177

- rhetorische Tradition: 30

- Schultradition: 23

- Schultraditionen: 24

- stoische Tradition: 108

- Weisheitstradition: 23

Troja: 64

Trophonios: 33

Tugend: 13f., 16, 20, 25, 31, 35, 37, 40, 65, $69,71,76,83,89-91,128,133,141 \mathrm{f}$, 158f., 164, 167, 171-173, 176

- ethische Tugend: 27

- philosophische Tugend: 21

- politische Tugend: 158

Tyche: siehe auch Schicksal, Zufall, 62f., $69,83 \mathrm{f}, 88$

- als Ursache des Schlechten: 69, 83

Tyros: 9

Übel: $3,23,28,32,35,81,83 f ., 100$

Unterricht: 15

- philosophischer Elementarunterricht 6

- philosophischer Unterricht: 10f., 14, 17, 21, 37

Unwissenheit: 63,112

Vaterunser: $94 f ., 104,118,125,145 f$.

- Vaterunser-Auslegung: 118, 125, 127, 146

- Vaterunser-Bitten: 126

Vatikan: 157

Venus Victrix: 163

Verlangen: 21

Vernunft: 25, 35, 108

- göttliche Vernunft: 20,32, 132

- menschliche Vernunft 33

- praktische Vernumft: 137

- Weltvernunft: 101

virtus: 165

Volk Gottes: 102, 112

Vollkommenheit: 87, 141, 186

Voltaire: 41f.
Vorsehung: 18, 23, 26, 34, 40, 65f, 70,76 , 84, 86-89, 93, 96, 98f., 110, 115, 130 , 132-134, 138-140

- göttliche Vorsehung: 33, 35, 41, 65-67, 69, 86f., 98f., 131, 133, 146

Vos, Gerrit: 42

Wahrheit: 19f., 24, 31, 63, 113, 126, 137, 142, 144, 185f.

- verborgene Wahrheit: 19

- Wahrheitssuche: 114, 118

Weisheit: siehe auch Gott, 24, 39, 85, 91, 130

- Lebensweisheit: 63

Welt: siehe autch Kosmos, 20, 23, 26, 29, $38,41,66,76,89,115,120,133,182$

- Ideenwelt: 77

-irdische Welt: 83

- körperliche Welt: 7, 35

- physische Welt: 17

-Weltordnung: 35, 68, 98, 110, 132

- Weltstruktur: 35

Wiedererinnerung (anamnesis): 15,76 , 126

Wille: siehe auch Gott, 88, 183

- freier Wille: $76,82,88 \mathrm{f}$., $130,135,138$

Wissen: $15,30,76,92,99,113,180$

Wissenschaft: 16, 32, 69

Witsitus, Herman: 42

Wortspiele: 68

Würdigkeit: $7,26 f ., 40,65,70,85,95$,

99-102, 104, 106f., 110, 123, 135, 138

Xenophanes: 15

Xenophon: 15

Xerxes: 16

Zebecätts: 183

Zenon: 15

Zeus: $4 f ., 8,18,27,30,32,35,67 f, 81,97$, $108,132,180,182$

-Zeus Stratios/Labrancetus: 151

Zufall: siehe auch Tyche, 26, 34, 40, 66, $83 f ., 86,88,96,98,133,135$

Zurückhaltung: 5, 20, 67, 101

Zuträglichkeit: 99

Zuversicht: 101

Zwang: 67

Zweite Sophistik: 9, 28,76 



\section{Die Autoren dieses Bandes}

Prof. Dr. Barbara E. Borg ist Professorin für Klassische Archäologie an der University of Exeter. Ihre Forschungsschwerpunkte sind u.a. die griechische und römische Ikonographie und die römische Grabkultur.

Schriftenauswahl: Der Logos des Mythos - Allegorien und Personifikationen in der frithen griechischen Kunst (München 2002); (Hg.) Paideia. The World of the Second Sophistic (Berlin 2004); Crisis and ambition. Tombs and burial customs in third-century CE Rome (Oxford 2013); (Hg.) Blackwell Companion to Roman Art (Malden, MA 2015).

Prof. Dr. Franco Ferrari ist Ordentlicher Professor für Antike Philosophie an der Universität Salerno und unterrichtet Spätantike Philosophie an der Universität Pavia. Seit 2013 ist er Direktor vom Editorial Board der Reihe "International Plato Studies". Im Jahr 2014 war er wissenschaftlicher Direktor des UNESCO-Projektes "La via dell'essere: Elea/Velia". Seine Forschungsinteressen umfassen Platons Denken und den antiken Platonismus (Mittelplatonismus, Chaldäische Orakel, Plotin).

Schriftenauswahl: Kommentierte Übersetzung folgender Dialoge Platons: Pamenide (Milano 2004); Teeteto (Milano 2011); Menone (Milano 2016); Introduzione a Platone (Bologna 2018); (zusammen mit I. Männlein-Robert) „Mittelplatorismus und Neupythagoreismus“ in: Ch. Riedweg / Ch. Hom / D. Wyrwa (Hg.), Die Philosophie der Antike, Bd. 5, Die Philosophie der Kaiserzeit und der Spätantike. Grundriss der Geschichte der Philosophie / Ueberweg (Basel 2018).

Prof. Dr. Dr. Alfons Fürst ist Ordentlicher Professor für Alte Kirchengeschichte, Patrologie und Christliche Archäologie sowie Leiter der Forschungsstelle Origenes an der Katholisch-Theologischen Fakultät der Westfälischen Wilhelms-Universität Münster. Seine Forschungsschwerpunkte sind die Geschichte und Theologie des antiken Christentums und die altkirchliche Epistolographie, die Geschichte und Rhetorik des Monotheismus in der Antike und die Freiheitsphilosophie des alexandrinischen Theologen Origenes samt ihrer Wirkungsgeschichte bis in die Neuzeit.

Schriftenauswahl: Streit unter Freunden. Ideal und Realität in der Freundschaftslehre der Antzke (Stuttgart / Leipzig 1996); Augustins Briefwechsel mit Hieronymus (Münster 1999); Hieronymus. Askese und Wissenschaft in der Spätantike (Freiburg u.a. 2003; erweiterte Neuausgabe 2016); Christentum als Intellektuellen-Religion. Die Anfange des Christentums in Alexandria (Stuttgart 2007); Von Origenes und Hieronymus zu Augustinus. Studien zur antiken Theologiegeschichte (Berlin / Boston 2011); Origenes. Die Homilien zum Ersten Buch Samtiel (Berlin u.a. 2014); Origenes. Grieche und Christ in römischer Zeit (Stuttgart 2017).

Prof. Dr. Rainer Hirsch-Luipold ist Ordentlicher Professor für Netues Testament und Antike Religionsgeschichte an der Universität Bern und seit 2015 zusätzlich Extraordinary Professor at Stellenbosch University (SA), Department of Ancient Studies. Zu seinen Forschungsschwerpunkten zählen das Johannesevangelium und die paulinischen Briefe ebenso wie der religiöse Platonismus der frühen Kaiserzeit (insb. religiöse Tradition und philosophische Theologie bei Plutarch).

Schriftenauswahl: Plutarchs Denken in Bildern. Studien zur literarischen, philosophischen und religiösen Funktion des Bildhaften. STAC 14 (Tübingen 2002); (Hg.) Gott und die Götter bei Plutarch. Götterbilder - Gottesbilder - Weltbilder. RGVV 54 (Berlin / New York 2005); (Hg. zusammen mit H. Görgemanns / M. v. Albrecht, unter Mitarbeit v. T. Thum) Religiöse Philosophie und philosophische Religion der frühen Kaiserzeit. Literaturgeschichtliche Perspektiven. 
Ratio Religionis Studien I. STAC 51 (Tübingen 2009); Gott wahrnehmen. Die Sinne im Johannesevangelium. Ratio Religionis Studien IV. WUNT 374 (Tübingen 2017).

Prof. Dr. Michael Trapp ist Professor für griechische Literatur am King's College London. Seine Forschungsschwerpunkte sind die griechische Prosaliteratur der römischen Kaiserzeit, die Rolle der Philosophie in Kultur und. Gesellschaft derselben Epoche, die Rezeption und das Vorkommen der Figur des Sokrates von der Antike bis zur Gegenwart sowie das Nachleben der Antike im 19. und frühen 20. Jh. Großbritanniens.

Schriftenauswahl: Maximi Tyrii Dissertationes (Stuttgart / Leipzig 1994); Maximus of Tyre. The Philosophical Orations (Oxford 1997); Greek and Latin Letters. An anthology (Cambridge 2003); Philosophy in the Roman Empire: ethics, politics and society (Aldershot 2007); (Hg.) Socrates from Antiguity to the Enlightenment (Aldershot 2007); $(\mathrm{Hg}$.) Socrates in the Nineteenth and Twentieth Centuries (Aldershot 2007); Aelitus Aristides. Orations I. Loeb Classical Library (Cambridge, Ma/London 2017).

Prof. Dr. Dr. h.c. Vincenzo Vitiello, Ordentlicher Professor für Theoretische Philosophie, unterrichtet z.Zt. politische Theologie an der Universität "San Raffaele" in Mailand. Seine Forschungsschwerpunkte sind Kant und der Deutsche Idealismus, Vico, Nietzsche, Husserl und Heidegger, in engem Zusammenhang mit griechischem Denken, der christlichen Tradition und dem hebräischen Denken. In seiner theoretischen Forschung hat sich Vitiello mit der Entwicklung des topos-Begriffes als nicht geschichtlichen sondern transzendentalen Sinneshorizont des menschlichen Handelns beschäftigt.

Schriftenauswahl: Cristianesimo senza redenzione (Rom 1996; spanische Übers. Madrid 1999); "Wüste Ethos Verlassenheit Beitrag zu einer Topologie des Religiösen", in: J. Derrida / G. Vattimo (Hg.), Die Religion (Frankfurt/M. 2001) 172-207; Il Dio possibile (Roma 2003); "Ley, Fe e Historia. La influencia de Pablo de Tarso en el Occidente Cristiano", in: Deseo de Ley, Primer Coloquio International (Buenos Aires 2003) Bd. I, 181-204; „Religion und Nihilismus", in: E. Bidese / A. Fidora / P. Renen (Hg), Philosophische Gotteslehre heute. Der Dialog der Retigionen (Darmstadt 2008) 129-144; Ripensare il cristianesimo. De Europa (Torino 2008); Oblio e memoria del Sacro (Bergamo 2008); Paolo el'Europa (zusammen mit G. Rossé, Roma 2014). 